\author{
UNIVERSIDADE FEDERAL DE SÃO CARLOS \\ DEPARTAMENTO DE ENGENHARIA DE PRODUÇÃO \\ PROGRAMA DE PÓS-GRADUAÇÃO EM ENGENHARIA DE PRODUÇÃO
}

Tatiane da Cunha Villela

\title{
CARACTERÍSTICAS DA COOPERAÇÃO DA UNIVERSIDADE FEDERAL DE SÃO CARLOS COM A SOCIEDADE NO PERÍODO DE 2008 A 2012
}


Tatiane da Cunha Villela

\section{CARACTERÍSTICAS DA COOPERAÇÃO DA UNIVERSIDADE FEDERAL DE SÃO CARLOS COM A SOCIEDADE NO PERÍODO DE 2008 A 2012}

Dissertação apresentada ao Programa de Pós Graduação em Engenharia de Produção da Universidade Federal de São Carlos para obtenção de Título de Mestre em Engenharia de Produção. Área de concentração: Gestão da Tecnologia e Inovação

Orientadora: Prof. $^{\text {a }}$ Dr. $^{\text {a }}$ Ana Lúcia Vitale Torkomian 
Ficha catalográfica elaborada pelo DePT da Biblioteca Comunitária da UFSCar

Villela, Tatiane da Cunha.

Características da cooperação da Universidade Federal de São Carlos com a Sociedade no período de 2008 a 2012 / Tatiane da Cunha Villela. -- São Carlos : UFSCar, 2015. $149 \mathrm{f}$.

Dissertação (Mestrado) -- Universidade Federal de São Carlos, 2014.

1. Alianças estratégicas (Negócios). 2. Universidade Federal de São Carlos. 3. Gestão de projetos. I. Título.

CDD: $658.042\left(20^{\mathrm{a}}\right)$ 


\section{UNIVERSIDADE FEDERAL DE SÃO CARLOS}

Centro de Ciências Exatas e de Tecnologia

Programa de Pós-Graduação em Engenharia de Produção

\section{Folha de Aprovação}

Assinaturas dos membros da comissão examinadora que avaliou e aprovou a defesa de dissertaçăo de Mestra em Engenharia de Produçăo da candidata Tatiane da Cunha Villela, realizada em 28/11/2014:

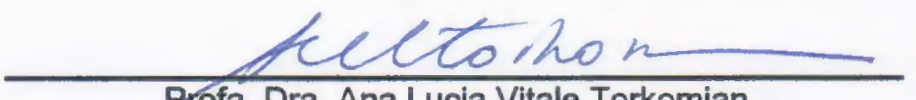

Profa. Dra. Ana Lucia Vitale Torkomian UFSCar

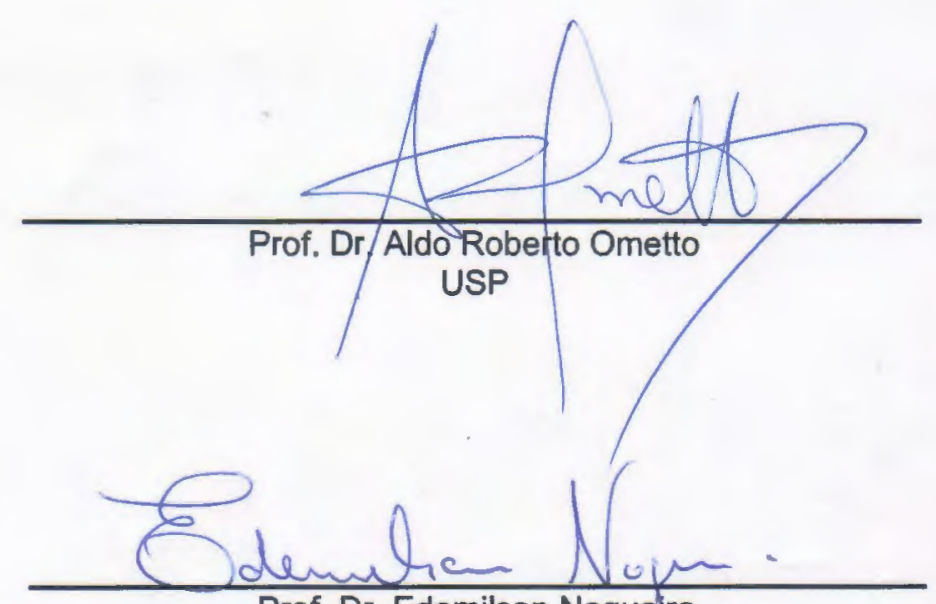

Prof. Dr. Edemilson Noguevra

UFSCar 
Dedico este trabalho a todos que me ajudaram a ter força e perseverança para concluir essa importante etapa da minha vida. 


\section{AGRADECIMENTOS}

Acima de tudo agradeço a Deus, base da minha vida, por toda a força que me proporcionou e proporciona.

Ao Departamento de Engenharia de Produção da Universidade Federal de São Carlos, que me acolheu para o Mestrado e pelo apoio e dedicação dos funcionários nele presentes, que sempre foram muito prestativos.

À minha orientadora Ana Lúcia Vitale Torkomian, minha querida orientadora, por todo o auxilio e incentivo ao longo desses anos. Obrigada pela paciência, e por todo o conhecimento compartilhado.

Ao minha antiga orientadora de graduação, Professora Carla Cristina Rosa de Almeida, do Departamento de Economia da Universidade Federal do Estado de Mato Grosso, que foi a pessoa que me inseriu na área acadêmica e que me ensinou lições valiosas sobre este meio.

Às minhas colegas - Andreia Abreu, Annelise Nascimento e Carol Belotti, por terem sido tão especiais.

Aos professores que dedicaram algum tempo para este trabalho, incluindo os aqui participantes da banca de qualificação e defesa.

Aos meu amigos que, mesmo estando longe, sempre me apoiaram e me incentivaram a fazer um trabalho melhor. 
"Concentre-se nos pontos fortes, reconheça as fraquezas, agarre as oportunidades e proteja-se contra as ameaças"

(SUN TZU, 500 a.C.) 


\section{RESUMO}

O conhecimento gerado na academia é de suma importância para o avanço tecnológico e para o aumento da competitividade. A transferência de tecnologia universidade-empresa refere-se às distintas formas de parcerias entre estes dois domínios. A inovação resultante desse processo é um pré-requisito para a sobrevivência em ambientes concorrenciais. No entanto, apesar da articulação cada vez mais próxima entre as universidades e as empresas, a cooperação está "longe" de ser um processo tranquilo, principalmente, devido às diferenças estruturais e objetivos entre os agentes, podendo gerar expectativas e percepções contraditórias. Diante deste cenário, este trabalho teve como objetivo apresentar e analisar as características do perfil de cooperação da UFSCar com a empresa atualmente, e verificar se houve alguma mudança nas características da cooperação da UFSCar com a empresa, utilizando como objeto de análise os projetos estabelecidos entre a universidade e seus parceiros externos, nos últimos cinco anos (2008-2012), que são gerenciados pela Fundação de Apoio Institucional ao Desenvolvimento Científico e Tecnológico (FAI). Dentre os resultados obtidos, destaca-se que os projetos de cooperação da UFSCar com o meio externo caracterizaram-se, na grande maioria, por baixos intervalos de duração. Em relação ao tipo de financiador, empresas privadas, as principais atividades desenvolvidas com a universidade em estudo foram as atividades de Consultoria/Assessoria e Projetos de Pesquisa e Desenvolvimento. Outro fator importante foi o de que a maior parte das parcerias com as empresas privadas ocorreram no Centro de Ciências Exatas e Tecnológicas (CCET) e nos Departamentos de Engenharia Civil e de Engenharia de Materiais, tanto em número de projetos quanto em volume de recursos. Além disso, foi possível notar o potencial de crescimento da atividade de cooperação entre a UFSCar e a empresa.

Palavras-chave: cooperação Universidade-Empresa-Governo; UFSCar; gestão de projetos. 


\begin{abstract}
ABSCTRACT
The knowledge generated in academia is of paramount importance to technological advances and increasing competitiveness. Technology transfer university-business refers to the different forms of partnerships between these two domains. The result of this process innovation is a prerequisite for survival in competitive environments. However, despite the ever closer links between universities and firms, cooperation is "far" from being a smooth process, mainly due to structural differences between agents and goals and can create conflicting expectations and perceptions. Against this backdrop, this paper aims to present and analyze the characteristics of the profile UFSCAR cooperation with the company today, and see if there was any change in the characteristics of the UFSCAR cooperation with the company, using as an object of analysis projects established between the university and its external partners in the last five years (2008-2012), which are managed by the Foundation for Institutional Support of Scientific and Technological Development (FAI). Among the results, it is emphasized that the cooperation projects of UFSCAR with the external environment characterized, in most cases, by low ranges of duration. Regarding the type of financing, private companies, the main activities developed with the university in the study were the activities of Consultancy / Project Consultancy and Research and Development. Another important factor was that $88 \%$ of partnerships with private companies took place at the Center of Exact Sciences and Technology (CCET) and the Departments of Civil Engineering and Materials Engineering, both in number of projects and volume of resources. Furthermore, it was possible to note the growth potential of cooperative activity between the company and UFSCAR.
\end{abstract}

Keywords: University-Industry-Government cooperation; UFSCar; project management. 


\section{LISTA DE GRÁFICOS}

Gráfico 1 - Pedidos de patentes depositados no INPI entre 2008-2012 e acumulados desde 1990 73

Gráfico 2 - Evolução do número de projetos por período de tempo, 2008 a 2012 .74

Gráfico 3 - Distribuição do volume dos recursos captados pela FAI por ano de início de projeto de 2008 a 2012 .75

Gráfico 4 - Distribuição do número de projetos por intervalo de duração .76

Gráfico 5- Distribuição do volume de recursos financeiros por intervalo de duração .............77

Gráfico 6 - Distribuição do número de projetos FAI por tipo de atividade ............................79

Gráfico 7 - Distribuição do volume de recursos financeiros por tipo de atividade ..................80

Gráfico 8 - Distribuição dos projetos por Centro Científico no período de2008 a 2012 .........81

Gráfico 9 - Distribuição total dos projetos e percentual por Centro Científico 82

Gráfico 10 - Distribuição do volume de recursos financeiros por Centro Científico e distribuição percentual

Gráfico 11 - Distribuição total dos projetos e volume dos recursos por departamento científico .84

Gráfico 12 - Distribuição do número de projetos e volume de recursos por tipo de financiador 86

Gráfico 13 - Distribuição do número de projetos por tipo de financiador e tipo de atividade 88 Gráfico 14 - Distribuição do volume de recursos financeiros por tipo de financiador e tipo de atividade

Gráfico 15 - Distribuição do número de projetos por tipo de financiador e centro científico.90 Gráfico 16 - Distribuição do número de projetos por tipo de financiador e pelo Centro Científico de Ciência Exatas e Tecnológicas (CCET).

Gráfico 17 - Distribuição do número de projetos por tipo de financiador e pelo Centro Científico de Ciências Biológicas e da Saúde (CCBS) e Centro de Educação e Ciências Humanas $(\mathrm{CECH})$.

Gráfico 18 - Distribuição do volume de recursos por tipo de financiador e Centro Científico

Gráfico 19 - Distribuição do volume de recursos por tipo de financiador e departamento científico 
Gráfico 20 - Distribuição do volume de recursos por tipo de financiador e Departamento Científico

Gráfico 21 - Distribuição percentual do número de projetos em função da localidade (região) do financiador

Gráfico 22 - Distribuição do número de projetos em função da localidade (região) do financiador.

Gráfico 23 - Distribuição do número de projetos e volume de recursos por localidade (estado)

Gráfico 24 - Distribuição do número de projetos com parceiros locais por período de tempo99 Gráfico 25 - Distribuição do volume dos recursos para os projetos com parceiros locais .... 100 Gráfico 26 - Distribuição percentual do número de projetos estabelecidos com parceiros locais por Centro Científico. 101

Gráfico 27 - Distribuição do número de projetos gerenciados pelas empresas privadas e estatais por localidade (estados) 102

Gráfico 28 - Distribuição dos recursos financeiros pelas empresas privadas e estatais por localidade (estados) 102

Gráfico 29 - Distribuição do número de projetos e volume de recursos por localidade (estado) 


\section{LISTA DE FIGURAS}

Figura 1 - Coevolução e multilinearidade das relações universidade-indústria .....................26

Figura 2 - O modelo estático das relações universidade-indústria-governo ............................30

Figura 3 - O modelo laissez-faire das relações universidade-indústria-governo......................31

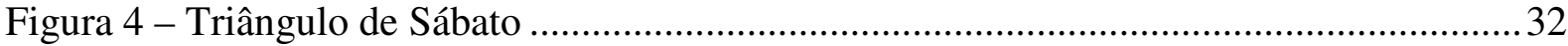

Figura 5 - O modelo da Hélice Tripla das relações universidade-indústria-governo ...............34

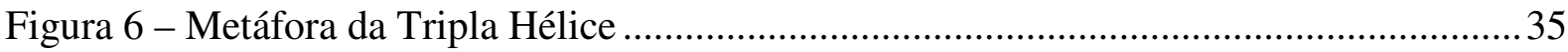

Figura 7 - Fluxo de Conhecimento entre a Universidade e a Empresa.................................49

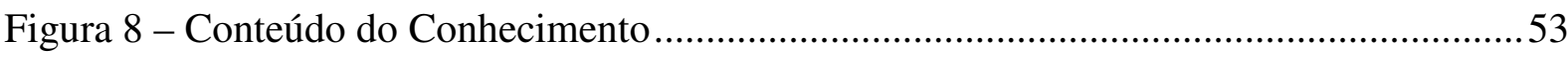




\section{LISTA DE QUADROS}

Quadro 1 - Benefícios resultantes da cooperação universidade-empresa...............................39

Quadro 2 - Barreiras à cooperação entre universidades e empresas ...................................... 43

Quadro 3 - Trabalhos com discussão sobre os canais de transferência de conhecimento .......48

Quadro 4 - Características dos métodos de pesquisa .............................................................58

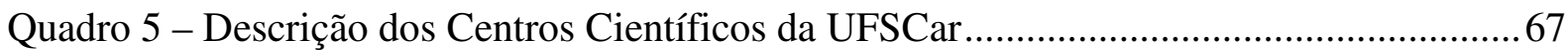

Quadro 6 - Classificação dos projetos gerenciados pela FAI................................................ 71

Quadro 7 - Características do conjunto de dados a serem analisados................................... 104

Quadro 8 - Quadro resumo com os principais resultados obtidos na pesquisa desenvolvida por

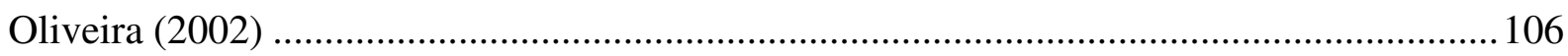

Quadro 9 - Comparação do critério intervalo de duração................................................... 107

Quadro 10 - Comparação do critério projetos por tipo de atividade....................................... 108

Quadro 11 - Comparação do critério projetos por tipo de atividade...................................... 109

Quadro 12 - Comparação do critério distribuição dos projetos por Centro Científico ........... 111

Quadro 13 - Comparação do critério distribuição dos projetos por departamento ................. 112

Quadro 14 - Comparação do critério distribuição dos projetos por tipo de financiador.........114

Quadro 15 - Comparação do critério distribuição dos projetos por tipo de financiador........ 115

Quadro 16 - Quadro resumo com os principais resultados obtidos na pesquisa...................119

Quadro 17 - Quadro resumo com os principais resultados obtidos na pesquisa referente ao

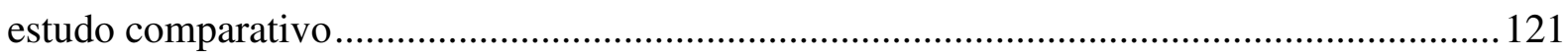




\section{SUMÁRIO}

1. INTRODUÇÃ̃ ..............................................................................................14

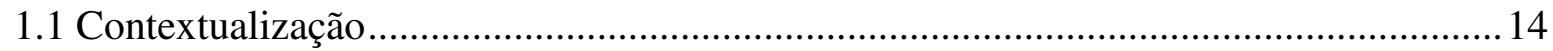

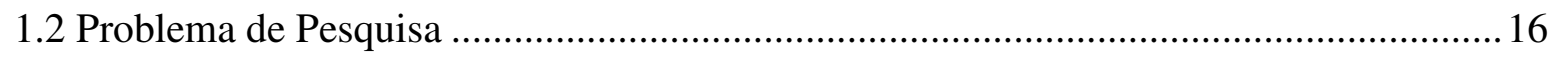

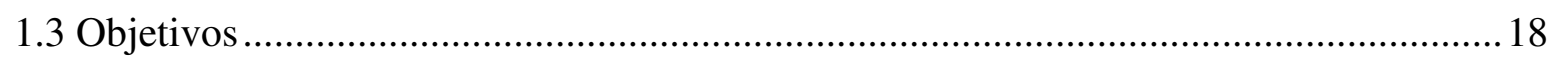

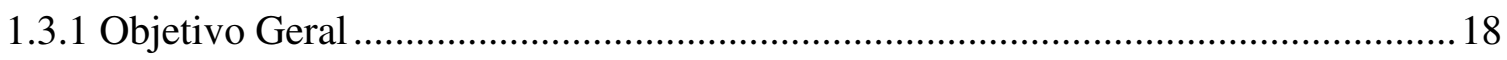

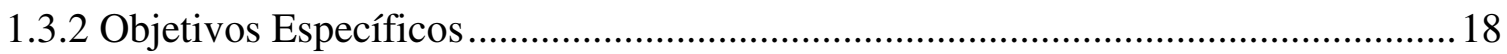

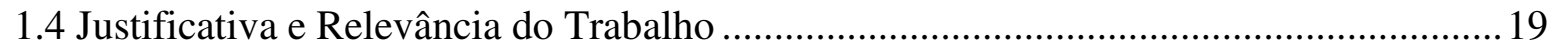

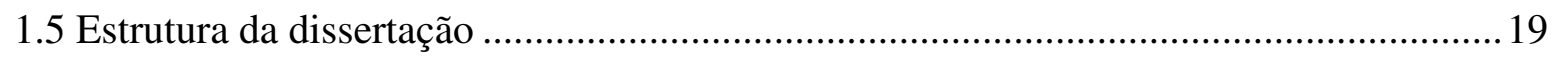

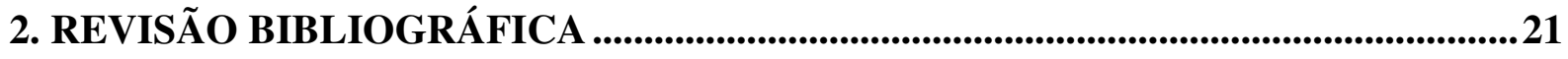

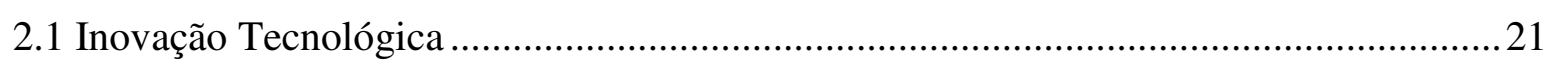

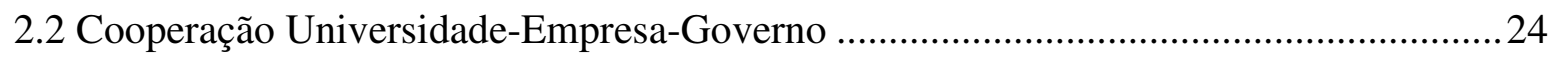

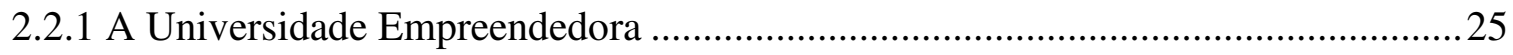

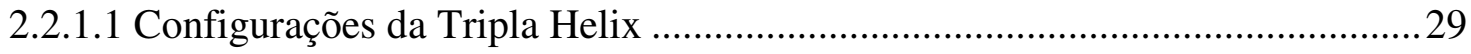

2.2.2 Benefícios e Barreiras à Cooperação Universidade-Empresa...................................36

2.2.2.1 Benefícios Percebidos na Cooperação Universidade-Empresa .......................... 36

2.3.2.2 Barreiras à Cooperação Universidade-Empresa ............................................. 40

2.2.3 Canais de Transferência de Tecnologia .................................................................. 43

2.2.3.1 Transferência de Tecnologia: aspectos conceituais.........................................44

2.2.3.2 Principais Canais de Transferência de Tecnologia........................................... 46

2.2.4 Fluxo de Conhecimento na Cooperação Universidade-Empresa ..............................49

3. PROCEDIMENTOS METODOLÓGICOS ................................................................55

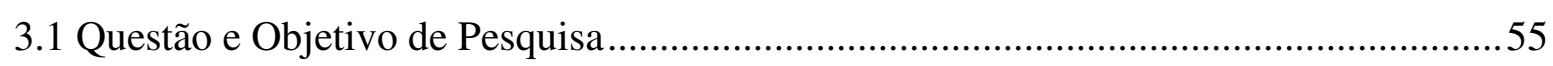

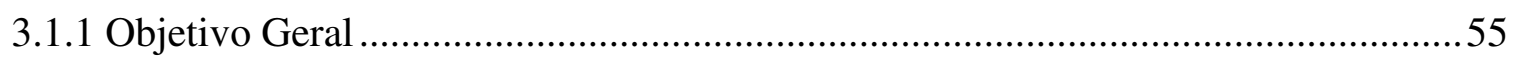

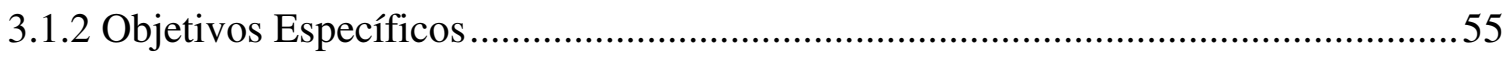

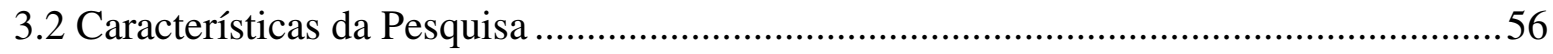

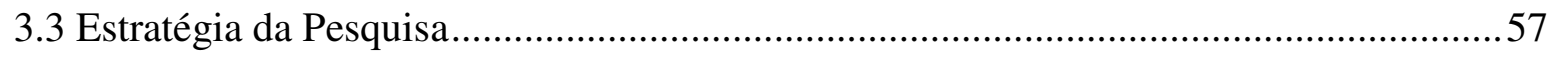

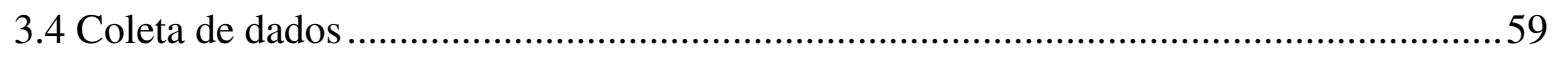

3.4.1 Ajustes, Contabilização e Consolidação dos Dados .............................................. 61

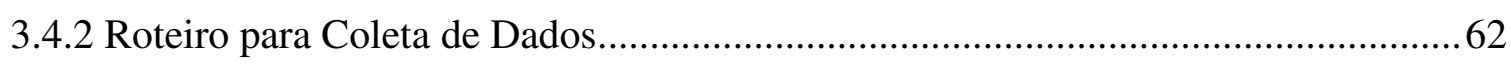

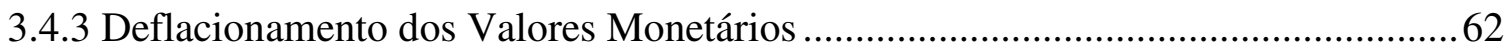


4.1 A UFSCar no Processo de Cooperação Universidade-Empresa....................................65

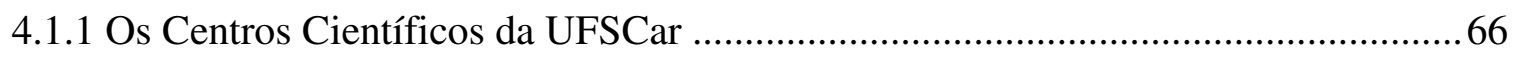

4.1.2 A Fundação de Apoio Institucional (FAI) ..........................................................69

4.2 Caracterização geral dos projetos de cooperação da UFSCar com a empresas ..............74

4.2.1 Distribuição dos projetos por tipo de atividade..................................................... 77

4.2.2 Distribuição dos projetos por centro científico ..................................................... 80

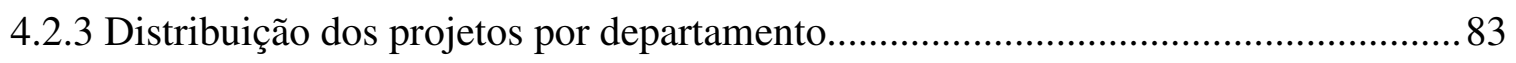

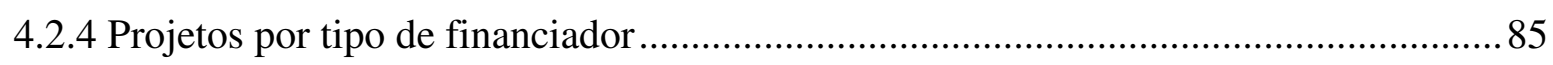

4.2.4.1 Distribuição dos projetos por tipo de financiador e tipo de atividade ................87

4.2.4.2 Distribuição dos projetos por tipo de financiador e centro científico................89

4.2.4.3 Distribuição dos projetos por tipo de financiador e departamento .....................93

4.2.4.4 Distribuição dos Projetos por Localidade do Financiador.................................96

4.4 Apresentação e análise comparativa da cooperação da UFSCar com o meio externo .104

4.4.1 Características da cooperação da UFSCar com a sociedade (1990-2000) .............. 105

4.4.2 Apresentação e análise dos projetos por intervalo de duração................................ 106

4.4.3 Apresentação e análise dos projetos por tipo de atividade ................................. 108

4.4.4 Apresentação e análise dos projetos por Centro Científico e Departamento .......... 110

4.5.5 Apresentação e análise dos projetos por tipo de financiador ................................. 113

4.4.6 Apresentação e análise dos projetos por localidade do financiador....................... 115

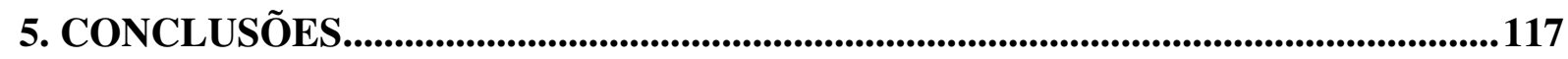

5.1 Considerações sobre as características da Cooperação da UFSCar com empresa entre o

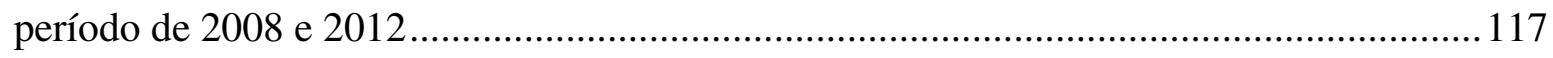

5.2 Considerações sobre a análise comparativa da cooperação da UFSCar com o meio

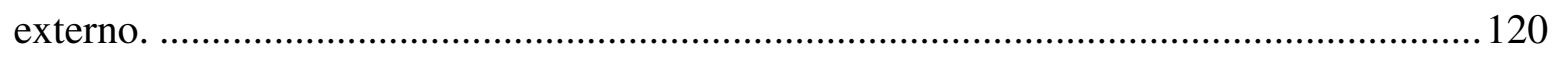

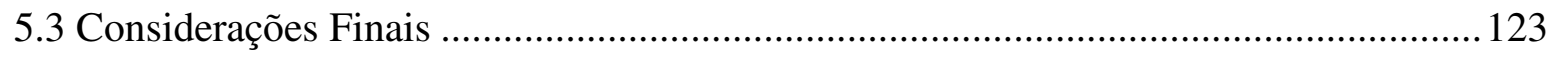

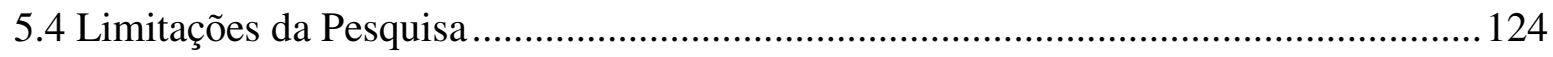

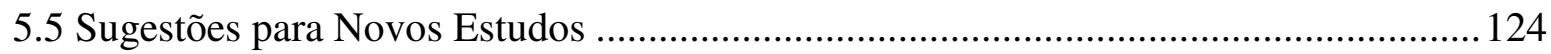

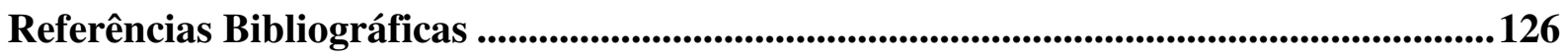

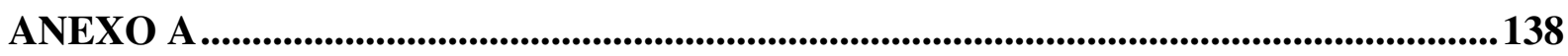

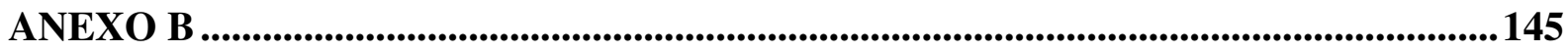




\section{INTRODUÇÃO}

Neste capítulo, são apresentadas as considerações iniciais, o problema de pesquisa, os objetivos, as justificativas, a relevância da pesquisa e a estrutura geral do trabalho.

\subsection{Contextualização}

Grandes transformações vêm ocorrendo na economia nos últimos anos, o que têm afetado diretamente as empresas, levando a uma crescente mudança na forma de atuação no mercado (FUENTES; DUTRÉNIT, 2012). Novos padrões de concorrência vêm sendo estabelecidos, fazendo com que as empresas procurem novas formas de sobrevivência no mercado. Nesta perspectiva, a inovação tecnológica tem se sobressaído entre as estratégias competitivas adotadas pelas empresas em resposta ao desafio colocado pela intensificação da concorrência no mercado (CHESBROUGH, 2006).

De acordo com a Pesquisa Industrial de Inovação Tecnológica (PINTEC), realizada pelo Instituto Brasileiro de Geografia e Estatística (IBGE), entre os anos de 2006 e 2008, a inovação tecnológica é definida pela implementação de produtos e/ou processos tecnologicamente novos ou substancialmente aprimorados. A implementação do produto ocorre quando o mesmo é introduzido no mercado e a do processo no momento em que este passa a ser operado pela empresa.

Segundo o Manual de Oslo da Organização para a Cooperação e o Desenvolvimento Econômico (OCDE, 2005) deve-se levar em consideração que a natureza das atividades de inovação varia muito de empresa para empresa. Algumas executam projetos de inovação bem definidos, como o desenvolvimento e a introdução de um novo produto, enquanto outras realizam melhoramentos contínuos em seus produtos, processos e operações. Ambos os tipos podem ser inovadores: (i) uma inovação pode constituir-se na implementação de uma única mudança significativa ou (ii) em uma série de pequenas mudanças incrementais que juntas constituem uma mudança significativa.

As empresas realizam as atividades de inovação através de projetos de Pesquisa, Desenvolvimento e Inovação (PD\&I) que implicam investimentos caracterizados pelo risco inerente a qualquer pesquisa, pelo simples fato que não há certeza quanto ao grau de sucesso em termos de exequibilidade técnica de uma solução. São marcados, também, pela longa maturação, uma vez que só após a conclusão (com o sucesso) é que a empresa decidirá pelo investimento industrial propriamente dito. 
A complexidade no processo de desenvolvimento de novas tecnologias e o alto custo para a realização de pesquisa têm proporcionado um aumento cada vez maior por fontes alternativas de conhecimento, o que elege o conhecimento científico como um dos fatores principais para o desenvolvimento de processos inovativos (RAPINI, 2007), tornando-se, cada vez mais, uma das estratégias utilizadas para a geração de produtos e processos inovadores (SUZIGAN; ALBUQUERQUE, 2011).

A contribuição do conhecimento científico para o processo tecnológico enfatiza o importante papel desempenhado pelas universidades, na medida em que se constituem uma fonte de suma importância para geração deste conhecimento (CHESBROUGH, 2006; RAPINI et al., 2009). A partir deste contexto, alguns pesquisadores têm argumentado que a universidade vive um processo de transformação, no que diz respeito às suas funções sociais ligadas à produção e à transferência de conhecimento para a sociedade (WEBSTER; ETZKOWITZ, 1991; ETZKOWITZ; LEYDESDORFF, 2000; MOWERY et al., 2001; RIGHI; CRUZ, 2009).

Dentre as várias possibilidades de dispor o conhecimento acadêmico à sociedade, a transferência de tecnologia tem alcançado significativo destaque, principalmente, por meio da execução de projetos de PD\&I cooperativos entre universidades e empresas (BISHOP; D’ESTE; NEELY, 2011). Deste modo, a cooperação universidade-empresa tem se tornado uma realidade não apenas para garantir o futuro da ciência e tecnologia, mas, também, para disponibilizar conhecimento e capacitações para a estrutura produtiva do país.

Olhando mais atentamente para a universidade, alguns autores (SUTZ, 2000; ETZKOWITZ, 2003) sugerem que atualmente, ela encontra-se inserida em um ambiente caracterizado por mudanças organizacionais, por modificações no comportamento dos principais atores envolvidos com o desenvolvimento econômico e social e pela expectativa de que se envolva em novos arranjos interinstitucionais que resultem em benefícios baseados em conhecimento científico e tecnológico e na inovação tecnológica.

Nesse campo teórico, um dos modelos mais referenciados na literatura é o modelo da Tripla Hélice (ETZKOWITZ; LEYDESDORFF, 2000). Este modelo caracteriza as interrelações entre universidade, governo e empresas, e explora como criar um ambiente propício à inovação, à geração e à difusão do conhecimento necessário ao desenvolvimento da sociedade. Neste caso, além de desempenhar suas tradicionais atividades de ensino e pesquisa, a universidade estaria assumindo a missão (Terceira Missão) de usar o conhecimento científico produzido em suas pesquisas para apoiar o desenvolvimento social e econômico do ambiente no qual se insere. 
Entretanto, Laredo (2007) oferece um contraponto ao conceito da Terceira Missão quando indica que as universidades não se estruturam em função destas missões, mas as articulam convenientemente de acordo com as possibilidades apresentadas pela história e tradição de cada universidade, pelos recursos financeiros e humanos de que dispõe, pela "clientela" que deve atender, pelo contexto social em que se insere, pelas políticas públicas e privadas que a afetem direta ou indiretamente.

O autor sugere, então, três diferentes maneiras em que as universidades articulam suas diferentes funções, quais sejam: (i) ensino superior em massa (licenciatura); (ii) ensino superior profissional (bacharelado) e a pesquisa para a resolução de problemas; e (iii) a formação de pesquisadores acadêmicos (formação de mestres e doutores e publicação de artigos científicos). $\mathrm{O}$ autor argumenta ainda que as inúmeras combinações possíveis destas três "funções" são as variáveis chave na explicação da posição ocupada pelas universidades em quaisquer classificações.

Adicionalmente, outros subtemas ajudam a conformar o universo de estudos que tratam da relação entre universidades e empresas, tais como o efeito do arcabouço legal que designa a própria universidade como beneficiária da exploração comercial dos resultados de suas pesquisas, ainda que financiadas com recursos governamentais (MOWERY; SAMPAT; ZIEDONIS, 2002; MOWERY et al., 2001), o processo de criação e a avaliação de desempenho dos escritórios de transferência de tecnologia (BERCOVITZ et al., 2001; CARLSSON; FRIDH, 2002; SIEGEL; VEUGELERS; WRIGH 2007), o processo de criação de empresas dedicadas a explorar os resultados das pesquisas acadêmicas (spin-offs acadêmicas) como iniciativa empreendedora dos seus pesquisadores (LOUIS et al., 1989; MEYER, 2003; LOCKETT et al., 2005), dentre outros.

Ademais, a cooperação universidade-empresa possui a capacidade de reunir recursos e potencializar oportunidades, incentivando projetos de inovação para apoiar o desenvolvimento tecnológico. Com isso, são gerados processos cooperativos com a sociedade para o aperfeiçoamento, no qual a transferência de tecnologia universidade-empresa emerge como uma alternativa para a inovação nas empresas, aproveitando o potencial existente nas universidades (COHEN; NELSON; WALSH, 2002).

\subsection{Problema de Pesquisa}

No cenário que destaca a inovação tecnológica tanto como instrumento político de desenvolvimento econômico para as nações quanto como instrumento estratégico para as 
empresas, autores (COHEN; NELSON; WALSH, 2002; D'ESTE; PERKMANN, 2010; DUTRÉNIT; ARZA, 2010; FERNANDES et al., 2010; DUTRÉNIT; ARZA, 2010; SUZIGAN; ALBUQUERQUE, 2011) argumentam em seus estudos a existência de uma articulação cada vez mais próxima entre as universidades e sociedade no desenvolvimentos de produtos ou processos inovativos.

Nos países desenvolvidos, circuitos de retroalimentação positiva entre as universidades e o setor empresarial são frequentemente relatados em estudos especializados (RAPINI, et. al. 2009). Contudo, no que concerne ao Brasil, diversos trabalhos apontam a existência de um sistema de inovação imaturo, com conexões apenas parciais entre as dimensões científica e tecnológica, sendo que os fluxos bidirecionais parecem limitados a alguns setores e são mais densos em algumas regiões (ALBUQUERQUE et al., 2008; SUZIGAN; ALBUQUERQUE, 2011).

Ocorre que por um longo período, as instituições de ensino e pesquisa no Brasil voltaram sua atuação às atividades de ensino, prática que perdurou até a década de 90, quando intensificaram suas ações no campo da pesquisa científica (SUZIGAN; ALBUQUERQUE, 2011).

No entanto, apesar da articulação cada vez mais próxima entre as universidades e as empresas, a cooperação está "longe" de ser um processo tranquilo, principalmente, devido às diferenças estruturais e de objetivos entre os agentes, podendo gerar expectativas e percepções contraditórias. Em especial, diversos autores argumentam que a relação entre a comunidade acadêmica e o setor operacional se move segundo objetivos distintos, os quais refletem os padrões de comportamento dos agentes inseridos em cada contexto (ETZKOWITZ; LEYDESDORFF, 2000; COHEN; NELSON; WALSH, 2002; D'ESTE; 2008; WRIGHT et al., 2008; ARZA, 2010; FUENTES; DUTRÉNIT, 2012).

Mowery e Sampat (2004) e Porto et al. (2011), argumentam que a universidade foca seu investimento na geração de conhecimentos, na formação de profissionais, pesquisadores, produção e difusão científica. Autores como Albuquerque et al. (2008) e Rapini (2007) sugerem que as empresas centralizem suas atenções na geração de lucros, primordial para sua sobrevivência no mercado, justificando a tecnologia como instrumento estratégico de participação e permanência no mercado.

Diante deste contexto, algumas inquietações decorrentes da complexidade e incipiência do processo de cooperação entre universidade e setor produtivo no contexto brasileiro motivaram a presente pesquisa. Mais apropriadamente, a necessidade de uma análise detalhada e profunda sobre a existência de circuitos de retroalimentação positivos de 
cooperação universidade-empresa, com o intuito de verificar se já se pode observar nas universidades um novo perfil de cooperação com a sociedade, sugeriu a seguinte pergunta de pesquisa:

\section{Quais são as principais características do perfil de cooperação da Universidade Federal de São Carlos (UFSCar) com a sociedade atualmente? \\ Houve alguma mudança em relação às características históricas da cooperação?}

Após a definição do problema de pesquisa, é importante ressaltar que este estudo dá continuidade ao trabalho já desenvolvido na UFSCar sobre o tema em questão. Oliveira (2002) estudou como estava configurado o panorama da cooperação da Universidade Federal de São Carlos e o meio externo, no qual utilizou como objeto de análise os projetos estabelecidos entre a universidade e seus parceiros externos, gerenciados pela Fundação de Apoio Institucional ao Desenvolvimento Científico e Tecnológico (FAI) entre o período de 1992-2000, daí a possibilidade de comparação do perfil de cooperação atual e histórico.

\subsection{Objetivos}

Tendo em vista a definição do problema de pesquisa, tornou-se possível a formulação do objetivo geral, bem como de maneira complementar, a proposição de objetivos específicos.

\subsubsection{Objetivo Geral}

Este trabalho tem como objetivo geral apresentar e analisar as características do perfil de cooperação da UFSCar com a sociedade atualmente, e verificar se houve alguma mudança nas características da cooperação da UFSCar com a sociedade, utilizando como objeto de análise os projetos estabelecidos entre a universidade e seus parceiros externos, nos últimos cinco anos (2008-2012), que são gerenciados pela Fundação de Apoio Institucional ao Desenvolvimento Científico e Tecnológico (FAI).

\subsubsection{Objetivos Específicos}

Os objetivos específicos que decorreram do objetivo principal puderam ser divididos em: 
- Apresentar as características da cooperação universidade-empresa da Universidade Federal de São Carlos, a partir dos projetos gerenciados da Fundação de Apoio Institucional ao Desenvolvimento Científico e Tecnológico (FAI), realizados entre o período de 2008-2012;

- Comparar os resultados dos projetos gerenciados pela FAI no período de 20082012 com os dados da cooperação da UFSCar com o meio externo desenvolvidos por Oliveira (2002);

- Identificar se houve alguma mudança no perfil da cooperação da UFSCar com a sociedade.

\subsection{Justificativa e Relevância do Trabalho}

A justificativa e relevância de se estudar este tema baseou-se no fato de ainda serem relatados, tanto por parte das universidades quanto por parte das empresas, diversos entraves para que a cooperação entre universidade e sociedade ocorra de maneira satisfatória.

Observou-se que este processo necessita ser enriquecido com uma maior abertura e adequação das empresas para a utilização do conhecimento de fontes externas, assim como, maior clareza para as universidades das reais necessidades do setor produtivo, a partir do compartilhamento de uma visão de gestão de negócios que o mercado exige.

Levantar tais necessidades, não significa que os princípios que norteiam a geração do conhecimento nas universidades foram deixados, porém enfatiza-se a necessidade de reconhecer a realidade do ambiente competitivo em que estão inseridas as empresas que buscam desenvolver suas inovações com participação de parceiros, ou seja, as universidades.

Analisar se houve alguma mudança nas características da cooperação universidadeempresa, por meio de um estudo realizado na UFSCar, é claramente oportuno ao se considerar a importância da pesquisa para o desenvolvimento da própria sociedade, visto que as universidades ocupam um papel importante neste contexto. Desta forma, parte-se do princípio que a inovação tecnológica é um elemento crucial para o fortalecimento, sobrevivência e competitividade em longo prazo para as empresas.

\subsection{Estrutura da dissertação}

O Capítulo $1 \mathrm{fez}$ as considerações preliminares referentes ao tema, apresentando o problema da pesquisa, os objetivos e as justificativas pertinentes para a realização do trabalho. 
Na sequencia, o Capítulo 2 apresenta a literatura que deu base a esta pesquisa, apresentando de forma detalhada os resultados da revisão sistemática.

O Capítulo 3 explicita os procedimentos metodológicos adotados neste estudo, enquanto no Capítulo 4 são descritos os resultados do estudo realizado na UFSCar. Finalmente, o Capítulo 5 traz as conclusões da pesquisa. 


\section{REVISÃO BIBLIOGRÁFICA}

Este capítulo tem por objetivo apresentar a revisão sistemática da literatura a respeito do assunto principal que constitui o problema de pesquisa proposto, em outras palavras, a relação de cooperação universidade-empresa. Neste contexto, os procedimentos utilizados para a obtenção dos dados referentes à revisão sistemática da literatura e a análise bibliométrica referente à cooperação universidade-empresa, realizada a partir dos 68 artigos resultantes da consulta às bases de dados Scopus; Web of Science e Science Direct, encontram-se no Anexo A e no Anexo B, respectivamente.

Inicialmente, são apresentados conceitos e características da inovação tecnológica, de modo a dar suporte ao leitor sobre o assunto deste trabalho. Posteriormente, a relação de cooperação universidade-empresa é abordada a partir de seus condicionantes, benefícios, possibilidades e entraves que são encontrados tanto na literatura nacional quanto na literatura estrangeira.

Além disso, tece considerações sobre o processo de transferência de tecnologia, ressaltando os principais canais de transferência, como a formação de spin-offs acadêmicas e a realização de pesquisas conjuntas e, por fim, é abordado como ocorre o fluxo de conhecimento na cooperação universidade-empresa.

\subsection{Inovação Tecnológica}

O rápido crescimento econômico proveniente do ritmo intenso de inovação tecnológica, somente pode ser mantido através de novas formas de se usar os recursos inovativos, isto é, as possibilidades de crescimento econômico poderiam se esgotar rapidamente sem o avanço tecnológico (OLAVE; AMATO NETO, 2001). Desta forma, o ambiente de concorrência no qual as organizações estão instaladas impõe uma necessidade permanente por inovação, para que se tornem capazes de se adaptar às mudanças que ocorrem em seu ambiente (ABREU, 2007).

Neste sentido, observa-se a inovação tecnológica como uma das principais fontes de crescimento econômico. No entanto, esta abordagem é relativamente recente, com indícios a partir dos anos 50 (FREEMAN, 1994). Schumpeter, no período precedente aos anos 50, foi uma exceção. Dentre os economistas do início do século XX, Schumpeter (1989) tentou colocar a inovação como elemento fundamental, abordando a inovação em um sentido amplo ao incluir não apenas inovações de processo e produto, mas também a conquista de novas 
fontes de fornecimento de matéria-prima, a abertura de novos mercados e a reestruturação organizacional.

Para Schumpeter (1989), o processo inovativo caracteriza-se pela introdução de novas combinações produtivas ou mudanças nas funções de produção, classificando estas mudanças em cinco situações: i) a introdução de um novo produto que, pode ser novo para os consumidores, ou como uma nova qualidade de um produto já existente; ii) a abertura de um novo mercado em que outras empresas do mesmo setor ainda não tenham entrado; iii) o estabelecimento de uma nova organização industrial, seja pela criação de um monopólio ou por sua fragmentação; iv) introdução de um novo método de produção que ainda não foi testado pelo setor em que a empresa está inserida, não sendo, necessariamente, uma descoberta científica; v) a conquista de uma nova fonte de insumos.

Neste processo de transformações, o qual não basta somente copiar o que as empresas fazem, novas estratégias de diferenciação, capazes de produzir produtos e serviços de maior valor para os consumidores ou ainda produtos de igual valor a custos menores, devem ser desenvolvidas, estabelecendo desta forma vantagem competitiva ao longo do tempo (PORTER, 1996). Desta forma, para Franko (1989), a inovação deve ser colocada no centro do processo de mudança do sistema econômico, alterando e criando novas posições no mercado.

De modo geral, o processo de desenvolvimento de inovação engloba um conjunto de atividades que contribuem para aumentar a capacidade de produzir novos bens e serviços ou para iniciar novas formas de produção (ANTOLIN, 2002). O Manual de Oslo da Organização para a Cooperação e o Desenvolvimento Econômico (OCDE, 2005) define inovação como a implementação de um produto, bem ou serviço, novo ou significativamente melhorado ou um processo, bem como um novo método de marketing ou um novo método organizacional nas práticas de negócios, na organização do local de trabalho ou nas relações externas. Ainda, conforme o Manual de Oslo, a inovação tecnológica pode ser classificada como:

- Inovação de produto: é a introdução de um bem ou serviço novo ou significativamente melhorado no que concerne a suas características ou usos previstos. Incluem-se melhoramentos significativos em especificações técnicas, componentes e materiais, softwares incorporados, facilidade de uso ou outras características funcionais;

- Inovação de processo: é a implementação de um método de produção ou distribuição novo ou significativamente melhorado. Incluem-se mudanças significativas em técnicas, equipamentos e/ou softwares; 
- Inovação de marketing: é a implementação de um novo método de marketing com mudanças significativas na concepção do produto ou em sua embalagem, no posicionamento do produto, em sua promoção ou na fixação de preços;

- Inovação organizacional: é a implementação de um novo método organizacional nas práticas de negócios da empresa, na organização do seu local de trabalho ou em suas relações externas.

As inovações tecnológicas também podem ser caracterizadas como radicais ou incrementais. De acordo com Cassiolato e Lastres (2000), a inovação radical pode ser definida como eventos descontínuos que implicam mudança técnica e organizacional de um sistema produtivo ou industrial. Desta maneira, não emerge de um produto, processo ou sistema existente e sua introdução implica novas formas de produção, distintas das exploradas até aquele momento.

A inovação incremental refere-se ao aperfeiçoamento ou melhoria de produtos, processos, sistemas de produção e serviços já existentes. É altamente sensível à demanda, redução de custos e melhora na qualidade, em outras palavras, quando a inovação se dá de forma incremental, significa dizer que houve investimento em melhorias e não em mudanças nos produtos ou serviços oferecidos pela empresa.

Portanto, o conceito de inovação é amplo e as abordagens adotam diversas perspectivas teóricas diferentes, cada uma fornecendo entendimentos significativos, não se restringindo apenas em produto e processo, mas também em abertura de novos mercados consumidores, utilização de diferentes fontes de suprimentos, entre outros (RAPINI, 2007).

Desta forma, a adoção ou geração de uma inovação requer não somente um processo técnico para se obter um resultado com sucesso (ABREU, 2007), mas necessita também de um conjunto de rotinas organizacionais internas que proporcionem as bases competitivas em um determinado mercado ou em diferentes mercados (BUENO, 2011; NOVELI; SEGATTO, 2012).

Em uma abordagem mais ampla, Sbicca e Pelaez (2006, p.418) argumentam que a “inovação é fruto de um processo que só pode ser analisado quando se leva em conta seu caráter interativo".

Nesta perspectiva, a universidade constitui o principal centro de produção de conhecimento e, por este motivo, a interação entre e o meio empresarial vem ganhando importância estratégica ao longo dos anos para o desenvolvimento econômico das nações (SUZIGAN; ALBUQUERQUE, 2011). 


\subsection{Cooperação Universidade-Empresa-Governo}

O desenvolvimento tecnológico dos diferentes países é influenciado pelos elementos e relacionamentos que interagem na produção, difusão e uso do conhecimento novo e economicamente útil (DOSI, 1998). Os países, hoje, desenvolvidos começaram seu modelo industrial por meio do trabalho de artesão que, devido ao desenvolvimento econômico, buscaram alternativas para melhorar o processo artesanal, dando o passo inicial para o surgimento da indústria. Em meados do século XIX, com os ganhos de produção, iniciou a demanda pela contração de pessoas ligadas à pesquisa, o que contribuiu para o desenvolvimento de atividades de pesquisa em longo prazo (MOWERY; SAMPAT, 2004).

Somente o conhecimento criado dentro da empresa não era suficiente para acompanhar o desenvolvimento econômico e tecnológico, o que levou as empresas a buscarem conhecimento que não estava disponível no mercado, em fontes como as universidades, o que fez a relação entre as universidades e empresas crescerem mais rapidamente nos países desenvolvidos (NELSON, 2006).

Entretanto, em países emergentes, o desenvolvimento e a instalação de uma estrutura acadêmica de ensino e pesquisa ocorreram de forma tardia. No Brasil, por exemplo, o início da construção das instituições de ensino e pesquisa pode ser considerado tardio, limitado e problemático. Mesmo depois da criação das primeiras universidades, demorou muito para que se efetivasse o sistema de inovação no país e, ainda hoje, pode-se dizer que existem deficiências neste processo, pois em várias regiões do país o mesmo é inexistente ou existe de forma limitada e acanhada (SUZIGAN; ALBUQUERQUE, 2011).

Suzigan e Albuquerque (2011), discutindo a importância da cooperação entre universidades e empresas tanto para os países desenvolvidos quanto para o caso dos países em desenvolvimento, sugerem que as universidades e institutos de pesquisa têm desempenhado um importante papel ao longo da história para o desenvolvimento tecnológico de empresas de diversos países.

O estudo de Pinho e Fernandes (2012) sobre a relevância da cooperação universidadeempresa, para empresas em países em desenvolvimento, evidencia que a demanda tecnológica das empresas para as universidades no Brasil é diferente do que acontece em países desenvolvidos, mas não necessariamente mais fraca ou menos relevante, mesmo possuindo objetivos diferentes para desenvolverem relações com as universidades. Nos países em desenvolvimento, normalmente, as empresas estão preocupadas com a adaptação de produtos, processos e melhorias incrementais. 
No entanto, Albuquerque et al. (2008), mesmo reconhecendo a existência de relações relevantes entre as universidades e as empresas dos países em desenvolvimento, ponderam que isso não implica que este padrão de relacionamento seja suficiente para suportar os esforços mais ambiciosos em inovações radicais e em setores intensivos em PD\&I.

Neste contexto, a cooperação universidade-empresa é descrita pela aproximação entre o ator criador do conhecimento, a universidade, e o ator responsável pela aplicação econômica do conhecimento, a empresa, visando o desenvolvimento de atividades inovadoras (DOSI, 1998; NELSON; WINTER, 2005; ALBUQUERQUE et al., 2008).

Para Plonski (1992) a cooperação universidade-empresa é um modelo interinstitucional entre distintas organizações que podem possuir diferentes finalidades nos mais diversos formatos. Esta cooperação pode ocorrer de diversos modos e se utilizando de diferentes instrumentos, desde relações pouco comprometedoras, como o oferecimento de estágios profissionalizantes, até vinculações intensas e extensas, como os grandes programas de pesquisas cooperativas, chegando a ocorrer repartições advindas da comercialização de seus resultados.

Neste sentido, a universidade, capaz de cooperar com empresas e demais instituições da sociedade, não tem como única função a formação de pessoal qualificado, mas também a função de pesquisa e de extensão no sentido amplo de viabilizar formas de apoiar o desenvolvimento econômico (ETZKOWITZ, 2004).

\subsubsection{A Universidade Empreendedora}

A abordagem de cooperação da universidade com o setor produtivo nem sempre foi a característica principal das universidades. Com relação ao fato, Etzkowitz (2004) esclarece que o conceito de cooperação da universidade com o setor produtivo reflete um processo de evolução das atividades desenvolvidas, uma vez que por muito tempo a característica principal das universidades foi o ensino, evoluindo gradativamente para pesquisa e cooperação com a sociedade.

A universidade tem sido tradicionalmente conhecida como uma instituição núcleo para o desenvolvimento de conhecimento (CODURAS; URBANO; ROJAS, 2008), uma vez que os professores e estudantes são inventores em potencial e têm um importante papel nos grupos de pesquisa (ETZKOWITZ; LEYDESDORFF, 2000).

Autores, como D'Este e Patel (2007) e Renault (2006), argumentam que a discussão sobre uma terceira missão para as universidades está recebendo cada vez mais atenção de 
novas pesquisas. As universidades estão passando por uma mudança no seu papel junto à sociedade, focando em sua contribuição para o desenvolvimento social e para o crescimento econômico (ETZKOWITZ, 2003), por meio de novas tecnologias originárias de pesquisas acadêmicas (ETZKOWITZ; VIALE, 2010).

Nesta perspectiva, a universidade adquire a função de pesquisa e de extensão no sentido amplo de viabilizar formas de apoiar o desenvolvimento econômico, desta forma tem ganhado força a ideia de uma universidade empreendedora, como resultado da incorporação de novas funções pela universidade, observado na Figura 1 que esboça este processo descrito por Etzkowitz (2004).

Figura 1 - Coevolução e multilinearidade das relações universidade-indústria

\begin{tabular}{|l|}
\hline Grupos de Pesquisa \\
Empreendedores \\
Fluxo de conhecimento \\
Publicações \\
Egressos (indivíduos)
\end{tabular}

Grupos de Pesquisa

Empreendedores

Fluxo de conhecimento

Publicações

(20.

Escritórios de Interação
Consultoria
Pesquisa
Contratos

Escritórios de Transferência
de Tecnologia
Propriedade intelectual
Patentes
Licenças

Incubadoras

Tecnologia

Empreendedorismo

Criação de empresas

Egresso (Organizações)

Fonte: Adaptado de ETZKOWITZ (2004).

Inicialmente, ainda na idade média, a universidade tinha como objetivo principal a transmissão do conhecimento, por isso suas atividades eram totalmente voltadas para o ensino (ETZKOWITZ, 2004). As relações entre universidades e empresas iniciaram-se na Alemanha, com o desenvolvimento da indústria química, química sintética, inserindo na universidade a pesquisa científica alinhada ao ensino (STOKES, 2005).

O pioneirismo da Alemanha e dos Estados Unidos em unir as atividades de pesquisa com o ensino auxiliou o processo de desenvolvimento da indústria nacional e a formação da capacidade e absorção de novos conhecimentos destas empresas (MAZZOLENI; NELSON, 2007). Como resultado deste processo pode-se citar a conquista da liderança dos EUA e da Alemanha na indústria de base científica no início do século XX, ultrapassando os países 
líderes, Grã-Bretanha e França. A partir destas experiências, este modelo de universidade disseminou-se por outros países (NELSON, 2006).

À medida que a universidade torna-se a principal fonte de conhecimento, através de suas atividades de pesquisa, passa a ser considerada um agente crucial no progresso tecnológico dos países. Desde então, a universidade conquista progressivamente um papel de destaque no desenvolvimento de tecnologias e, principalmente, da economia de um país ao fornecer apoio e novo conhecimento científico à atividade inovativa das empresas no desenvolvimento de novos produtos e processos (MAZZOLENI; NELSON, 2007).

Desta forma, a união dessas atividades, formação de pessoas e pesquisa, para o desenvolvimento da economia se torna mais importante do que a especialização em apenas uma delas (MOVERY; SAMPAT, 2004). Etzkowitz (2003) chamou a inclusão da missão de pesquisa nas universidades de primeira revolução acadêmica que aconteceu no final do século XIX e no início do século XX. Neste período, a atividade de pesquisa deixou de ser, em grande parte, uma atividade individual praticada nas casas ou laboratórios particulares dos cientistas e foi institucionalizada, levada para dentro da universidade, tornando-se uma atividade profissional e adicional ao ensino.

Webster e Etzkowitz (1991) propõem, por meio de trabalhos conduzidos e publicados ainda no final dos anos 80 e início dos anos 90, a ideia de uma segunda revolução acadêmica. Tal conceito se desenvolve com base no argumento de que têm existido importantes modificações de tendências com respeito à comercialização da pesquisa acadêmica e mudanças que afetam os relacionamentos que acontecem dentro da universidade e entre academia e indústria.

Os autores vão além, afirmando que o que se observa é o início de um novo "contrato social" entre academia e sociedade, sendo que o apoio financeiro oferecido pelo Estado para a pesquisa acadêmica é mantido apenas quando e enquanto a pesquisa executar um papel chave na nova economia.

De acordo com Codura et al. (2009) e Etzkowitz (2009), a universidade, desde a segunda revolução acadêmica, tem convivido com as tensões geradas pelo novo ambiente, envolvendo a sua missão de ensino (original), pesquisa (primeira revolução) e desenvolvimento econômico e social (segunda revolução). Etzkowitz (2004) acredita que, no auge do progresso dessa segunda revolução acadêmica, sejam fundadas novas estruturas transacionais híbridas que combinem atividades de P\&D acadêmicas e industriais.

Desta forma, as instituições que passaram pela segunda revolução acadêmica constituem as universidades empreendedoras, que tem a habilidade de gerar uma direção 
estratégica focada tanto para a formulação de objetivo acadêmico quanto para a tradução de conhecimento produzido na universidade (ETZKOWITZ, 2003). Nesta perspectiva, para o autor Etzkowitz (2009), uma universidade empreendedora apoia-se em quatro pilares:

1. Liderança acadêmica capaz de formular e implementar uma visão estratégica;

2. Controle jurídico sobre os recursos acadêmicos, incluindo propriedades físicas, como os prédios da universidade, e a propriedade intelectual que resulta da pesquisa;

3. Capacidade organizacional para transferir tecnologia através de patenteamento, licenciamento e incubação;

4. Um ethos empreendedor entre administradores, corpo docente e estudantes.

Sendo assim, além de formar pessoal especializado e gerar conhecimento novo, a universidade tem o papel social de contribuir efetivamente para a discussão, para a proposição de alternativas e para a resolução dos problemas da sociedade em que se insere (ETZKOWITZ; LEYDESDORFF, 2000), isto é, a universidade que cooperar com empresas e demais instituições da comunidade não tem apenas o objetivo de formar pessoal qualificado, mas também de apoiar o desenvolvimento econômico (ETZKOWITZ; ZHOU, 2008).

O objetivo da universidade empreendedora não é apenas promover a transferência de tecnologia e aumentar o número de empresas iniciantes, mas garantir que as pessoas prosperem no ambiente no qual estão inseridas, contribuindo assim para a criação de um pensamento empreendedor (AUDRETSCH, D. B.; STEPHAN, 1999).

Com base nisto, universidades empreendedoras estão envolvidas em parcerias, redes e outros relacionamentos com organizações públicas e privadas que são de suma importância para a inovação, o que significa que a universidade empreendedora implementa diversas estratégias e novas configurações institucionais para trabalhar em conjunto com o governo e empresas, facilitando, assim, a geração e exploração de conhecimento e tecnologia (LEYDESDORFF; MEYER 2006).

Em resumo, as universidades modernas estão se tornando cada vez mais empreendedoras, fazendo não só o ensino e pesquisa, mas fornecendo também serviços para a indústria ou participando do estabelecimento de novas empresas que trazem resultados de pesquisas para o mercado (SEPPO; ROOLAHT, 2012). 


\subsubsection{Configurações da Tripla Helix}

A universidade deve ser a instituição núcleo da economia do conhecimento e a cooperação entre governo, universidade e empresa, elementos importantes para viabilizar o desenvolvimento científico e tecnológico exigido pela economia moderna. Tais interações entre os agentes vêm se transformado ao longo dos anos.

Nesta perspectiva, este novo modelo de pesquisa multidirecional, conhecido como "Modelo da Hélice Tripla" (Triple Helix), começou a ser discutido a partir de uma proposta feita por Etzkowitz e Leydesdorff (1995) e continua sendo alvo de uma série de conferências internacionais. A primeira delas, realizada em janeiro de 1996, na cidade de Amsterdã, na Holanda, reuniu um grupo de 80 pesquisadores e analistas políticos de 30 diferentes países. Atualmente, a conferência já acumula passagem por vários países, tais como: EUA (Nova Iorque), Brasil (Rio de Janeiro), Dinamarca (Copenhagen), Suécia (Lund), Itália (Turim) e Inglaterra (Londres).

As proposições teóricas decorrentes do modelo da Hélice Tripla, de Etzkowitz e Leydesdorff (1995), apresentam um modelo de interação coparticipativa entre governo, empresa e universidade, contrastando com o modelo tradicional do fluxo de conhecimento num sentido único, isto é, da pesquisa básica para a inovação.

Conforme Etzkowitz e Leydesdorff (2000), o modelo apresenta evoluções e parte do pressuposto de que mesmo que relações bilaterais existam entre estes atores, estas não são suficientes para promover as inovações. Além disso, as relações entre os agentes estão em constante evolução, exigindo, assim, novas formas de representação geométrica do processo.

De acordo com o trabalho dos autores Tonelli e Zambalde (2007), o modelo da Tríplice Hélice interpreta a dinâmica da inovação a partir de redes de comunicação que remodelam permanentemente os arranjos institucionais a partir das expectativas que vão surgindo, sem privilégio a qualquer um dos agentes. Etzkowitz e Leydesdorff (2000) argumentam que há quem prefira rotular com diferentes nomes os diversos modelos que, historicamente, apareceram para representar as relações entre universidade-indústria-governo, versões I, II e III da Hélice Tripla.

Na concepção de Hélice Tripla I, o estado-nação, engloba as universidades e empresas e dirige as relações entre elas, como observado na Figura 2. O estado comanda a relação entre a universidade e as empresas, como na antiga União Soviética e em muitos países latinoamericanos durante os regimes ditatoriais, porém nesse tipo de organização havia poucos estímulos à inovação (ETZKOWITZ, 2009). 
Neste modelo, predominam relações unilaterais e não há um direcionamento preciso das ações do governo para desenvolvimento científico e tecnológico em relação ao mercado e à universidade. Por tal motivo, os autores optaram pela representação através de esferas com fronteiras bem definidas (RODRIGUES e LACERDA, 2010).

Figura 2 - O modelo estático das relações universidade-indústria-governo

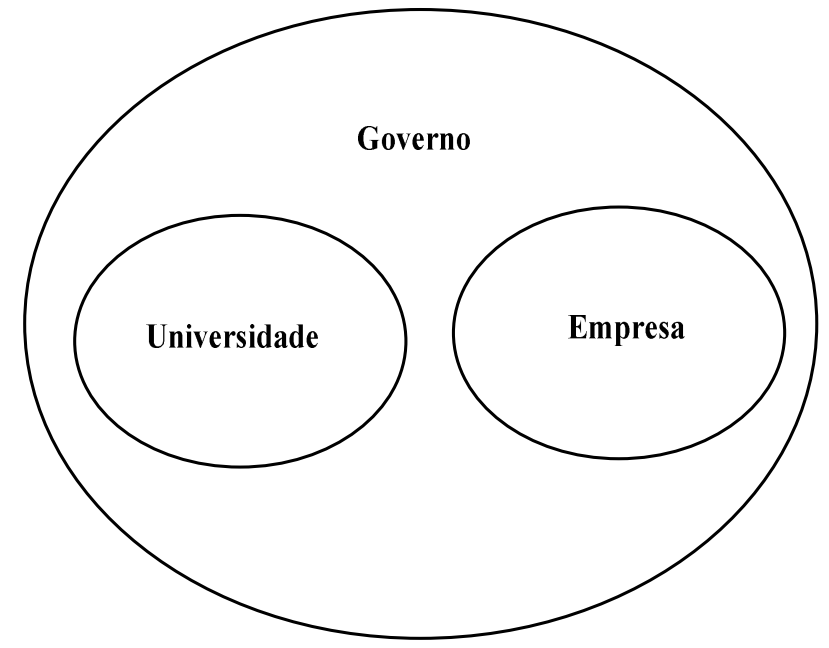

Fonte: Adaptado de ETZKOWITZ; LEYDESDORFF (2000).

No entanto, a Hélice Tripla I é vista como um modelo de desenvolvimento falho, com poucas possibilidades para as iniciativas bottom-up ${ }^{l}$ e no qual a inovação foi mais desencorajada do que estimulada. Usando alguns casos específicos ocorridos na América Latina, Sutz (2000) afirma que, com raras exceções, os resultados dos mecanismos top-down ficaram bem abaixo das expectativas dos políticos de Ciência e Tecnologia (C\&T), policy makers, na medida em que não houve melhoria significativa no baixo envolvimento histórico da indústria com atividades de conhecimento e de inovação tecnológica.

Ainda de acordo com a autora, alguns aspectos que conformavam o contexto latinoamericano do final do século XX ajudam a explicar tais resultados insatisfatórios, sendo eles: (i) o drástico emagrecimento do Estado seguido pelo processo de privatização e internacionalização do processo de geração e acúmulo de conhecimento; (ii) a inserção "periférica" da América Latina na economia mundial, mantendo o padrão histórico da troca de bens e serviços com baixo conteúdo tecnológico por outros com alto conteúdo tecnológico;

\footnotetext{
${ }^{1}$ SUTZ (2000) apresenta as duas diferentes abordagens, bottom-up e top-down, com foco sobre as relações universidade-indústria-governo no contexto latino-americano. Na abordagem bottom-up, a análise ocorre sobre as experiências concretas de relações de conhecimento entre usuário-produtor. Enquanto na abordagem top-down a análise recai sobre os resultados dos esforços de institucionalização das relações universidade-indústriagoverno, com foco no papel de cada ator.
} 
(iii) a manutenção da tradição da Universidad de la Reforma impregnada de desconfiança e repugnância sobre as relações entre universidades públicas, indústria e governo; (iv) a elevada desigualdade socioeconômica dificultando significativamente a melhoria das capacidades técnico-produtivas; e (v) a fragilidade dos Sistemas Nacionais de Inovação Latino Americanos, devido, principalmente, à negligência histórica da inovação técnica.

O segundo modelo identificado pelos mesmos autores (ETZKOWITZ; LEYDESDORFF, 2000), o da Tríplice Hélice II, representado na Figura 3, consiste em esferas institucionais separadas por fortes limites e independência entre o governo, as empresas e a academia, próximo ao estilo laissez-faire. Tal versão vincula-se à política de mercado, defendida como sendo uma "terapia de choque" para reduzir o papel do Estado tão presente na primeira versão.

Na Hélice Tripla II, há uma evolução em relação à anterior, pois se observa a ausência de um espaço integrante entre as ações do governo-universidade-empresa e a maior parte das relações é do tipo bilateral (RODRIGUES; LACERDA, 2010).

Figura 3 - O modelo laissez-faire das relações universidade-indústria-governo

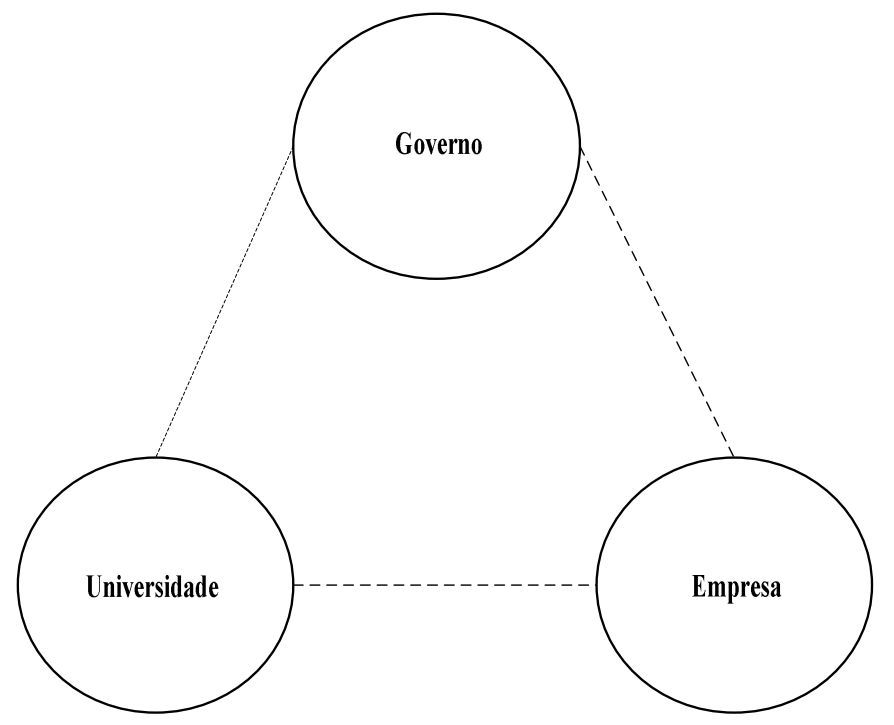

Fonte: Adaptado de ETZKOWITZ; LEYDESDORFF, 2000.

Um modelo semelhante, surgido na América Latina e denominado como Triângulo de Sábato, foi apresentado em 1968 por Jorge Sábato - na época, diretor da Comissão Nacional de Energia Atômica da Argentina - e Natalino Botana - na época, pesquisador do Instituto para a Integração da América Latina - que propuseram, para a superação do subdesenvolvimento da região e o seu acesso à condição de sociedade moderna, a realização de uma ação decisiva no campo da pesquisa científico-tecnológica. 
O conceito de Triângulo de Sábato representava uma estratégia para a inserção da América Latina entre os países desenvolvidos, por meio da articulação de três atores fundamentais: o governo, as universidades e as empresas, cada um destes representado por meio de um vértice que dá origem ao Triangulo de Sábato (Figura 4).

Os argumentos expostos por Sábato e Botana (1968) compreendiam (i) uma maior eficiência na absorção de tecnologias e a existência no país receptor de uma sólida infraestrutura científico-tecnológica; (ii) o reconhecimento da especificidade das condições de cada país para conseguir uma utilização inteligente dos fatores de produção; (iii) a necessidade de exportar bens com maior valor agregado e (iv) o fato de que ciência e tecnologia são catalisadores da mudança social (TERRA, 2001).

Figura 4 - Triângulo de Sábato

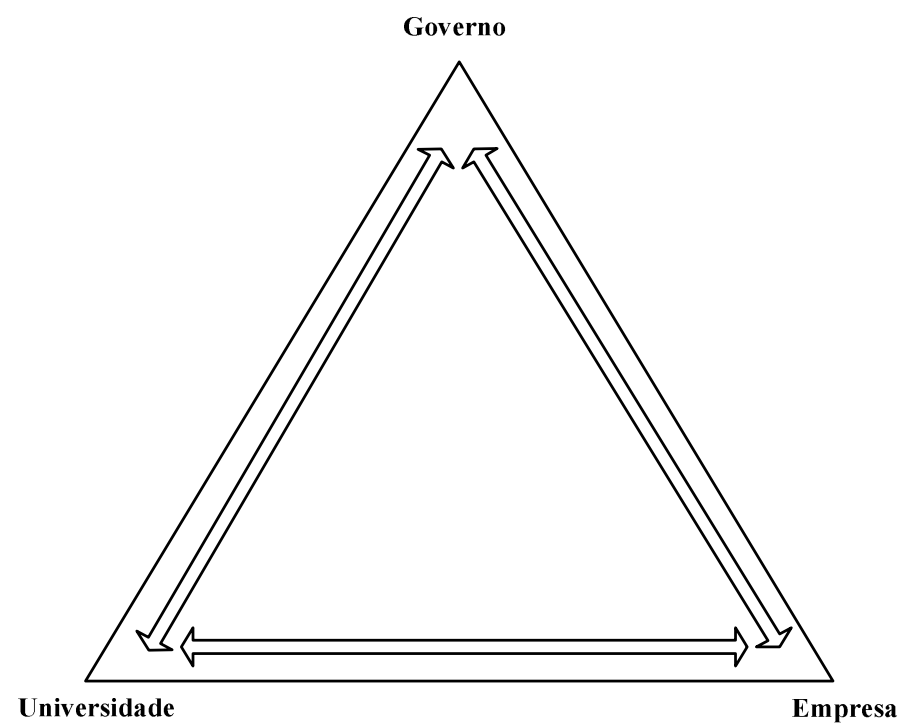

Fonte: TERRA, 2001.

Com base no Triângulo de Sábato, as relações podem acontecer dentro de cada vértice, intra-relações, relações que ocorrem entre os três vértices do triângulo, inter-relações, e ainda as relações entre os três atores do triângulo e o meio externo, extra-relações (PLONSKI, 1995).

As intra-relações são as que se estabelecem dentro de cada vértice e têm como objetivo básico capacitar as instituições a criarem, incorporarem e transformarem necessidades em um produto final, que é a inovação tecnológica. Esta capacidade é considerada uma qualidade que hipoteticamente é atribuída às instituições em cada um dos vértices e que, logicamente, terá uma conotação particular de acordo com o vértice considerado. 
As inter-relações podem ser classificadas em horizontais e verticais. As primeiras referem-se às relações que ocorrem entre a infraestrutura tecno-científica e a estrutura produtiva, já as segundas são as estabelecidas entre o governo e a infraestrutura tecnocientífica ou entre o governo e a estrutura produtiva.

As extra-relações ocorrem entre cada um dos vértices com o contorno externo do espaço no qual se situam. A compra de tecnologia pronta constitui um exemplo deste tipo de relação bastante vivenciado pelos países desenvolvidos.

De acordo com Terra (2001) as inter-relações horizontais são as mais difíceis de se estabelecer e, ao mesmo tempo, as mais interessantes de serem exploradas, pois evidenciam o fato de que o esforço de aprimorar as inter-relações verticais, com o governo, é uma condição necessária, porém insuficiente, para o desenvolvimento da sociedade. Assim, inovação é um produto deste sistema de relações, ressaltando-se o caráter fundamental das inter-relações entre a estrutura científico-tecnológica, representada pelas universidades e a estrutura produtiva, representada pelas empresas.

Em suma, as versões I e II da Hélice Tripla demonstram uma preocupação com a configuração estática destes modelos. A versão III procura avançar além dessa linha de pensamento, incluindo novos elementos nos vértices da representação geométrica, com ênfase adicional para a dinâmica do modelo.

Assim, de acordo com Etzkowitz (2009), atualmente, a maioria dos países estão tentando buscar o modelo da Hélice Tripla III, uma vez que os outros dois modelos, estático e laissez-faire, são mais desencorajadores que encorajadores. Nesta perspectiva, a Figura 5, demonstra tal modelo. Segundo Etzkowitz e Leydesdorff (2000):

a Hélice Tripla III baseia-se em uma infraestrutura de conhecimento representada por esferas institucionais superpostas, com cada uma delas executando o seu papel e também parte das ações das demais, com organizações híbridas surgindo das interfaces. (ETZKOWITZ; LEYDESDORFF, 2000, p. 111) 
Figura 5 - O modelo da Hélice Tripla das relações universidade-indústria-governo

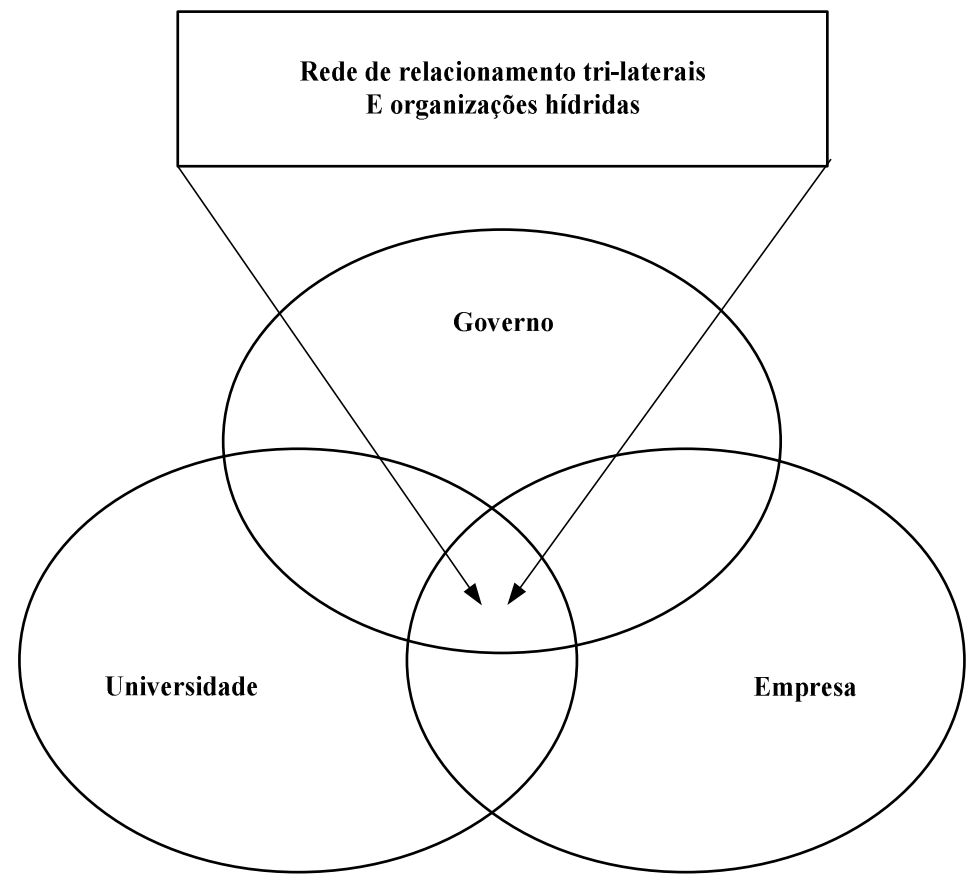

Fonte: Adaptado de ETZKOWITZ; LEYDESDORFF, 2000.

A área superposta pelas três esferas, como observado na Figura acima, representa a região na qual se encontram as cadeias trilaterais e as organizações híbridas. Portanto, o objetivo comum da maioria dos países é desenvolver um ambiente inovativo constituído de spin-offs acadêmicas, iniciativas trilaterais de desenvolvimento de uma economia baseada no conhecimento, alianças estratégicas entre empresas de diferentes tamanhos e nível de desenvolvimento tecnológico, laboratórios governamentais e grupos de pesquisa acadêmicos. Tais arranjos são encorajados e fomentados pelo governo, porém não são controlados por ele (ETZKOWITZ; LEYDESDORFF, 2000).

Assim, por ser a Hélice Tripla um modelo analítico que adiciona a explicação de sua dinâmica à descrição de uma variedade de arranjos institucionais e modelos políticos, marcado por esferas interligadas com zonas comuns e por relações complexas - comunicação, negociação, trocas, acordos, feedback, pressões, tensões - que se dão em vários níveis dentro das instituições, não se espera que este seja um modelo estável, mas sim em constante mutação. Este modelo, portanto, é mais bem representado pela Figura 6 que demonstra a sobreposição de comunicações, redes e organizações e orienta a reconstrução dos arranjos institucionais (ETZKOWITZ; LEYDESFORFF, 2000). 
Figura 6 - Metáfora da Tripla Hélice

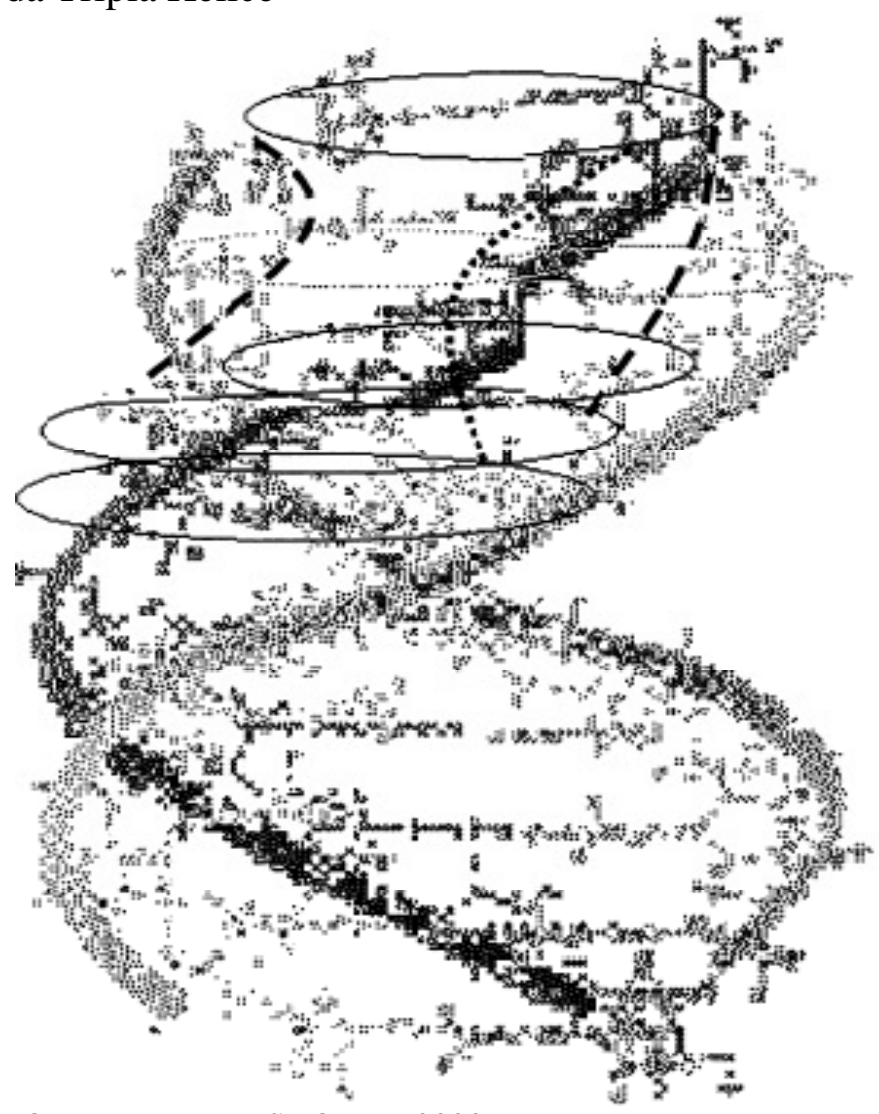

Fonte: adaptado de ETZKOWITZ; LEYDESDORFF, 2000.

Rodrigues e Lacerda (2010) afirmam que o modelo da Tríplice Hélice III representa uma nova realidade de relações trilaterais entre empresas, governo e universidades, no qual a intersecção das setas indica a ação conjunta dos três agentes para a promoção de inovação científica e tecnológica.

De acordo com Etzkowitz et al (2000) e Etzkowitz (2003) o modelo da Hélice Tripla III indica quatro processos importantes na produção, troca e uso do conhecimento: (i) a transformação interna em cada uma das hélices, bem como o desenvolvimento de ligações laterais entre as companhias através de alianças estratégicas e uma apropriação da missão do desenvolvimento econômico pelas universidades; (ii) a influência de uma esfera institucional sobre a outra produzindo transformações; (iii) a criação de uma nova 'camada' das ligações trilaterais, redes e organizações entre as três hélices, servindo para institucionalizar e reproduzir interfaces, assim como estimular criatividade institucional e uma natureza regional coesiva e por fim, (iv) o efeito destas redes interinstitucional representando a academia, a empresa e o governo sobre suas esferas originais e sobre toda a sociedade.

À medida que o conhecimento se torna cada vez mais um insumo importantíssimo para o desenvolvimento socioeconômico é natural que a universidade, enquanto um espaço 
institucional de geração e transmissão de conhecimentos, seja vista e analisada como um ator social de destaque. A tese da Hélice Tríplice é de que a cooperação universidade, empresa e governo é a chave para melhorar as condições para inovação numa sociedade baseada no conhecimento (RENAULT, 2006).

Em síntese, as transformações de um modelo linear de inovação para um modelo interativo, focado na formação de redes de produção de conhecimento, conforme Etzkowitz e Zhou (2008), podem ser observadas nos mecanismos organizacionais que vêm surgindo no âmbito das universidades a fim de viabilizar a interface com o setor empresarial, tais como incubadoras de empresas, escritórios de transferência de tecnologia, parques científicos tecnológicos, entre outros.

Por fim, é importante esclarecer que, de modo geral, aceita-se como válida a tese de que a universidade vive um processo de transformação ou revolução interna, muito embora não se tenha escolhido um modelo preferencial a ser seguido para a interpretação do fenômeno. A este respeito sugere-se que a escolha de um ou outro modelo conceitualanalítico deverá estar condicionada ao contexto no qual a universidade se insere - localização, natureza e cultura institucional.

\subsubsection{Benefícios e Barreiras à Cooperação Universidade-Empresa}

A cooperação universidade-empresa apresenta grande potencial de alavancar o crescimento econômico. Alguns trabalhos já propõem e discutem esta temática, apresentando levantamentos teóricos e resultados empíricos. Mesmo nos trabalhos cujo tema não é central no debate, os resultados terminam por, de alguma forma, apontar os benefícios e as barreiras que se obtém na cooperação. Diante disso, as seções a seguir apresentarão os benefícios e as barreiras na cooperação universidade-empresa, que correspondem aos resultados obtidos na revisão sistemática da literatura.

\subsubsection{Benefícios Percebidos na Cooperação Universidade-Empresa}

A revisão sistemática desenvolvida evidenciou que existem diversos benefícios voltados a cooperação, que podem ser percebidos junto as universidades e as empresas. Nesse sentido, Mowery e Sampat (2004) e Porto et. al (2011) argumentam que ao interagir com as empresas as universidades transferem não apenas a tecnologia resultante de suas pesquisas, mas também a criatividade de seus pesquisadores, induzindo ao desenvolvimento de um 
processo criativo na indústria no lugar de uma relação de dependência. Autores como Albuquerque (2005) e Rapini et al. (2009) sugerem que as empresas se beneficiem da utilização de pessoal qualificado, utilização de conhecimentos advindos da pesquisa acadêmica para resolverem problemas que não foram solucionados pelo departamento de P\&D da empresa.

O setor produtivo, em alguns casos, realiza inovação de produto ou processo que sem a cooperação com a universidade não seria possível (COHEN; NELSON; WALSH, 2002). Os autores, Dutrénit e Arza (2010); Albuquerque et al. (2008); Arza (2010); Fuentes e Dutrénit (2012), apontam que a universidade tem as seguintes vantagens: os pesquisadores tem ideias para novos projetos de pesquisa, obtenção de recursos financeiros para a execução de pesquisas básicas e aplicadas e intercâmbio de conhecimentos.

Nesta perspectiva, estudos têm demonstrado que os benefícios percebidos da cooperação são diferentes tanto para as universidades quanto para as empresas. A partir da perspectiva de Arza (2010), os benefícios da cooperação com as empresas, podem ser agrupados em duas categorias principais: econômico e intelectual.

Os benefícios econômicos referem-se, por exemplo, à obtenção de materiais para a pesquisa e à obtenção de recursos financeiros. Por sua vez, os benefícios intelectuais dizem respeito à troca de conhecimento, ideias para novos projetos científicos, publicações acadêmicas, ideias para novos projetos de colaboração e para a possibilidade de moldar o conhecimento que está a ser produzido. Outros autores, ERKMANN; WALSH (2009), WRIGHT et al. (2008) e DUTRÉNIT; ARZA (2010), analisaram os benefícios para os pesquisadores de quatro países latino-americanos, de acordo com a classificação já referida.

Com relação às empresas, as vantagens da cooperação podem ser agrupadas em: benefícios de curto prazo e de longo prazo. Benefícios de curto prazo estão relacionados com questões de produção, como utilização de recursos disponíveis na universidade para realizar teste e controle de qualidade (DUTRÉNIT; ARZA, 2010; FERNANDES et al., 2010; ARZA, 2010; FUENTES; DUTRÉNIT, 2012), conforme a contribuição para a conclusão de projetos existentes e melhoria de compreensão de problemas particulares (D ESTE, 2008; BISHOP; D'ESTE; NEELY, 2011).

Benefícios de longo prazo referem-se às questões de inovação, tais como profissionais qualificados (COHEN; NELSON; WALSH, 2002; D ESTE, 2008; FUENTES; DUTRÉNIT, 2012), identificação de novos projetos de $P \& D$ e acesso à pesquisa na universidade, licenças de tecnologia e patentes (LEE, 2000; BISHOP; D'ESTE; NEELY, 2011). Seppo e Roolaht (2012) enfatizam em seu trabalho que a empresa vai manter relação com a universidade 
quando não pode alcançar seu objetivo sozinha ou quando é mais rápido ou econômico fazêlo em colaboração com a universidade.

Dan (2013) acrescenta que as razões que justificam o crescimento das alianças tecnológicas estão relacionadas ao fato de que as empresas não possuem internamente todos os recursos necessários, incluindo conhecimento para desenvolver sozinhas as pesquisas e que as empresas desejam reduzir os riscos associados à inovação.

De acordo com a autora, tomando como princípio a necessidade de redução de custos, a empresa busca o conhecimento externo, sendo que uma das fontes mais importantes é constituída pelas universidades. Tal aproximação tem viabilizado o acesso a suporte técnico especializado como forma de complementar a P\&D interna destas organizações.

A universidade é vista pela empresa como um centro de conhecimento que pode ser acessado via licenciamento, parcerias, qualificação de profissionais e desenvolvimento de pesquisa. Usualmente, as empresas têm a visão de que as universidades podem complementar o seu esforço tecnológico e com isso reduzir o custo de pesquisa. Além disso, as empresas também sofrem com a restrição de recursos internos suficientes para desenvolver pesquisas isoladamente (PORTO, 2006).

A restrição de recursos públicos para as universidades ao longo das duas últimas décadas intensificou a competição entre os grupos de pesquisas e motivou a busca por parcerias com empresas, como fonte complementar de recursos financeiros. Como resultado, os grupos de pesquisas começaram a adotar um pensamento mais empresarial para o desenvolvimento de suas pesquisas (PORTO et al., 2011).

Conforme observado, vários são os benefícios proporcionados pela relação que transparecem nos trabalhos exemplificados. Diante disso, os benefícios da cooperação universidade-empresa, assim como os autores que os mencionam, encontram-se representados no Quadro 1, a seguir. 
Quadro 1 - Benefícios resultantes da cooperação universidade-empresa.

\begin{tabular}{|c|c|c|}
\hline & $\begin{array}{c}\text { Benefícios da cooperação Universidade- } \\
\text { Empresa }\end{array}$ & Referências \\
\hline & Resolução de problemas & $\begin{array}{l}\text { BISHOP; D'ESTE; NEELY (2011); D Este } \\
\text { (2008); Fuentes; Dutrénit (2012) }\end{array}$ \\
\hline & Desenvolvimento de novos produtos & Cohen; Nelson; Walsh (2002); \\
\hline & Desenvolvimento de novos processos & $\begin{array}{l}\text { Cohen; Nelson; Walsh (2002); Albuquerque } \\
\text { (2005); Rapini et al. (2009) }\end{array}$ \\
\hline & $\begin{array}{l}\text { Utilização de recursos disponíveis nas } \\
\text { universidades para realização de testes e } \\
\text { controle de qualidade }\end{array}$ & $\begin{array}{l}\text { Albuquerque (2005); Rapini et al. (2009); } \\
\text { Dutrénit; Arza (2010); Fernandes (2010); Fuentes; } \\
\text { Dutrénit (2012); Arza (2010) }\end{array}$ \\
\hline & Fontes de informação para novos projetos & $\begin{array}{l}\text { BISHOP; D'ESTE; NEELY (2011); D Este } \\
\text { (2008); Arza (2010) }\end{array}$ \\
\hline & Redução de custos & Lundberg; Andresen (2012); Arza (2010) \\
\hline 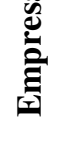 & Profissionais qualificados & $\begin{array}{l}\text { Cohen; Nelson; Walsh (2002); Albuquerque } \\
\text { (2005); D Este (2008); Rapini et al. (2009); } \\
\text { Fuentes; Dutrénit (2012) }\end{array}$ \\
\hline & Acesso à universidade de pesquisa & $\begin{array}{l}\text { D Este (2008); Lundberg; Andresen (2012); } \\
\text { Fuentes; Dutrénit (2012) }\end{array}$ \\
\hline & $\begin{array}{l}\text { Melhoria de compreensão de problemas } \\
\text { particulares }\end{array}$ & BISHOP; D’ESTE; NEELY, 2011; D Este (2008) \\
\hline & $\begin{array}{l}\text { Aumento da capacidade das empresas para } \\
\text { encontrar e absorver informações tecnológicas }\end{array}$ & $\begin{array}{l}\text { D Este (2008); Lundberg; Andresen (2012); } \\
\text { Fuentes; Dutrénit (2012); }\end{array}$ \\
\hline & Redução de riscos associados à P\&D & $\begin{array}{l}\text { Lundberg; Andresen (2012); Fuentes; Dutrénit } \\
\text { (2012) }\end{array}$ \\
\hline & Serviços de consultoria & $\begin{array}{l}\text { Albuquerque et al. (2008); Rapini et al. (2009); } \\
\text { Arza (2010) }\end{array}$ \\
\hline & Identificação de novos projetos de $\mathrm{P} \& \mathrm{D}$ & $\begin{array}{l}\text { Cohen; Nelson; Walsh (2002); Dutrénit; Arza } \\
\text { (2010); Fernandes (2010); Fuentes; Dutrénit } \\
\text { (2012); Arza (2010) }\end{array}$ \\
\hline & Ideia para novos projetos de colaboração & Fuentes; Dutrénit (2012); Arza (2010) \\
\hline & Promover a pesquisa & $\begin{array}{l}\text { D Este; Perkmann (2011); Dutrénit; Arza (2010); } \\
\text { Arza (2010) }\end{array}$ \\
\hline & $\begin{array}{l}\text { Participação dos pesquisadores } \\
\text { desenvolvimento dos produtos/processos }\end{array}$ & D Este; Perkmann (2011) \\
\hline 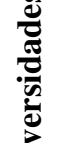 & Obtenção de recursos financeiros & $\begin{array}{l}\text { D Este; Perkmann (2011); Dutrénit; Arza (2010); } \\
\text { Albuquerque et al. (2008); Fuentes; Dutrénit } \\
\text { (2012); Arza (2010) }\end{array}$ \\
\hline 尚 & Intercâmbio de conhecimento & $\begin{array}{l}\text { Dutrénit; Arza (2010); Albuquerque et al. (2008); } \\
\text { Fernandes (2010); Fuentes; Dutrénit (2012); Arza } \\
\text { (2010) }\end{array}$ \\
\hline & $\begin{array}{l}\text { Utilização de recursos disponíveis nas empresas } \\
\text { para realização de testes para produtos e } \\
\text { processos }\end{array}$ & $\begin{array}{l}\text { Dutrénit; Arza (2010); Albuquerque et al. (2008); } \\
\text { Fuentes; Dutrénit (2012) }\end{array}$ \\
\hline & Fornecimento de materiais para a pesquisa & Fuentes; Dutrénit (2012); Arza (2010) \\
\hline & Publicações acadêmicas & $\begin{array}{l}\text { Cohen; Nelson; Walsh (2002); Dutrénit; Arza } \\
\text { (2010); Fuentes; Dutrénit (2012) }\end{array}$ \\
\hline
\end{tabular}

Fonte: Elaborado pela autora a partir das consultas nas bases Scopus; Web of Science e Science Direct - 2013. 


\subsubsection{Barreiras à Cooperação Universidade-Empresa}

Apesar dos diversos benefícios da cooperação universidade-empresa, deve-se entender que os dois setores possuem dinâmica e objetivos diferentes que criam barreiras a serem superadas.

Entre os trabalhos sobre o tema Seppo e Roolaht (2012) e D'Este e Salter (2010) argumentam que as principais barreiras para a cooperação entre universidade e empresa são os objetivos diferentes, foco diferente da pesquisa, conflitos sobre a propriedade intelectual, falta de recursos financeiros e de financiamento, baixa capacidade de absorção da empresa, baixa capacidade tecnológica da universidade e distância geográfica entre a empresa e a universidade.

Belkhodja e Landry (2007) argumentam que os conflitos são originários na diferença entre os objetivos de cada segmento. A universidade tem como objetivo principal a geração de conhecimento, a formação de profissionais e a produção e difusão científica. A empresa centraliza sua atenção na geração de lucros, primordial para sua sobrevivência, justificando a tecnologia como instrumento estratégico de participação e permanência no mercado. D'Este e Patel (2007) ressaltam que o interesse das empresas é usar os resultados da pesquisa para resolver problemas e, assim, aumentar o lucro.

Apesar de complementares em seus papeis sociais, as empresas esperam que as universidades desempenhem as metas em curto prazo (BRUNEEL; D'ESTE; SALTER, 2010; D'ESTE; PERKMANN, 2010; D’ESTE, 2007), enquanto que na universidade o horizonte de tempo é longo prazo (BRUNEEL; D’ESTE; SALTER, 2010).

As empresas geralmente têm limitações de tempo muito apertado e precisam de soluções para seus problemas de imediato, entretanto, nas universidades as pesquisas e publicações dos resultados das investigações leva tempo. Nesta perspectiva, como as empresas nem sempre estão dispostas a esperar os resultados das pesquisas desenvolvidas pelas universidades, usam a possibilidade de importar a solução, ao invés de colaborar com as universidades (SEPPO; ROOLAHT, 2012).

As empresas visam o lucro, sendo assim, selecionam cuidadosamente os projetos nos quais deverão se engajar, conforme o risco e o retorno econômico (OLIVEIRA, 2002). Todas as informações importantes são cuidadosamente mantidas em sigilo de seus concorrentes. Assim, ao contrário da universidade, a empresa é fechada quanto às informações e extremamente seletiva quanto à sua utilização (BRUNEEL; D’ESTE; SALTER, 2010). 
Ipiranga, Freitas e Paiva (2010) ressaltam que a universidade não está acostumada à pesquisa de forma dirigida, através de solicitações precisas, com prazos determinados, pois existe liberdade de escolha dos temas de pesquisa, diferentemente das empresas que têm interesse em pesquisas aplicadas, exigem exclusividade, sigilo de resultados e cumprimento de prazos.

O problema com o direito de propriedade intelectual é um dos conflitos entre as universidades e a empresa mais citados por Bruneel, D’Este e Salter (2010). Ambos os parceiros estão interessados em obter os direitos, uma vez que com os direitos de propriedade intelectual é possível garantir lucro e retorno sobre o que foi investido na pesquisa (ROHRBECK; ARNOLD, 2006; FREITAS; MARQUES; SILVA, 2008; D'ESTE; PERKMANN, 2010).

A falta de recurso financeiro e de financiamento é um obstáculo importante na cooperação entre universidades e empresas, especialmente para as universidades, pois com apoio financeiro e benefícios torna-se possível estabelecer e manter as relações com a empresa. Normalmente, as empresas não compreendem a forma como o orçamento da universidade é formado, ao mesmo tempo em que as universidades não percebem as forças do mercado, prazos e os processos dentro da empresa. Este tipo de desconhecimento traz consigo problemas de comunicação (ELMUTI; ABEBE; NICOLOSI, 2005).

Belkhodja e Landry (2007), Freitas, Marques e Silva (2008) e Bishop, D’Este e Neely (2011) citam a distância física entre as empresas e a universidade como um fator que influencia fortemente o comportamento de interação, pois se a distância entre os parceiros é extensa, as barreiras crescerão, já que, mesmo com o avanço das tecnologias de comunicação, os contatos diretos ainda são de crucial importância e seus custos aumentam com a distância.

A partir da perspectiva de Bruneel, D’Este e Salter (2010) as barreiras à cooperação universidade-empresa podem ser agrupadas em dois tipos principais: barreiras relacionadas ao relacionamento e barreiras relacionadas à transação. As barreiras de relacionamento dizem respeito, por exemplo, à pesquisa universitária ser voltada para a ciência pura, o enfoque de curto prazo das empresas, o longo prazo das universidades e a falta de compreensão de ambas as partes sobre as expectativas e práticas do trabalho. Por sua vez, as barreiras relacionadas à transação referem-se principalmente aos conflitos sobre a propriedade intelectual, preocupação com confidencialidade, regras e regulamentações impostas pelas universidades e governos.

Em geral, para o sucesso da colaboração universidade-empresa, é importante encontrar possibilidades que reduzam os entraves que limitam a expansão da relação e que, ao mesmo 
tempo, possam aumentar a motivação para a cooperação entre ambas. Seppo e Roolaht (2012) destacam em seu trabalho que é preciso um longo tempo para diminuir os obstáculos em relação à cooperação universidade-empresa.

Os autores sugerem que dentre as políticas necessárias para diminuir as barreiras devese buscar uma maior troca de informação, distribuição de propriedade intelectual e as universidades devem concentrar-se em pesquisa aplicada. Adicionalmente, o apoio financeiro para a cooperação entre universidades e empresas também é importante para aumentar a consciência dos potenciais benefícios deste tipo de colaboração em toda a sociedade.

Siegel et al. (2003a), em um estudo com 98 representantes institucionais envolvendo administradores de universidades, cientistas acadêmicos e industriais gerentes e empreendedores, identificaram possibilidades de melhorias para os relacionamentos de colaboração entre universidade e empresa, agrupadas em melhorias sugeridas para as universidades e melhorias sugeridas para as empresas.

No primeiro caso, os autores recomendam melhorar o atendimento universitário em relação às empresas que podem comercializar as suas tecnologias, adotar uma postura mais flexível na negociação dos acordos de transferência de tecnologia e disponibilizar recursos adicionais para os escritórios de transferência de tecnologia e patenteamento. No que diz respeito às melhorias sugeridas para as empresas, as mesmas, segundo os autores, necessitam contratar gerentes de tecnologia com experiência universitária e explorar meios alternativos para dinamizar as redes sociais de transferência de tecnologia.

Cabe à universidade aprender a interagir com as empresas, entender seus problemas e buscar ajuda na solução ou na proposição de novas tecnologias. Há que criar condições para a superação de problemas, tais como o grau de incerteza dos projetos, a localização geográfica das instituições, apoio governamental, sistema de distribuição de incentivos financeiros a universidades e a diferença do nível de conhecimento entre as universidades e empresas (SEGATTO-MENDES; SBRAGIA, 2002). Assim, as empresas precisam desenvolver capacidade para absorver as tecnologias, internalizar atividades de P\&D e, principalmente, aprenderem a inovar (RIGHI, 2009).

Nesta perspectiva, o Quadro 2 apresenta as barreiras da cooperação universidadeempresa e os autores que as mencionam. 
Quadro 2 - Barreiras à cooperação entre universidades e empresas

\begin{tabular}{|c|c|c|}
\hline & Barreiras & Referências \\
\hline \multirow{7}{*}{ Empresa } & Enfoque de longo prazo da universidade & $\begin{array}{l}\text { Freitas; Marques; Silva (2008); } \\
\text { Bruneel; D’Este; Salter (2010); }\end{array}$ \\
\hline & $\begin{array}{l}\text { Desejo da universidade de publicar os resultados da } \\
\text { pesquisa }\end{array}$ & $\begin{array}{l}\text { Bruneel; D'Este; Salter (2010); } \\
\text { Dan (2013) }\end{array}$ \\
\hline & Pesquisa da universidade foca em ciência pura & Bruneel; D’Este; Salter (2010); \\
\hline & $\begin{array}{l}\text { Regras e regulamentações impostas pelas universidades } \\
\text { e governos }\end{array}$ & $\begin{array}{l}\text { Bruneel; D'Este; Salter (2010); } \\
\text { D'Este; Perkmann (2010); D'Este } \\
\text { (2007) }\end{array}$ \\
\hline & $\begin{array}{l}\text { Conflitos sobre direitos de propriedade intelectual e } \\
\text { royalties }\end{array}$ & $\begin{array}{l}\text { Freitas; Marques; Silva (2008); } \\
\text { Bruneel; D'Este; Salter (2010); } \\
\text { D'Este; Perkmann (2010); Dan } \\
\text { (2013) }\end{array}$ \\
\hline & $\begin{array}{l}\text { Falta de compreensão sobre as expectativas e práticas } \\
\text { de trabalho }\end{array}$ & $\begin{array}{l}\text { Bruneel; D’Este; Salter (2010); } \\
\text { Perkmann (2010); D’Este (2007) }\end{array}$ \\
\hline & Experiências anteriores ruins com universidades & Kaymaz; Eryiğit (2011) \\
\hline \multirow{9}{*}{ Universidade } & Problemas de comunicação & $\begin{array}{l}\text { Lundberg; } \quad \text { Andresen } \quad \text { (2012); } \\
\text { Kaymaz; Eryiğit (2011) }\end{array}$ \\
\hline & $\begin{array}{l}\text { Empresas tentam atrasar as publicações dos resultados } \\
\text { da pesquisa }\end{array}$ & $\begin{array}{ll}\text { Bruneel; D'Este; Salter } & \text { (2010); } \\
\text { Lundberg; Andresen } & \text { (2012); } \\
\text { D’Este (2007) } & \end{array}$ \\
\hline & Preocupação com a confidencialidade dos resultados & $\begin{array}{l}\text { Bruneel; D'Este; Salter (2010); } \\
\text { Lundberg; Andresen (2012) }\end{array}$ \\
\hline & Regulamentos por parte da empresa & $\begin{array}{l}\text { Freitas; Marques; Silva (2008); } \\
\text { Bruneel; D’Este; Salter (2010); } \\
\text { Kaymaz; Eryiğit (2011); Dan } \\
\text { (2013); }\end{array}$ \\
\hline & Enfoque de curto prazo da empresa & $\begin{array}{l}\text { Freitas; Marques; Silva (2008); } \\
\text { D'Este; Perkmann (2010); D’Este } \\
\text { (2007) }\end{array}$ \\
\hline & $\begin{array}{l}\text { Ausência de procedimentos para colaborar com as } \\
\text { empresas }\end{array}$ & $\begin{array}{l}\text { D'Este; Perkmann (2010); D’Este } \\
\text { (2007) }\end{array}$ \\
\hline & $\begin{array}{l}\text { A natureza da pesquisa não é adequada para os } \\
\text { interesses da empresa }\end{array}$ & $\begin{array}{l}\text { D'Este (2007); Kaymaz; Eryiğit } \\
\text { (2011); Lundberg; Andresen } \\
\text { (2012); D’Este; Perkmann (2010) }\end{array}$ \\
\hline & Dificuldade de encontrar parceiros adequados & D’Este (2007) \\
\hline & Falta de interesse da empresa & Kaymaz; Eryiğit (2011) \\
\hline
\end{tabular}

Fonte: Elaborado pela autora a partir das consultas nas bases Scopus; Web of Science e Science Direct-2013.

\subsubsection{Canais de Transferência de Tecnologia}

A viabilização dos meios para transferir o que se produz na universidade para o mercado tem sido uma busca constante, devido à crescente importância do conhecimento científico para o avanço tecnológico e da competitividade, constituindo-se um dos processos que ocorre a partir da parceria da universidade e empresa (MARTINS, 2010). A universidade, 
geradora de novos conhecimentos, quer a aplicação deles em prol da sociedade, além da possibilidade de se aproximar dos problemas da realidade empresarial colocando na prática os conhecimentos e recebendo novos recursos para a continuidade de suas pesquisas (GARNICA, 2007; PÓVOA, 2008). Diante do exposto, as seções a seguir apresentarão o conceito de transferência de tecnologia e os principais canais de transferência de tecnologia.

\subsubsection{Transferência de Tecnologia: aspectos conceituais}

O conceito "transferência de tecnologia" depende grandemente do contexto em que ocorre, variando conforme a abordagem do pesquisador e do objetivo dos estudos desenvolvidos. Para Bozeman (2000) e Póvoa e Rapini (2010) é necessário definir o que é tecnologia e delimitar o que é transferência, pois o tema envolve estes dois elementos que são bastante amplos em seus significados.

Dosi (1982) inclui em sua definição de tecnologia conhecimentos teóricos. Para o autor, a tecnologia constitui-se em um conjunto de conhecimento, tanto prático (relacionado a problemas) quanto teórico (mais aplicável, embora não necessariamente já aplicado), experiências de sucessos, fracassos e know-how. Póvoa (2008) conceitua tecnologia como um meio para cumprir um objetivo, o que significa que tecnologia é um conjunto de instrumentos, métodos e técnicas que permitem o aproveitamento prático do conhecimento científico. Portanto, a simples transferência implica a ida de conhecimento e informação para quem estiver recebendo (BOZEMAN, 2000).

Barbieri (1990), por exemplo, admite que a transferência de tecnologia deve indicar um processo em que uma empresa passa a dominar um conjunto de conhecimento que constitui uma tecnologia que ela não produzia. Tomada enquanto processo, a transferência de tecnologia pode partir de diferentes origens, destinando-se geralmente às empresas.

A transferência de tecnologia para os autores Ritter e Solleiro (2004) é um processo que consiste em várias etapas que, inclui a revelação da invenção, o patenteamento, o licenciamento, o uso comercial da tecnologia pelo licenciado e a percepção dos royalties pela universidade.

Conforme Thursby e Thursby (2002) os estudos de transferência de tecnologia da universidade para a empresa concentram-se no licenciamento de patentes. Deste modo, a tecnologia, refere-se ao conteúdo de patentes e sua transferência é o processo de licenciamento da mesma. No entanto, para Póvoa e Rapini (2010) esta abordagem restringe o assunto, já que nem toda a tecnologia desenvolvida na universidade é patenteada, uma vez 
que existe uma grande quantidade de tecnologia gerada e transferida que não é objeto de estudo de grande parte da literatura.

Para Lipinsk, Minutolo e Crothers (2008) a transferência de tecnologia das universidades para o setor produtivo é vista como um processo complexo, com possibilidade de utilização de grande número de estratégias e está sujeita às especificações de cada setor da economia (ARVANTINS; SUDOW; WOERTER, 2008). Há transferência de tecnologia e de conhecimento tanto no sentido de entrada quanto de saída das universidades.

De acordo com Arvanitis, Sydow e Woerter (2008), a transferência de conhecimento e tecnologia ocorre por várias vias, como troca de informações técnicas e científicas, formação de profissionais qualificados em $\mathrm{P} \& \mathrm{D}$, cursos de informações técnicas e científicas, cursos para funcionários das empresas, cursos específicos, consultorias, uso de infraestrutura técnicas e cooperação em pesquisas.

Desta forma, com foco em tecnologias geradas no contexto acadêmico, a transferência de tecnologia diz respeito a um processo de várias etapas, pelo qual uma invenção ou uma propriedade intelectual da pesquisa acadêmica é licenciada ou transferida, através do uso de direitos, para uma entidade com fins lucrativos e, posteriormente, comercializada (FRIEDMAN; SILBERMAN, 2003).

Vale relatar que para Thursby e Thursby (2002) não há mudança na maneira de conduzir as pesquisas universitárias, isto é, não significa que as universidades estão mudando seu foco, passando dar maior importância a pesquisas que estejam mais relacionadas com as necessidades do mercado, mas sim uma mudança de percepção das possibilidades de uso dos resultados das pesquisas. Desta forma, os pesquisadores mostram-se mais interessados em se aproximar das empresas para aplicação de suas invenções, ao invés de focarem apenas na publicação de suas pesquisas sem a geração de retornos financeiros.

Como citado por Thursby e Thursby (2002), na literatura, a transferência de tecnologia tem sido considerada a patente e o licenciamento como um dos meios de transferência. Contudo, alguns autores têm destacado a importância de outros canais de transferência, como publicações, consultoria, troca informal de informações (AGRAWAL; HENDERSON, 2002) e criação de empresas, as spin-offs acadêmicas, advindas dos resultados de pesquisas acadêmicas (COSTA; TORKOMIAN, 2008). Nesta perspectiva, a seguir, são analisados os principais mecanismos de transferência abordados na literatura nacional e internacional. 


\subsubsection{Principais Canais de Transferência de Tecnologia}

A cooperação universidade-empresa ocorre através do arranjo de diferentes relações entre os atores, a saber, universidade, empresa e governo, e principalmente nos canais de transferência de conhecimento. O conhecimento desenvolvido na universidade, aliado ao nível tecnológico da empresa influencia, não só como os atores se relacionam entre si, mas também os canais de transferência de conhecimento utilizados (ZAWISLAK; DALMARCO, 2011).

Mecanismos de transferência de tecnologia e conhecimento são mecanismos que visam criar condições e facilidades para o avanço tecnológico, permitindo a transferência de dados, informações, conhecimento e tecnologia entre universidades, centros de pesquisas, laboratórios e empresas. Estes visam criar condições e facilidades que permitam maior fluidez nas relações com a sociedade e, especialmente, no processo interação universidade-empresa (COHEN; NELSON; WALSH, 2002).

Nesta perspectiva, como forma de levar o conhecimento científico produzido na universidade para as empresas e, consequentemente, para a sociedade, vários canais de transferência de tecnologia são abordados nos trabalhos que envolvem o tema cooperação universidade-empresa. Conforme Cohen, Nelson e Walsh (2002) a escolha e utilização dos canais para transferência de conhecimento dependem das características individuais destes, tais como o grau de codificação, facilidade de aplicação ou possibilidade de transferência por meio das relações pessoais.

Como descrevem Cohen, Nelson e Walsh (2002), os canais utilizados para a transferência de tecnologia dependem do propósito da relação. Por sua vez, Schrtinger et al. (2002) e Bekkers e Freitas (2008) relatam a reduzida influência dos setores produtivos nos canais utilizados, sendo as características individuais do conhecimento mais importantes, enquanto D’Este e Patel (2007) afirmam que as características pessoais dos pesquisadores, como idade, cargo e experiência prévia em pesquisa conjunta influenciam os canais utilizados.

Alguns autores apresentam as spin-offs como um caminho alternativo para a transferência de tecnologia da universidade para o mercado, que não envolve a interação com empresas já estabelecidas (COSTA; TORKOMIAN, 2008; SCHARTINGER ET AL., 2002; BEKKERS; FREITAS, 2008; DUTRÉNIT; ARZA, 2010). Inicialmente, a universidade transfere a tecnologia para as spin-offs e, depois, estes transferem para seus consumidores, 
completando o fluxo de transferência e beneficiando a sociedade (ZAWISLAK; DALMARCO, 2011).

Costa e Torkomian (2008) e Mowery, Sampat e Ziedonis (2002) evidenciam que as spin-offs acadêmicas, advindas dos resultados das pesquisas acadêmicas, proporcionam a geração de empregos altamente qualificados com geração de riqueza para a sociedade e intensificação da capacidade inovativa da indústria nacional.

Analisando os dados de um survey com 1.478 laboratórios de P\&D de empresas do setor de manufatura dos EUA que avalia como as empresas protegem os lucros decorrentes das suas invenções, Cohen, Nelson e Walsh (2002) mostram que na maior parte das empresas, o patenteamento e licenciamento não são considerados como mecanismos de transferência de tecnologia importantes. Setores de alta tecnologia, como equipamentos de comunicação e aeroespacial, indicaram a importância das patentes como sendo, no máximo, moderada. A indústria farmacêutica foi a principal a considerar as patentes e licenciamentos como mecanismos pelo menos moderadamente importante.

Os autores concluíram que os canais de transferência de tecnologia mais importantes para que as universidades tenham um impacto sobre a $P \& D$ industrial são os mecanismos informais e publicação de artigos e relatórios. Para Póvoa e Rapini (2011) a patente parece ser necessária para a realização da transferência de tecnologia apenas em circunstâncias bastante restritivas, sendo que, somente alguns setores industriais a consideram um mecanismo eficaz de apropriação, pois depende da característica da invenção (se é processo ou produto) e se está em seu estágio embrionário ou acabado.

O estudo de Pinho (2011) sobre a relevância da relação universidade-empresa no Brasil evidencia que, pesquisa conjunta, publicações, contratação de pessoal, conferências, troca informal de informações e pesquisa encomendada são meios de interação que superam por boa margem a relevância de instrumentos usuais de transferência de tecnologia, como licenciamento de tecnologia, incubadoras, parques tecnológicos e spin-offs. O autor argumenta que os resultados para o Brasil são consistentes, como os encontrados por Cohen, Nelson e Walsh (2002) que identificaram o licenciamento de tecnologia como o segundo menos importante numa lista de dez canais de conexão entre universidades e empresas.

Como observado, é através dos canais de transferência que os atores se relacionam, aplicando o conhecimento científico no mercado. Nesta perspectiva, vários são os canais utilizados para a transferência de tecnologia e conhecimento, embora muitos sejam complementares, os principais canais descritos pelos autores podem ser resumidos em feiras e congressos, relações informais, contratação de alunos, spin-off, patentes, palestra/treinamento 
e consultoria. Diante disto, o Quadro 3 apresenta os principais canais de transferência de conhecimento e os autores que os citam, demonstrando que, apesar de variar conforme o enfoque do estudo e do autor, no geral são complementares.

Quadro 3 - Trabalhos com discussão sobre os canais de transferência de conhecimento

\begin{tabular}{|c|c|}
\hline Canais de transferência de conhecimento & Referências \\
\hline Contratação de alunos & $\begin{array}{l}\text { Schartinger et al (2002); Cohen; Nelson; Walsh (2002); } \\
\text { Bekkers; Freitas (2008); Dutrénit; Arza (2010); Fernandes } \\
\text { et al. (2010); Zawislak; Dalmarco (2011); Pinho (2011) }\end{array}$ \\
\hline Feiras e congressos & $\begin{array}{l}\text { Schartinger et al (2002); Cohen; Nelson; Walsh (2002); } \\
\text { D'Este; Patel (2007); Bekkers; Freitas (2008); Zawislak; } \\
\text { Dalmarco (2011) }\end{array}$ \\
\hline $\begin{array}{l}\text { Nova empresa formada por pesquisadores científicos } \\
\text { (Spin-off) }\end{array}$ & $\begin{array}{l}\text { Schartingeret et al. (2002); Bekkers; Freitas (2008); } \\
\text { Dutrénit; Arza (2010); Fernandes et al. (2010); Zawislak; } \\
\text { Dalmarco (2011); Pinho (2011) }\end{array}$ \\
\hline Relações informais & $\begin{array}{l}\text { Cohen; Nelson; Walsh (2002); Bekkers; Freitas (2008); } \\
\text { Dutrénit; Arza (2010); Fernandes et al. (2010); Zawislak; } \\
\text { Dalmarco (2011); Pinho (2011) }\end{array}$ \\
\hline Pesquisa realizada em conjunto com a universidade & $\begin{array}{l}\text { Schartingeret et al. (2002); D’Este; Patel (2007); Bekkers; } \\
\text { Freitas (2008); Zawislak; Dalmarco (2011); Pinho (2011) }\end{array}$ \\
\hline Palestra em universidades, realizadas pela empresa & Schartinger et al (2002); Dutrénit; Arza (2010) \\
\hline Contrato de pesquisa & $\begin{array}{l}\text { Schartinger et al (2002); Cohen; Nelson; Walsh (2002); } \\
\text { D'Este; Patel (2007); Bekkers; Freitas (2008); Fernandes et } \\
\text { al. (2010); Zawislak; Dalmarco (2011) }\end{array}$ \\
\hline Consultoria & $\begin{array}{l}\text { Schartinger et al (2002); Cohen; Nelson; Walsh (2002); } \\
\text { D'Este; Patel (2007); Bekkers; Freitas (2008); Fernandes et } \\
\text { al. (2010); Zawislak; Dalmarco (2011); Pinho (2011) }\end{array}$ \\
\hline Joint Ventures & Cohen; Nelson; Walsh (2002) \\
\hline $\begin{array}{l}\text { Utilização das instalações da universidade por parte } \\
\text { das empresas }\end{array}$ & $\begin{array}{l}\text { Schartinger et al (2002); Bekkers; Freitas (2008); Zawislak; } \\
\text { Dalmarco (2011) }\end{array}$ \\
\hline Treinamento de pesquisadores acadêmicos & Schartinger et al (2002); D’Este; Patel (2007) \\
\hline Treinamento de pesquisadores da empresa & Bekkers; Freitas (2008) \\
\hline Patentes & $\begin{array}{l}\text { Cohen; Nelson; Walsh (2002); Bekkers; Freitas (2008); } \\
\text { Dutrénit; Arza (2010); Fernandes et al. (2010); Pinho } \\
\text { (2011) }\end{array}$ \\
\hline Licenciamento de tecnologia & $\begin{array}{l}\text { Schartinger et al. (2002); Cohen; Nelson; Walsh (2002); } \\
\text { Bekkers; Freitas (2008); Dutrénit; Arza (2010); Fernandes } \\
\text { et al. (2010); Zawislak; Dalmarco (2011); Pinho (2011) }\end{array}$ \\
\hline Publicações conjuntas & Schartinger et al (2002); Zawislak; Dalmarco (2011) \\
\hline Contratação de pesquisadores & Bekkers; Freitas (2008) \\
\hline $\begin{array}{l}\text { Mobilidade de pesquisadores entre universidade e } \\
\text { empresa }\end{array}$ & Schartinger et al (2002); Zawislak; Dalmarco (2011) \\
\hline Publicações científicas & $\begin{array}{l}\text { Cohen; Nelson; Walsh (2002); Bekkers; Freitas (2008); } \\
\text { Dutrénit; Arza (2010); Fernandes et al. (2010); Pinho } \\
\text { (2011) }\end{array}$ \\
\hline Financiamento de projetos de doutorado & Bekkers; Freitas (2008) \\
\hline Compra de protótipo & Zawislak; Dalmarco (2011) \\
\hline Parque científico/ tecnológico & $\begin{array}{l}\begin{array}{l}\text { Dutrénit; Arza (2010); Fernandes et al. (2010); Pinho } \\
\text { (2011) }\end{array} \\
\end{array}$ \\
\hline Participação em redes que envolvem universidades & Pinho (2011) \\
\hline Incubadoras & $\begin{array}{l}\text { Dutrénit; Arza (2010); Fernandes et al. (2010); Pinho } \\
\text { (2011) }\end{array}$ \\
\hline
\end{tabular}

Fonte: Elaborado pela autora a partir das consultas nas bases Scopus; Web of Science e Science Direct-2013. 


\subsubsection{Fluxo de Conhecimento na Cooperação Universidade-Empresa}

Com o objetivo de aumentar o conhecimento da universidade e do setor empresarial, é necessário estabelecer um fluxo de conhecimento entre ambas as partes, por meio da transferência de tecnologia. O fluxo de conhecimento é caracterizado pela transferência de conhecimento da universidade para a empresa, no qual o estimulo é dado pelo ator, a saber, a universidade, a empresa ou o governo, responsável por tomar a iniciativa em estabelecer o fluxo de conhecimento (DALMARCO; ZAWISLAK; HULSINK, 2011).

De acordo com Wang e Lu (2007), o desenvolvimento de atividades de transferência de conhecimento universidade-empresa incorpora a universidade e empresa e as tendências organizacionais, bem como os esforços do governo na construção e melhoria competitividade da empresa com base na criação de conhecimento eficaz. Nesta perspectiva, o fluxo de conhecimento é descrito pela instituição responsável por estabelecer a relação, pelo sentido do fluxo e pelo conteúdo que será transferido, como mostra a Figura 7.

Figura 7 - Fluxo de Conhecimento entre a Universidade e a Empresa

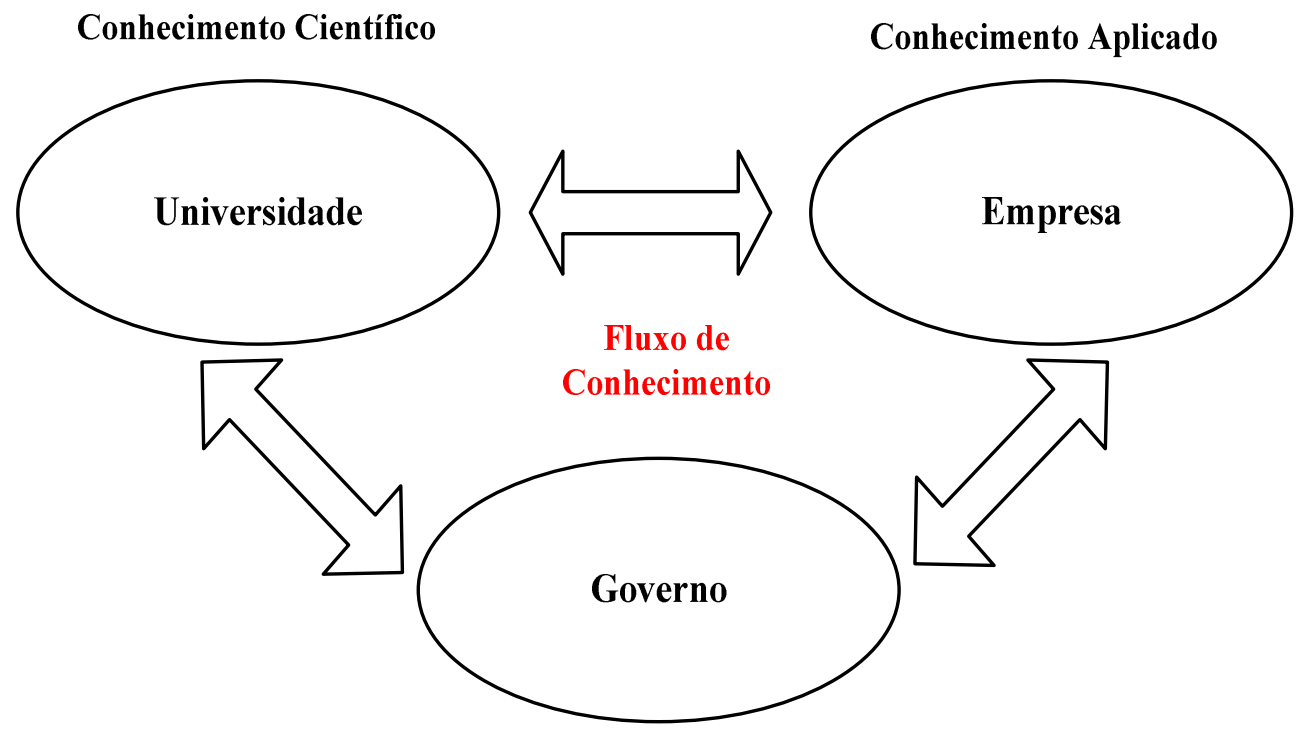

Fonte: ZAWISLAK; DALMARCO (2011, p. 69).

O desenvolvimento da transferência de conhecimento requer relações estreitas entre a geração do conhecimento e aplicação do conhecimento (SCHARTINGER et al., 2002). Ainda que a universidade seja o principal ator por desenvolver um conhecimento, o fluxo de conhecimento é estimulado por três atores:

1. Universidade: cria o conhecimento científico e o transfere para o setor empresarial; 
2. Empresa: busca aplicar o conhecimento criado para alterar e incrementar sua base de tecnologia;

3. Governo: por meio de leis ou recursos possibilita a relação universidade-empresa, por meio da transferência de conhecimento.

O fluxo de conhecimento oriundo da universidade e que flui para a empresa é baseado, principalmente, no acúmulo de conhecimento científico que flui para as empresas como fonte de ideias para novos projetos ou para incrementar projetos existentes (COHEN; NELSON; WALSH, 2002; LANGFORD et al., 2006; ARAUJO; TEIXEIRA, 2010; D'ESTE; PATEL, 2007).

Neste critério o fluxo de conhecimento pode ser estimulado tanto pelo escritório de transferência de tecnologia (ETT) quanto pelo contato direto entre pesquisadores que toma a iniciativa para o estabelecimento da relação com a empresa e, assim, transfere-se o conhecimento advindo da universidade (ZAWISLAK; DALMARCO, 2011).

De acordo com D’Este e Patel (2007) quando o fluxo de conhecimento é estimulado por uma empresa, significa que esta toma a iniciativa de manter relação com a universidade, em outras palavras, o fluxo é iniciado por uma demanda da empresa. Deste modo, o conhecimento que flui da empresa para a universidade abre uma gama de possibilidades de pesquisa aos acadêmicos, baseadas nos problemas tecnológicos enfrentados pelo setor produtivo.

Conforme Cohen, Nelson e Walsh (2002) a demanda de conhecimento feita às universidades é normalmente definida por informações de mercado, solicitações de clientes, fornecedores ou dos próprios funcionários, sendo que as empresas procuram a universidade visando desenvolver um novo produto ou processo, complementar projetos ou solucionar problemas técnicos (RAPINI, 2007).

Por sua vez, o governo estimula o fluxo de conhecimento "com níveis científico e aplicado, com o intuito de assim incrementar o nível tecnológico dos atores, favorecendo o desenvolvimento do setor produtivo" (DALMARCO; ZAWISLAK; KARAWEJCZYK, 2012, p. 6). Quando a interação não ocorre de maneira espontânea, é papel do governo atuar como um catalisador da interação, estimulando atividades de pesquisa científica e aplicada entre os atores.

Fundos de apoio à pesquisa básica visam fomentar o desenvolvimento científico das universidades, mantendo sua base de conhecimento de fronteira e assim disponibilizando novas tecnologias ao setor industrial (NELSON, 2006). Nas relações de estímulo entre 
governo e empresa, o objetivo é fomentar o desenvolvimento do nível tecnológico da empresa, através de recursos para pesquisa e incentivos fiscais (DOS; LLERENA; LABINI, 2006).

Como visto, o estímulo ao fluxo de conhecimento na relação universidade-empresa é dado por um dos atores, universidade, empresa ou governo. De acordo com Østergaard (2009) o estímulo está relacionado ao nível tecnológico do ator, determinando o conteúdo de conhecimento transferido através do fluxo. Nesta perspectiva, depois que o fluxo de conhecimento é estabelecido, constitui-se um fluxo dinâmico, circulando entre as instituições, independente do estimulo estabelecido para o desenvolvimento da relação (SIEGEL et al., 2003a). Neste processo de transferência, o receptor precisa de um mínimo de capacitação para identificar, escolher, negociar e adquirir a tecnologia necessária (GARNICA, 2007).

De forma a internalizar e integrar o conhecimento oriundo da universidade, empresas estabelecem estímulos ao fluxo de conhecimento com conteúdos específicos. Como descrito por Fontana et al. (2006), a estrutura de P\&D torna a empresa mais capacitada a internalizar o conhecimento científico, influenciando o conteúdo de conhecimento transferido. Em empresas sem atividade de $\mathrm{P} \& \mathrm{D}$ formal, as relações de transferência de tecnologia estão mais próximas do conhecimento de mercado, propiciando um fluxo com conteúdo de conhecimento aplicado (TETHER; TAJAR, 2008).

Neste contexto, Dalmarco e Zawislak (2011) elaboraram indicadores que têm como objetivo descrever o conteúdo de conhecimento presentes no fluxo. Para os autores, apesar de cada tipo de relação ter um nível de conhecimento científico e aplicado definido, as relações de troca de conhecimento podem ser representadas por diferentes indicadores de conteúdo, de acordo com o propósito da interação. O modelo proposto foi agrupado em quatro critérios de conteúdo de conhecimento: (i) pesquisa básica; (ii) pesquisa estratégica; (iii) pesquisa aplicada; e (iv) tecnologia.

A pesquisa básica é representada pela transferência de tecnologia oriunda de projetos de pesquisa científica, como nos canais descritos por artigos, protótipos e contatos informais (REAMER; ICERMAN; YOUTIE, 2003).

A transferência ocorre essencialmente por duas formas: através do resultado final da pesquisa, como artigos ou protótipos, ou da pesquisa em andamento, na qual o conhecimento é transferido através de contatos informais. Nos casos em que a pesquisa já foi finalizada, a empresa pode transferir o conhecimento formal disponibilizado pela universidade, aplicando às suas necessidades. Quando a pesquisa ainda está em andamento, a relação entre a empresa e a universidade pode auxiliar na aplicação da tecnologia, por intermédio do feedback das 
necessidades de mercado, sendo transferida ao seu término. Em ambos os casos, a pesquisa científica é envolta em incerteza, demandando estruturas de pesquisa e recursos financeiros da empresa para que resulte em um novo produto ou processo (DALMARCO; ZAWISLAK, 2011).

A pesquisa estratégica é representada por atividades de pesquisa conjunta entre empresas e universidades, envolvendo a colaboração entre pesquisadores e possibilitando o direcionamento da pesquisa básica para o desenvolvimento de uma nova tecnologia (ETZKOWITZ; LEYDESDORFF, 2000; CHESBROUGH, 2006; PERKMANN; WALSH, 2009).

O conteúdo de conhecimento aqui descrito é caracterizado pela pesquisa básica com considerações de uso, envolvendo universidade e empresa. Este critério pode ser definido por projetos desenvolvidos em consórcios de pesquisa formados por universidades e empresas, no qual a universidade inicia a pesquisa, e, no momento que a pesquisa aponta para um resultado prático, o desenvolvimento é assumido pela empresa (STOKES, 2005).

De acordo com D’Este e Patel, (2007), a transferência de conhecimento por intermédio do desenvolvimento de projetos conjuntos permite o crescimento da empresa e da universidade, pois propicia um fluxo constante de conhecimento entre os atores durante o desenvolvimento do projeto. Além disso, a aproximação da universidade com a indústria gera mais artigos, inclusive em conjunto com a própria empresa, reduzindo a distância entre a pesquisa científica e as demandas de mercado e estimula o empreendedorismo nos pesquisadores.

No que consiste a pesquisa aplicada, o fluxo de conhecimento contém principalmente conhecimento aplicado, representado por projetos de pesquisa direcionados a uma necessidade específica (BALCONI; LABORANTI, 2006; STOKES, 2005; ØSTERGAARD, 2009). Neste caso, as empresas buscam, através de canais como contratos de pesquisa ou consultoria, solução para demandas específicas de mercado ou incrementos para produtos e processos existentes. Como afirmam Siegel, Waldman e Link (2003b), o conhecimento aplicado é mais facilmente integrado pelas empresas, pois está mais próxima do mercado.

A contratação de alunos e pesquisadores - também descrita pelos canais de transferência de conhecimento - tem por objetivo a utilização do conhecimento tácito aos alunos para desenvolver aplicações baseadas em pesquisa (BALCONI; LABORANTI, 2006). Soma-se a isto a proximidade do aluno com seus antigos colegas e professores na universidade. Como descrito por Balconi e Laboranti (2006) e Østergaard (2009), professores 
favorecem links com ex-alunos quando estabelecem relações com as empresas, pela proximidade no raciocínio científico e nas relações pessoais.

Por fim, a tecnologia corrente, é representada pela transferência de tecnologia baseada no rearranjo do conhecimento disponível na universidade de acordo com a necessidade da empresa (SIEGEL; WALDMAN; LINK, 2003b). Embora este critério utilize canais de transferência de conhecimento similares ao critério anterior, como contratos de pesquisa e consultoria, neste caso, o conhecimento transferido é baseado em atividades rotineiras, de pouca complexidade e sofisticação (RAPINI, 2007).

Seja pela dificuldade em integrar o conhecimento de fronteira das universidades ou pela especificidade do projeto, a empresa busca o conhecimento necessário para solucionar problemas técnicos ou dificuldades encontradas nas suas atividades de pesquisa (COHEN; NELSON; WALSH, 2002; RAPINI, 2007).

Nesta perspectiva, a Figura 8 relaciona o estímulo e o conteúdo do fluxo de conhecimento, demonstrando o nível de conhecimento presente no fluxo quando estimulado por cada um dos atores. Como pode ser visto, Dalmarco e Zawislak (2011) traçaram duas curvas representando as diferentes relações de estímulo e o conteúdo de acordo com o nível tecnológico dos atores.

Figura 8 - Conteúdo do Conhecimento

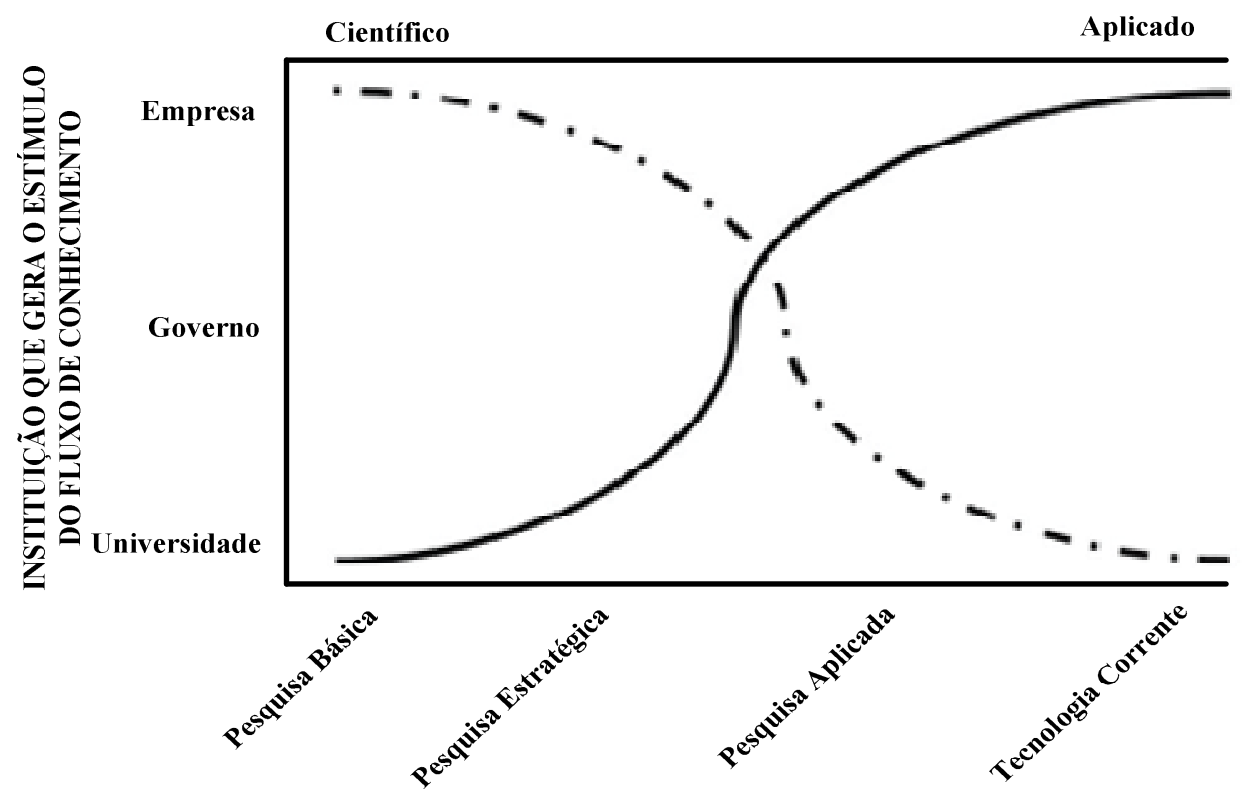

Fonte: Dalmarco; Zawislak (2011).

Na curva sólida, as relações baseadas no critério pesquisa básica são normalmente estimuladas pela universidade, enquanto as relações baseadas no critério tecnologia corrente 
são normalmente estimuladas pelas empresas. Com isto, a curva do nível de conhecimento (científico ou aplicado) tem sua base no conhecimento científico da universidade e seu topo no conhecimento aplicado da empresa. Na parte intermediária, as relações estimuladas pelo governo catalisam um fluxo de conhecimento com níveis de conteúdo intermediários entre o científico e aplicado, isto é, o conteúdo desenvolvido através de pesquisa científica, mas voltado às necessidades da empresa ou do setor. Este comportamento fica claro na função do governo de desenvolver o nível tecnológico acadêmico e industrial, estimulando o desenvolvimento econômico e social (DALMARCO; ZAWISLAK, 2011).

Os autores ainda ressaltam que, em outras situações, a curva pode apresentar um formato oposto, como demonstrado pela linha tracejada. Neste caso, empresas com elevado nível tecnológico estimulam um fluxo de conhecimento baseado em pesquisa básica, utilizando o conhecimento de fronteira gerado pela universidade como fonte de novos produtos ou processos tecnologicamente avançados. Em setores de alta tecnologia este tipo de interação é fundamental para que as empresas mantenham-se em vantagem frente aos concorrentes. 


\section{PROCEDIMENTOS METODOLÓGICOS}

Uma dissertação como aqui se apresenta, relata uma pesquisa que busca, sobretudo, uma reflexão sobre o tema ou problema expondo ideias de forma ordenada e fundamentada (TAFNER; TAFNER; FISCHER, 1999). Neste contexto, de acordo com Lakatos e Marconi (2001), a metodologia da pesquisa pode ser entendida como um conjunto de atividades sistemáticas e racionais que permitem alcançar um determinado objetivo, através da definição do caminho a ser seguido, da detecção dos possíveis erros e no auxílio da tomada de decisão científica.

Portanto, observando-se a necessidade de expor devidamente os detalhes acerca desta pesquisa, este capítulo contém a descrição dos procedimentos metodológicos utilizados para atingir os objetivos propostos, em busca da resposta ao problema de pesquisa.

\subsection{Questão e Objetivo de Pesquisa}

A fim de retornar a discussão apresentada na introdução que justifica este estudo, a questão geral a partir nesta pesquisa é: Quais são as principais características do perfil de cooperação da Universidade Federal de São Carlos (UFSCar) com a sociedade atualmente? Houve alguma mudança em relação às características históricas da cooperação?

\subsubsection{Objetivo Geral}

Este trabalho tem como objetivo geral apresentar e analisar as características do perfil de cooperação da UFSCar com a sociedade atualmente, e verificar se houve alguma mudança nas características da cooperação da UFSCar com a sociedade, utilizando como objeto de análise os projetos estabelecidos entre a universidade e seus parceiros externos, nos últimos cinco anos (2008-2012), que são gerenciados pela Fundação de Apoio Institucional ao Desenvolvimento Científico e Tecnológico (FAI).

\subsubsection{Objetivos Específicos}

Os objetivos específicos que decorreram do objetivo principal puderam ser divididos em: 
- Apresentar as características da cooperação universidade-empresa da Universidade Federal de São Carlos, a partir dos projetos gerenciados da Fundação de Apoio Institucional ao Desenvolvimento Científico e Tecnológico (FAI), realizados entre o período de 2008-2012;

- Comparar os resultados dos projetos gerenciados pela FAI no período de 20082012 com os dados da cooperação da UFSCar com o meio externo desenvolvidos por Oliveira (2002);

- Identificar se houve alguma mudança no perfil da cooperação da UFSCar com a sociedade.

\subsection{Características da Pesquisa}

A pesquisa "é uma indagação minuciosa ou exame crítico e exaustivo na procura de fatos e princípios; uma diligente busca para averiguar algo" (MARCONI; LAKATOS, 2007, p.15). Uma pesquisa, para ser científica, necessita de um método, isto é, pesquisar não é apenas procurar a verdade, é encontrar respostas para as questões propostas, utilizando métodos científicos (GIL, 1998).

De acordo com Gil (1998), a pesquisa pode ser entendida como um procedimento racional e sistemático, com o objetivo de proporcionar respostas aos problemas que são propostos. Desse modo, desenvolve-se ao longo de um processo que envolve inúmeras fases, desde a adequada formulação do problema até a satisfatória apresentação dos resultados.

Em síntese e de uma forma geral, pesquisa é um conjunto de ações propostas para controlar a solução para um problema, as quais têm por base procedimentos racionais e sistemáticos (SALOMON, 1999; BRYMAN, 1992). Neste sentido, as primeiras classificações para pesquisa são caracterizadas de acordo com a sua finalidade:

- Pesquisa teórica ou pura: tem por objetivo descobrir uma teoria a partir de hipóteses e métodos científicos de coleta de dados, controle e análise, procurando a interpretação, a explicação e a predição do problema, através da experimentação ou da observação;

- Pesquisa aplicada: pesquisa que se destina a solucionar problemas, aplicando leis, teorias e modelos existentes, em outras palavras, é aquela pesquisa que procura solucionar problemas a partir de testes práticos de ideias existentes ou posições teóricas. 
Levando em consideração os objetivos propostos por uma pesquisa, ela também é classificada em três tipos:

- Pesquisa exploratória: visa proporcionar maior familiaridade com o problema com vistas a torná-los explícitos. Geralmente este tipo de pesquisa é realizado quando o tema escolhido é pouco explorado e torna-se difícil formular conclusões precisas e operacionalizáveis sobre ele;

- Pesquisa descritiva: tem como principal objetivo a descrição das características de determinada população ou fenômeno ou mesmo estabelecer relação entre certas variáveis;

- Pesquisa explicativa ou explanatória: identifica e explica os fatores que determinam a ocorrência de fenômenos ou contribuem para que eles ocorram.

Nesta perspectiva, para a realização deste estudo, classificou-se a pesquisa, quanto ao método científico, como pesquisa aplicada, pois nesta pesquisa houve a necessidade de diagnosticar a realidade da cooperação, universidade em estudo, por meio dos projetos que estão sob coordenação da FAI, para que fosse possível, em seguida, analisar as principais características da cooperação da UFSCar com o meio externo e verificar se houve alguma mudança no perfil de cooperação.

Além disso, considerando o objetivo da pesquisa, ela pode ser classificada como exploratória e descritiva, pois foi necessário explorar os aspectos relacionados à cooperação da UFSCar com a empresa, para poder analisar se houve alguma mudança no perfil da cooperação da UFSCar com as empresas. Já a pesquisa descritiva foi utilizada por ser necessário descrever as evidências referentes à cooperação da UFSCar, por meio dos projetos que estão sob coordenação da FAI. Além do mais, esse tipo de análise permitiu uma visão geral dos dados, fornecendo bases para o desenvolvimento de novas pesquisas capazes de realizar análises mais profundas.

\subsection{Estratégia da Pesquisa}

Considerando um contexto metodológico de pesquisa Berto e Nakano (2000) definem que podem ser adotados quatro tipos de estratégias de pesquisa, sendo pesquisa experimental, pesquisa de avaliação (survey), estudo de caso e pesquisa-ação e modelagem. Cada método possuiu suas vantagens e desvantagens que dependem do tipo de questão de pesquisa e, para optar por um deles, é necessário conhecer a diferenças de cada um dos métodos (BERTO; 
NAKANO, 2000). Sob essa perspectiva, o Quadro 4 apresenta as características dos principais métodos de pesquisa adotados.

Quadro 4 - Características dos métodos de pesquisa

\begin{tabular}{|c|c|c|}
\hline $\begin{array}{c}\text { Método de } \\
\text { pesquisa }\end{array}$ & Características & Autores \\
\hline Survey & $\begin{array}{l}\text { Está associado aos questionários e a entrevistas estruturadas. Requer uma } \\
\text { coleta de dados num número de unidades. O pesquisador não interfere na } \\
\text { organização, tendo como objetivo examinar o relacionamento entre as } \\
\text { variáveis, observando os efeitos de uma interferência. }\end{array}$ & $\begin{array}{l}\text {-Miguel; Ho } \\
\text { (2010) }\end{array}$ \\
\hline $\begin{array}{l}\text { Estudo de } \\
\text { caso }\end{array}$ & $\begin{array}{l}\text { O método de estudo de caso procura manter juntas, como uma unidade, } \\
\text { aquelas características importantes para o problema que está sendo } \\
\text { investigado. As fontes de informação podem incluir observações pessoais, } \\
\text { conversas informais, visitas a empresas e análise de documentos. Ênfase } \\
\text { em fenômeno contemporâneo dentro de um ambiente natural, no qual o } \\
\text { pesquisador define o que deve e o que não deve ser levado em } \\
\text { consideração na coleta de dados. }\end{array}$ & $\begin{array}{l}\text {-Miguel } \\
(2010) \\
\text {-Yin }(2001)\end{array}$ \\
\hline $\begin{array}{l}\text { Pesquisa- } \\
\text { ação }\end{array}$ & $\begin{array}{l}\text { É uma abordagem aplicada na pesquisa social, na qual o pesquisador e um } \\
\text { cliente colaboram no desenvolvimento de um diagnóstico e solução } \\
\text { científica de um problema. A diferença desse método do estudo de caso é } \\
\text { que na pesquisa-ação desenvolve-se um relacionamento com o pesquisador } \\
\text { e as pessoas da organização que participam do projeto de pesquisa. }\end{array}$ & $\begin{array}{l}\text {-Turrioni; } \\
\text { Mello (2010) }\end{array}$ \\
\hline Modelagem & $\begin{array}{l}\text { É de caráter quantitativo. Define-se como métodos de construção e } \\
\text { manipulação de modelos operacionais, de representação física ou } \\
\text { simbólica para todos ou alguns aspectos de processos sociais ou } \\
\text { psicológicos. }\end{array}$ & $\begin{array}{l}\text {-Morabito; } \\
\text { Pureza (2010) }\end{array}$ \\
\hline $\begin{array}{l}\text { Pesquisa } \\
\text { experimental }\end{array}$ & $\begin{array}{l}\text { Baseia-se em determinar um objeto de estudo, selecionar variáveis capazes } \\
\text { de influenciá-lo. Há pelo menos dois motivos que validam a importância } \\
\text { da pesquisa experimental na pesquisa organizacional. O primeiro é a } \\
\text { possibilidade do investigador realizar fortes considerações sobre } \\
\text { casualidade. O segundo motivo é o fato de que o experimento é } \\
\text { frequentemente visto como um modelo de pesquisa. }\end{array}$ & $\begin{array}{l}\text {-MIGUEL } \\
(2010)\end{array}$ \\
\hline
\end{tabular}

Fonte: Elaborado a partir de MIGUEL; HO (2010); MIGUEL (2007); MIGUEL (2010); MORABITO; PUREZA (2010); TURRIONI; MELLO (2010); YIN (2001).

O tipo de questão de pesquisa é condição importante para a escolha de qualquer método de pesquisa. Posteriormente, deve ser analisado o controle sobre os eventos comportamentais e o foco, ou não, em acontecimentos contemporâneos. Assim, será possível escolher a estratégia que mais se adequa à pesquisa a ser realizada.

O estudo de caso é direcionado a uma ou poucas unidades, as quais podem ser entendidas por uma pessoa, um produto ou uma empresa. O estudo de caso se caracteriza, principalmente, por ser um processo detalhado e que busca atingir com profundidade o tema abordado, além de poder ser ou não realizado no campo (MIGUEL, 2010). 
Para Bryman (1989), o estudo de caso tem uma maneira exploratória de criar insights, testando teorias e confirmando resultados de outros estudos. Já para Yin (2005), o estudo de caso é a estratégia escolhida ao se examinar acontecimentos contemporâneos, acrescentando fontes importantes, como observação direta dos acontecimentos que estão sendo estudados e entrevistas das pessoas neles envolvidos. Ainda de acordo com o autor, o que diferencia é a sua capacidade de lidar com uma ampla variedade de evidências - documentos, artefatos, entrevistas e observações, além do que pode estar disponível em um estudo histórico convencional.

As várias estratégias não são excludentes entre si. Cabe ao pesquisador identificar qual estratégia para a coleta de dados possui mais vantagens para a realização da pesquisa. Em relação ao estudo de caso pode acontecer quando "faz-se uma questão do tipo, como ou por que, sobre um conjunto contemporâneo de acontecimentos, sobre o qual o pesquisador tem pouco ou nenhum controle" (YIN, 2005, p.28).

Mesmo que nesta pesquisa de dissertação não foi utilizada a entrevista como fonte de informação para a coleta de dados para o desenvolvimento deste estudo, foi adotado o método de pesquisa de estudo de caso por se tratar de uma investigação empírica que investiga um fenômeno contemporâneo dentro de seu contexto de vida real, especialmente quando os limites entre o fenômeno e o contexto não estão claramente definidos (YIN, 2005).

De acordo com o autor supracitado, a pesquisa de estudo de caso inclui tanto estudos múltiplos como casos únicos. No estudo de caso único, existe uma maior possibilidade de aprofundamento da pesquisa, no entanto, podem ocorrer limitações quanto à generalização analítica das conclusões e teorias geradas (VOSS; TSIKRIKTSIS; FROHLICH, 2002). No estudo múltiplo, é possível obter uma maior abrangência, bem como comparação entre os casos e a replicação. Entretanto, as desvantagens do estudo múltiplo são a necessidade de mais recurso e tempo para o pesquisador poder concluir a pesquisa (YIN, 2001).

Nesta pesquisa, foi utilizado o estudo de caso único, sendo a Universidade Federal de São Carlos o caso estudado a fim de que se possa explicar, descrever e explorar em profundidade as evidências que envolvem a cooperação da UFSCar com empresas.

\subsection{Coleta de dados}

A coleta de dados para o estudo de caso pode se basear em muitas fontes de evidências. Desta forma, como técnicas de coleta de dados do estudo de caso, de acordo com Yin (2005), estão, principalmente, a pesquisa documental, o registro em arquivos, as 
observações em campo e as entrevistas semiestruturadas ou não estruturadas (questões mais abertas, sem definição das variáveis pelo pesquisador).

Nesta perspectiva, para se alcançar as respostas das questões apresentadas e se atingir os objetivos propostos. Iniciou-se um trabalho intenso de pesquisa bibliográfica, através de fontes primárias como artigos de periódicos, anais de congressos, eventos científicos, dissertações e teses que permitiram o entendimento sobre o tema abordados, a saber, cooperação universidade-empresa. Foram utilizadas fontes eletrônicas, que permitiram o acesso às informações mais atualizadas sobre o processo de cooperação da Universidade Federal de São Carlos com a sociedade, por meio do site da Agência de Inovação da UFScar.

Como o intuito desta pesquisa foi o de avaliar como se tem caracterizado a cooperação da UFSCar, o procedimento mais adequado foi a base de dados fornecida pela Fundação de Apoio Institucional ao Desenvolvimento Científico e Tecnológico (FAI) ao longo de cinco anos (2008-2012), uma vez, que os projetos de cooperação da UFSCar com o meio externo encontram-se sob coordenação da FAI.

Nesta perspectiva, vale ressaltar que o universo de relações que compõem a interface entre a UFSCar e o meio externo não se limita apenas ao conjunto de projetos gerenciados pela FAI, pois as possíveis relações entre a universidade e as empresas podem ser classificadas como: (i) projetos que se caracterizam pela ausência de registro das relações, caracterizando, assim, como relações informais; (ii) projetos que apresentam relações formais entre a universidade e o meio externo sem capacidade de financiamento e por isso não são executados pela FAI; (iii) relações formais com financiadores externos definidos, estabelecidos por meio de contratos que utilizam a utilizam a FAI como agente de apoio no gerenciamento jurídico e financeiro.

Desta forma, os projetos gerenciados pela FAI foram escolhidos como unidade de análise desta pesquisa, pois contêm dados formais dos diferentes tipos de relações da UFSCar com o meio externo, como atividades referentes à realização de pesquisa, desenvolvimento tecnológico, prestação de serviço, realização de seminários, simpósios, reuniões, entre outras.

Neste contexto, os projetos que são estabelecidos por meio de contratos com a FAI encontram-se arquivados em uma seção específica dentro da Fundação, disponíveis para consulta e manipulação jurídica e administrativa. A identificação de cada contrato é feita através de um código de identificação numérico denominado como sistema de Gerenciamento de Projetos e Finanças (GPF). 


\subsubsection{Ajustes, Contabilização e Consolidação dos Dados}

O primeiro contato com a FAI visou à liberação dos dados dos projetos estabelecidos entre a UFSCar e o meio externo, intermediados pela Fundação, que disponibilizou uma listagem de arquivo digital que continha mais de 5.500 projetos desde o período de 1992 até 2012.

Desta forma, levando em consideração que os projetos gerenciados pela FAI são caracterizados como projetos de extensão, governamental e convênios de cooperação institucional (CCIs), inicialmente, foi necessário analisar o tipo de convênio estabelecido, uma vez que no arquivo disponibilizado além dos projetos de extensão, governamental e CCIs, existiam os projetos estabelecidos com instâncias administrativas, como Pró-reitoras, Núcleos de Extensão, Secretaria de Informática, programas de fomentos, entre outros. Tal análise foi necessária para eliminar os projetos estabelecidos com instâncias administrativas, resultando em um total de 3.280 projetos desde o período de 1992 até 2012, sendo estes, projetos de extensão ou projetos governamentais ou de CCIs.

No entanto, como esta dissertação teve como objetivo analisar as características do perfil de cooperação da UFSCar com a empresa, utilizando como objeto de análise os projetos estabelecidos entre a universidade e seus parceiros externos, nos últimos cinco anos (20082012), mais uma análise foi necessária para a eliminação dos projetos que não foram estabelecidos no período entre 2008 e 2012. Desta forma, foram considerados somente os projetos estabelecidos por ano e que movimentaram recursos financeiros pela FAI entre 20082012.

Para a tomada de decisão relacionada ao processo de coleta de dados, foi realizado um levantamento para identificar quais tipos de dados e informações estavam disponíveis nos projetos estabelecidos entre a UFSCar e seus parceiros, gerenciados pela FAI. Após verificação, foi possível confirmar que a grande maioria dos projetos, o equivalente a 619 projetos, continha os seguintes dados e informações:

- Código GPF: número de identificação do projeto;

- Descrição: resumo do conteúdo de contrato, normalmente incluindo título do projeto e o nome do parceiro;

- Espécie: classificação do tipo de atividade estabelecida entre a UFSCar e o parceiro;

- Valor: montante de recursos financeiros envolvidos na cooperação entre a UFSCar e o seu parceiro; 
- Centro Científico: indica qual área do conhecimento da UFSCar está executando a atividade em relação com a sociedade;

- Departamento: semelhante ao dado acima, mas de forma mais específica, indica qual departamento está envolvido na atividade de relacionamento com o meio externo;

- Financiador: dado que identifica o parceiro externo da universidade;

- Data de assinatura: indica a data na qual o contrato foi assinado pelas partes, entretanto, não significa que essa data seja a data de inicio do projeto;

- Data de início: indica a data prevista para o início do projeto, sendo que essa data pode ser anterior, coincidente ou posterior à data de assinatura;

- Data de término: indica a data prevista para o término do projeto.

\subsubsection{Roteiro para Coleta de Dados}

Após o levantamento da base de dados composta por 619 projetos, foi possível traçar um roteiro metodológico que abarcasse alguns tópicos primordiais para a realização da pesquisa:

- Evolução dos projetos por períodos de tempo;

- Intervalos de duração dos projetos firmados por período de tempo;

- Distribuição dos projetos por tipo de atividade;

- Distribuição dos projetos por área de conhecimento (Centro Científico e Departamento);

- Evolução dos projetos por tipo de financiador;

- Distribuição dos projetos por localidade do financiador.

O desdobramento deste roteiro permitiu que objetivo principal desta dissertação fosse atendido, bem como torná-la possível. Sendo assim, o mesmo pode ser visto no capítulo 4, referente à análise dos resultados.

\subsubsection{Deflacionamento dos Valores Monetários}

Antes de passar para o capítulo referente as análises e os resultados obtidos, é importante destacar a preocupação despendida no tratamento dos valores de recursos dos projetos. Desta forma, para que os valores monetários possam ser comparados em diferentes 
períodos de tempo torna-se necessário tratá-los por meio de fatores (indices deflatores) que os transformem de valores nominas para valores corres, ou seja, comparáveis numa mesma base de tempo.

No Brasil, costuma-se utilizar os índices deflatores gerados pela Fundação Getílop Vargas (FGV), sendo que o mais conhecidos deles é o Índice Geral de Preços (IGP). A própria Fundação Getúlio Vargas reconhece que, de início, o propósito das estimativas desses índices era indicar simplesmente a tendência evolutiva de negócios. Mas com a introdução da correção monetária no Brasil em 1964, juntamente com a aceleração do ritmo inflacionário, o uso de IGPs se intensificou. Desse período em diante, o IGPs passaram a ser usados nas Contas Nacionais, como deflator implícito do produto interno bruto (PIB), quanto em diferentes operações financeira, especialmente em reajustes contratuais e em atualizações salariais de modo geral.

O IGP possui quatro versões: IGP-DI (Disponibilidade Interna, IGP-OG (Oferta Global), IGP-M (mercado e IGP-10(Versão 10), com metodologia de cálculo idêntica para todas as versões, diferenciando apenas na periodicidade da pesquisa de preços, na estrutura de pesos e de seus componentes e na composição de produtos.

O cálculo do IGP é uma composição do Índice de Preços por Atacado (IPA) com peso de 60\%, do Índice de Preços ao consumidor (IPC), com participação de $30 \%$, e o Índice Nacional da Construção Civil (INCC), com pedo de 10\%. Trata-se de um índice composto cuja expressão matemática (1) é a seguinte:

$$
I G P=(0,6 x I P A)+(0,3 x I P C)+(0,1 x I N C C)
$$

A escolha da versão do índice foi baseada em dois critérios: na disponibilidade das séries históricas e na amplitude temporal de cada índice. Dessa forma, o IGP-DI e o IGP-M foram previamente escolhidos por serem mais comumente escontratos nas bases de indicadores econômicos disponíveis. Dentre eles, optou-se pelo IGP-DI por apresentar uma série histórica com índices desde janeiro de 1944 permitindo que seja utilizado em outras pesquisas.

O deflacionamento consiste em multiplicar o valor nominal (valor na data do desembolso) pela variação percentual dos índices, que representam a variação inflacionária entre os períodos. A expressão matemática (2) que apresenta esse cálculo aparece a segui

$$
V c=\left(\frac{I c}{I d}\right) x V n
$$


Sendo:

$\mathrm{V}_{\mathrm{c}}=$ Valor no período constante (dezembro/2013)

$\mathrm{I}_{\mathrm{c}}=$ Índice no período constante (dezembro/2013)

$\mathrm{Id}=$ Índice do período do desembolso;

Vn Valor nominal (no período do desembolso)

Como neste trabalho, o tempo utilizado na análise dos projetos varia entre 2008-2012, todos os valores nominais foram corrigidos para o último período de 2012 (dezembro de 2012). Sendo assim a expressão acima (2) se transforma em uma nova expressão (3), cujo valor Ic se torna constante.

$$
V c=\left(\frac{I(12 / 12}{I d}\right) x V n
$$




\section{APRESENTAÇÃO E DISCUSSÃO DOS RESULTADOS}

Esta pesquisa teve como objetivo analisar como tem se caracterizado a cooperação da UFSCar com o meio externo. Diante disso, este capítulo apresenta os resultados obtidos junto aos projetos gerenciados pela FAI ao longo de cinco anos (2008-2012).

No que tange à cooperação da UFSCar com a 'empresa', vale ressaltar que a 'empresa' se refere a qualquer ator que esteja fora dos limites institucionais da UFSCar, dentre os quais se destacam pessoa física, instituições governamentais, instituições públicas ou privadas, dentre outras. Portanto, o conjunto de dados coletados sustenta uma análise que configurou a cooperação da UFSCar com todos os tipos de parceiros, dentre os quais as empresas privadas.

Os dados obtidos para o ano de 2012 não abrangem o período de doze meses, uma vez que os dados concentram informações de janeiro a outubro de 2012, diferentemente dos anos anteriores, os quais englobam doze meses completos.

Desta forma, este capítulo apresenta e discute os resultados estatísticos obtidos nesta pesquisa. Primeiramente, serão expostos os principais órgãos, entidades e instituições que compõem o contexto ambiental da Universidade Federal de São Carlos, seguido da apresentação e discussão dos resultados obtidos com os projetos gerenciados pela FAI entre os anos de 2008-2012.

\subsection{A UFSCar no Processo de Cooperação Universidade-Empresa}

Esta seção visa apresentar um pouco da história da UFSCar, os cursos oferecidos, os centros acadêmicos que a compõem, as suas produções científicas bem como a sua Agência de Inovação, as políticas estabelecidas, e os indicadores no que diz respeito aos pedidos de propriedade intelectual.

A Universidade Federal de São Carlos é uma instituição pública federal de ensino superior vinculada ao Ministério da Educação (MEC) localizada no interior do estado de São Paulo. Foi fundada em 1968, porém, somente, em 1970 que as aulas foram iniciadas. É responsável pela oferta de 2.577 vagas de graduação e aproximadamente 2.200 vagas de pósgraduação (UFSCar, 2013a).

Em 1991, foi criado o segundo campus, em Araras, incorporando as unidades paulistas do extinto Programa Nacional de Melhoramento da Cana-de-Açúcar (Planasulcar), órgão ligado ao Instituto do Açúcar e do Álcool (IAA) (UFSCar, 2013a). O terceiro campus foi 
criado em 2006, na cidade de Sorocaba, a partir do plano de expansão do Ensino Superior do Governo Federal. No decorrer do ano de 2010, a UFSCar ofereceu 57 cursos de graduação presenciais e a distância. A pós-graduação conta com 60 programas, sendo 34 cursos de mestrado, 24 de doutorado e 02 cursos de mestrado profissional.

Esses programas e cursos são organizados em cinco centros científicos: o Centro de Ciências Biológicas e da Saúde (CCBS), Centro de Ciências Exatas e de Tecnologia (CCET), Centro de Educação e Ciências Humanas $(\mathrm{CECH})$ e Centro de Ciências Agrárias (CCA) e o Centro de Ciências e Tecnologias para a Sustentabilidade (CCTS).

O CCA está instalado na cidade de Araras e o CCTS está localizado no campus Sorocaba. Esse foi criado pelo Conselho Universitário em 2011 a partir da estrutura existente desde 2006, quando foram iniciadas as atividades acadêmicas e administrativas da UFSCar no município de Sorocaba, e os demais centros estão localizados na cidade de São Carlos. Tal estrutura abriga 32 departamentos acadêmicos (UFSCar, 2013b).

A universidade também possui unidades nas cidades paulistas de Anhembi, Piracicaba e Valparaíso que, juntamente com o campus de Araras, ocupam uma área física total de 302,8 hectares (UFSCar, 2013a).

Por fim, é importante evidenciar a implantação do novo campus da UFSCar, Campus Lagoa do Sino, localizado município de Buri/SP. A propriedade foi doada à UFSCar pelo escritor Raduan Nassar com o compromisso de instalar uma instituição que participasse do desenvolvimento regional pela promoção de atividades de ensino, pesquisa e extensão. Os primeiros cursos, Engenharia Agronômica, Engenharia Ambiental e Engenharia de Alimentos, começaram a ser oferecidos no ano de 2014 (UFSCar, 2013b).

\subsubsection{Os Centros Científicos da UFSCar}

A UFSCar possui uma divisão em sua estrutura que compreende 5 Centros Científicos. Cada centro agrupa os departamentos de áreas científicas relacionadas, como descrito no Quadro 5. 
Quadro 5 - Descrição dos Centros Científicos da UFSCar

\begin{tabular}{|c|c|c|}
\hline Centros Científicos & Descrição & Departamentos \\
\hline $\begin{array}{l}\text { Centro de Ciências } \\
\text { Agrárias (CCA) }\end{array}$ & $\begin{array}{l}\text { Localizado na cidade de Araras. O curso de } \\
\text { Engenharia Agronômica foi o primeiro curso a } \\
\text { ser implantado, em 1993. Em 2006, teve início o } \\
\text { segundo curso de graduação no campus, } \\
\text { Bacharelado em Biotecnologia, e o primeiro } \\
\text { Programa de Pós-Graduação, com mestrado em } \\
\text { Agroecologia e Desenvolvimento Rural. }\end{array}$ & $\begin{array}{l}\text {-Biotecnologia e Produção Vegetal e } \\
\text { Animal (DBPVA); } \\
\text {-Recursos Naturais e Proteção Ambiental } \\
\text { (DRNPA); } \\
\text {-Tecnologia Agroindustrial e } \\
\text { Socioeconômica Rural (DTAiSER); } \\
\text {-Desenvolvimento Rural (DDR); } \\
\text {-Ciências da Natureza, Matemática e } \\
\text { Educação (DCNME). }\end{array}$ \\
\hline $\begin{array}{l}\text { Centro de Ciências } \\
\text { Biológicas e da Saúde } \\
(\mathrm{CCBS})\end{array}$ & $\begin{array}{l}\text { Localizado no campus de São Carlos. O curso de } \\
\text { graduação em Ciências foi um dos primeiros a } \\
\text { serem oferecidos pela UFSCar em meados de } \\
\text { 1970. Em 1972, esse curso foi extinto e, em seu } \\
\text { lugar, foi criada a graduação de Ciências } \\
\text { Biológicas, surgindo assim o CCBS. O próximo } \\
\text { curso criado foi o de Enfermagem em 1977, } \\
\text { seguido pelos de Terapia Ocupacional e } \\
\text { Fisioterapia, no ano seguinte. O mais novo curso } \\
\text { do CCBS é o de Medicina, criado em } 2006 \text {. }\end{array}$ & $\begin{array}{l}\text {-Botânica (DB); } \\
\text {-Ciências Fisiológicas (DCF); } \\
\text {-Ecologia e Biologia Evolutiva (DEBE); } \\
\text {-Educação Física e Motricidade Humana } \\
\text { (DEFMH) } \\
\text {-Enfermagem (Denf); } \\
\text {-Fisioterapia (Dfisio); } \\
\text {-Genética e Evolução (DGE); } \\
\text {-Hidrobiologia (DHb); } \\
\text {-Medicina (DMed); } \\
\text {-Morfologia e Patologia (DMP); } \\
\text {-Terapia Ocupacional (DTO). }\end{array}$ \\
\hline $\begin{array}{l}\text { Centro de Ciências } \\
\text { Exatas e de } \\
\text { Tecnologia (CCET) }\end{array}$ & $\begin{array}{l}\text { Localizado no campus de São Carlos. É o centro } \\
\text { científico mais antigo, originado em } 1972 \text { com o } \\
\text { curso de Engenharia de Materiais, também é o } \\
\text { maior centro em termos de número de alunos de } \\
\text { professores e de cursos de graduação e pós- } \\
\text { graduação. }\end{array}$ & $\begin{array}{l}\text {-Departamento de Computação (DC); } \\
\text {-Engenharia Civil (DECiv); } \\
\text {-Engenharia de Materiais (DEMa); } \\
\text {-Engenharia de Produção (DEP); } \\
\text {-Engenharia Química (DEQ); } \\
\text {-Estatística (DES); } \\
\text {-Física (DF); } \\
\text {-Matemática (DM); } \\
\text {-Química (DQ); } \\
\text {-Engenharia Elétrica (DEE); } \\
\text {-Engenharia Mecânica (DEM). }\end{array}$ \\
\hline $\begin{array}{l}\text { Centro de Educação e } \\
\text { Ciências Humanas } \\
(\mathrm{CECH})\end{array}$ & $\begin{array}{l}\text { O primeiro curso oferecido pelo Centro de } \\
\text { Educação e Ciências Humanas (CECH) foi } \\
\text { desenvolvido em 1971. O corpo docente estava } \\
\text { ligado em sua maior parte ao Departamento de } \\
\text { Fundamentos Científicos e Filosóficos da } \\
\text { Educação até o final dos anos } 80 \text { e somente após } \\
\text { o processo de departamentalização é que os } \\
\text { docentes foram recolocados nos atuais } \\
\text { departamentos. }\end{array}$ & $\begin{array}{l}\text {-Artes e Comunicação (DAC); } \\
\text {-Ciência da Informação (DCI); } \\
\text {-Ciências Sociais (DCSo); } \\
\text {-Educação (DEd); } \\
\text {-Filosofia e Metodologia das Ciências } \\
\text { (DFMC); } \\
\text {-Letras (DL); } \\
\text {-Metodologia de Ensino (DME); } \\
\text {-Psicologia (DPsi); } \\
\text { Sociologia (DS). }\end{array}$ \\
\hline $\begin{array}{l}\text { Centro de Ciências e } \\
\text { Tecnologias para a } \\
\text { Sustentabilidade } \\
\text { (CCTS) }\end{array}$ & $\begin{array}{l}\text { Localizado no campus Sorocaba. Foi criado pelo } \\
\text { Conselho Universitário em } 2011 \text { a partir da } \\
\text { estrutura existente desde 2006, quando foram } \\
\text { iniciadas as atividades acadêmicas e } \\
\text { administrativas da UFSCar no município de } \\
\text { Sorocaba. }\end{array}$ & $\begin{array}{l}\text {-Departamento de Biologia (DBio); } \\
\text {-Economia (DEco); } \\
\text {-Ciências Ambientais (DCA); } \\
\text {-Geografia, Turismo e Humanidades } \\
\text { (DGTH); } \\
\text {-Computação (DComp); } \\
\text {-Ciências Humanas e Educação (DCHE); } \\
\text {-Engenharia de Produção de Sorocaba } \\
\text { (DEPS); } \\
\text {-Física, Química e Matemática (DFQM). }\end{array}$ \\
\hline
\end{tabular}

Fonte: Adaptado da UFSCar, 2013b. 
O centro CCA possui um dos programas de melhoramento genético da cana-de-açúcar mais importantes do país, Programa de Melhoramento Genético da Cana-de-Açúcar (PMGCA). O PMGCA tem como objetivo a obtenção de variedades de cana-de-açúcar melhoradas e adaptadas às diversas condições climáticas, com variedades iguais ou superiores às plantadas hoje e comercializadas, atendendo as necessidades do setor sucroalcooleiro. Essas pesquisas resultam em novas cultivares de planta com a sigla RB (de República do Brasil), possuindo centros experimentais localizados nos municípios de Araras e Valparaíso. Em 2010, o programa ocupava 58\% de toda a área plantada de cana-de-açúcar no Brasil (UFSCar, 2012).

As cultivares são protegidas via Sistema Nacional de Proteção de Cultivares (SNPC) e são patrimônio da UFSCar. Outro ponto a ser destacado é que o CCA tem uma grande interação com as usinas do Brasil, efetivando, assim, a aproximação universidade-empresa.

O CCBS é referência no desenvolvimento de pesquisa principalmente em Ecologia, Genética, bem como em diferentes áreas da Saúde, contabilizando um total de 63 grupos cadastrados no Diretório de Grupos de Pesquisa do Conselho Nacional de Desenvolvimento Científico e Tecnológico (CNPq) (UFSCar, 2012). Sob uma perspectiva interdisciplinar, este centro científico oferece apoio em Fisioterapia, Terapia Ocupacional, Enfermagem, Psicologia e Educação Física.

Por sua vez, o Centro de Ciências Exatas e de Tecnologia (CCET) possui em seu prédio um laboratório que foi construído com recursos da ALCOA (Empresa de alumínio), proporcionando aos alunos uma interação com as empresas e vivências com o ensino. Entre suas principais atividades, figuram a elaboração de diagnósticos e a proposição de alternativas para a solução de problemas industriais relacionados à área de materiais, realização de estudos de prospecção sobre tendências e oportunidades tecnológicas nessa área, criação de base de dados com informações tecnológicas e divulgação de produtos de informação, tais como boletins, manuais e guias de fontes.

No CCET também funciona o Centro de Caracterização e Desenvolvimento de Materiais (CCDM), cuja missão é apoiar a pesquisa e o desenvolvimento científico e tecnológico na área de materiais. A estrutura do CCDM é voltada para a prestação de serviço, visando à resolução de problemas de caracterização e desenvolvimento de materiais poliméricos, metálicos, cerâmicos e compósitos, desde a matéria-prima até a utilização do produto final (UFSCar, 2013b).

O CCDM possui acreditação junto à Coordenação Geral de Acreditação/Instituto Nacional de Metrologia (Cgcre/Inmetro), certificação NBR ISO 9001, habilitação da Rede 
Brasileira de Laboratórios Analíticos em Saúde/Agência Nacional de Vigilância Sanitária (Reblas/ANVISA) e qualificação junto à Associação Brasileira de Tubos Poliofenílicos (ABPE), além de atender requisitos de toda cadeia produtiva específicos de qualidade de empresas, como Volkswagen, CVRD, Petrobrás, Pirelli, dentre outras (UFSCar, 2013b).

No $\mathrm{CECH}$, alguns dos dados interessantes são sobre seus arquivos e núcleos, a saber: arquivo Ana Lagôa (arquivo montado pela jornalista que lhe dá o nome com 1.600 livros, dois mil fascículos de periódicos, monografias, dissertações de mestrado e doutorado, 20 mil recortes de jornal e seis mil laudas escritas pela jornalista), Unidade Especial de Informação e Memória (UEIM), Núcleo de Investigação e Documentação; o Núcleo de Estudos AfroBrasileiros (UFSCar, 2004-2008), Revista Olhar, Núcleo de Estudos sobre Comportamento, Cognição e Ensino (ECCE), Laboratório de Interação Social (LIS), Laboratório de Análise e Prevenção da Violência (LAPREV), Laboratório de Aprendizagem Humana, Multimídia Interativa e Ensino Informatizado (LAHMIEI) e Revista Brasileira de Letras.

No que concerne à pesquisa, o $\mathrm{CECH}$ conta com 67 grupos cadastrados e reconhecidos pelo $\mathrm{CNPq}$ e 176 linhas de pesquisa. Sua comunidade desenvolve cerca de 170 atividades de extensão, todas elas contribuindo significativamente para aproximar universidade e sociedade.

Por fim, tem-se o Centro de Ciências e Tecnologias para a Sustentabilidade (CCTS) que, desde o planejamento de ocupação e métodos construtivos empregados, até os projetos pedagógicos e os temas de pesquisa, todas as atividades são regidas pelo princípio do desenvolvimento sustentável.

O curso de Turismo dá ênfase à Educação Ambiental e Turismo Histórico-Cultural. O curso de Engenharia Florestal firmou um convênio com o Ministério do Meio Ambiente para desenvolvimento de projetos de pesquisas na Floresta Nacional de Ipanema, um dos mais importantes remanescentes de Mata Atlântica do Brasil e para projetos socioambientais envolvendo comunidades tradicionais.

\subsubsection{A Fundação de Apoio Institucional (FAI)}

Identificada a necessidade da criação de uma instituição responsável por viabilizar juridicamente as relações institucionais entre a UFSCar e o meio externo, antes mesmo da promulgação da Lei das Fundações (Lei no 8.958/94), foi fundada em 1992 pela Associação Brasileira de Polímeros (ABPol), a Fundação de Apoio Institucional ao Desenvolvimento Científico e Tecnológico (FAI) (FAI, 2011). 
A fundação é uma entidade de direito privado, sem fins lucrativos, que tem como objetivo principal apoiar a UFSCar no desenvolvimento científico e tecnológico, por meio do desenvolvimento de contratos, acordos e convênios entre a universidade e outras instituições de ensino, pesquisa, financiamento e fomento de pesquisa. É credenciada junto à Secretaria de Ensino Superior (SESu), do Ministério da Educação (MEC) (sob n. ${ }^{\circ}$ 062/2009) e à Secretaria de Desenvolvimento Científico e Tecnológico do Ministério da Ciência, Tecnologia e Inovação (MCTI), conforme a Lei no 8.958/94 (FAI, 2013).

A Lei ${ }^{\circ}$ 8.958/94, conhecida comumente como a Lei das Fundações, foi sancionada pelo Presidente da República em dezembro de 1994 e dispõe sobre as relações entre as instituições federais de ensino superior e de pesquisa científica e tecnológica e as fundações de apoio. Esta Lei regulamenta que as Instituições Federais de Ensino Superior (IFES) poderão contratar instituições criadas com a finalidade de dar apoio a projetos de pesquisa, ensino e extensão e de desenvolvimento institucional, científico e tecnológico de interesse dessas instituições.

Para o desenvolvimento de suas atividades de pesquisa, a FAI possui Certificado de Credenciamento junto ao Conselho Nacional de Desenvolvimento Científico e Tecnológico (CNPq), o que lhe confere o direito de importar bens, materiais permanentes e equipamentos, assim como partes e peças de reposição, acessórios, matérias-primas e de consumo destinados à execução de pesquisa cientifica ou tecnológica, de acordo com a Lei 8.010/90 que dispõe sobre as importações de bens destinados à pesquisa científica e tecnológica e outras providências (FAI, 2011).

De acordo com o relatório da FAI de 2011, a fundação é forte parceira da UFSCar em todas as áreas do conhecimento e atua como interface junto às entidades e agências de financiamento e fomento à pesquisa, sejam elas públicas ou privadas, nacionais ou estrangeiras, realizando atividades, como assessoria na elaboração de projetos de pesquisa e de propostas de prestação de serviços, negociação de convênios e contratos, além do gerenciamento de recursos financeiros de projetos da universidade em estudo.

Com base no Quadro 6, os projetos gerenciados pela FAI podem ser categorizados em três formas. 
Quadro 6 - Classificação dos projetos gerenciados pela FAI

\begin{tabular}{|c|c|}
\hline Tipo de projeto & Descrição \\
\hline Projetos de Extensão & $\begin{array}{l}\text { São aqueles desenvolvidos em parceria com empresas que procuram na UFSCar } \\
\text { parcerias para o desenvolvimento de pesquisas tecnológicas e desenvolvimento } \\
\text { ou aperfeiçoamento de processos de produção, bem como com instituições } \\
\text { públicas e privadas, órgãos públicos municipais, estaduais ou federais. }\end{array}$ \\
\hline $\begin{array}{l}\text { Projetos } \\
\text { Governamentais }\end{array}$ & $\begin{array}{l}\text { Convênios de pesquisa ou extensão com financiamento de órgãos de fomento } \\
\text { governamentais como FINEP, CAPES, e CNPq, entre outros administrados } \\
\text { segundo a Lei de Licitações ( } \mathrm{n}^{\circ} \text { 8.666/93) e Lei } 10.520 / 02 \text { (Pregão), ou ainda } \\
\text { pela Portaria Interministerial MPOG/SRH e MPOG/SOF n }{ }^{\circ} 127 \text { e de acordo com } \\
\text { a programação definida pelo órgão financiado. }\end{array}$ \\
\hline $\begin{array}{l}\text { Convênios de } \\
\text { Cooperação } \\
\text { Institucional - CCIs }\end{array}$ & $\begin{array}{l}\text { São os celebrados entre a FAI e a própria UFSCar, sendo a FAI responsável pelo } \\
\text { gerenciamento administrativo e financeiro dos mesmos, os quais devem respeitar } \\
\text { a Lei de Licitações Públicas e Contratos Administrativos ( } n^{\circ} \text { 8.666/93) e Lei } \\
10.520 / 02 \text { (Pregão), inclusive nas compras de materiais, equipamentos, } \\
\text { contratação de obras etc. }\end{array}$ \\
\hline
\end{tabular}

Fonte: Adaptado do relatório anual da FAI, 2011.

Nesta perspectiva, convém explicar que a FAI discrimina anualmente projetos gerenciados e projetos captados. Os projetos captados dizem respeito ao montante de projetos no ano, referente às três categorias sob sua administração e que podem ou não ter movimentado recursos financeiros. Os projetos gerenciados consistem na soma do saldo dos projetos do ano anterior e dos captados no exercício por meio das diferentes modalidades desenvolvidas pela fundação, tanto os que geraram recursos financeiros quanto os que não movimentaram recursos.

A FAI atua de maneira articulada com Agência de Inovação da UFSCar, criada por meio da Portaria GR no 823/08 de 02 de dezembro de 2008, como um órgão vinculado diretamente à Reitoria, e com a finalidade principal de gerir a política de inovação da Universidade e dar celeridade à tramitação de procedimentos e iniciativas que visem à inovação tecnológica, à proteção da propriedade intelectual e à transferência de tecnologia no âmbito institucional.

A Agência de Inovação da UFSCar assessora a comunidade acadêmica na promoção da proteção dos registros de patentes, marcas, programas de computador, desenho industrial e cultivares, além de buscar parceiros industriais para promover o transbordamento do conhecimento gerado na universidade para a sociedade.

De acordo com o relatório da Agência de Inovação da UFSCar (2013), além de sua finalidade principal, a Agência possui as seguintes finalidades específicas:

- Implementar a política institucional de estímulo à proteção das criações, licenciamento, inovação e outras formas de transferência de tecnologia da UFSCar; 
- Avaliar e classificar os resultados decorrentes de atividades e projetos acadêmicos da UFSCar para o atendimento das disposições da Lei $n^{\circ} 10.973 / 2004$ e do Decreto $n^{\circ}$ $5.563 / 2005$;

- Avaliar solicitação de inventor independente para adoção de invenção na forma do art. 22da Lei no 10.973/2004 e do Decreto n ${ }^{\circ}$ 5.563/2005;

- Analisar e julgar a viabilidade técnica e econômica dos pedidos de proteção à propriedade intelectual a ela encaminhados;

- Executar, acompanhar e zelar pelo processamento dos pedidos e pela manutenção dos títulos de propriedade intelectual da UFSCar;

- Promover as ações de transferência, licenciamento e comercialização de tecnologia da UFSCar e diligenciar toda e qualquer iniciativa que vise esse propósito;

- Assessorar a administração superior da UFSCar em assuntos pertinentes à propriedade intelectual, à transferência de tecnologia e à inovação;

- Contribuir para o aumento da conscientização da comunidade acadêmica e da sociedade em geral a respeito da propriedade intelectual, da transferência de tecnologia e da inovação;

- Coordenar as ações da UFSCar na concepção e funcionamento de redes cooperativas em inovação;

- Coordenar as ações da UFSCar, em conjunto com os órgãos públicos e privados, no sentido de planejar, implementar e apoiar a gestão das Incubadoras de Empresas e dos Parques Tecnológicos nos municípios de interesse da UFSCar;

- Apoiar a criação e a manutenção das empresas geradas a partir dos resultados da política de inovação tecnológica da UFSCar;

- Outras atribuições pertinentes à gestão da política de propriedade intelectual, transferência de tecnologia e inovação, no âmbito da UFSCar.

Nesta perspectiva, vale ressaltar que a UFSCar inicia sua participação no processo de inovação através de suas políticas institucionalizadas que refletem a interação universidadeempresa, a política de inovação e as questões da proteção por direito de propriedade industrial. Dentre suas políticas, as principais são: Portaria GR nº 664/99 que dispõe sobre as normas de atividades de extensão (parceria universidade-empresa), Portaria GR nº 627/03 que institui o Programa de Proteção à Propriedade Intelectual e Transferência de Tecnologia no âmbito da universidade, regulamentando os direitos e obrigações pertinentes à propriedade 
intelectual e a Portaria GR n ${ }^{\circ} 823 / 08$ que dispõe sobre a política de inovação tecnológica e institui a Agência de Inovação da UFSCar.

Apesar da Agência de Inovação da UFSCar ter sido criada em 2008, suas ações no âmbito da proteção de propriedade intelectual na UFSCar são anteriores. Um estudo feito por Garnica, Oliveira e Torkomian (2006), que consiste em um levantamento nas bases de dados gratuitas de patentes utilizando o nome completo de todos os professores do Centro de Ciências Exatas e Tecnologia e dos pesquisadores inativos da UFSCar, mostra que desde 1982 a UFSCar vem desenvolvendo pesquisas passíveis de proteção.

Nesse contexto, conforme resultados do relatório da Agência de Inovação (2013), os resultados gerais nas mais diferentes áreas protegidas e apoiadas pela Agência são 88 depósitos de patentes, 22 patentes concedidas, 12 patentes licenciadas, 8 registros de patentes de computadores, 16 cultivares protegidas e 4 registros de marcas. O Gráfico 1 demonstra a soma dos depósitos feitos entre 2008 e 2012 com os obtidos anteriormente. Assim, no que se refere às patentes, de 2008 a 2012 foram protegidos 39 inventos junto ao Instituto Nacional de Propriedade Intelectual (INPI).

Gráfico 1 - Pedidos de patentes depositados no INPI entre 2008-2012 e acumulados desde 1990

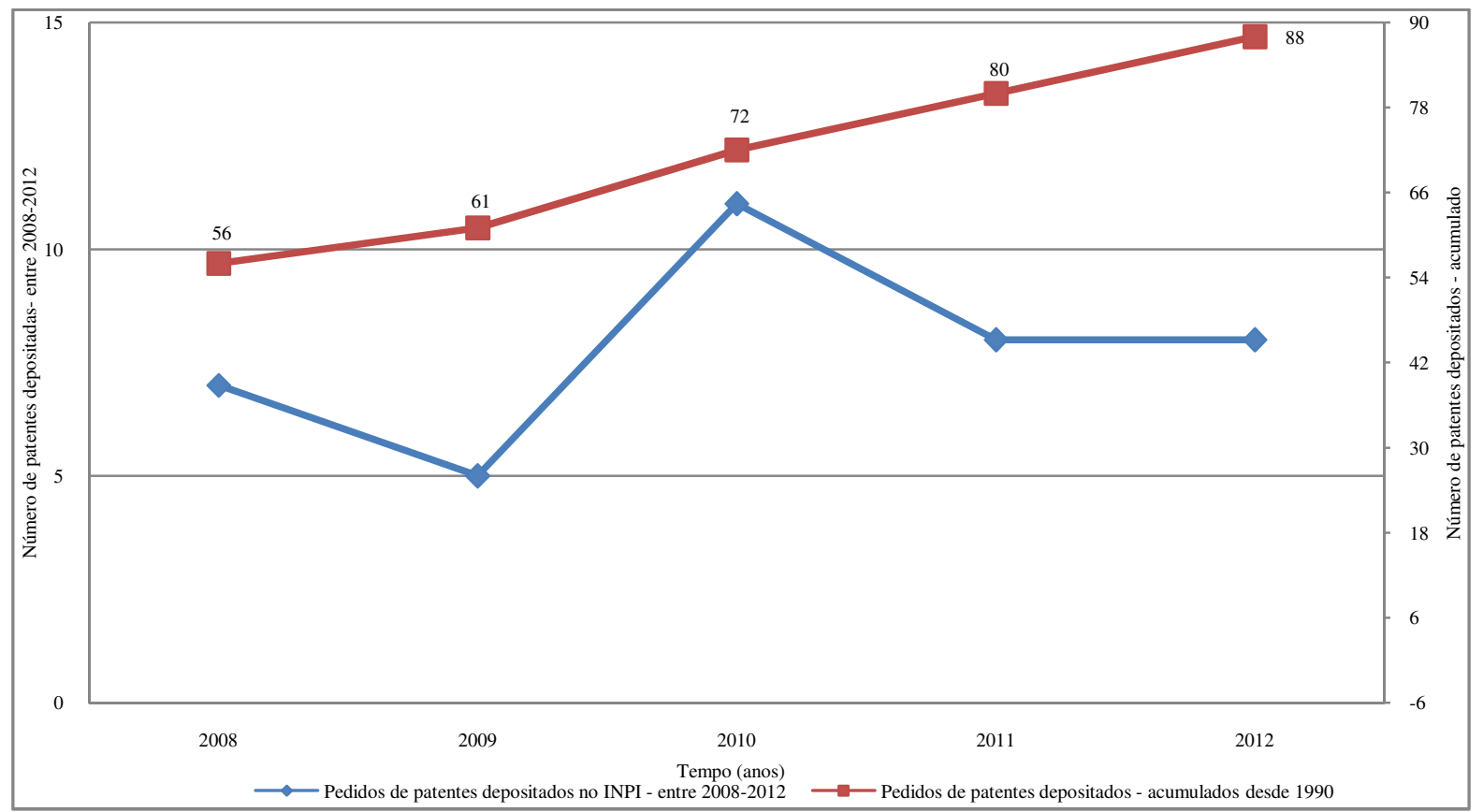

Fonte: Adaptado da Agência de Inovação da UFSCar, 2013.

Em relação aos programas de computados, entre 2008 e 2012 foram registrados um total de oito, sendo dois em 2009, três em 2010 e três em 2012. Além das patentes, há 16 
cultivares protegidas pelo Programa de Melhoramento Genético de Cana-de-Açúcar que estão licenciadas para mais de 150 usinas de açúcar e álcool. Nesse sentido, vale ressaltar que alguns depósitos de patentes são decorrentes de projetos de extensão entre a universidade e empresa, tramitada pelos órgãos internos preestabelecidos.

\subsection{Caracterização geral dos projetos de cooperação da UFSCar com a empresas}

O Gráfico 2, a seguir, demonstra o crescimento do número de projetos estabelecidos por ano, que movimentaram recursos financeiros, pela FAI, entre 2008 a 2012, período que fornece um conjunto de 619 projetos sob gerenciamento da FAI. Os dados demonstraram a importância que os projetos em parceria com a sociedade vêm ganhando no âmbito acadêmico nos últimos anos, tendo seu auge no ano de 2011, oriundos principalmente de projetos de extensão, com cerca de 129 projetos do total dos projetos captados no ano de 2011, como observado no Gráfico abaixo.

Gráfico 2 - Evolução do número de projetos por período de tempo, 2008 a 2012

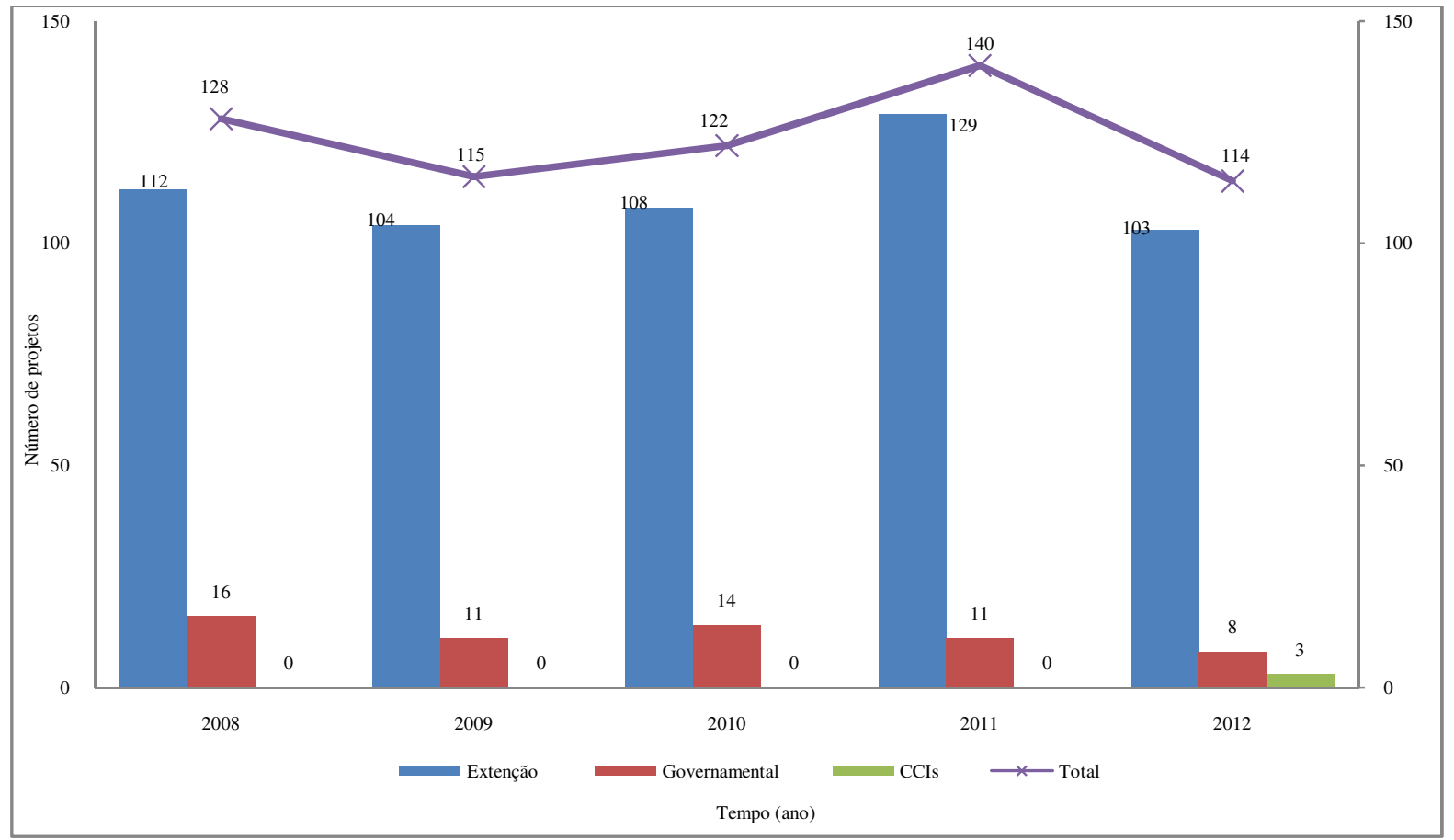

Fonte: Elaborado a partir dos dados fornecidos pela FAI, 2008 a 2012.

Como pode ser observado, os projetos de extensão se destacam dentre os demais, com 112 projetos captados em 2008, passando para 129 em 2011. Esses dados demonstram a importância da cooperação da UFSCar com o meio externo, uma vez que são desenvolvidos 
em parceria tanto com empresas privadas quanto com instituições públicas, órgãos públicos municipais, estaduais ou federais, bem como evidencia o esforço despendido pelo seu corpo docente, discente e técnico administrativo na difusão do conhecimento gerado na universidade.

Transferindo a análise para o volume de recursos $\operatorname{captados}^{2}$, por ano de início de projeto entre 2008 e 2012, conforme Gráfico 3, é possível verificar que do montante de 50.589.520 milhões de reais, $64,60 \%$ provêm de projetos de extensão, 34,5\% de projetos governamentais e $0,81 \%$ de CCIs. Outro aspecto evidenciado foi o de que os recursos em 2009 tiveram uma queda de aproximadamente 9\% em relação ao ano anterior. Por sua vez, os recursos financeiros em 2010 obtiveram um aumento de 13,96\% em relação a 2009.

Gráfico 3 - Distribuição do volume dos recursos captados pela FAI por ano de início de projeto de 2008 a 2012

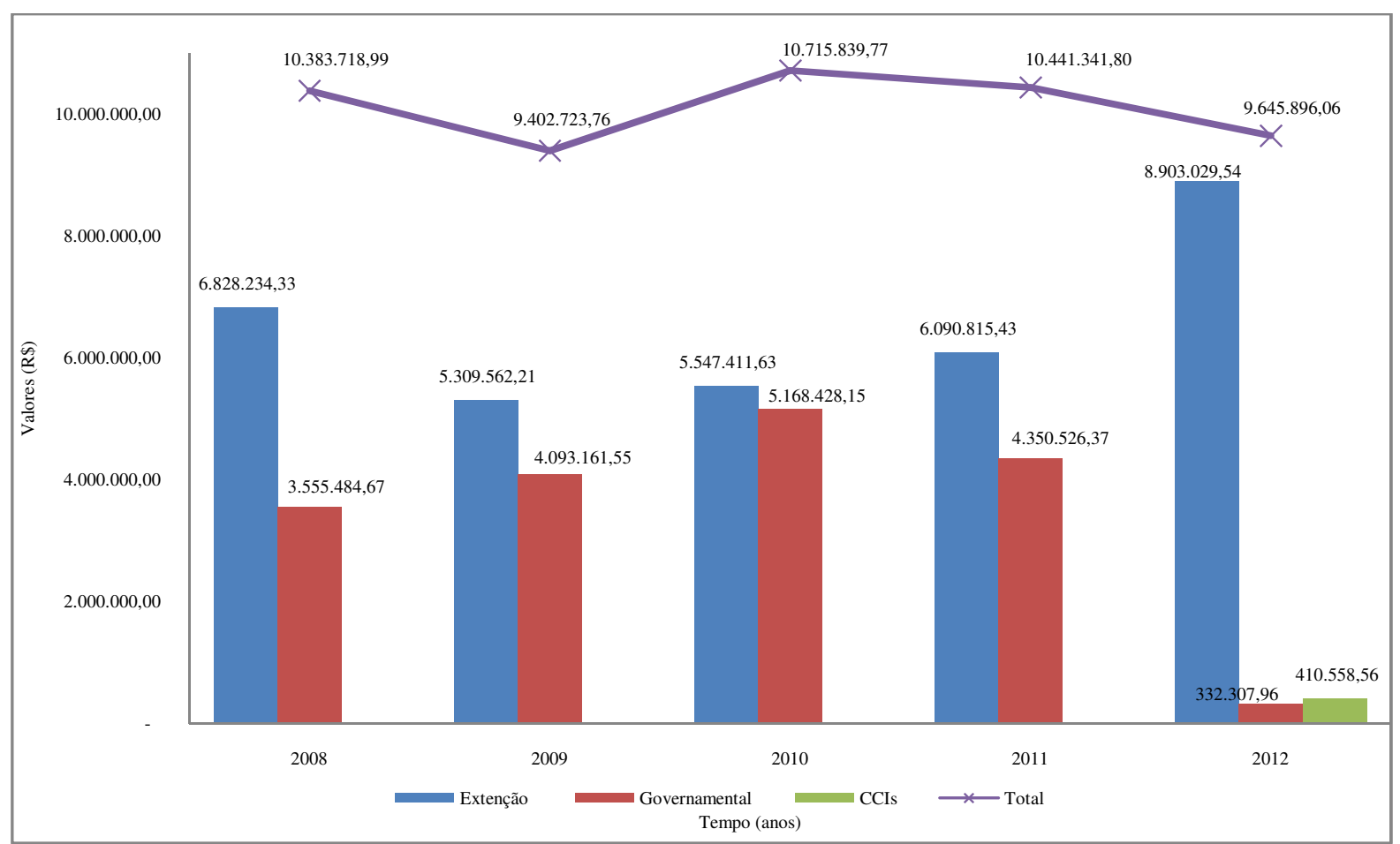

Fonte: Elaborado a partir dos dados fornecidos pela FAI, 2008 a 2012.

Nessa perspectiva, vale ressaltar que tal resultado está atrelado à proibição do estabelecimento de novos convênios de cooperação institucional (CCIs) entre a UFSCar com a fundação de apoio em geral, decorrentes das determinações do Tribunal de Contas da União (TCU). No caso dos CCIs, celebra-se um convênio entre universidade e a fundação, no qual a universidade elabora um projeto, no qual a universidade repassa recursos orçamentários

\footnotetext{
${ }^{2}$ Todos os valores apresentados nesse trabalho foram deflacionados, os valores foram transformados de valores nominais para valores correntes, podendo, assim ser comparados em diferentes períodos de tempo.
} 
recebidos do Ministério da Educação à fundação que executará o projeto, em geral contratando terceiros especializados nesta atividade (FAI, 2010).

Por proibição do TCU, os recursos oriundos dessa modalidade foram impedidos de ser gerenciados pela fundação a partir de 2008, permanecendo somente convênios já firmados anteriormente e ainda em execução.

Por fim, o Gráfico 4 apresenta os resultados referentes à distribuição dos projetos estabelecidos por período de duração. A máxima variação encontrada abrange projetos estabelecidos por um único dia e período superior a 3 anos. A maioria dos projetos, cerca de $373(60,26 \%$ do total), foi estabelecido por intervalos de duração menores ou iguais a 12 meses.

Gráfico 4 - Distribuição do número de projetos por intervalo de duração

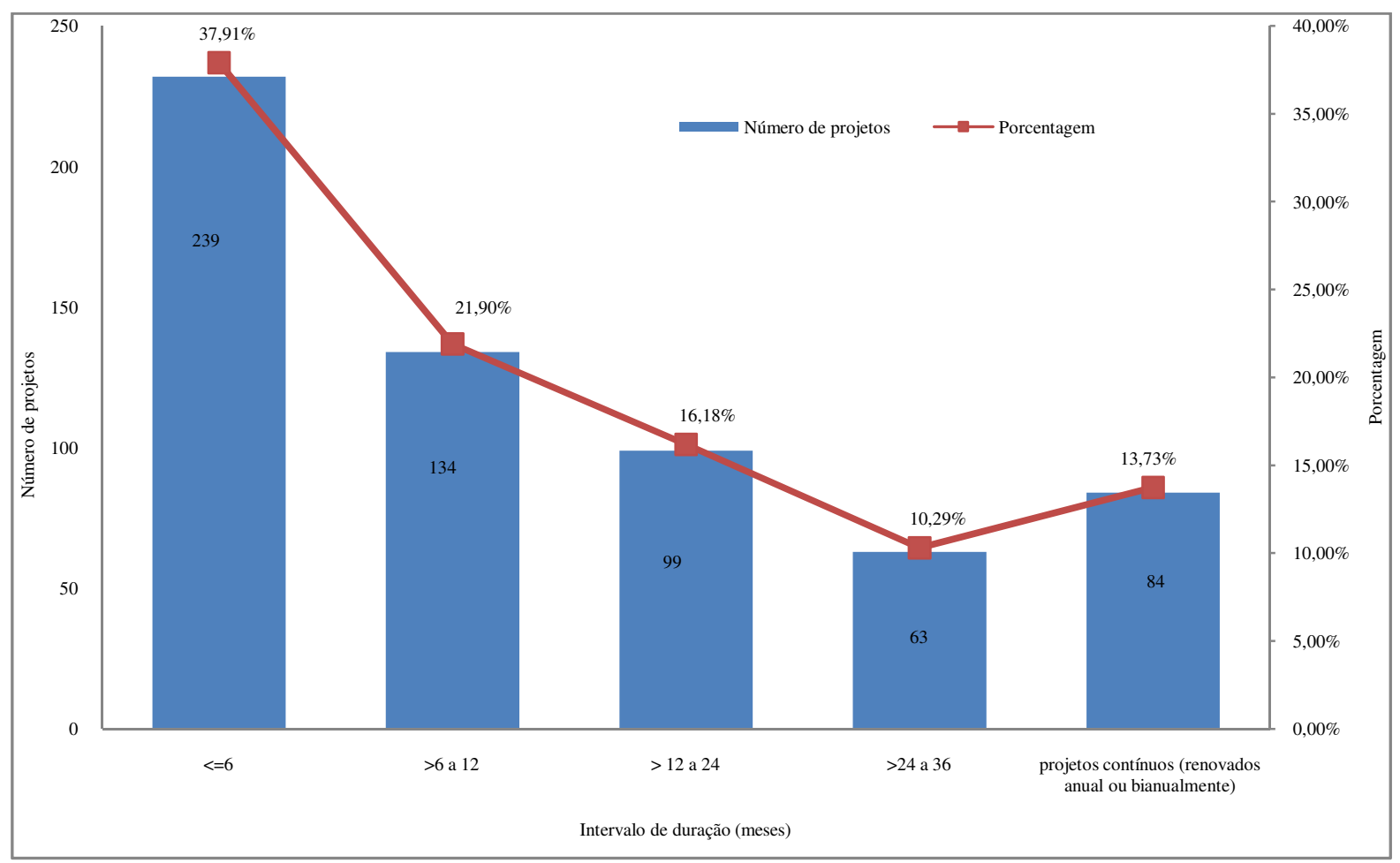

Fonte: Elaborado a partir dos dados fornecidos pela FAI, 2008 a 2012.

Neste ponto é importante ressaltar que, considerando a definição de que um projeto é um esforço temporário, com início e fim determinado, não é possível dizer que há projetos com mais de 36 meses. Na realidade, tratam-se de projetos contínuos que são renovados anualmente e bianualmente. Neste estudo, esse dado representa 84 projetos, o equivalente a $13,51 \%$ do total de projetos. 
Quando se transfere a análise para o volume de recursos financeiros dos projetos (Gráfico 5), o montante de recursos apresenta resultados semelhantes da figura anterior. Nesse caso, o volume de recurso para os projetos estabelecidos por até 12 meses supera $37 \%$ do total, sendo que $47 \%$ do total advêm de projetos estabelecidos por intervalos maiores que 36 meses. Nesta perspectiva, o resultado demonstra a importância dos projetos de maiores intervalos de duração, pois os projetos com maiores intervalos de duração implicam em maiores volumes de recursos para a sua execução.

Gráfico 5- Distribuição do volume de recursos financeiros por intervalo de duração

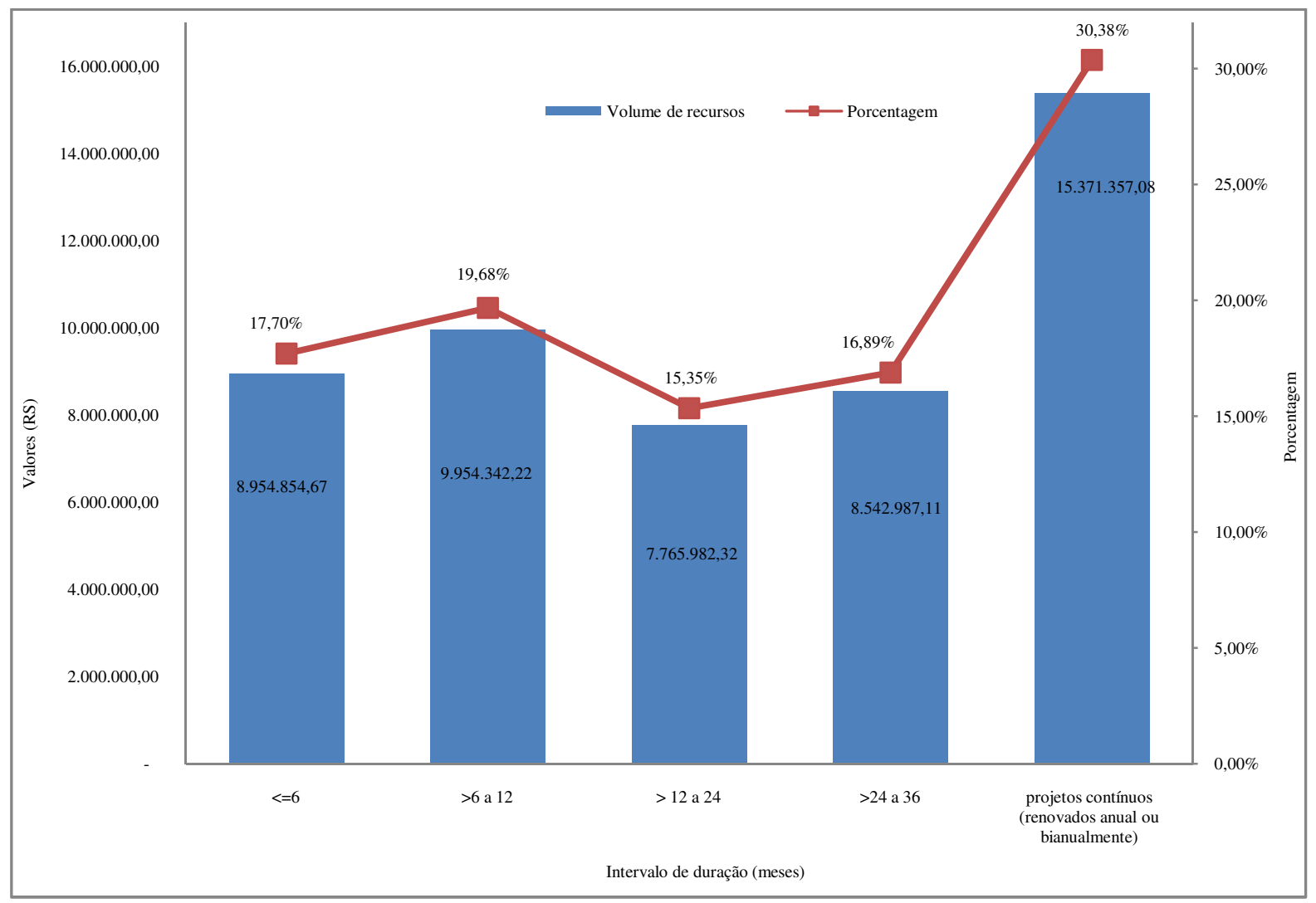

Fonte: Elaborado a partir dos dados fornecidos pela FAI, 2008 a 2012.

\subsubsection{Distribuição dos projetos por tipo de atividade}

Neste tópico, as análises do número de projetos e do volume de recursos são apresentadas em função do tipo de atividade desenvolvida, sendo os projetos classificados de acordo com os tipos de atividades de extensão referidos no art. $9^{\circ}$ da Portaria 664/99 de 06 de abril de 1999: 
- Publicações: livros, revistas, artigos, anais, resenhas, etc. - divulgação, através de linguagem escrita, da produção de conhecimento da Universidade e da humanidade em geral, em veículos que tornem essa produção disponível e maximizem sua disseminação à comunidade;

- Eventos: promoção de atividades que coloquem a comunidade em contato com o patrimônio cultural da humanidade, tais como peças de teatro, apresentação de corais, etc., de modo que as pessoas possam ter acesso a esse patrimônio;

- Consultoria/Assessoria: oferta de subsídios através de um processo de acompanhamento de tomada de decisão na realização de trabalhos, intervenções, etc. $\mathrm{Na}$ assessoria há um envolvimento com todas as etapas do trabalho, incluindo avaliação de resultados;

- Prestação de Serviços: realização direta de trabalhos profissionais, como consultas médicas, cirurgias, psicoterapia, tratamento de saúde, produção de materiais e objetos, realização de tarefas técnicas, elaboração de protótipos, de diagnósticos profissionais, de provas técnicas para seleção de pessoal, etc., em campos de atuação para os quais a universidade desenvolve conhecimento ou forma alunos;

- Cooperação interinstitucional: toda e qualquer atividade, dentro desta categoria, que vise auxiliar outra instituição ou organismos de representação da sociedade civil e científica a realizar atividades de disciplinas de curso de graduação ou pós-graduação, participação em projetos de pesquisa, bancas de concurso e realização de atividades em conjunto para viabilizar projetos de ambas as instituições;

- Cursos (extensão cultural, extensão universitária, aperfeiçoamento profissional, atualização científica e especialização): visam a aumentar o conhecimento geral das pessoas, sobre um determinado assunto, independentemente de sua formação específica.

Com o objetivo de aprimorar a análise, seguem as classificações de Pesquisa e Pesquisa e Desenvolvimento (P\&D), conforme Oliveira (2002):

- Pesquisa: refere-se aos projetos estabelecidos, geralmente, com Agências de financiamento governamentais e intervalos de duração elevados;

- Pesquisa e Desenvolvimento (P\&D): refere-se a projetos de pesquisas cooperativos que visam à aplicação imediata nas empresas. Exemplos dessa classificação são os projetos estabelecidos com usinas de açúcar e álcool. 
O Gráfico 6 mostra a distribuição decrescente do número de projetos em função do tipo de atividade desenvolvida. Nele, constatou-se que as atividades de Cursos e Consultoria/Assessoria supera uma centena de projetos, o equivalente a 223 e 122 projetos captados pela FAI, seguida por Eventos com 97 projetos. Essas três atividades contemplam aproximadamente $71 \%$ do total de projetos com o meio externo. Um grupo intermediário varia entre 57 e 45 projetos, isto é, Pesquisa e Desenvolvimento (P\&D), Pesquisa e Prestação de Serviço. As demais atividades representaram uma pequena contribuição, cerca de $4,7 \%$ do total de projetos.

Gráfico 6 - Distribuição do número de projetos FAI por tipo de atividade

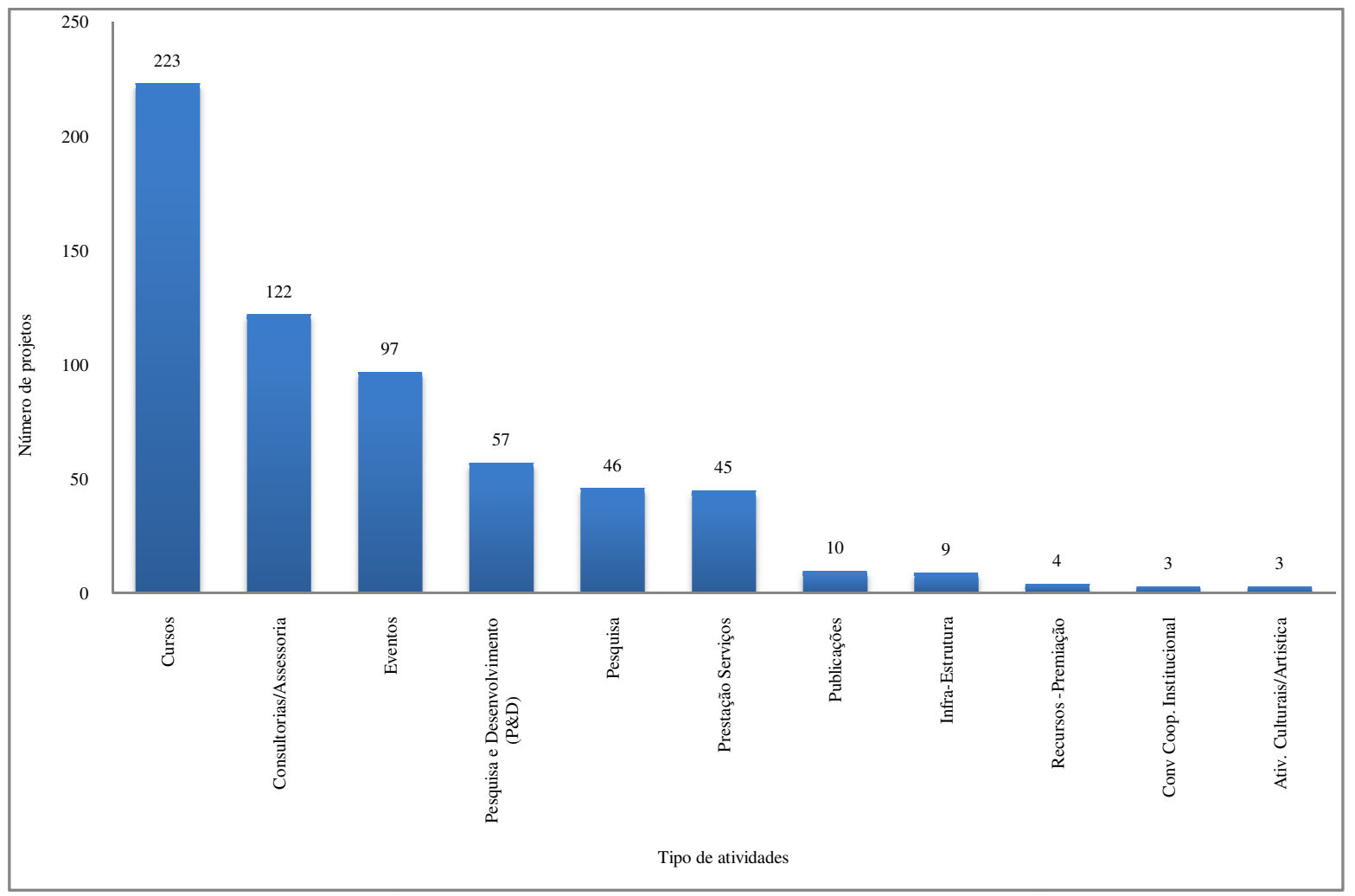

Fonte: Elaborado a partir dos dados fornecidos pela FAI, 2008 a 2012.

Por outro lado, conforme o Gráfico 7, o volume de recursos não varia do mesmo modo que o número de projetos. O tipo de atividade que apresentou maior volume de recursos é a de Pesquisa com um pouco mais de 16 milhões de reais, o equivalente a $32,56 \%$ do total de recursos. Em segundo lugar encontrou-se a atividade de Pesquisa e Desenvolvimento (P\&D), com cerca de 11 milhões de reais (21,81\% do montante dos recursos), seguida de Cursos, com 10.693 milhões de reais $(21,44 \%$ do total de recursos). 
Gráfico 7 - Distribuição do volume de recursos financeiros por tipo de atividade

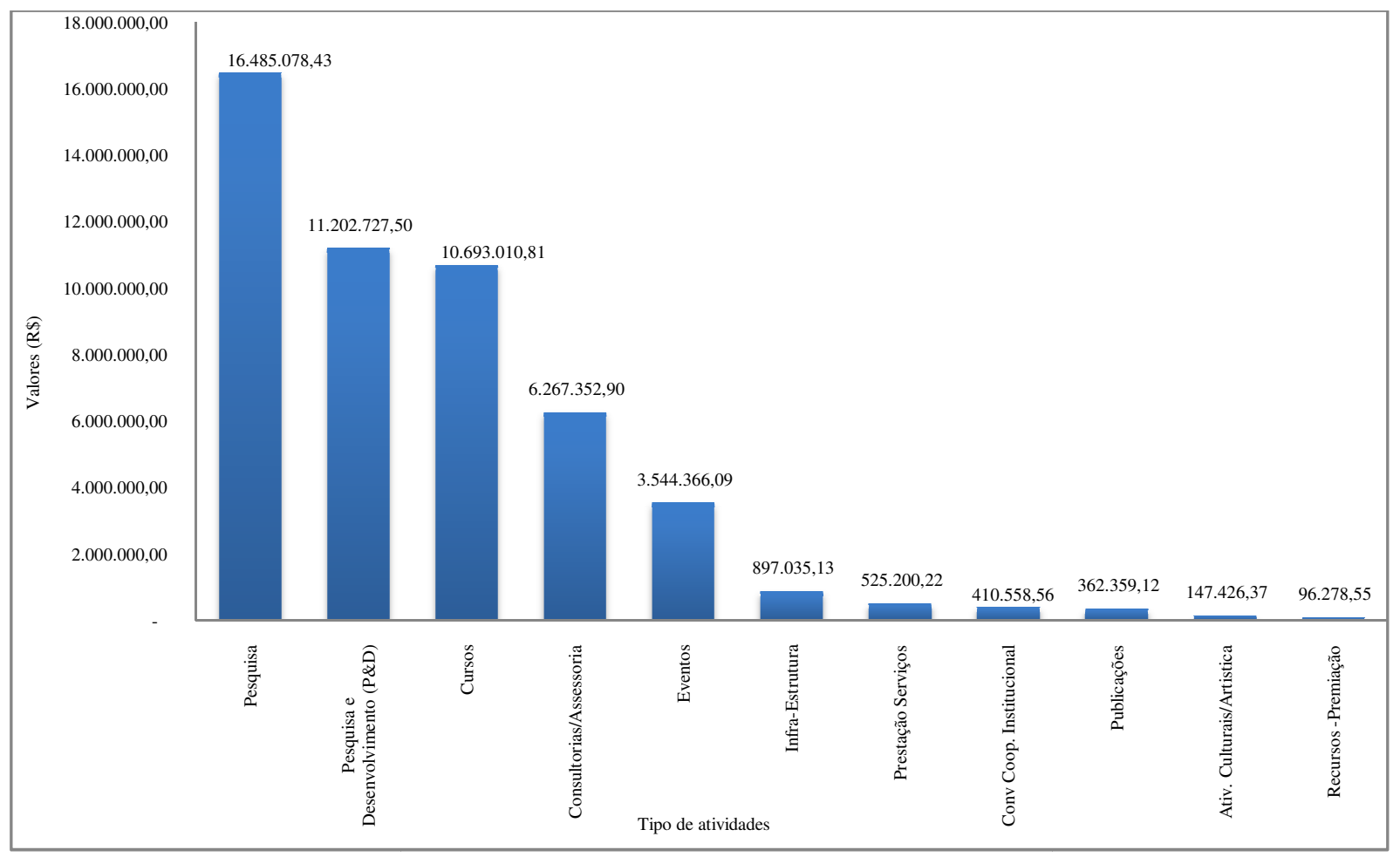

Fonte: Elaborado a partir dos dados fornecidos pela FAI, 2008 a 2012.

Na sequência, encontraram-se as atividades de Consultoria/Assessoria, 6 milhões de reais e eventos, com 3.544.366 milhões de reais. Essas atividades juntas representaram $28,72 \%$ do total de recursos. As demais, as atividades de infraestrutura, prestação de serviço, publicações, dentre outras atividades restantes, não atingiram a cifra de 1 milhão de reais e representaram cerca de $7 \%$ do montante de recursos.

De modo geral, observou-se que existem diferenças na distribuição do número de projetos por ano de início de projeto e no volume de recursos para cada tipo de atividade. Dentre elas, destacou-se o expressivo volume de recursos captados pelas atividades de Pesquisa e Desenvolvimento (P\&D) e Pesquisa que, apesar de se encontrarem, respectivamente, em quarto e quinto lugar no número de projetos, as atividades de Pesquisa e Pesquisa e Desenvolvimento (P\&D) encontraram-se em primeiro segundo lugar em relação ao volume de recursos.

\subsubsection{Distribuição dos projetos por centro científico}

Outro importante resultado consistiu na distribuição dos projetos em relação à área de conhecimento da UFSCar. Nesse caso, vale indicar que a análise tem duas dimensões diferentes, sendo a primeira delas mais abrangente, quando são apresentadas as distribuições 
em relação aos Centros Científicos da UFSCar envolvidos nos projetos com o meio externo, e a segunda que traz um detalhamento através da distribuição em relação aos departamentos e unidades administrativas da UFSCar.

O primeiro resultado referiu-se à distribuição do número de projetos por Centro Científico entre o período de 2008 e 2012. Conforme o Gráfico 8, notou-se que o Centro de Ciências Exatas e Tecnológicas (CCET) é predominante em relação aos demais ao longo do período analisado, atingindo um volume total de 315 projetos com o meio externo. Em segundo lugar, encontrou-se o Centro de Ciências Biológicas e da Saúde (CCBS), com 86 do total de projetos com o meio externo, seguido do Centro de Educação de Ciências Humanas $(\mathrm{CECH})$, no qual a distribuição ocorre em torno de 10 e 15 projetos, com um montante total de 72 projetos.

Por último, encontrou-se o Centro de Ciências e Tecnologia para Sustentabilidade (CCTS) com um total de 11 projetos captados em 2012. Neste caso, cabe evidenciar que, apesar do CCTS ter sido criado em 2011, o campus de Sorocaba tem desenvolvido projetos em parceria com o meio externo desde o seu início, o que resultou no total de 72 projetos durante o período analisado.

Gráfico 8 - Distribuição dos projetos por Centro Científico no período de2008 a 2012

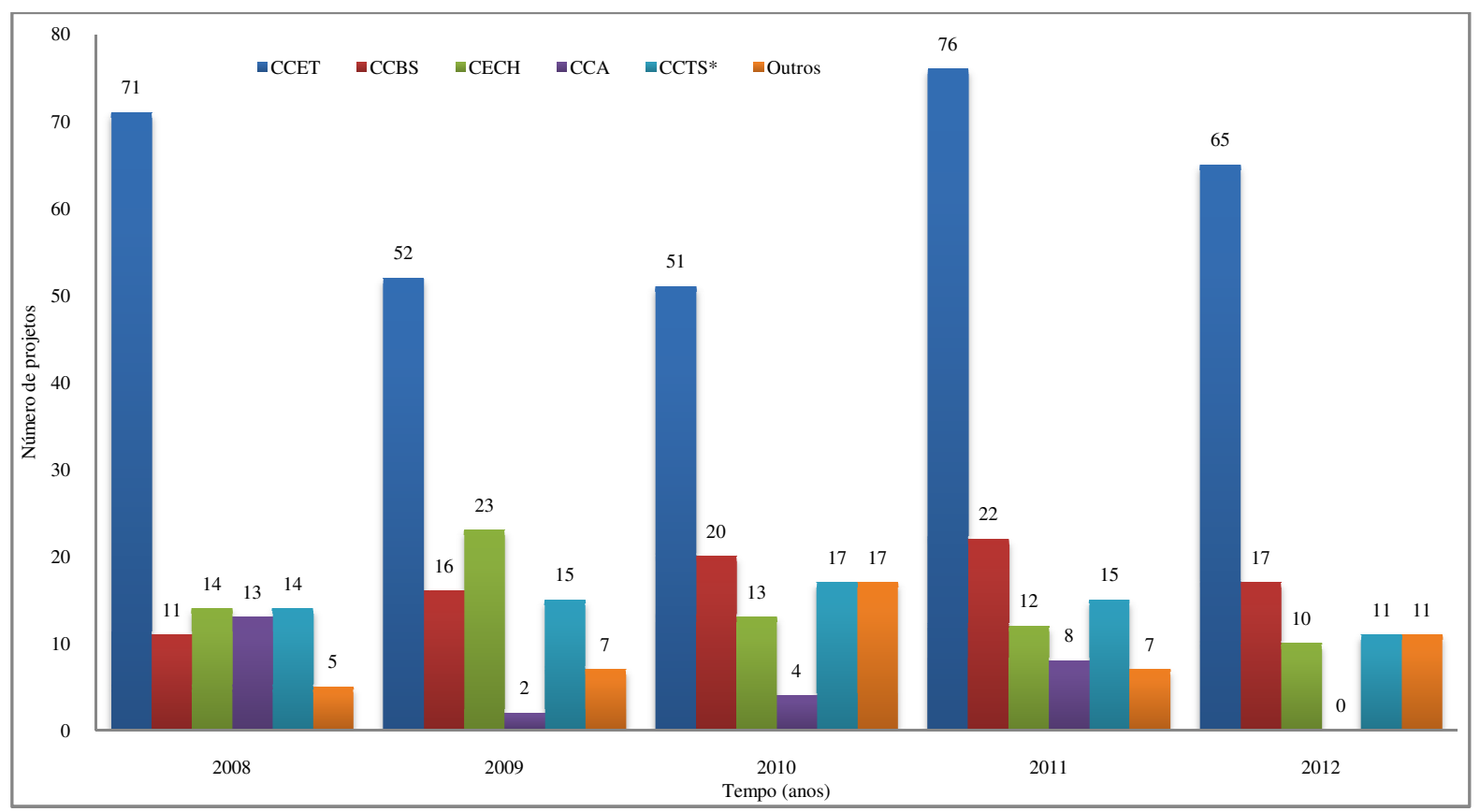

Fonte: Elaborado a partir dos dados fornecidos pela FAI, 2008 a 2012.

Nota: * Os dados dos projetos de 2008 a 2011 dizem respeito aos projetos desenvolvidos pelo campus de Sorocaba antes da criação do CCTS em 2011. 
Vale ressaltar que a classe denominada outros, com 47 do total de projetos, referem-se aos projetos estabelecidos com instâncias administrativas que não se enquadram na classificação dos Centros de Ciências, como as Pró-Reitorias, Núcleos de Extensão, Secretaria de Informática etc. Nesta perspectiva, observou-se no Gráfico 9 a expressividade do valor percentual do CCET, superando 50\% dos projetos estabelecidos com o meio externo.

Gráfico 9 - Distribuição total dos projetos e percentual por Centro Científico

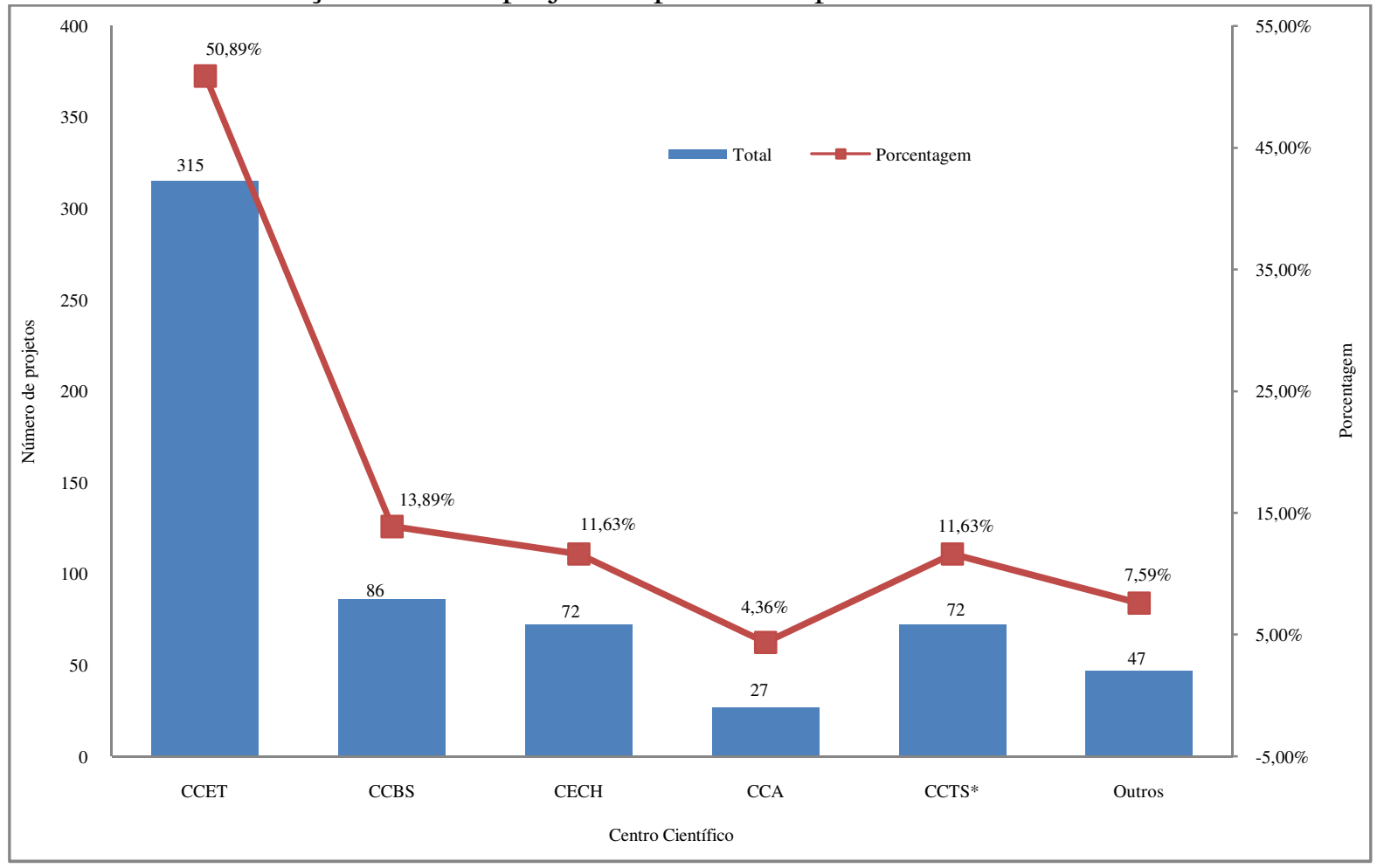

Fonte: Elaborado a partir dos dados fornecidos pela FAI, 2008 a 2012.

Transferindo a análise para o volume de recursos para cada Centro Científico da UFSCar, conforme Gráfico 10, verificou-se uma troca de posição do CECH com o CCA quando comparada à distribuição do número de projetos gerenciados, pois o volume dos recursos gerenciados pelo CCA é de 4.343.917 milhões de reais. Já o $\mathrm{CECH}$, na quarta posição, apresentando um montante de pouco mais de 3.5 milhões de reais. 
Gráfico 10 - Distribuição do volume de recursos financeiros por Centro Científico e distribuição percentual

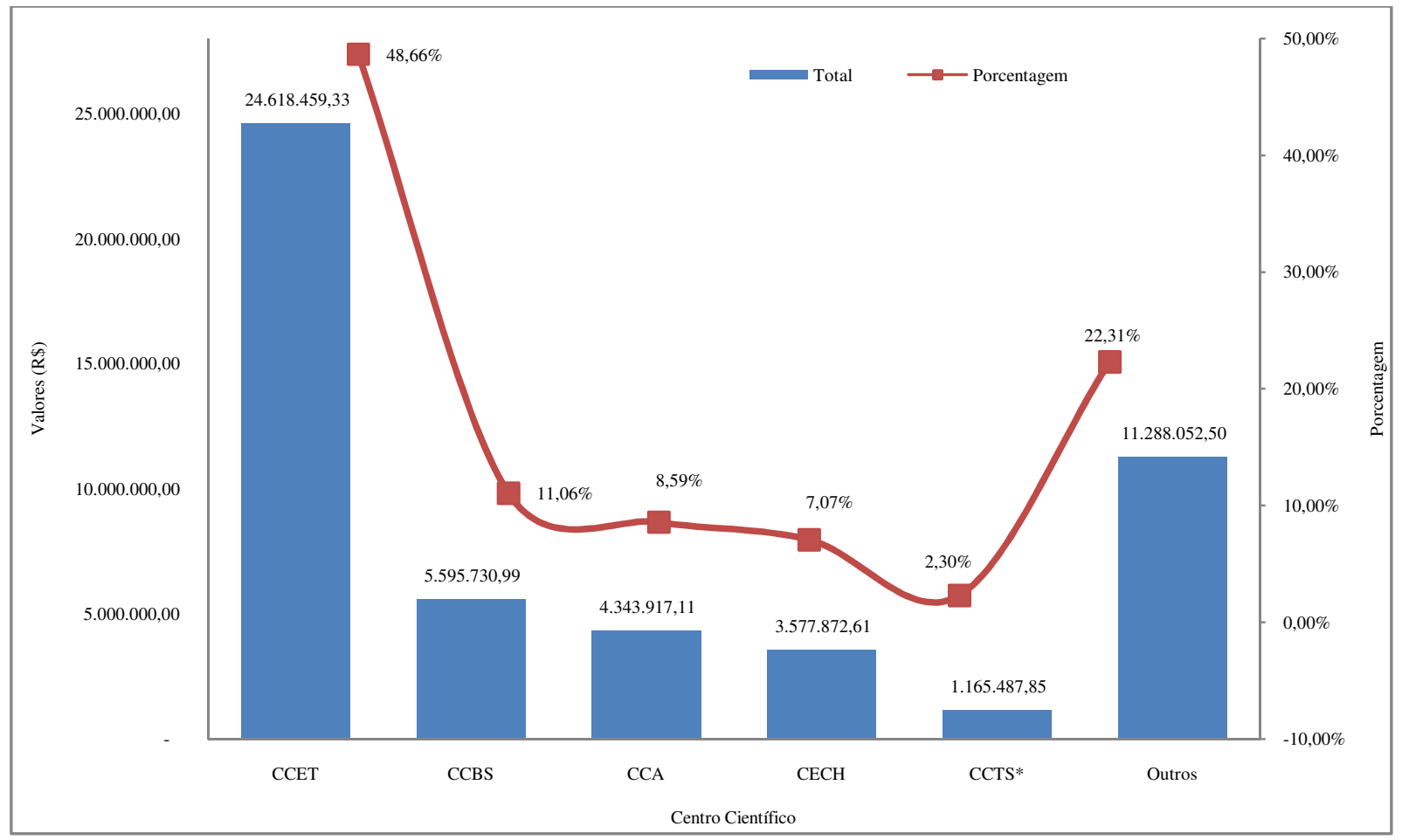

Fonte: Elaborado a partir dos dados fornecidos pela FAI, 2008 a 2012.

No entanto, no caso do CCA o volume dos recursos gerenciados foi significativamente maior do que o número de projetos estabelecidos, os valores percentuais passam de $4.36 \%$ no número de projetos para $7.07 \%$ no volume de recursos total, o inverso acontece para o CCBS, na qual o percentual diminuiu aproximadamente $6,16 \%$ em relação ao montante de recursos gerenciados. O que evidenciou que, apesar da quantidade de projetos do CCA ser menor que o do CCBS o Centro de Ciências Agrárias estabeleceu projetos com meio externo com volume de recursos maior que o CCBS.

\subsubsection{Distribuição dos projetos por departamento}

Em complemento ao resultado anterior, será apresentado o detalhamento da relação entre as áreas de conhecimento da UFSCar com o meio externo, através dos seus diversos departamentos. O Gráfico 11 mostra a distribuição do número de projetos por departamento científico. Foi possível identificar três departamentos que se destacam nos números de projetos estabelecidos durante o período analisado: o Departamento de Engenharia Civil (DECiv) e o Departamento de Engenharia de Materiais (DEMa), estabeleceram um total de 87 e 59 projetos, respectivamente, em cooperação com o meio externo cada, e o Departamento de 
Engenharia de Produção (DEP) com 56 projetos entre 2008 e 2012, o equivalente a 14,05\%, $9,53 \%$ e $9,05 \%$ do montante de projetos, respectivamente.

Um grupo intermediário, com variação total entre 19 e 61 projetos, abrangeu o campus de Sorocaba, com 61 projetos, o Departamento de Computação (DC), com 39 projetos, seguido do Departamento de Ciência da Informação (DCI) e Departamento de Fisioterapia (DFisio).

A percepção que se mantém após a apresentação desses resultados é de que poucos departamentos, cerca de três, realizam a maior parte dos projetos de cooperação, gerando uma concentração de atividades e consequentemente de recursos.

Gráfico 11 - Distribuição total dos projetos e volume dos recursos por departamento científico

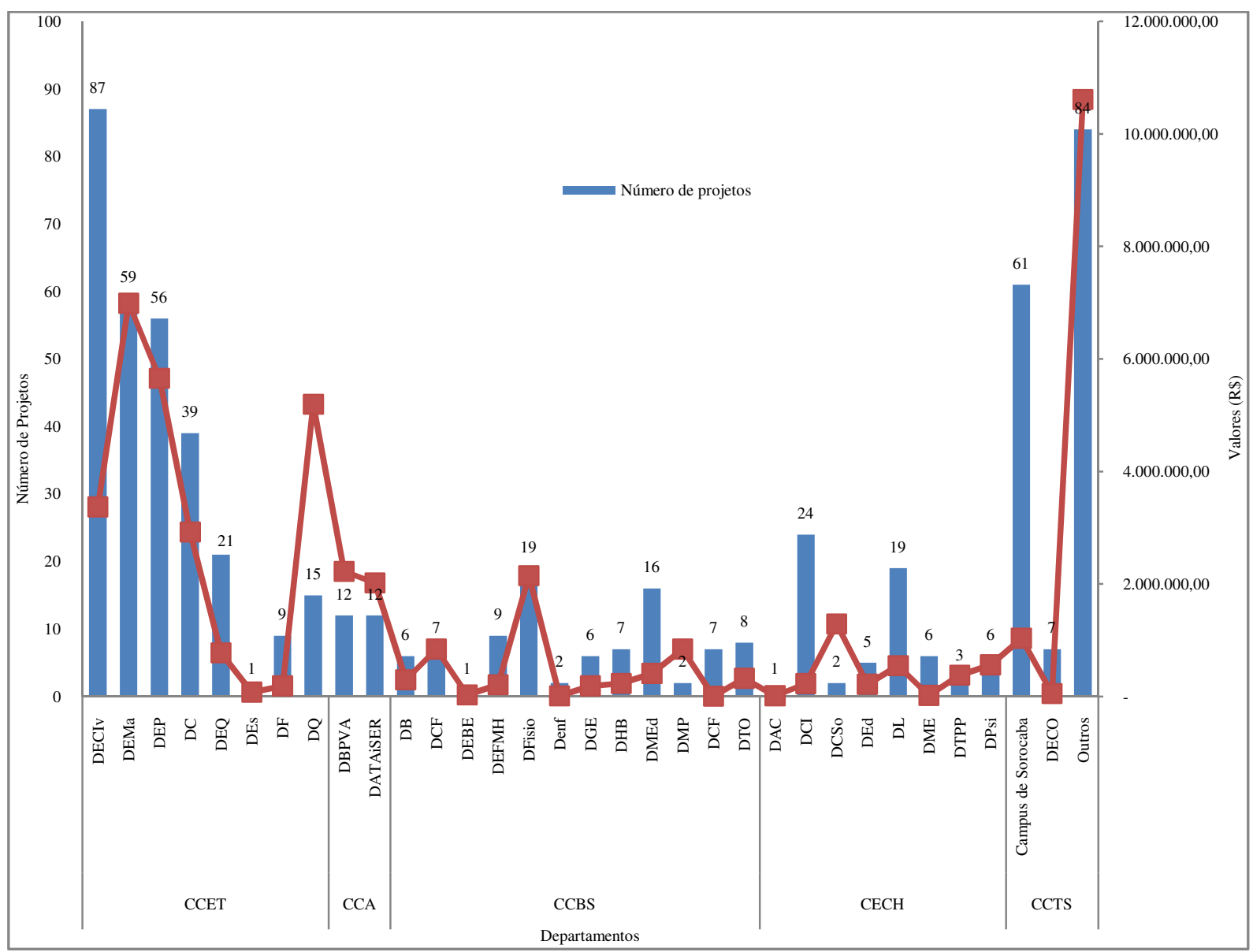

Fonte: Elaborado a partir dos dados fornecidos pela FAI, 2008 a 2012.

No entanto, quando a análise foi transferida para o volume de recursos, observou-se que há uma diferença significativa nas posições relacionadas ao número de projetos estabelecidos por departamento e ao volume de recursos financeiros, com destaque para o 
DEMa, pertencente ao CCET, que, apesar de estar em segundo lugar em número de projetos, encontra-se em primeiro lugar no que concerne ao montante de recursos, o equivalente a 6.8 milhões de reais. Em segundo lugar tem-se o DEP, com cerca de 5.6 milhões de reais, seguido pelo DQ, com pouco mais de 5 milhões de reais.

Além disso, ressalta-se a posição ocupada pelo DECiv, pois há uma grande quantidade de projetos com o meio externo, no entanto, esse departamento encontrou-se em quarto lugar em relação ao montante de recursos financeiros. Nesse sentido, observou-se que poucos departamentos, cerca de quatro concentram os recursos financeiros provenientes dos projetos de cooperação.

\subsubsection{Projetos por tipo de financiador}

Para compreender quem são os atores externos que estabelecem os projetos com a UFSCar, segue a lista das classificações utilizadas neste trabalho.

- Empresa privada: classe composta por organizações comerciais ou industriais dos mais diversos setores, tamanhos e natureza, tais como LTDA e S.A;

- Universidades e institutos de pesquisa: classes compostas por instituições de ensino superior públicas ou privadas e instituições de pesquisa;

- Agências de financiamento: agências governamentais voltadas para o financiamento de projetos de cunho científico e tecnológico (CAPES, CNPq e FINEP);

- Administração pública: classe composta por ministérios do governo federal, governos estaduais e suas secretarias e prefeituras e suas instâncias administrativas;

- Empresa estatal: empresas em que o poder acionário é detido majoritariamente pelo poder público, como a Petrobras, a Caixa Econômica Federal, os Correios etc;

- Associações/ONGs: classe de organismos representativos, como sindicados, cooperativas, associações, dentre outras.

- Entidades privadas sem fins lucrativos: empresas compostas basicamente por serviços sociais e de apoio, como SEBRAE e SENAI;

- Pessoa física: grupo composto basicamente por parceiros não institucionais que, em geral, são contabilizados em grupos.

A partir desta classificação foi possível apresentar os resultados obtidos, conforme verificado no Gráfico 12. As empresas privadas mostraram-se como grandes parceiras da 
UFSCar, com um total de 168 projetos, o equivalente a $27,14 \%$ do total de projetos no período entre 2008 a 2012. Em segundo lugar, encontraram-se os projetos estabelecidos com universidades e institutos de pesquisas com 154 projetos (24,91\% do total), seguidos por pessoa física com 141 projetos $(22,78 \%$ do total), pela administração pública e agencias de financiamentos, com respectivamente 44 projetos, associações/ONGS, empresas estatais e entidades privadas com $42(6,79 \%), 21(3,39 \%)$ e $5(0,81 \%)$ projetos, respectivamente.

Gráfico 12 - Distribuição do número de projetos e volume de recursos por tipo de financiador

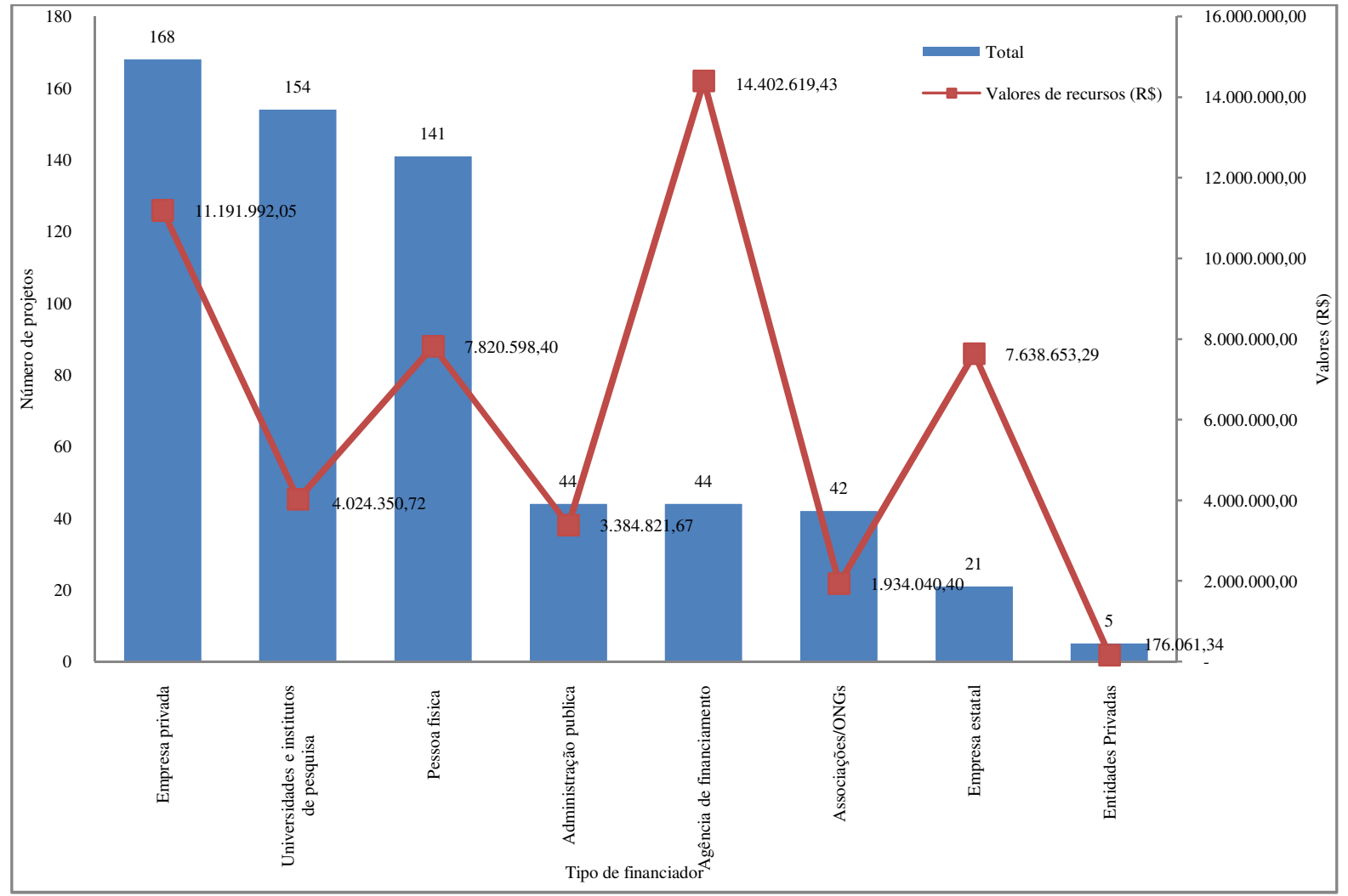

Fonte: Elaborado a partir dos dados fornecidos pela FAI, 2008 a 2012.

$\mathrm{Na}$ análise do volume de recursos foi possível observar algumas mudanças nas posições ocupadas pelos tipos de financiadores. As agências de financiamento encontraram-se em primeiro lugar no que concerne ao volume de recursos financeiros, com um montante de mais de 14 milhões de reais, o equivalente a 28,42\% do total. O segundo lugar foi ocupado pelas empresas privadas com um pouco mais de 11 milhões de reais, o que representa $22,12 \%$ do total do volume de recursos.

O terceiro e quarto lugares foram ocupados por pessoa física e empresas estatais, respectivamente, com volumes totais superiores a 7 milhões de reais, representando cerca de $15 \%$ do volume total. Ressalta-se a importância da participação de empresas privadas e 
agências de financiamento na composição do volume total de recursos, o equivalente a $55,59 \%$.

Como a caracterização dos parceiros externos da UFSCar é um dos mais importantes resultados a serem obtidos através deste trabalho, a seguir serão apresentados novos resultados gerados a partir do cruzamento de diversas variáveis em função do tipo de financiador, tais como: tipo de atividade, centro científico, departamento e localidade do financiador.

\subsubsection{Distribuição dos projetos por tipo de financiador e tipo de atividade}

Uma análise mais detalhada dos resultados apresentados acima relaciona a distribuição do número de projetos em função de duas variáveis: (i) o tipo de financiador e (ii) o tipo de atividade.

Em relação à distribuição do número de projetos por tipo de financiador e por tipo de atividade, como observado no Gráfico 13, ressalta-se, em primeiro lugar, que cada tipo de financiador relaciona-se com a universidade em estudo para desenvolver uma determinada atividade.

Nesse cenário, a classe formada por empresas privadas se relaciona com a universidade em estudo, com o objetivo principal de realizar atividades de Consultorias/Assessorias, com 79 projetos. Em segundo lugar, o tipo de atividade que apresentou maior número de projetos é a de Projetos de Pesquisa e Desenvolvimento, com 36 projetos estabelecidos com a UFSCar.

Uma interessante observação pode ser feita a partir desse último resultado, pois o financiador empresa privada, apresentou-se como o grande parceiro da UFSCar para o desenvolvimento de atividades relacionadas aos projetos de pesquisa e desenvolvimento, seguida da classe composta por universidades e institutos de pesquisas que se relacionam com a universidade para desenvolver atividades de projetos de pesquisa e desenvolvimento, com 10 projetos.

No que concerne ao financiador universidades e institutos de pesquisas, cabe evidenciar que a maioria dos projetos estabelecidos com a UFSCar, cerca de 75\%, referem-se a realização de dois tipos de atividades predominantes: cursos e prestação de serviço, com 75 e 37 projetos, respectivamente. 
Gráfico 13 - Distribuição do número de projetos por tipo de financiador e tipo de atividade

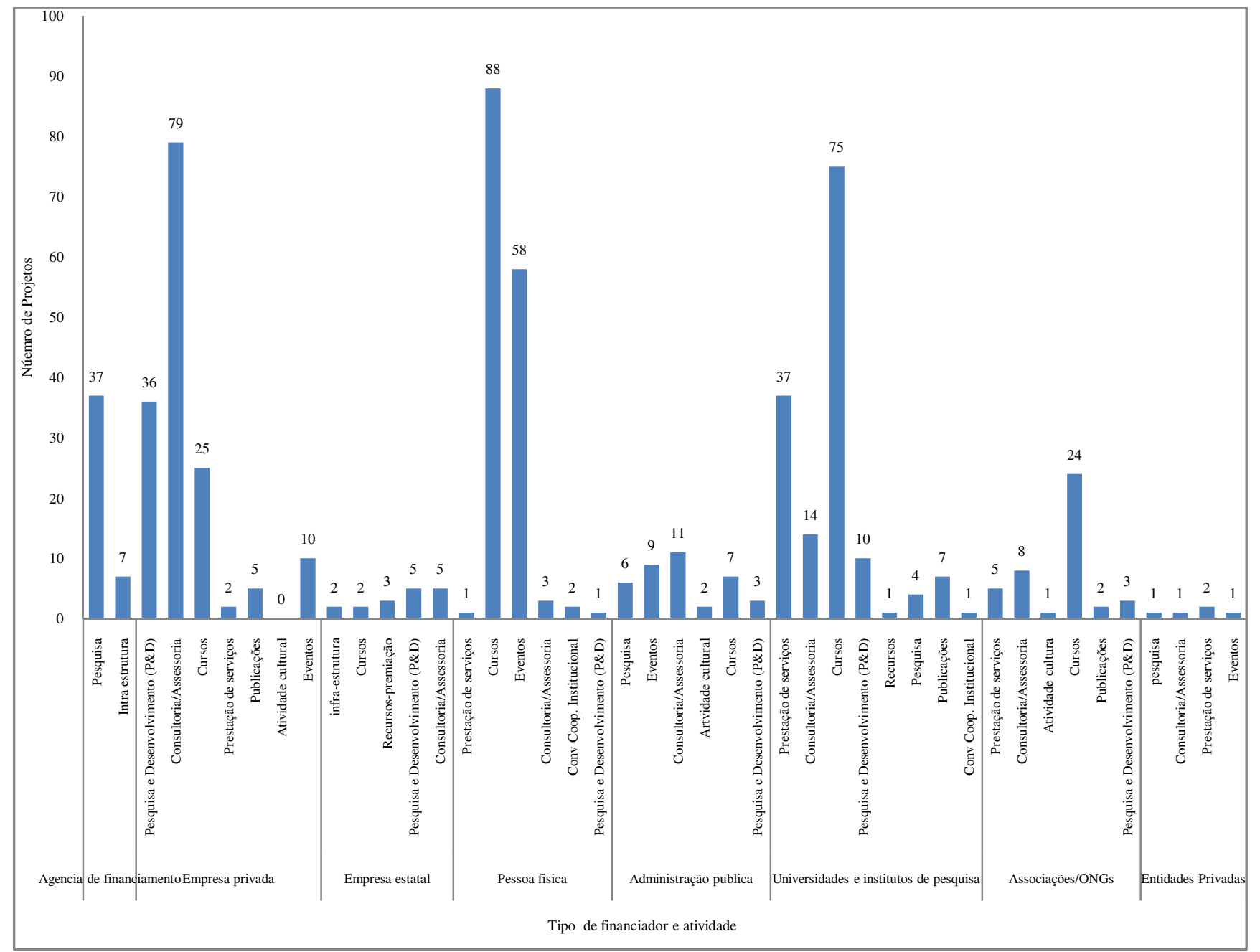

Fonte: Elaborado a partir dos dados fornecidos pela FAI, 2008 a 2012.

$\mathrm{Na}$ análise do volume de recursos, conforme Gráfico 14, foi possível observar que, em relação ao ator externo, denominado de agências de financiamentos, a atividade que mais movimenta recursos financeiros foram as atividades relacionadas à pesquisa, com aproximadamente $98 \%$ do total dos recursos deste financiador.

Em relação ao tipo de financiador empresas privadas, a maior quantidade de recursos financeiros foi proveniente das atividades de consultoria e assessoria, com um pouco mais de 4.3 milhões de reais, seguida pelas atividades relacionadas aos Projetos de Pesquisa e Desenvolvimento, com cerca de 3.2 milhões de reais.

Por sua vez, a classe formada por empresas estatais, a atividade que movimenta recursos foram as atividades relacionadas aos Projetos de pesquisa, com aproximadamente 5 milhões de reais, o que representou $71 \%$ do total de volume de recursos deste financiador, aproximadamente, 7.1 milhões de reais. 
Gráfico 14 - Distribuição do volume de recursos financeiros por tipo de financiador e tipo de atividade

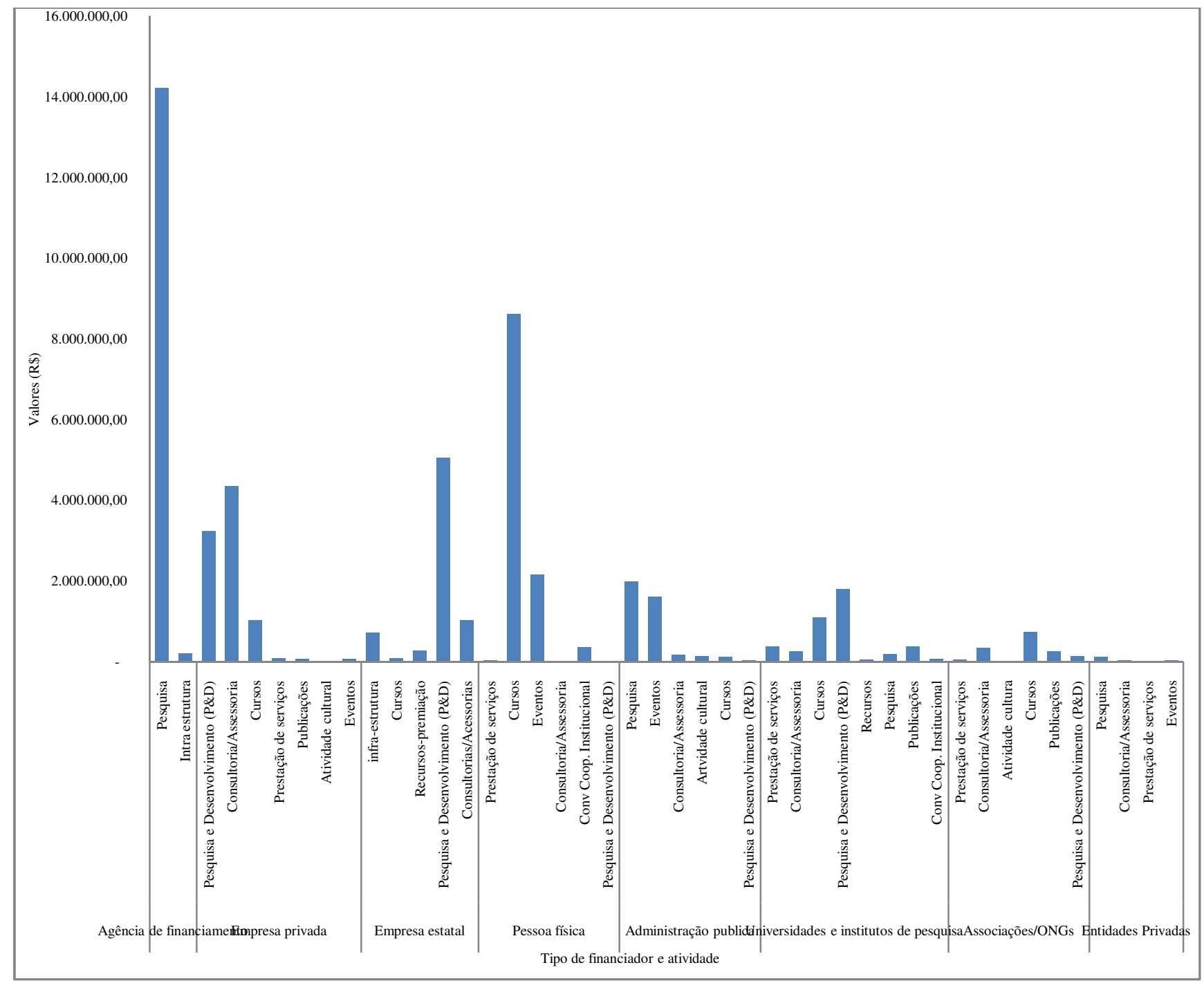

Fonte: Elaborado a partir dos dados fornecidos pela FAI, 2008 a 2012.

\subsubsection{Distribuição dos projetos por tipo de financiador e centro científico}

Uma nova análise, a ser apresentada, relaciona a distribuição do número de projetos em função do centro científico. O Gráfico 15 traz essa distribuição para o número total de projetos, 619 projetos.

Nota-se a permanência do CCET, 315 projetos, em relação à distribuição do número de projetos em todos os diferentes tipos de financiadores: empresas privadas, universidades e institutos de pesquisa, agência de financiamento, administração pública e associações/ONGs. 
Gráfico 15 - Distribuição do número de projetos por tipo de financiador e centro científico

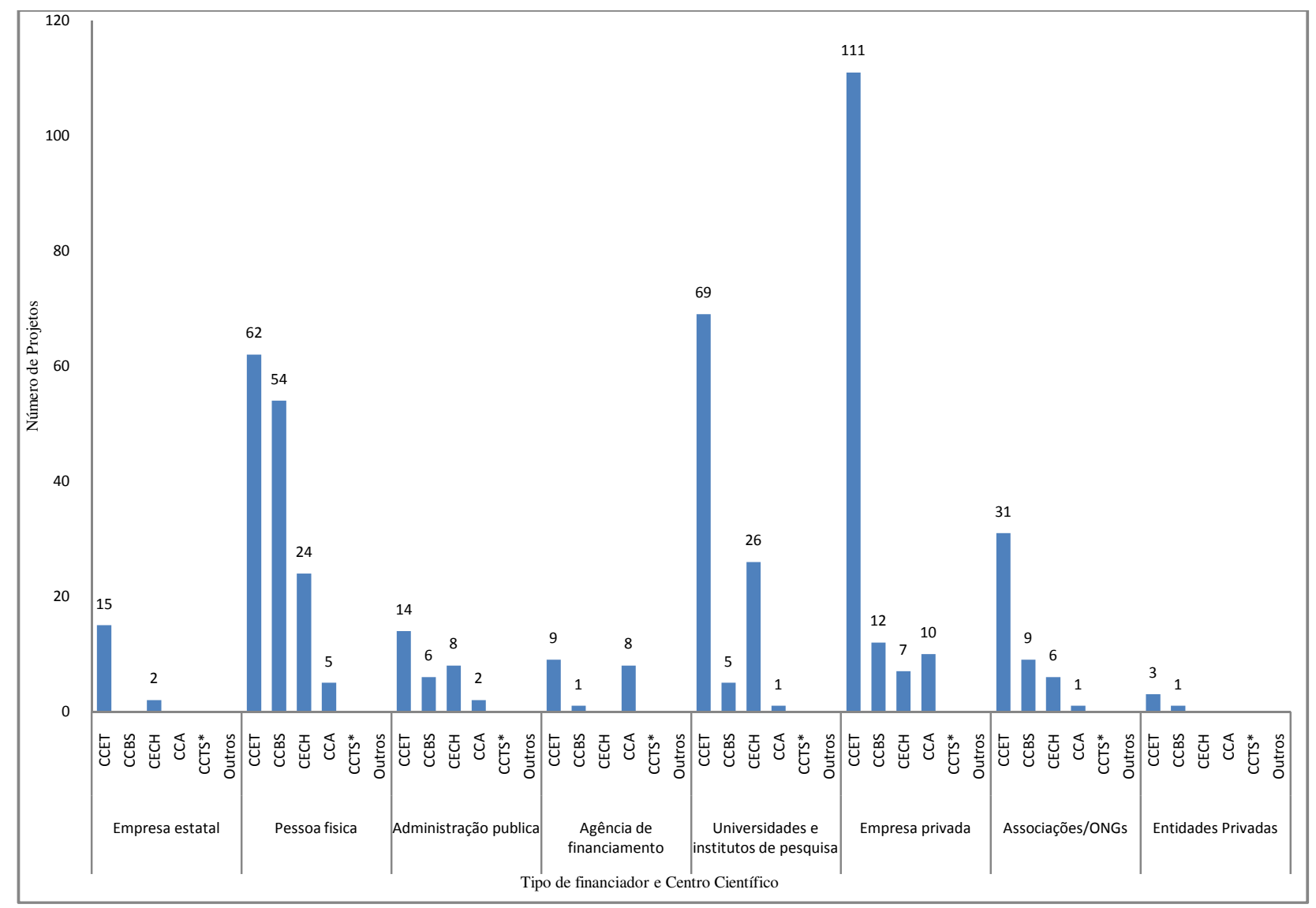

Fonte: Elaborado a partir dos dados fornecidos pela FAI, 2008 a 2012.

Ainda é possível apresentar mais alguns detalhes referentes a esse tipo de Centro Científico, conforme apresentado no Gráfico 16. A maioria dos projetos estabelecidos, equivalente a 57,37\%, referem-se à realização de parcerias com dois tipos predominantes de financiadores, a saber, as empresas privadas, com 111 projetos e universidades e institutos de pesquisa, com 69 projetos, que representam,respectivamente, $35,69 \%$ e $22,19 \%$ do total de projetos estabelecidos com o Centro de Ciências Exatas e Tecnológicas. Em seguida, destacaram-se as atividades em parcerias com pessoa física e associações/ONGs, com 69 e 62 projetos, respectivamente. 
Gráfico 16 - Distribuição do número de projetos por tipo de financiador e pelo Centro Científico de Ciência Exatas e Tecnológicas (CCET)

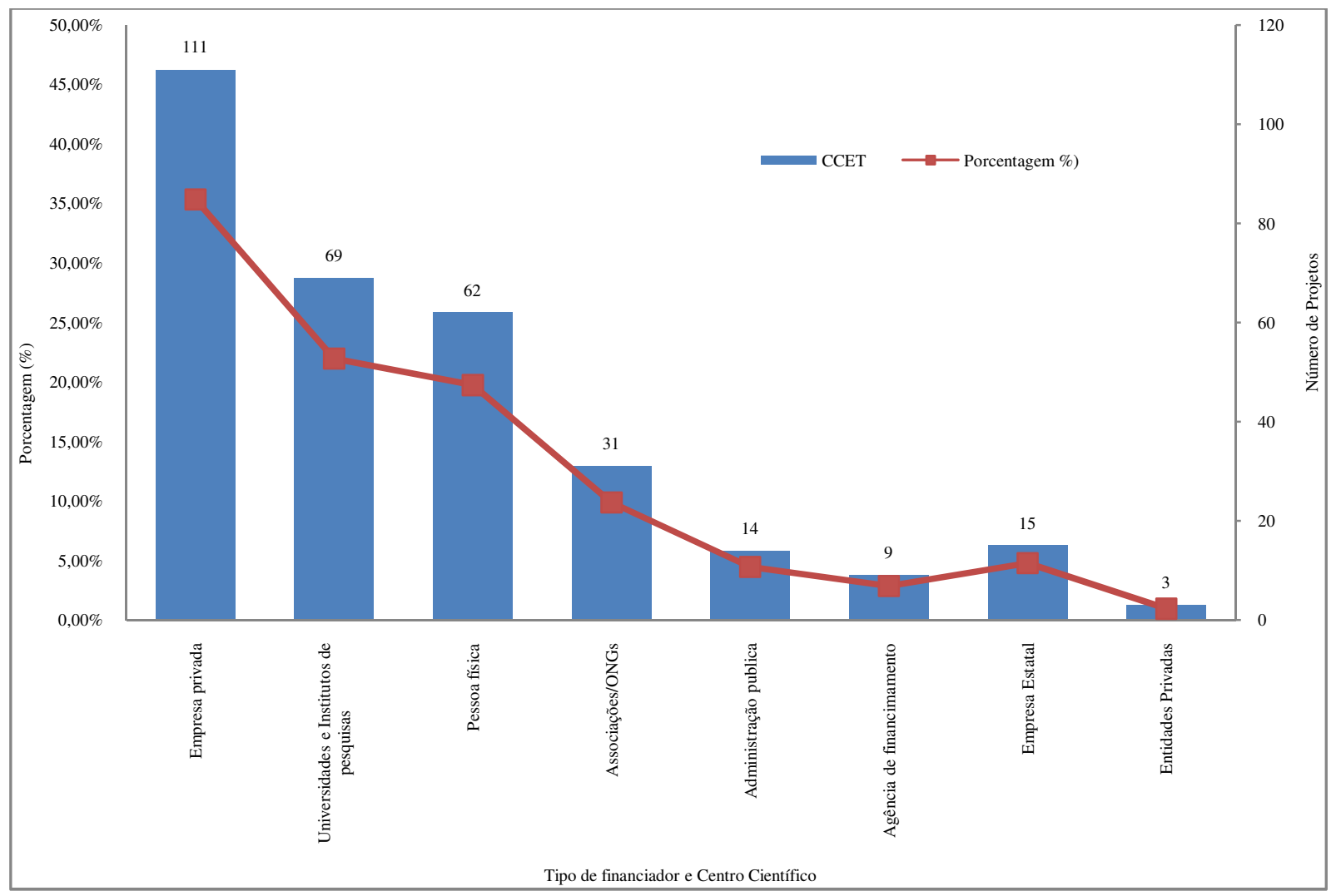

Fonte: Elaborado a partir dos dados fornecidos pela FAI, 2008 a 2012.

Entre os demais Centros Científicos, cabe evidenciar o Centro de Ciências Biológicas e da Saúde (CCBS) e o de Centro de Educação e Ciências Humanas (CECH), conforme indicado no Gráfico 17. O CCBS executou projetos principalmente com os seguintes tipos de financiadores: pessoa física com 54 projetos, seguida por empresas privadas, com apenas 12 projetos e associações/ONGs, com 9 projetos.

Por sua vez, o CECH desenvolveu parcerias para a execução de seus projetos principalmente com as universidades e institutos de pesquisa, com 25 projetos do total deste centro científico, em seguida, encontram-se as parcerias executadas com os tipos de financiadores: pessoas físicas e administração pública. 
Gráfico 17 - Distribuição do número de projetos por tipo de financiador e pelo Centro Científico de Ciências Biológicas e da Saúde (CCBS) e Centro de Educação e Ciências Humanas(CECH)

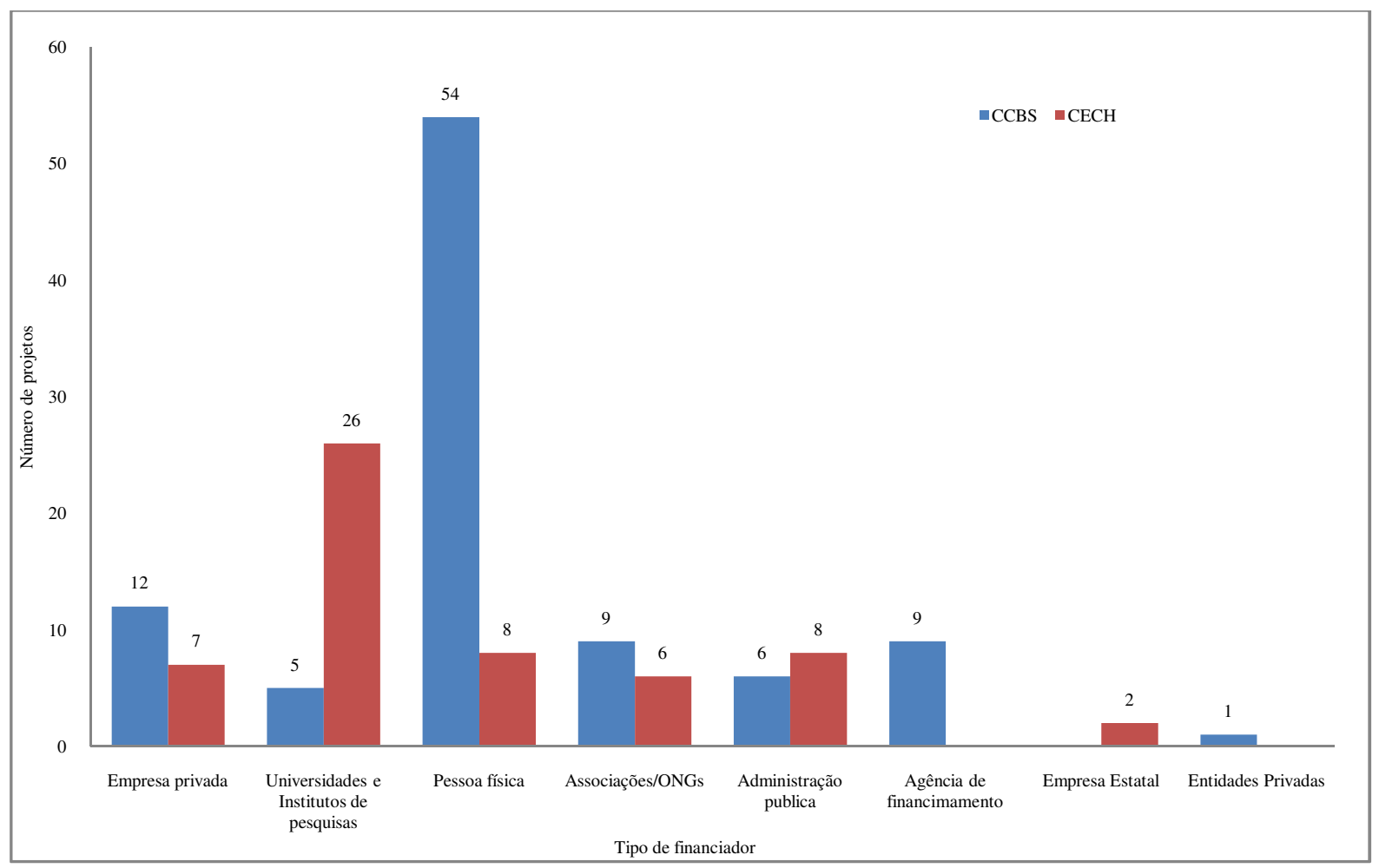

Fonte: Elaborado a partir dos dados fornecidos pela FAI, 2008 a 2012.

$\mathrm{Na}$ análise de recursos foi possível verificar algumas mudanças na distribuição dos projetos por financiadores e Centros Científicos. No que concerne à distribuição do número de projetos destacou-se a permanência do CCET, nos seguintes tipos de financiadores: empresas estatais com um montante de cerca de 5 milhões de reais, empresas privadas com mais de 4.4 milhões de reais e universidades e institutos de pesquisa, cerca de 4 milhões de reais. Além disso, para o caso de agências de financiamentos, o volume de recursos apresentou um maior destaque no CCA, conforme o Gráfico18. 
Gráfico 18 - Distribuição do volume de recursos por tipo de financiador e Centro Científico

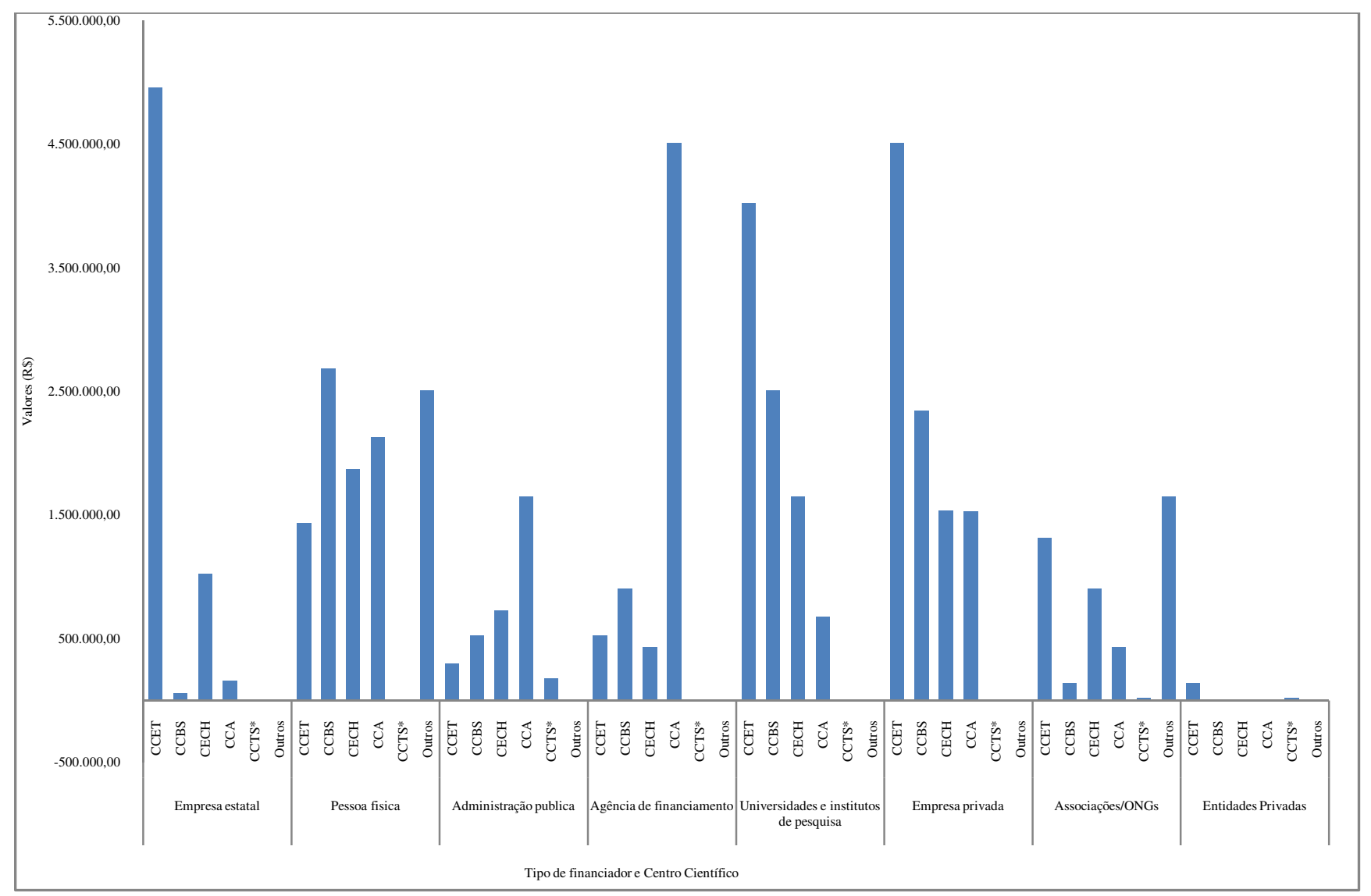

Fonte: Elaborado a partir dos dados fornecidos pela FAI, 2008 a 2012.

\subsubsection{Distribuição dos projetos por tipo de financiador e departamento}

Em complemento aos resultados da seção anterior, o Gráfico 19 apresenta um detalhamento da relação entre as áreas de conhecimento da UFSCar com o meio externo, através dos seus diversos departamentos.

Como o número de departamentos é relativamente grande, optou-se por apresentar os noves que mais se sobressaíram em termos de números de projetos e volume de recursos: Engenharia Civil (DECIv), Departamento de Engenharia de Materiais (DEMa), Departamento de Engenharia de Produção (DEP), Departamento de Computação (DC), Departamento de Engenharia Química (DEQ), Departamento de Química (DQ) e o Departamento de Fisioterapia (DFisio). Ressalta-se que, do total de departamento analisados, seis são pertencentes ao centro de Ciências Exatas e da Terra (CCET) e um ao centro de Centro de Ciências Biológicas e da Saúde (CCBS). 
Gráfico 19 - Distribuição do volume de recursos por tipo de financiador e departamento científico

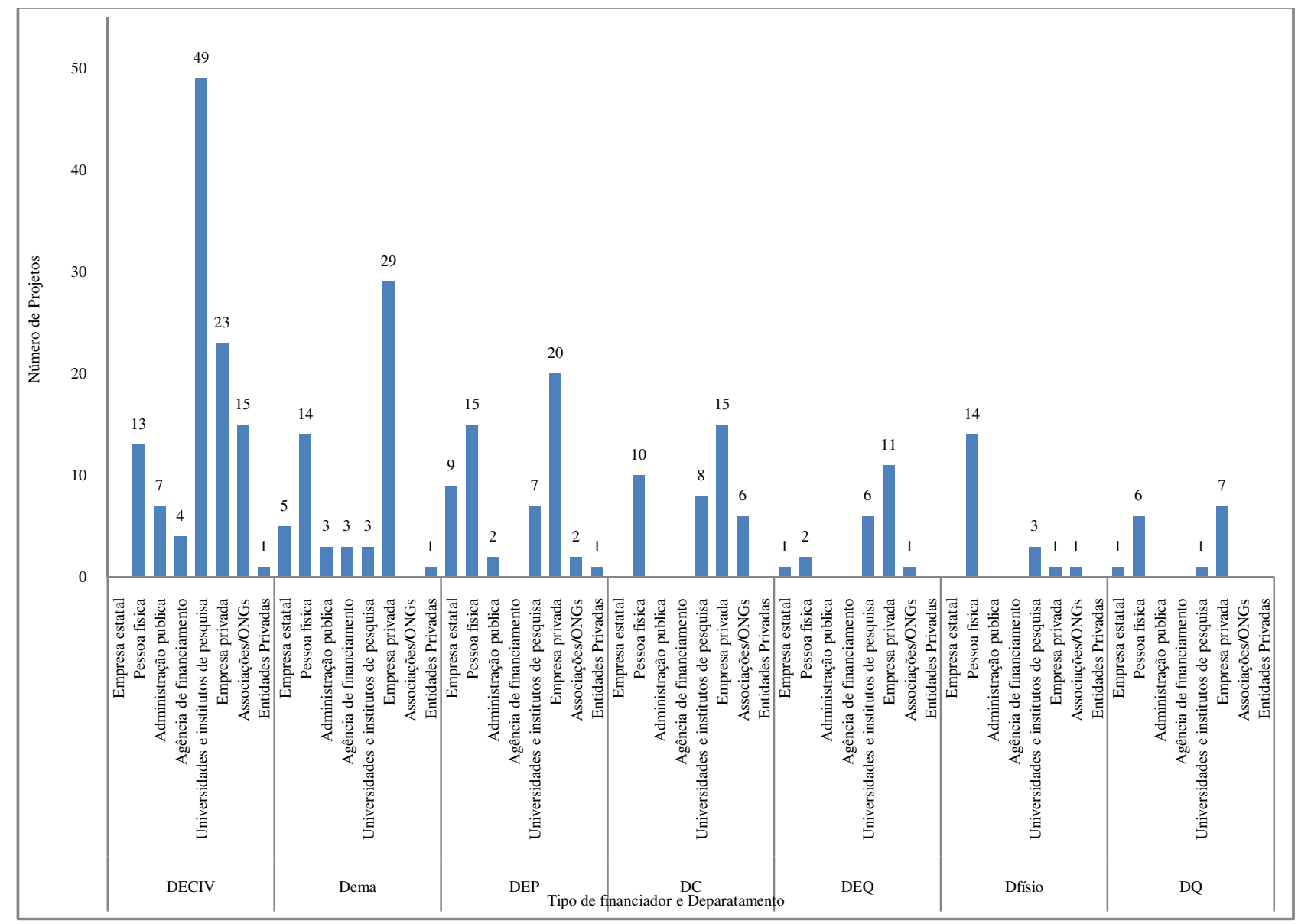

Fonte: Elaborado a partir dos dados fornecidos pela FAI, 2008 a 2012.

Como pôde ser observado no Gráfico 19, o Departamento de Engenharia Civil (DCIV), que se encontra em primeiro lugar em relação a número de projetos (87 projetos estabelecidos entre 2008-2012), teve como principal parceiro as Universidades e Institutos de Pesquisa, com 49 projetos, o equivalente a 56,32\% do total de projetos estabelecido por esse departamento. Seguido pelo tipo de financiador empresas privadas que, estabeleceram um total de 23 projetos em cooperação com o DCIV, o que representou cerca de $26.5 \%$ do montante de projetos.

Os departamentos de Engenharia de Materiais, Engenharia de Produção e Engenharia de Computação e Engenharia Química tiveram como principal parceiro a classe composta por empresas privadas, com 29, 20, 15 e 7 projetos, respectivamente.

Outra característica que deve ser observada foi o resultado obtido para a Universidade e os institutos de pesquisas nos setes departamentos em estudo, pois, as classes universidades e institutos de pesquisa mostraram-se como os grandes parceiros no Departamento de Engenharia Civil. Os demais departamentos, como o Departamento de Engenharia de 
Materiais, o Departamento de Engenharia de Produção, o Departamento de Computação e o Departamento de Química tiveram como principal parceiro as empresas privadas.

Uma interessante observação pode ser feita a partir desse ultimo resultado, pois a visão disseminada no tema da cooperação universidade-empresa é de que a área de ciências exatas e tecnológicas tem se destacado diante das demais. O interessante neste ponto é notar que, para o caso da UFSCar, mesmo quando o financiador deixa de ser o setor produtivo (empresas privadas) e passa a ser as instituições, como universidades e institutos de pesquisa, mantevese a predominância dos projetos na área de ciências exatas e tecnológicas.

No que concerne aos recursos provenientes dos projetos de cooperação conforme os financiadores e departamentos notou-se diferenças nas posições relacionadas ao número de projetos estabelecidos e ao volume de recursos, conforme observado no Gráfico 20.

Gráfico 20 - Distribuição do volume de recursos por tipo de financiador e Departamento Científico

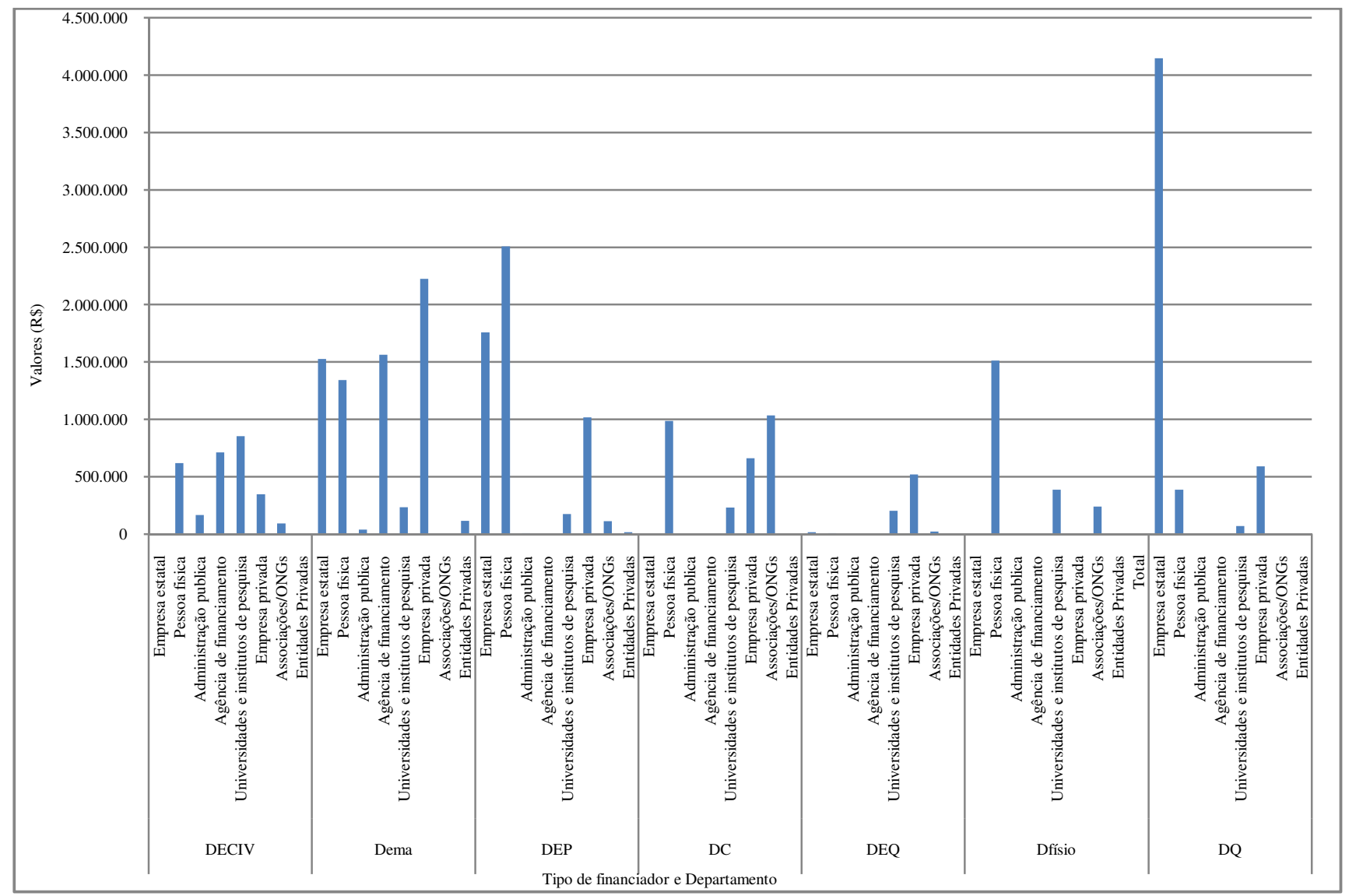

Fonte: Elaborado a partir dos dados fornecidos pela FAI, 2008 a 2012.

O Departamento de Engenharia Civil teve como principal financiador tanto em quantidade de projetos quanto em volume de recursos às universidades e os institutos de 
pesquisa, com um pouco mais de 850 mil reais, o equivalente, aproximadamente a $30 \%$ do total de recursos deste departamento, 3.3 milhões de reais.

No entanto, vale ressaltar as mudanças nas posições das classes formadas por empresas privadas e associações/ONGs que se encontraram em segundo e terceiro lugar, respectivamente, em número de projetos. Ao tratar de recursos financeiros, essas acabam posicionando-se em quarto e sexto lugar, com 348 mil reais e 93 mil reais, respectivamente, isto é, apesar desses financiadores apresentarem uma quantidade relativa de projetos em parceria com o DECiv, tais projetos geram poucos recursos financeiros para o departamento. A classe formada por empresas estatais e entidades privadas não executaram nenhum projeto que movimentasse recursos.

Os principais parceiros que movimentam recursos financeiros com os projetos no DEMa são as empresas privadas, com cerca de 2.2 milhões de reais, agências de financiamentos e empresas estatais com aproximadamente 1.5 milhões de reais cada, o equivalente a 75,3\% do total de recursos desse departamento, cerca de 7 milhões de reais.

Por sua vez, o Departamento de Engenharia de Produção que, apesar de ter como principal parceiro para a realização de projetos as empresas privadas, quando analisado o volume de recursos, encontrou-se em terceiro lugar com cerca de 1 milhão de reais. Em primeiro lugar encontrou-se a classe formada por pessoas físicas, com pouco mais de 2.5 milhões de reais, seguida pelas empresas estatais, com aproximadamente, 1.8 milhões de reais.

Nesse contexto merece destaque, o Departamento de Química (DQ) que, apesar de ter um único projeto em parceria com a classe formada por empresas estatais, foi responsável por 80\% do montante de recursos do DQ.Por fim, considera-se importante ressaltar que poucos departamentos concentram os recursos financeiros provenientes do financiador formado por universidades e institutos de pesquisa, com destaque principalmente para o DCiv.

\subsubsection{Distribuição dos Projetos por Localidade do Financiador}

Outra característica que foi observada em relação ao tipo de financiador foi a distribuição dos projetos e o resultado por localidade do financiador. Neste caso, os resultados estão baseados nas regiões e estados brasileiros, com um breve detalhamento para o estado de São Paulo e para o município de São Carlos.

O primeiro resultado refere-se às distribuições percentuais do número de projetos em função das regiões do Brasil (Gráfico 21). No Gráfico foi possível observar que a grande 
maioria dos projetos, aproximadamente $90 \%$ do total, refere-se aos parceiros (financiadores) localizados na região Sudeste do Brasil, com um total de 560 projetos (Gráfico 22). Em seguida apareceram as regiões Centro-Oeste (28 projetos), Sul (20 projetos), Nordeste ( 9 projetos) e Norte (2 projetos) com, respectivamente, $4,5 \% ; 3,23 \% ; 1,45 \% ; 0,32 \%$ do total de projetos estabelecidos com a UFSCar.

Gráfico 21 - Distribuição percentual do número de projetos em função da localidade (região) do financiador

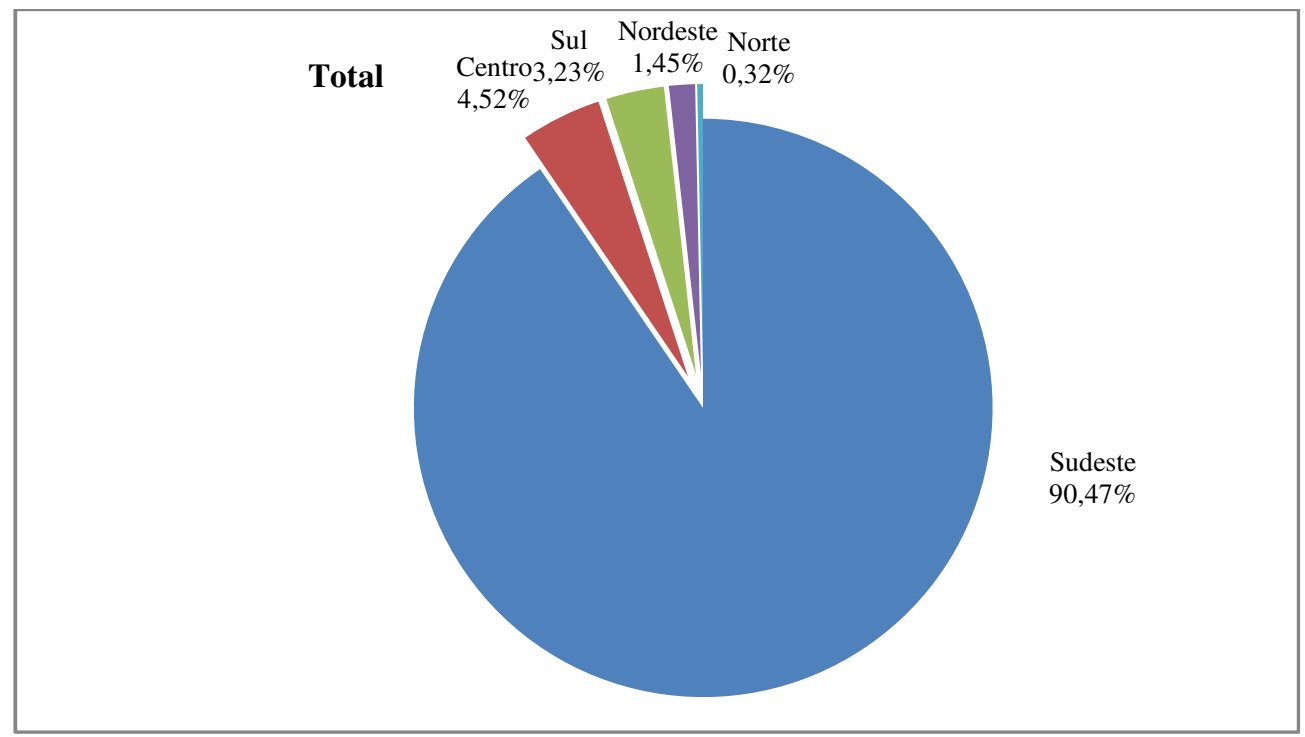

Fonte: Elaborado a partir dos dados fornecidos pela FAI, 2008 a 2012.

Gráfico 22 - Distribuição do número de projetos em função da localidade (região) do financiador

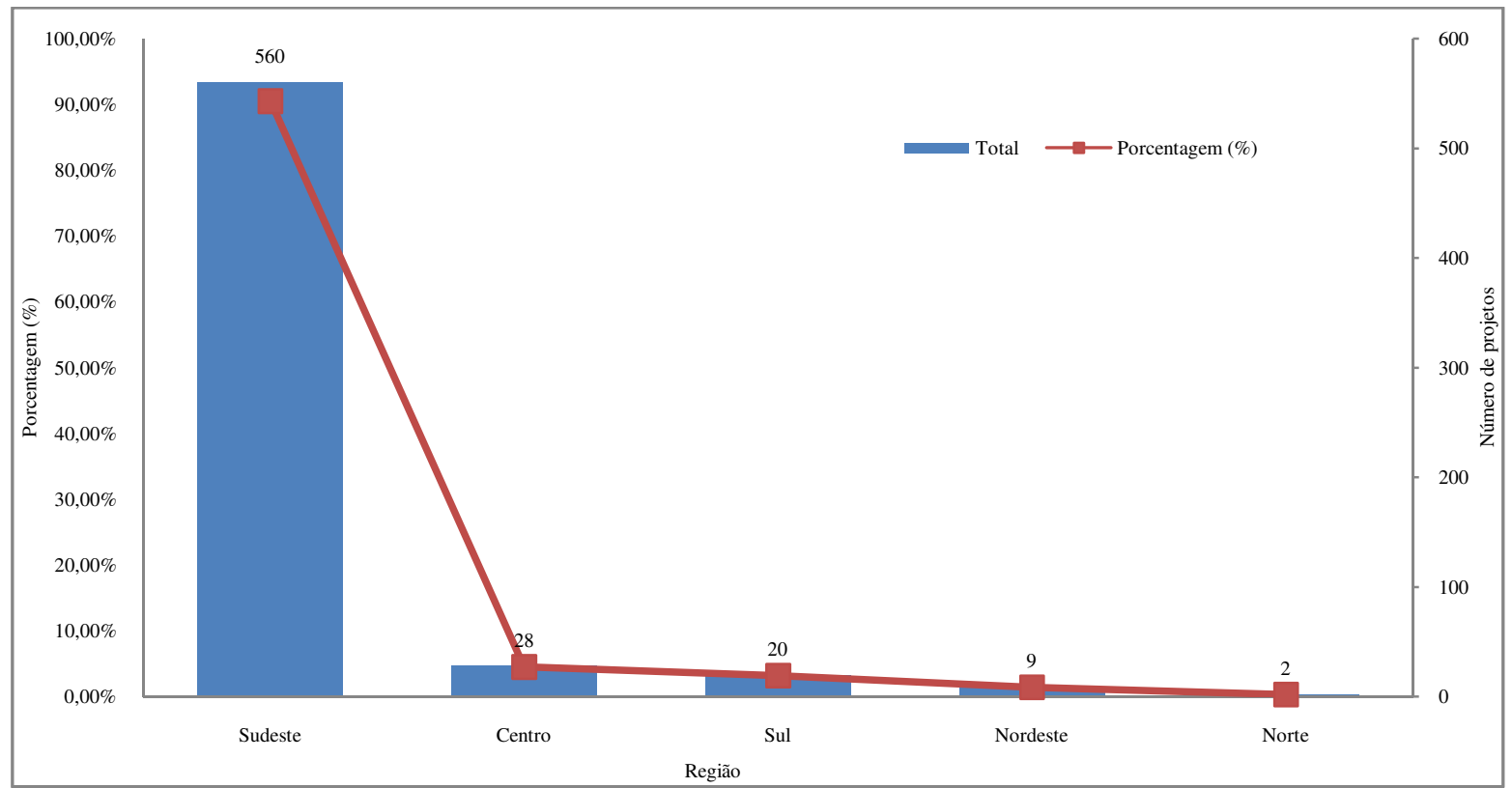

Fonte: Elaborado a partir dos dados fornecidos pela FAI, 2008 a 2012. 
O Gráfico 23 apresenta o mesmo resultado, mas com desdobramento para os estados, apresentando simultaneamente o número de projetos. Neste ponto, cabe o comentário referente ao expressivo número de projetos realizados com parceiros localizados no estado de São Paulo, com 432 projetos do total, o que representa 70\% do total. Em seguida encontramse os estados do Rio de Janeiro com 10 projetos, Minas Gerais com 7 projetos e o Mato Grosso do Sul com 4 projetos.Quando a análise foi transferida para volume de recursos, o estado de São Paulo aparece com o maior valor absoluto, estando diretamente associado ao elevado número de projetos estabelecidos com os parceiros deste estado.

Gráfico 23 - Distribuição do número de projetos e volume de recursos por localidade (estado)

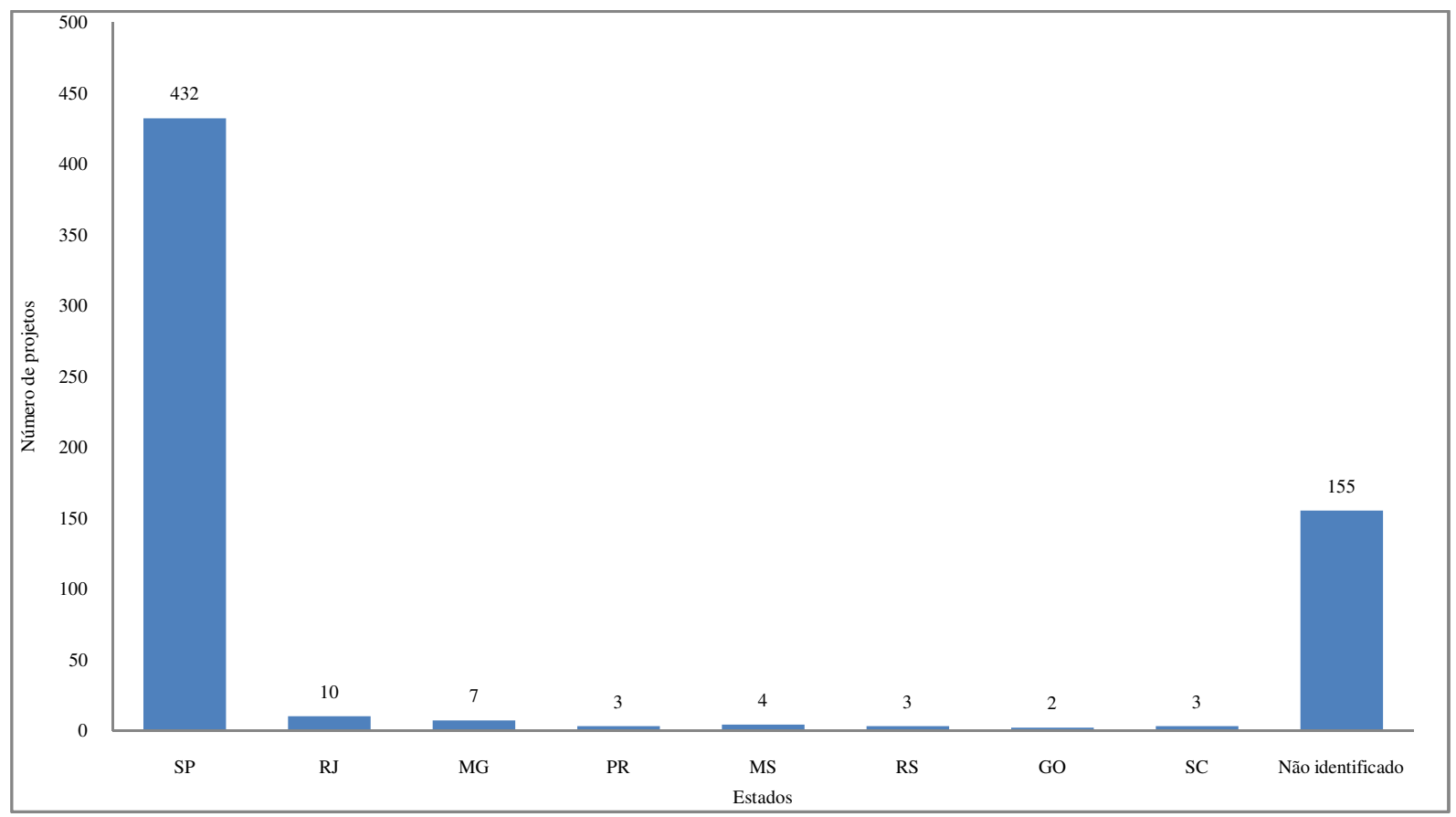

Fonte: Elaborado a partir dos dados fornecidos pela FAI, 2008 a 2012.

Neste contexto, é importante ressaltar que, entre os municípios do estado de São Paulo, encontrou-se o município de São Carlos apresentando 193 projetos estabelecidos com empresas, o equivalente a $31,17 \%$ do total de projetos estabelecidos entre a UFSCar e empresas.

Além disto, quando foi realizado uma análise regional encontrou-se cerca de 17 outras cidades que possuem parcerias com a UFSCar, dentre elas, as mais significativas são Limeira, Araraquara, Ribeirão Preto e Piracicaba, com equivalente a 16, 14, 11 e 10 projetos estabelecidos, respectivamente.

A partir desta perspectiva, a seguir são apresentados alguns detalhes dos projetos estabelecidos entre a universidade em estudo e os parceiros locais. 


\subsubsection{Distribuição dos Projetos estabelecidos por parceiros locais: São Carlos}

Com base na proposição de que São Carlos é um polo tecnológico, com alta concentração de universidades, centro de pesquisa, recursos humanos qualificados, empresas de base tecnológica e uma rede de apoio logístico e empresarial cercando o município, há cerca de um doutor para cada 160 habitantes, enquanto no Brasil a relação é de um doutor para cada 5.423 habitantes, de acordo com dados da Prefeitura Municipal de São Carlos (2013). Com três universidades (USP, UFSCar e UNICEP), dois centros de pesquisa da Embrapa (Instrumentação e Agropecuária Sudeste) e 4 escolas técnicas, a cidade possui mais de 200 empresas de base tecnológica e quatro multinacionais (Faber-Castell, Tecumseh, Volkswagen e Eletrolux).

Desta forma, considerou-se adequado realizar um breve detalhamento a respeito dos projetos desenvolvidos entre a UFSCar e os parceiros locais (São Carlos). A configuração dos projetos entre a UFSCar e parceiros locais foi composta por um conjunto de 193 projetos correspondendo a $\mathrm{R} \$ 18.100 .234,78$ milhões de reais. A distribuição do número de projetos por período de tempo é apresentada no Gráfico 24, no qual o número de projetos cresceu em função do tempo, acompanhando um perfil semelhante ao apresentado no início deste capítulo.

Gráfico 24 - Distribuição do número de projetos com parceiros locais por período de tempo

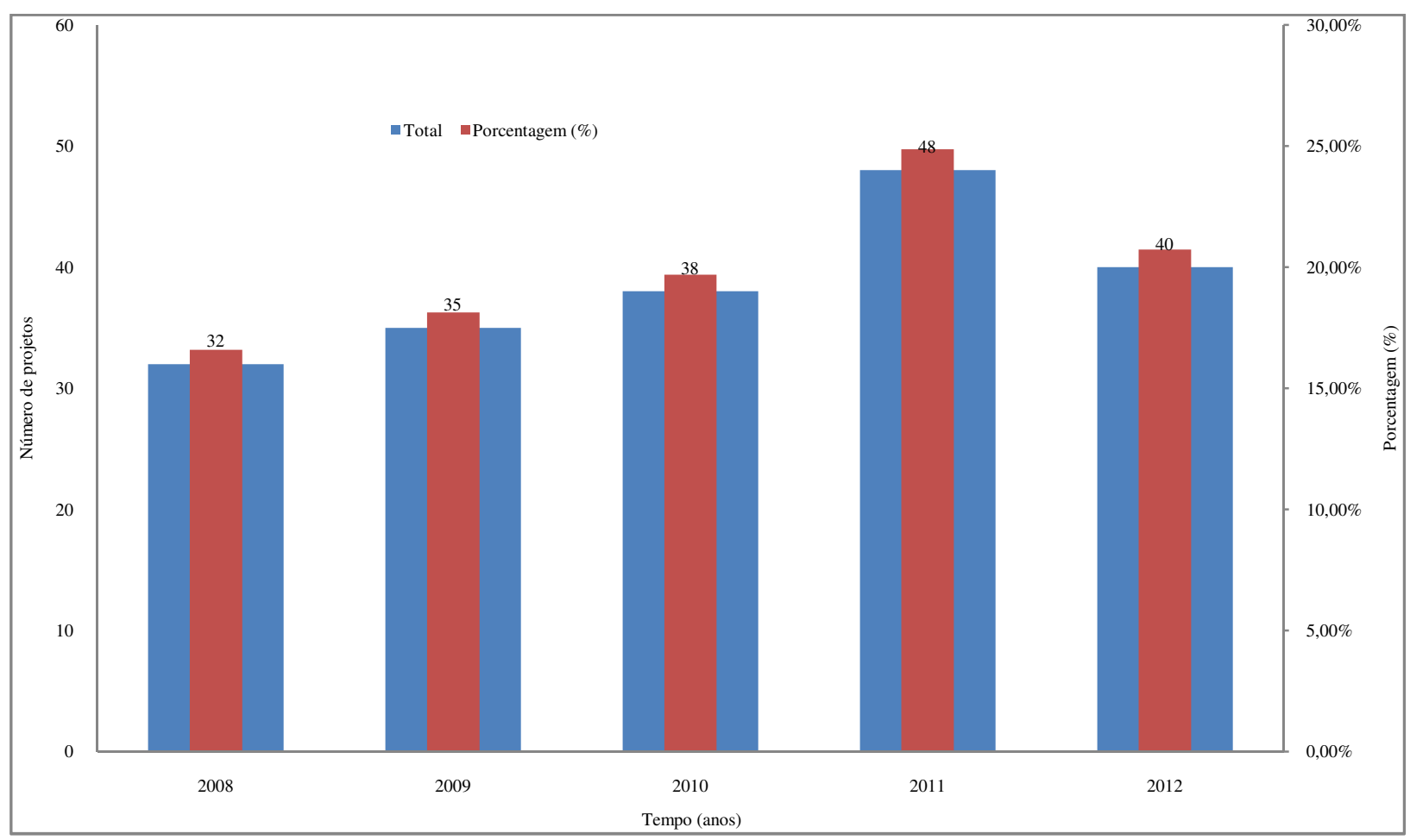

Fonte: Elaborado a partir dos dados fornecidos pela FAI, 2008 a 2012. 
Outro resultado desse grupo de projetos referiu-se à distribuição do volume de recursos em função do período de tempo (anos). Na comparação do Gráfico 24 com o Gráfico 25, percebe-se que a distribuição do volume de recursos possui um comportamento semelhante ao número de projetos (Gráfico 24).

Gráfico 25 - Distribuição do volume dos recursos para os projetos com parceiros locais

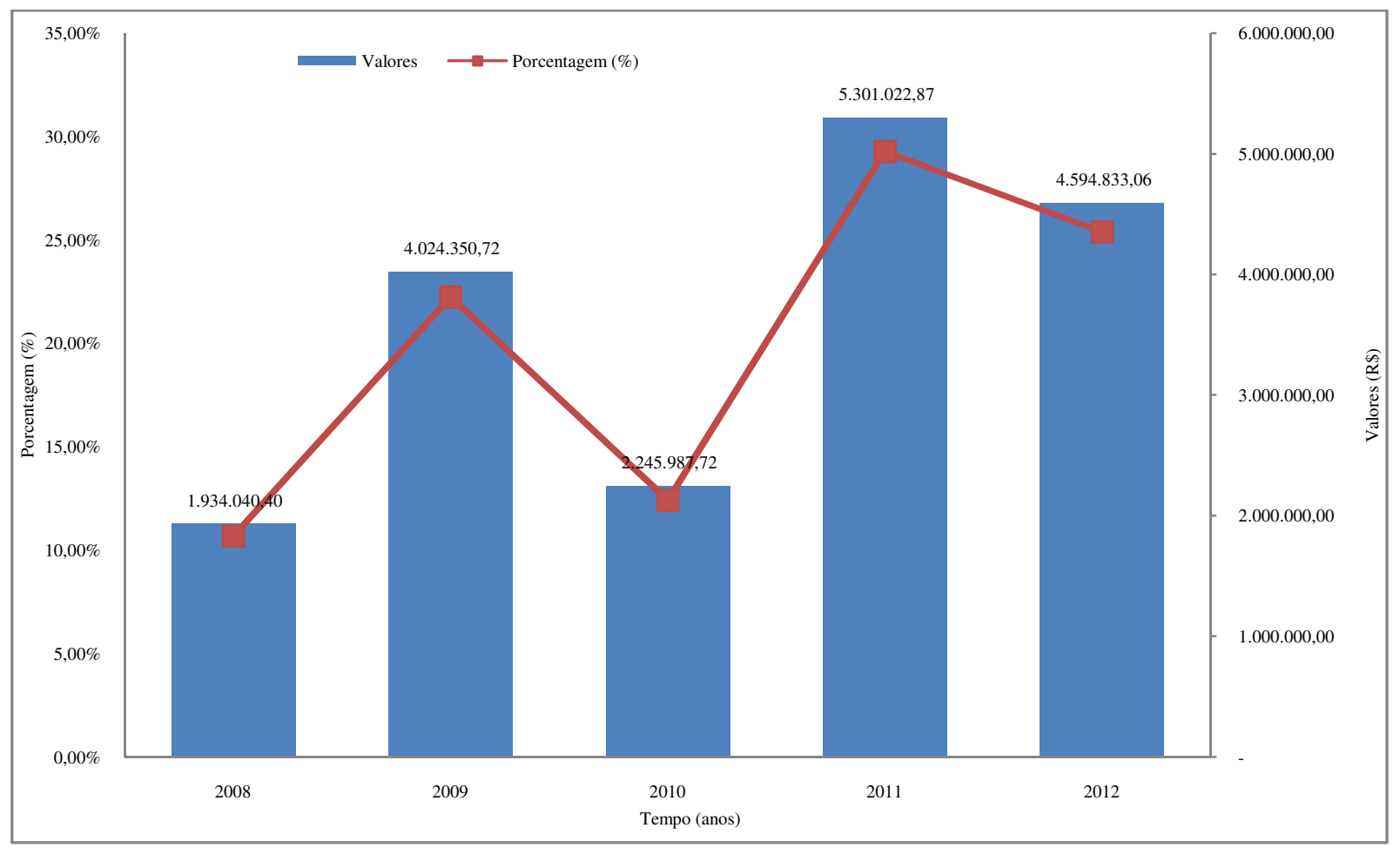

Fonte: Elaborado a partir dos dados fornecidos pela FAI, 2008 a 2012.

Ainda no que diz respeito aos projetos estabelecidos com parceiros locais, a saber, São Carlos, destacou-se a alta concentração do CCET que, sozinho, concentra 119 dos 193 projetos desse conjunto, o equivalente a 61,58\%, seguido pelo CCBS e CECH com, respectivamente, 45 e 23 projetos (Gráfico 25). $\mathrm{O} \mathrm{CCA}^{3}$ não apresentou nenhum parceiro local (São Carlos), no entanto, apresentou oito projetos com parceiros localizados em Araras/SP.

Consequentemente, os departamentos que mais se destacaram referem-se àqueles pertencentes ao CCET, tais como: Engenharia de Produção, com 11 projetos, Engenharia de Materiais com 15, projetos e o DEMa com 7 projetos. Dos outros dois Centros Científicos (CCBS e CECH) destacaram-se, respectivamente, o Departamento de Fisioterapia com 15 projetos e o de Artes com 9 projetos.

${ }^{3}$ O Campus II da UFSCar localiza-se no município de Araras/São Paulo, onde estão instalados os departamentos vinculados ao CCA. 
$\mathrm{Na}$ análise do volume de recursos por centro científico houve um aumento da concentração em relação ao número de projetos para o CCET e CCBS que juntos contabilizam mais de $95 \%$ do total de recursos, como observado no Gráfico 26.

Gráfico 26 - Distribuição percentual do número de projetos estabelecidos com parceiros locais por Centro Científico.

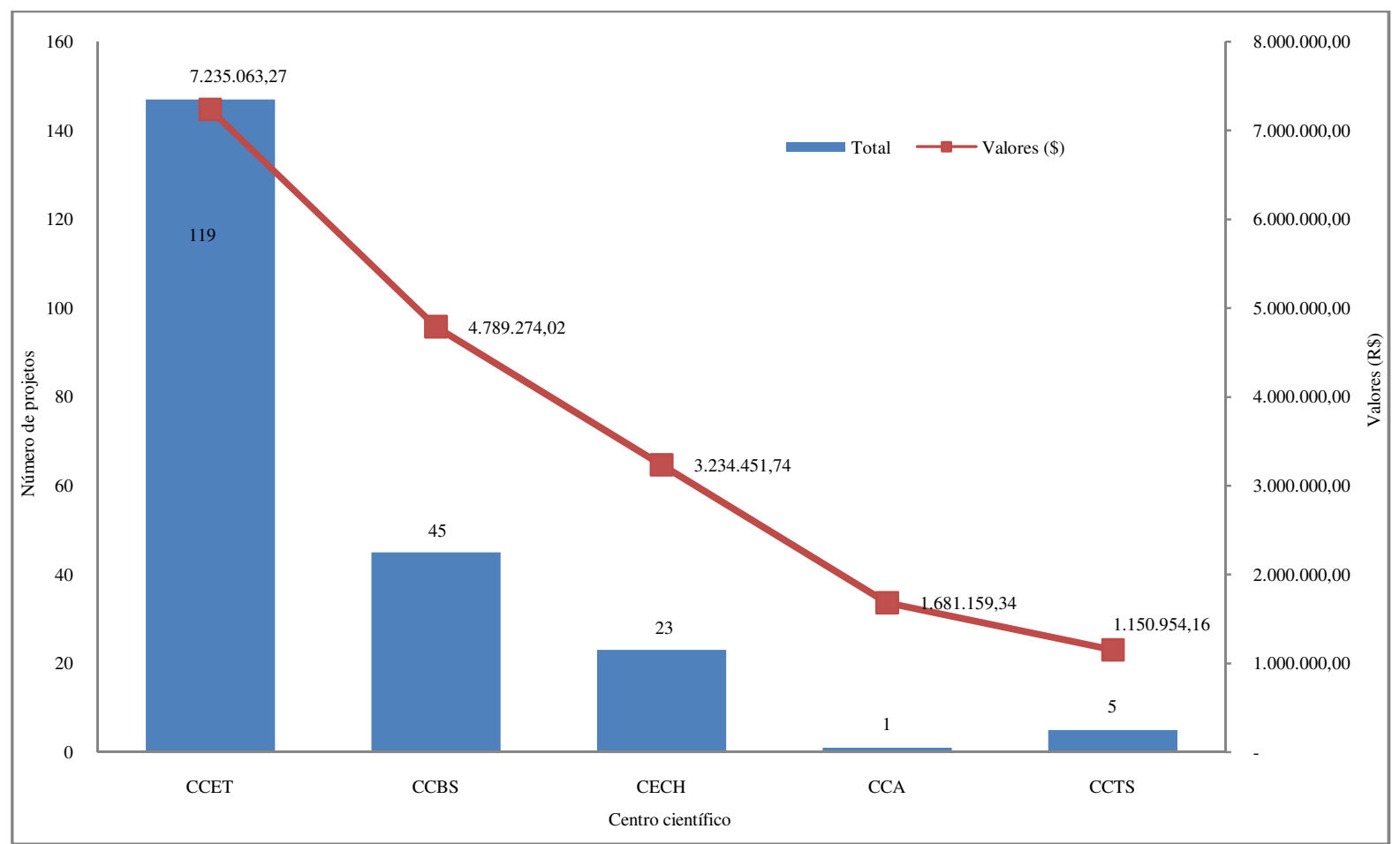

Fonte: Elaborado a partir dos dados fornecidos pela FAI, 2008 a 2012.

\subsubsection{Distribuição do número de projetos por localidade e Empresa privada}

Um último resultado a ser apresentado em função do tipo de financiador consiste na distribuição dos projetos por localidade em função do tipo de atividade desenvolvida entre a UFSCar e os parceiros locais. Neste caso, os resultados foram baseados nas regiões e estados brasileiros e classificados pelo tipo de financiador que obteve maior participação junto à universidade em estudo, neste caso, as empresas privadas (168 projetos).

O Gráfico 27 mostra a distribuição do número de projetos coordenados pela FAI em função das regiões do Brasil. Foi possível verificar que a grande maioria dos projetos realizados com empresas privadas, referiu-se aos parceiros (financiadores) localizados na região sudeste do Brasil, com 94 do total de projetos, o que representou um pouco mais de 61\%. Em seguida, aparecem as regiões Centro-Oeste (4 projetos), Sul (4 projetos) e Nordeste 
(2 projetos). Sendo assim, foi possível verificar que cerca de $18.4 \%$ do total de projetos da região Sudeste (560 total) referem-se aos parceiros denominados de empresas privadas.

Gráfico 27 - Distribuição do número de projetos gerenciados pelas empresas privadas e estatais por localidade (estados)

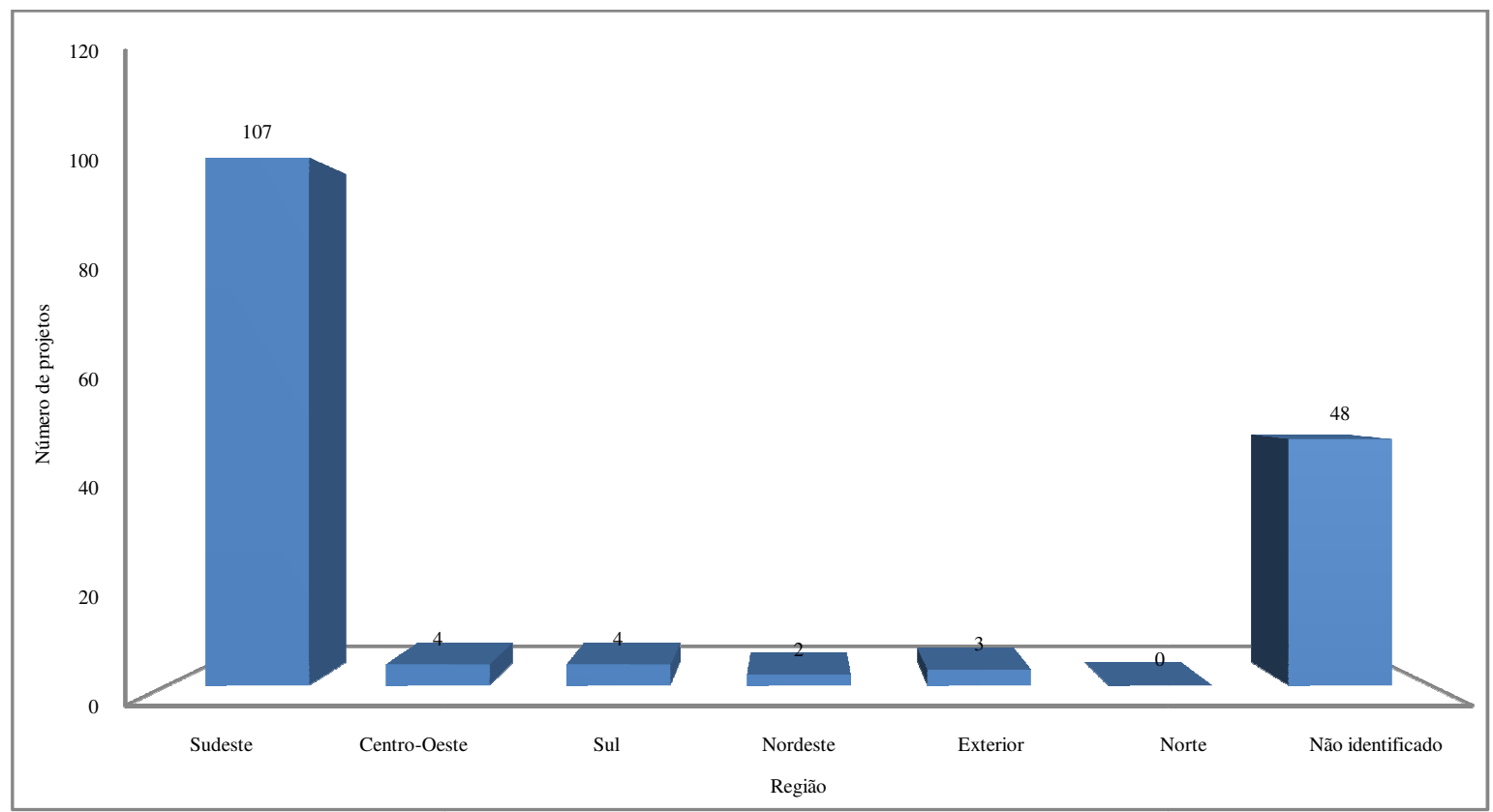

Fonte: Elaborado a partir dos dados fornecidos pela FAI, 2008 a 2012.

Gráfico 28 - Distribuição dos recursos financeiros pelas empresas privadas e estatais por localidade (estados)

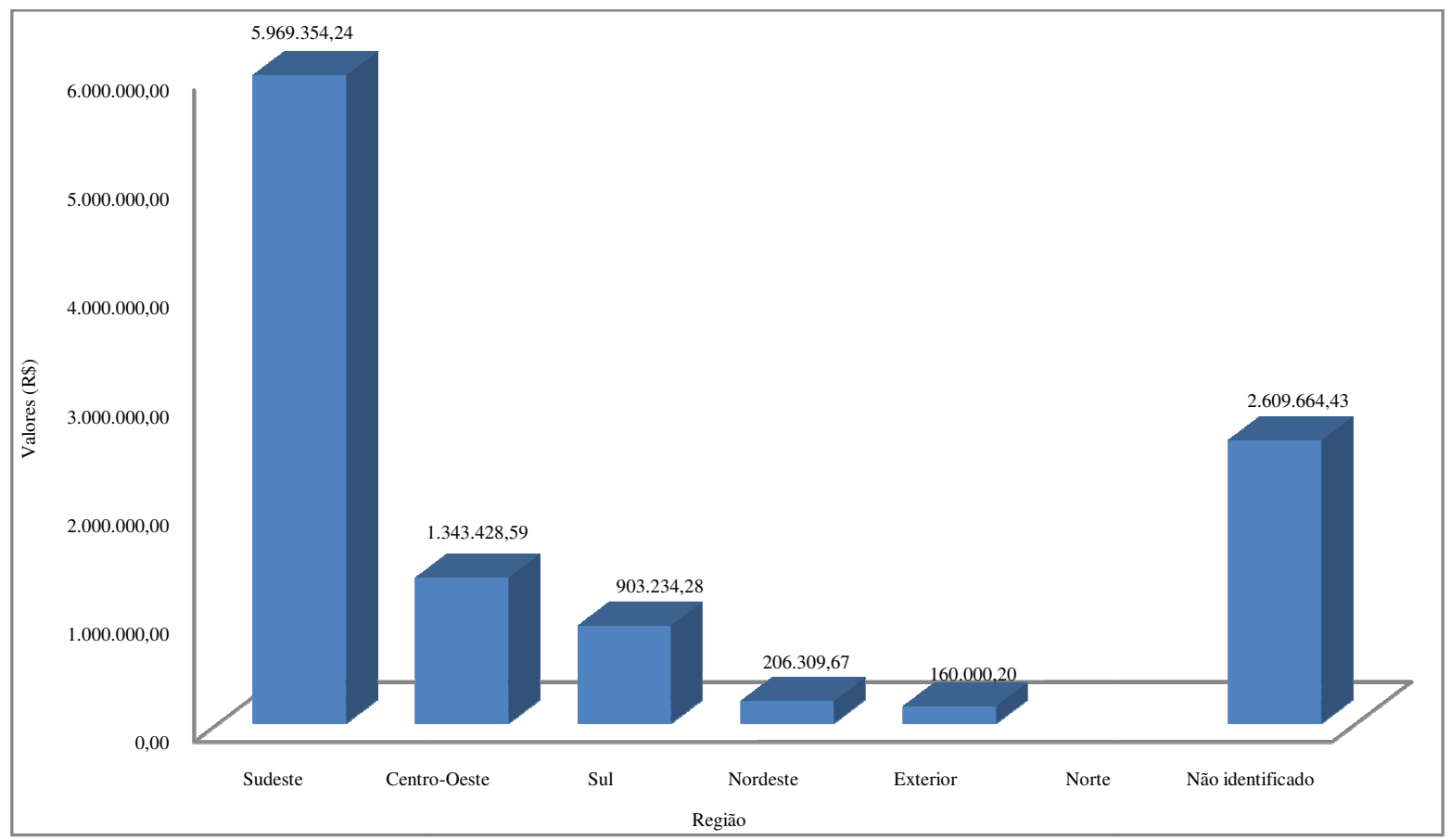

Fonte: Elaborado a partir dos dados fornecidos pela FAI, 2012. 
Quando a análise foi transferida para o volume de recursos (Gráfico 28), o estado de São Paulo aparece com o maior valor absoluto, estando diretamente associado ao elevado número de projetos estabelecidos com os parceiros deste estado, coerente com o resultado no Gráfico 29.

Neste ponto cabe o comentário referente ao expressivo número de projetos realizados com parceiros localizados no estado de São Paulo com 89 projetos do total. Em seguida, encontraram-se os estados do Rio de Janeiro com 12 projetos, Minas Gerais com 5 projetos e o estado de Paraná com 4 projetos

Gráfico 29 - Distribuição do número de projetos e volume de recursos por localidade (estado)

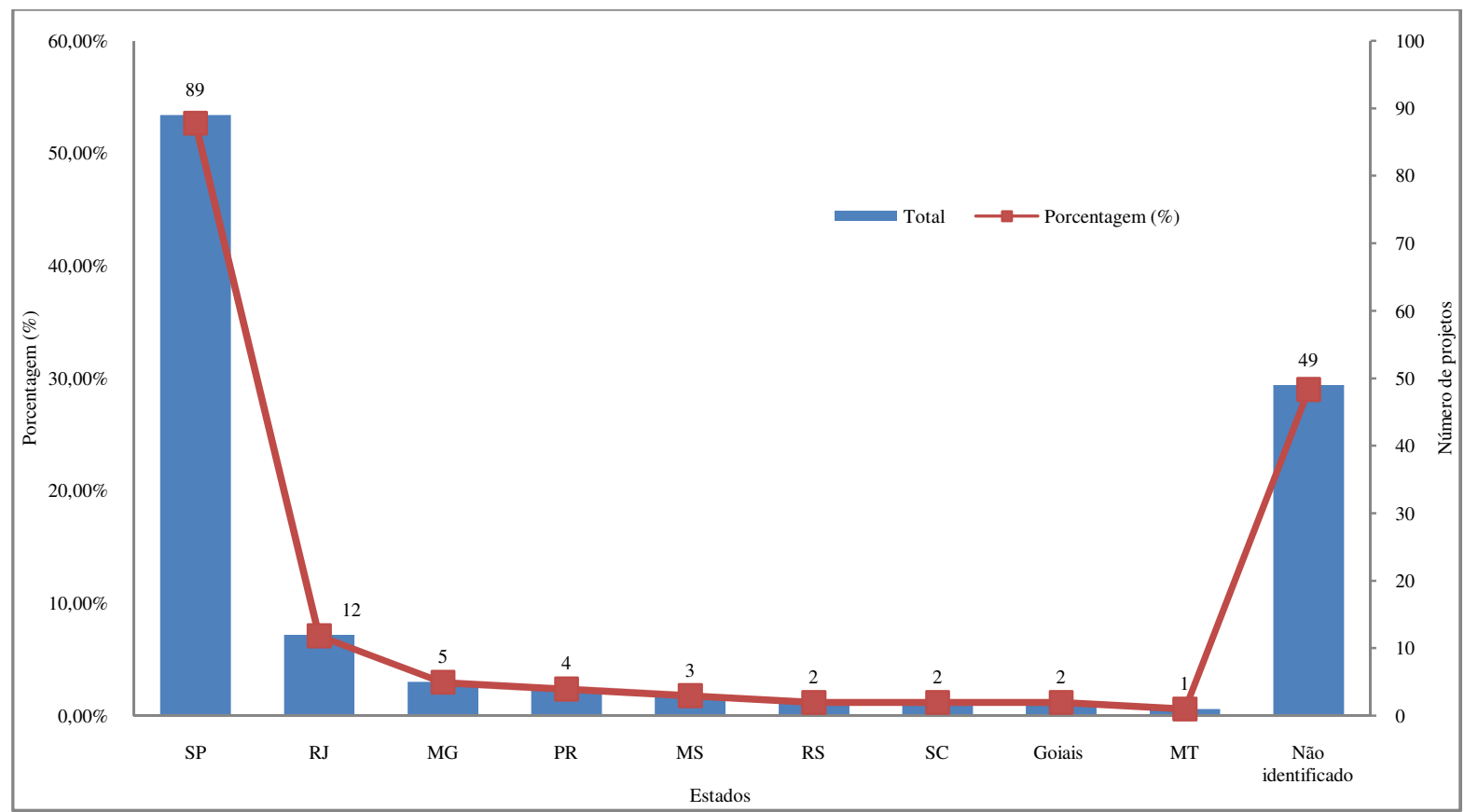

Fonte: Elaborado a partir dos dados fornecidos pela FAI, 2008 a 2012.

Por fim, apresentam-se os resultados referentes ao número de projetos em parceria com empresas privadas localizados no município São Carlos. Nesta análise o primeiro e segundo lugar foram ocupados, respectivamente, pelos financiadores Pessoa Física e Administração Pública, tanto no número de projetos como no volume de recursos

A posição de destaque ocupada pela Pessoa Física é justificada pelos tipos de atividades nas quais esta envolvida como parceira, isto é, nos cursos (especialização, aperfeiçoamento profissional etc.) cujo volume de recursos está diretamente relacionado com o número de inscritos ou de participantes.

Esse conjunto de resultados, apresentados em função do tipo de financiador, valoriza a imagem da universidade como agente local de difusão do conhecimento, seja através do 
oferecimento e realização de cursos e eventos científicos ou por meio do reconhecimento da concentração de mão-de-obra altamente especializada (pesquisadores e técnicos), abrangendo diversas áreas do conhecimento.

\subsection{Apresentação e análise comparativa da cooperação da UFSCar com o meio externo}

Este estudo também se propôs a fazer uma análise comparativa dos projetos estabelecidos entre a UFSCar e as empresas que se encontram sob coordenação da Fundação de Apoio Institucional ao Desenvolvimento Científico e Tecnológico (FAI).Tal realização teve o intuito de verificar se houve alguma mudança no perfil da cooperação da UFSCar com o meio externo.

Neste contexto, é importante ressaltar que o estudo comparativo, realizado nesta seção, só se torna possível, pois o presente trabalho dá continuidade ao tema em questão desenvolvido na UFSCar. Tal pesquisa foi realizada por Oliveira (2002), entre o período de 1990-2000 e, com a finalidade de analisar como estava configurado o panorama da cooperação da UFSCar com os meios externo, por meio dos projetos que se encontravam sob coordenação da FAI.

Diante disso, esta seção irá apresentar a análise comparativa da cooperação da UFSCar com o meio externo, à luz dos resultados obtidos da cooperação da UFSCar com o meio externo para o período de 2008-2012, discutidos no início do capítulo 4, e dos resultados obtidos da pesquisa desenvolvida por Oliveira (2002), na qual, tinha como objetivo caracterizar a cooperação da UFSCar com a sociedade entre 1992-2000.

Levando em consideração as categorias analíticas do estudo, o Quadro 7, mostra as principais características do conjunto de dados analisados para o desenvolvimento do estudo comparativo da cooperação da universidade em estudo com o meio externo.

Quadro 7 - Características do conjunto de dados a serem analisados

\begin{tabular}{|l|l|l|}
\hline \multicolumn{2}{|c|}{ Características do conjunto de dados analisados } \\
\hline Período estudado & $2008-2012$ & $\begin{array}{l}1990-2000 \text { desenvolvido por } \\
\text { Oliveira (2002) }\end{array}$ \\
\hline Número total de projetos estudados & 619 projetos & 601 projetos \\
\hline Volume total de recursos & R \$ 50.589,520 milhões de reais & R \$ 37.336.053,65 milhões de reais \\
\hline
\end{tabular}

Fonte: Elaborado pela autora a partir dos dados de Oliveira (2002) e dos dados fornecidos pela FAI, entre 20082012. 


\subsubsection{Características da cooperação da UFSCar com a sociedade (1990-2000)}

De forma a desenvolver o estudo comparativo da cooperação da UFSCar com o meio externo, inicialmente, é importante apresentar as principais características da cooperação para o período entre 1990 a 2000, desenvolvido por Oliveira (2002).

Neste contexto, considerando as informações obtidas pelo trabalho do autor supracitado, a cooperação da UFSCar com a sociedade entre 1992-2000 é caracterizada pelo conjunto de cerca de 600 contratos, o que corresponde a 43.576.433,52 milhões de reais, cuja distribuição anual de recursos representa cerca de $12 \%$ do volume de Recursos do Tesouro Nacional destinados à UFSCar.

De forma mais específica, esses projetos caracterizam-se na grande maioria, por baixos intervalos de duração ( $\leq 12$ meses) e menores faixas de valor ( $\leq 10$ mil reais). Além disso, são executados, em maior parte, pelos Departamentos do Centro de Ciências Exatas e de Tecnologia (CCET). Como exceção, pode-se citar o Departamento de Biotecnologia Vegetal do Centro de Ciências Agrárias (CCA) que executa o maior número dos contratos com intervalos de duração de volume de recursos elevados $(\geq 54$ meses e $>60$ mil a 80 mil reais).

Em relação à natureza dos projetos, pode-se destacar o grupo composto pelas atividades de Pesquisa, Pesquisa e Desenvolvimento, Prestação de Serviços, Consultoria/Assessoria, tanto para o número de contratos como para o volume de recursos. Por fim, caracterizam-se como os principais tipos de financiadores a empresa privada (número de contratos) e as agências de financiamentos governamentais (volume de recursos).

No Quadro 8, podem ser observados os principais resultados da cooperação da UFSCar com o meio externo (1990-2000), desenvolvido por OLIVEIRA (2002). 
Quadro 8 - Quadro resumo com os principais resultados obtidos na pesquisa desenvolvida por Oliveira (2002)

\begin{tabular}{|c|c|}
\hline Características & Resultados (OLIVEIRA, 2002) \\
\hline Objeto de estudo & Projetos sob coordenação da FAI \\
\hline Período estudado & $1990-2000$ \\
\hline Número total de projetos estudados & 601 \\
\hline Volume total de recursos & $\mathrm{R} \$ 37.336 .053,65$ \\
\hline \multirow{2}{*}{ Intervalo de duração } & $\begin{array}{l}\text { Maior concentração do total de contratos }(60 \%) \text { para os } \\
\text { intervalos } \leq 12 \text { meses }\end{array}$ \\
\hline & $\begin{array}{l}\text { Maior concentração do volume de recursos (53\%) para } \\
\text { intervalos } \geq 42 \text { meses }\end{array}$ \\
\hline \multirow{2}{*}{ Tipo de atividade } & $\begin{array}{l}\text { P\&D (107 contratos), seguindo por Prestação de Serviços, } \\
\text { Assessoria e Pesquisa }\end{array}$ \\
\hline & $\begin{array}{l}\text { Pesquisa ( } \mathrm{R} \$ 14,8 \text { milhões), seguindo por P\&D, Assessoria e } \\
\text { Prestação de Serviço }\end{array}$ \\
\hline Área de conhecimento: Centro Científico & $\begin{array}{l}\text { Centro de Ciências Exatas e de } \text { Tecnologia } \\
\text { contratos e R } \$ 23,1 \text { milhões) }\end{array}$ \\
\hline Área de conhecimento: Departamento & 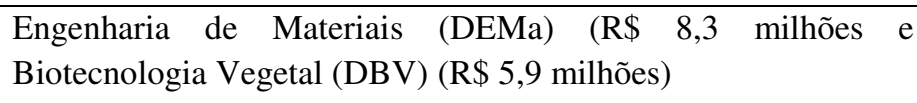 \\
\hline Tipo de financiador & $\begin{array}{l}\text { Empresa privada ( } 242 \text { contratos), seguida por Universidades e } \\
\text { Institutos de Pesquisa e Agência de Financiamento }\end{array}$ \\
\hline \multirow[b]{2}{*}{ Localidade do financiador } & Concentração na Região Sudeste - São Paulo (450 contratos) \\
\hline & $\begin{array}{l}\text { Concentração na Região Sudeste - São Paulo (R } \$ 13,7 \text { milhões) } \\
\text { e Rio de Janeiro R } \$ 12,9 \text { milhões }\end{array}$ \\
\hline
\end{tabular}

Fonte: Elaborado pela autora a partir dos dados de Oliveira (2002).

\subsubsection{Apresentação e análise dos projetos por intervalo de duração}

Uma comparação entre os dados para verificar se houve alguma mudança no perfil na cooperação da UFSCar com o meio externo, refere-se ao estudo comparativo da distribuição dos projetos por intervalo de duração. Desta forma, este tópico evidencia as semelhanças referentes aos resultados relacionados à distribuição dos projetos firmados pelo período de duração. Nesse contexto, considerando-se o número de projetos e volume de recursos, a distribuição dos projetos por período de tempo segue o que é apresentado no Quadro 9. 
Quadro 9 - Comparação do critério intervalo de duração

\begin{tabular}{|c|c|c|c|c|c|}
\hline \multirow{2}{*}{$\begin{array}{l}\text { Intervalos de } \\
\text { duração } \\
\text { (meses) }\end{array}$} & \multicolumn{2}{|c|}{ Período de tempo (1990-2000) } & \multirow{2}{*}{$\begin{array}{c}\text { Intervalos de duração } \\
\text { (meses) }\end{array}$} & \multicolumn{2}{|c|}{ Período de tempo (2008-2012) } \\
\hline & $\begin{array}{l}\text { Quantidade de } \\
\text { projetos }\end{array}$ & Valores $(\mathbf{R} \$)$ & & $\begin{array}{l}\text { Quantidade de } \\
\text { projetos }\end{array}$ & Valores (R\$) \\
\hline$<=6$ & 260 & $2.884 .354,38$ & $<=6$ & 239 & $8.954 .854,67$ \\
\hline$>6$ a 12 & 116 & $4.917 .406,06$ & $>6$ a 12 & 134 & $9.954 .342,22$ \\
\hline$>12$ a 18 & 28 & $1.767 .304,02$ & $>12$ a 24 & 99 & $7.765 .982,32$ \\
\hline$>18$ a 24 & 28 & $3.867 .049,92$ & $>24$ a 36 & 63 & $8.542 .987,11$ \\
\hline$>24$ a 30 & 9 & $1.619 .861,22$ & $\begin{array}{l}\text { Projetos contínuos } \\
\text { (renovados anualmente } \\
\text { ou bianualmente) }\end{array}$ & 84 & $15.371 .357,08$ \\
\hline$>30$ a 36 & 13 & $1.004 .198,64$ & & & \\
\hline$>36$ a 42 & 12 & $1.453 .518,56$ & & & \\
\hline$>42$ A 48 & 13 & $2.318 .733,07$ & & & \\
\hline$>48$ A 54 & 7 & $2.523 .085,14$ & & & \\
\hline$>54$ A 60 & 55 & $4.669 .814,67$ & & & \\
\hline$>60$ A 66 & 21 & $4.054 .059,66$ & & & \\
\hline$>66$ & 39 & $6.256 .668,30$ & & & \\
\hline Total & 601 & $37.336 .053,65$ & Total & 619 & $50.589 .523,40$ \\
\hline
\end{tabular}

Fonte: Elaborado pela autora a partir dos dados de Oliveira (2002) e dos dados fornecidos pela FAI, entre 20082012.

Analisando os projetos firmados com a UFSCar, como observado no quadro acima, a similaridade entre os projetos por intervalo de duração ocorre em todos os intervalos de tempos. Foi possível observar que há uma concentração do número de projetos em intervalos de tempos menores ou iguais a 12 meses. Nos dados fornecidos por Oliveira (2002), os projetos menores ou iguais a 12 meses representam cerca de 63\%, enquanto que a análise feira para o período entre 2008-2012, os projetos com intervalos de duração menores ou iguais a 12 meses representa aproximadamente $60 \%$ do total.

Quando a análise é transferida para o volume de recursos financeiros, é possível observar um resultado significativamente diferente quando comparado os dados atuais com os dados históricos. Na análise desenvolvida por Oliveira (2002), o volume de recursos para os projetos estabelecidos por até 12 meses não supera $21 \%$ do total, sendo que a maior parte dos recursos, aproximadamente $57 \%$ do total, advém dos projetos estabelecidos por intervalos de duração maiores de 36 meses. Transferindo a análise para o período atual, isto é, entre 20082012, os recursos financeiros para projetos estabelecidos por até 12 meses apresentou uma participação de cerca de $37 \%$ em relação ao montante total, sendo que a maior parte dos recursos, aproximadamente $47 \%$ to total, refere-se aos projetos com mais de 36 meses.

Nessa perspectiva, esses resultados demonstraram que não houve nenhuma mudança significativa em relação aos projetos estabelecidos por intervalos de duração. No que 
concerne ao número de projetos por intervalos de duração não ocorreu nenhuma mudança pois a maior parte dos projetos são executados em até 12 meses.

Quando a análise é transferida para o volume de recursos financeiros dos projetos, esses resultados demonstraram que atualmente os projetos com intervalos de tempos menores, tem aumentado a captação de recursos financeiros para a sua execução. No entanto, os projetos de maiores intervalos de duração continuam acarretando em maiores volume de recursos para a sua execução

\subsubsection{Apresentação e análise dos projetos por tipo de atividade}

Em relação ao estudo comparativo dos projetos de cooperação da UFSCar com o meio externo classificados por tipo de atividade, foi possível verificar algumas semelhanças em relação aos projetos classificados por tipo de atividade em ambos os períodos. Sendo, assim, cabe detalhar as principais atividades desenvolvidas, como demonstradas no Quadro 10.

Quadro 10 - Comparação do critério projetos por tipo de atividade

\begin{tabular}{|c|c|c|c|c|c|}
\hline \multirow[b]{2}{*}{ Tipo de atividade } & \multicolumn{2}{|c|}{ Período de tempo (1990-2000) } & \multirow[b]{2}{*}{ Tipo de atividade } & \multicolumn{2}{|c|}{ Período de tempo (2008-2012) } \\
\hline & $\begin{array}{c}\text { Quantidade de } \\
\text { projetos }\end{array}$ & $\begin{array}{c}\text { Porcentagem } \\
(\%)\end{array}$ & & $\begin{array}{l}\text { Quantidade } \\
\text { de projetos }\end{array}$ & $\begin{array}{c}\text { Porcentagem } \\
(\%)\end{array}$ \\
\hline $\begin{array}{l}\text { Pesquisa e } \\
\text { Desenvolvimento (P\&D) }\end{array}$ & 107 & $17,80 \%$ & Cursos & 223 & $36,03 \%$ \\
\hline Prestação de Serviços & 99 & $16,47 \%$ & Consultoria/Assessoria & 122 & $19,71 \%$ \\
\hline Assessoria & 90 & $14,98 \%$ & Eventos & 97 & $15,67 \%$ \\
\hline Pesquisa & 59 & $9,82 \%$ & \begin{tabular}{|l} 
Pesquisa e \\
Desenvolvimento (P\&D)
\end{tabular} & 57 & $9,21 \%$ \\
\hline Cursos de Especialização & 54 & $8,99 \%$ & Pesquisa & 46 & $7,43 \%$ \\
\hline $\begin{array}{l}\text { Cooperação } \\
\text { interinstitucional }\end{array}$ & 45 & $7,49 \%$ & Prestação de Serviços & 45 & $7,27 \%$ \\
\hline Consultoria & 37 & $6,16 \%$ & Publicações & 10 & $1,62 \%$ \\
\hline Reuniões Científicas & 31 & $5,16 \%$ & Intra-Estrutura & 9 & $1,45 \%$ \\
\hline $\begin{array}{l}\text { Cursos de } \\
\text { Aperfeiçoamento }\end{array}$ & 31 & $5,16 \%$ & Recursos-Premiação & 4 & $0,65 \%$ \\
\hline $\begin{array}{l}\text { Cursos de Extensão } \\
\text { Universitária }\end{array}$ & 17 & $2,83 \%$ & $\begin{array}{l}\text { Convênios de Cooperação } \\
\text { Institucional }\end{array}$ & 3 & $0,48 \%$ \\
\hline $\begin{array}{l}\text { Cursos de Atualização } \\
\text { Científica }\end{array}$ & 10 & $1,66 \%$ & \begin{tabular}{|l} 
Atividades. \\
Culturais/Artística
\end{tabular} & 3 & $0,48 \%$ \\
\hline $\begin{array}{l}\text { Cursos de Extensão } \\
\text { Cultural }\end{array}$ & 7 & $1,16 \%$ & & & \\
\hline Eventos & 4 & $0,67 \%$ & & & \\
\hline Supervisão & 4 & $0,67 \%$ & & & \\
\hline Sistema de informação & 2 & $0,33 \%$ & & & \\
\hline Vídeos e Filmes & 2 & $0,33 \%$ & & & \\
\hline Publicações & 2 & $0,33 \%$ & & & \\
\hline Total & 601 & $100,00 \%$ & Total & 619 & $100,00 \%$ \\
\hline
\end{tabular}

Fonte: Elaborado pela autora a partir dos dados de Oliveira (2002) e dos dados fornecidos pela FAI, entre 20082012. 
Conforme observado no Quadro acima, no período que compreende 2008 a 2012, as atividades relacionadas aos Cursos, Consultoria/Assessoria e eventos se destacaram em relação à quantidade de projetos desenvolvidos em cada tipo de atividade. Por sua vez, quando analisado os dados obtidos pela pesquisa realizada por Oliveira (2002) referente à caracterização da cooperação da UFSCar com o meio externo para o período de 1990-2000, as atividades que se sobressaíram em relação ao número de projetos eram as de Pesquisa e Desenvolvimento, Prestação de Serviços e Assessoria.

No entanto, para fins de comparação com os dados atuais, foi necessário agrupar os tipos de atividades, que Oliveira (2002) analisou separadamente, isto é, todas as atividades relacionada a Cursos foram agrupadas para obter o resultado total, as atividades relacionadas a Consultoria e Assessoria, também, foram agrupadas para obter o resultado total. Isto tornouse necessário, porque os resultados fornecidos para o período entre 2008-2012, estavam todos agrupados, fornecendo o total de cada atividade desenvolvida.

Sendo assim, as atividades relacionadas a cursos para o período compreendido entre 1990 a 200, gerou um resultado total de 119 projetos, as atividades relacionadas a Consultoria/Assessoria, resultou em um total de 127 projetos. Para efeito de simplificação e desenvolvimento da análise comparativa, o Quadro 11 apresenta os resultados por tipo de atividade obtidos por Oliveira (2002) agrupados, e em ordem decrescente e, os projetos por tipo de atividade desenvolvido no período entre 2008-2012.

Quadro 11 - Comparação do critério projetos por tipo de atividade

\begin{tabular}{|c|c|c|c|c|c|}
\hline \multirow[b]{2}{*}{ Tipo de atividade } & \multicolumn{2}{|c|}{ Período de tempo (1990-2000) } & \multirow[b]{2}{*}{ Tipo de atividade } & \multicolumn{2}{|c|}{ Período de tempo (2008-2012) } \\
\hline & $\begin{array}{l}\text { Quantidade } \\
\text { de projetos }\end{array}$ & $\begin{array}{c}\text { Porcentagem } \\
(\%)\end{array}$ & & $\begin{array}{c}\text { Quantidade de } \\
\text { projetos }\end{array}$ & $\begin{array}{c}\text { Porcentagem } \\
(\%)\end{array}$ \\
\hline Consultoria/Assessoria & 127 & $21,13 \%$ & Cursos & 223 & $36,03 \%$ \\
\hline Cursos & 119 & $19,80 \%$ & Consultoria/Assessoria & 122 & $19,71 \%$ \\
\hline $\begin{array}{l}\text { Pesquisa e } \\
\text { Desenvolvimento (P\&D) }\end{array}$ & 107 & $17,80 \%$ & Eventos & 97 & $15,67 \%$ \\
\hline Prestação de Serviços & 99 & $16,47 \%$ & $\begin{array}{l}\text { Pesquisa e } \\
\text { Desenvolvimento } \\
(\mathrm{P} \& \mathrm{D}) \\
\end{array}$ & 57 & $9,21 \%$ \\
\hline Pesquisa & 59 & $9,82 \%$ & Pesquisa & 46 & $7,43 \%$ \\
\hline $\begin{array}{l}\text { Cooperação } \\
\text { interinstitucional }\end{array}$ & 45 & $7,49 \%$ & Prestação de Serviços & 45 & $7,27 \%$ \\
\hline Reuniões Científicas & 31 & $5,16 \%$ & Publicações & 10 & $1,62 \%$ \\
\hline Eventos & 4 & $0,67 \%$ & Intra-Estrutura & 9 & $1,45 \%$ \\
\hline Supervisão & 4 & $0,67 \%$ & Recursos-Premiação & 4 & $0,65 \%$ \\
\hline Sistema de informação & 2 & $0,33 \%$ & $\begin{array}{l}\text { Convênios Cooperação } \\
\text { Institucional } \\
\end{array}$ & 3 & $0,48 \%$ \\
\hline Vídeos e Filmes & 2 & $0,33 \%$ & $\begin{array}{l}\text { Atividades. } \\
\text { Culturais/Artística }\end{array}$ & 3 & $0,48 \%$ \\
\hline Publicações & 2 & $0,33 \%$ & & & \\
\hline Total & 601 & $100,00 \%$ & \begin{tabular}{|l|} 
Total \\
\end{tabular} & 619 & $100,00 \%$ \\
\hline
\end{tabular}

Fonte: Elaborado pela autora a partir dos dados de Oliveira (2002) e dos dados fornecidos pela FAI, entre 20082012. 
Nesta perspectiva, é possível constatar que o número de projetos relacionados às atividades de Consultoria/Assessoria e Cursos, se destacaram em relação ao número de projetos, tanto nos dados obtidos por Oliveira (2002), como nos resultados obtidos para o período entre 2008-2012, com aproximadamente $41 \%$ e $55 \%$ do total de atividades, respectivamente.

No entanto, quando a análise comparativa foi transferida para o volume de recursos financeiros, os resultados demonstraram que não houve nenhuma mudança significativa em relação as atividades que mais movimentam recursos financeiros. $\mathrm{O}$ tipo de atividade que apresentou maior volume de recursos tanto nos dados históricos como nos dados atuais, foram as atividades de Pesquisa e Pesquisa e Desenvolvimento (P\&D). Segundo Oliveira (2002) essas duas atividades apresentaram cerca de $70 \%$ do total do volume de recursos financeiros, para o período entre 2008-2012, as atividades de Pesquisa e P\&D corresponde 55\% do montante total.

Sendo assim, destacou-se o expressivo volume de recursos captados pelas atividades de Pesquisa e Desenvolvimento P\&D e Pesquisa que, apesar de não se encontrarem, em primeiro ou em segundo lugar no número de projetos, as atividades de Pesquisa e P\&D encontraram-se, respectivamente, em primeiro segundo e segundo lugar em relação ao volume de recursos, tanto para os dados atuais como para os dados históricos. De modo geral, observou-se que existe poucas mudanças no perfil de cooperação da UFSCar em relação ao tipo de atividade desenvolvida.

\subsubsection{Apresentação e análise dos projetos por Centro Científico e Departamento}

Com relação á área de conhecimento da UFSCar que se propõe a cooperar com as empresas, conforme Quadro 12, foi possível observar a predominância do Centro Científico de Ciências Exatas e da Terra (CCET), em relação aos demais Centros Científicos, entre os dois períodos de tempo analisado. 
Quadro 12 - Comparação do critério distribuição dos projetos por Centro Científico

\begin{tabular}{|l|c|c|c|c|}
\hline \multirow{2}{*}{$\begin{array}{l}\text { Área } \\
\text { conhecimento: }\end{array}$} & \multicolumn{2}{|c|}{ Período de tempo (1990-2000) } & \multicolumn{2}{|c|}{ Período de tempo (2008-2012) } \\
\cline { 2 - 5 } & $\begin{array}{c}\text { Quantidade de } \\
\text { projetos }\end{array}$ & Valores (R\$) & $\begin{array}{c}\text { Quantidade de } \\
\text { projetos }\end{array}$ & Valores (R\$) \\
\hline CCET & 369 & $23.120 .334,39$ & 315 & $24.618 .459,33$ \\
\hline CCBS & 57 & $2.622 .933,253$ & 86 & $5.595 .730,99$ \\
\hline CECH & 37 & $1.065 .107,758$ & 72 & $3.577 .872,61$ \\
\hline CCA & 114 & $6.656 .282,678$ & 27 & $4.343 .917,11$ \\
\hline CCTS & - & 0 & 72 & $1.165 .490,85$ \\
\hline Outros & 24 & $3.871 .395,562$ & 47 & $11.288 .052,50$ \\
\hline Total & $\mathbf{6 0 1}$ & $\mathbf{3 7 . 3 3 6 . 0 5 3 , 6 5}$ & $\mathbf{6 1 9}$ & $\mathbf{5 0 . 5 8 9 . 5 2 3 , 4 0}$ \\
\hline
\end{tabular}

Fonte: Elaborado pela autora a partir dos dados de Oliveira (2002) e dos dados fornecidos pela FAI, entre 20082012.

Vale ressaltar a posição ocupada pelo CCA que, no período entre 1990-2000, ocupava a segunda posição tanto em número de projetos quanto em montante de recursos. Quando a análise da cooperação da UFSCar com o meio externo foi transferida para o período entre 2008-20012, o CCA encontra-se em quarto lugar em relação ao número de projetos desenvolvidos e, em terceira posição, em relação ao montante de recurso. Dessa forma, é possível verificar o aumento no número de projetos desenvolvidos juntamente ao Centro de Ciências Biológicas e da Saúde (CCBS).

Desagregando os dados por departamentos que apresentam maior quantidade de projetos e volume de recursos financeiros, inicialmente, cabe ressaltar que como o número de departamentos é relativamente grande, optou-se por apresentar os oitos que mais se sobressaíram em termos de números de projetos e volume de recursos financeiros no período entre 1990-2000: (i) Engenharia Civil (DECIv), (ii) Departamento de Engenharia de Materiais (DEMa), (iii) Departamento de Engenharia de Produção (DEP), (iv) Departamento de Computação (DC), (v) Departamento de Química (DQ), (vi) Departamento de Biotecnologia e Produção Vegetal e Animal (DBPVA), (vii) Departamento Agroindustrial e Socioeconômica Rural (DTAiSER) e (viii) Departamento de Fisioterapia (DFisio), conforme o Quadro 13.

Tal delimitação foi realizada para confrontar os resultados obtidos pela pesquisa de Oliveira (2002) com os dados obtidos por meio da caracterização da cooperação da UFSCar com empresa entre o período de 2008-20012. Desta forma, verificou-se que houve alguma mudança nos departamentos que mais desenvolvem projetos em parceria com o meio externo. 
Quadro 13 - Comparação do critério distribuição dos projetos por departamento

\begin{tabular}{|l|c|c|c|c|}
\hline \multirow{2}{*}{ Departamentos } & \multicolumn{2}{|c|}{ Período de tempo (1990-2000) } & \multicolumn{2}{c|}{ Período de tempo (2008-2012) } \\
\cline { 2 - 5 } & $\begin{array}{c}\text { Quantidade de } \\
\text { projetos }\end{array}$ & $\begin{array}{c}\text { Valores (R\$) } \\
\text { milhões }\end{array}$ & $\begin{array}{c}\text { Quantidade de } \\
\text { projetos }\end{array}$ & $\begin{array}{c}\text { Valores (R\$) } \\
\text { milhões }\end{array}$ \\
\hline DEP & 104 & 3.3 & 56 & 5.6 \\
\hline DBPVA & 102 & 5.9 & 12 & 2.2 \\
\hline DECIv & 94 & 1.5 & 87 & 367 (mil) \\
\hline DEMa & 56 & 8.3 & 59 & 2.9 \\
\hline DC & 34 & 2.1 & 39 & 5.2 \\
\hline DQ & 30 & 2.2 & 15 & 2.2 \\
\hline Dfísio & 19 & $740(\mathrm{mil})$ & 19 & 22.1 \\
\hline Outros & 162 & 2.5 & 331 & \\
\hline
\end{tabular}

Fonte: Elaborado pela autora a partir dos dados de Oliveira (2002) e dos dados fornecidos pela FAI, entre 20082012.

Conforme observado no Quadro acima, até o período de 2000, os três departamentos que se destacaram em números de projetos foram o Departamento de Engenharia de Produção e o de Biotecnologia Vegetal (DBV), com 104 e 102 projetos, respectivamente, seguido pelo Departamento de Engenharia Civil com 94 projetos. Diferentemente do que ocorre no período de 2008-2012, pois os departamentos que sobressaíram em número de projetos estabelecidos foram o Departamento de Engenharia Civil, Departamento de Engenharia de Materiais e o Departamento de Engenharia de Produção.

Dessa forma, analisando os dados apresentados, a similaridade entre os departamentos que se destacaram em relação ao número de projetos durante os períodos analisados foi identificado principalmente nos Departamentos de Engenharia Civil (DECIv) e Departamento de Engenharia de Produção (DEP), pois em ambos os períodos analisados, estes estão entre os três departamentos que apresentam uma maior quantidade de projetos em cooperação com o meio externo.

Nesse contexto, cabe evidenciar o Departamento de Engenharia de Materiais (DEMa) e o Departamento de Biotecnologia e de Produção Vegetal e Animal( DBPVA). O Departamento de Engenharia de Materiais, apesar de se encontrar em segundo lugar, no período entre 2008-2012, e em quarto lugar no período entre 1990-2000, em relação ao numero de projetos durante, quando a análise foi transferida para o volume de recursos este departamento continuou concentrando a maior parte dos recursos financeiros provenientes dos projetos de cooperação em ambos os períodos analisados.

Por sua vez, o Departamento de Biotecnologia e Produção Vegetal e Animal (DBPVA), de acordo com Oliveira (2000), no período entre 1990-2000, destacava-se em 
segundo lugar, tanto em número de projetos como em volume de recursos financeiros (102 projetos e 5.9 milhões de reais), entretanto, atualmente concentra uma pequena quantidade de projetos e recursos financeiros proveniente dos projetos de cooperação. A posição ocupada pelo DBPVA, tanto para o número de projetos como para o volume total de recursos, no período entre 1990-2000, sofreu grande influência dos projetos estabelecidos pelo Programa de Melhoramento Genético da Cana-de-Açúcar (PMGCA).

$\mathrm{O}$ autor ainda relata que se a mesma análise fosse feita desconsiderando os projetos estabelecidos pelo PMGCA, a posição do Departamento (DBPVA/CCA) cairia de segundo para quinto no número de projetos estabelecidos e de segundo para vigésimo segundo lugar em relação ao volume total de recursos.

Em síntese, a percepção que se mantém após a apresentação destes resultados oferece a imagem de que poucos departamentos realizam a maior parte dos projetos de cooperação com as empresas, gerando uma concentração de atividades e recursos. Assim, com base nos resultados obtidos nesse tópico, ficou evidente que o centro de Ciências Exatas e Tecnológicas (CCET) contínua superando os demais, tanto no número de projetos como no volume de recursos. Dentre os principais Departamentos desse Centro Científico, destacaramse os de maior aplicação técnica como a Engenharia de Produção, Engenharia de Materiais e Engenharia Civil.

\subsubsection{Apresentação e análise dos projetos por tipo de financiador}

Com relação ao número de projetos e montante dos recursos financeiros por tipo de financiador, pode-se afirmar que ocorreram algumas mudanças em relação aos principais financiadores da universidade em estudo. Para que se tenha uma visão mais panorâmica dos resultados analisados o Quadro 14 apresenta a comparação do número de projetos, o volume de recursos para cada tipo de financiador. 
Quadro 14 - Comparação do critério distribuição dos projetos por tipo de financiador

\begin{tabular}{|l|c|c|c|c|}
\hline \multirow{2}{*}{ Tipo de Financiador } & \multicolumn{2}{c|}{ Período de tempo (1990-2000) } & \multicolumn{2}{c|}{ Período de tempo (2008-2012) } \\
\cline { 2 - 5 } & $\begin{array}{c}\text { Quantidade de } \\
\text { projetos }\end{array}$ & Valores (R\$) & $\begin{array}{c}\text { Quantidade de } \\
\text { projetos }\end{array}$ & Valores (R\$) \\
\hline Empresa privada & 242 & $9.120 .301,10$ & 168 & $11.191 .992,05$ \\
\hline $\begin{array}{l}\text { Universidades e Institutos de } \\
\text { Pesquisa }\end{array}$ & 95 & $2.685 .558,02$ & 154 & $4.024 .350,72$ \\
\hline Agência de Financiamento & 73 & $16.376 .779,29$ & 44 & $14.402 .619,43$ \\
\hline Administração Pública & 71 & $4.358 .686,65$ & 44 & $3.384 .821,67$ \\
\hline Pessoa Física & 51 & $2.317 .223,98$ & 141 & $7.820 .598,40$ \\
\hline Empresa Estatal & 19 & $875.510,43$ & 21 & $7.638 .653,29$ \\
\hline Associação/ONGs & 17 & $151.645,44$ & 42 & $1.934 .040,40$ \\
\hline Entidades Privadas & 11 & $198.835,91$ & 5 & $176.061,34$ \\
\hline Outros & 22 & $1.251 .512,82$ & - & $16.383,10$ \\
\hline Total & $\mathbf{6 0 1}$ & $\mathbf{3 7 . 3 3 6 . 0 5 3 , 6 5}$ & $\mathbf{6 1 9}$ & $\mathbf{5 0 . 5 8 9 . 5 2 0 , 4 0}$ \\
\hline
\end{tabular}

Fonte: Elaborado pela autora a partir dos dados de Oliveira (2002) e dos dados fornecidos pela FAI, entre 20082012.

A partir do Quadro 14, destacou-se que a principal mudança em relação ao tipo de financiador que ocorreu ao longo dos anos, quando comparado com os dados obtidos pela pesquisa desenvolvida por Oliveira (2002), refere-se à classe formada por Pessoa Física que, durante o período de 5 anos (2008-2012), mostrou-se como o terceiro parceiro da UFSCar, tanto em número de projetos como em volume de recursos financeiros.

A classe formada por Universidades e Institutos de Pesquisa que, apesar de se encontrar em segundo lugar em relação ao número de projetos, tanto nos dados históricos como nos dados atuais, estes projetos movimentaram pouco recurso financeiro em ambos os períodos estudado.

Destacou-se ainda, a classe formada pela Administração Pública que perdeu posição tanto em número de projetos como em montante de recursos financeiro. Finalmente, vale ressaltar a contribuição das empresas estatais no financiamento de pesquisa acadêmica, pois este tipo de financiador apresentou tanto em número de projetos como em volume de recursos financeiros, resultados relativamente superiores aos obtidos para o período entre 1990-2000, desenvolvidos por Oliveira (2002).

O último resultado a ser apresentado em função do tipo de financiador consiste na classe formada por empresas privadas. As empresas privadas apareceram como o maior financiador em número de projetos estabelecidos em ambos os períodos estudado, cujo volume de recursos superou mais de 9 milhões de reais no período entre 1990-2000, o equivalente a $24 \%$, e ultrapassou a marca de 11 milhões de reais nos últimos cinco anos 
(2008-2012), o que representa cerca de 22\%. Desta forma, a contribuição do setor privado (empresas) no financiamento de pesquisa acadêmica manteve o mesmo perfil de quando comparado com a análise desenvolvida por Oliveira (2002).

\subsubsection{Apresentação e análise dos projetos por localidade do financiador}

Uma última comparação entre os dados, muito útil para verificar se houve alguma mudança no perfil na cooperação da UFSCar com o meio externo, refere-se ao estudo comparativo da distribuição dos projetos por localidade do financiador. Desta forma, o Quadro 15 evidencia, primeiramente, a distribuição dos projetos de cooperação em função das regiões brasileiras, para, posteriormente, ser analisado os projetos estabelecidos por estados e, por fim, por parceiros locais, a saber São Carlos.

Quadro 15 - Comparação do critério distribuição dos projetos por tipo de financiador

\begin{tabular}{|l|c|c|c|c|}
\hline \multirow{2}{*}{\begin{tabular}{c} 
Localidade do Financiador $\begin{array}{c}\text { Período de tempo (1990-2000) } \\
\text { Região) }\end{array}$ \\
\cline { 2 - 5 }
\end{tabular}} & $\begin{array}{c}\text { Quantidade de } \\
\text { projetos }\end{array}$ & $\begin{array}{c}\text { Porcentagem } \\
(\%)\end{array}$ & $\begin{array}{c}\text { Puantidade de tempo (2008-2012) } \\
\text { projetos }\end{array}$ & Valores (R\$) \\
\hline Sudeste & 528 & $87,9 \%$ & 560 & $90,47 \%$ \\
\hline Centro-Oeste & 41 & $6,8 \%$ & 28 & $4,52 \%$ \\
\hline Sul & 19 & $3,2 \%$ & 20 & $3,23 \%$ \\
\hline Nordeste & 10 & $1,7 \%$ & 9 & $1,45 \%$ \\
\hline Norte & 1 & $0,2 \%$ & 2 & $0,32 \%$ \\
\hline Exterior & 2 & $0,3 \%$ & 4 & $0,64 \%$ \\
\hline Total & $\mathbf{6 0 1}$ & $\mathbf{1 0 0 \%}$ & $\mathbf{6 1 9}$ & $\mathbf{1 0 0 \%}$ \\
\hline
\end{tabular}

Fonte: Elaborado pela autora a partir dos dados de Oliveira (2002) e dos dados fornecidos pela FAI, entre 20082012.

Dessa forma, foi possível verificar que a grande maioria dos projetos estabelecidos, continua sendo estabelecidos por parceiros (financiadores) localizados na região Sudeste do Brasil, em seguida aparecem as regiões Centro-Oeste, Sul e Nordeste, respectivamente. Observando os resultados da pesquisa realizada por Oliveira (2002) e do estudo desenvolvido neste trabalho para o período de 2008-2012, notou-se que não houve nenhuma mudança na distribuição dos projetos por localidade de financiado em função das regiões do Brasil.

O mesmo resultado foi obtido quando ocorre o desdobramento dos dados para os projetos realizados com parceiros localizados por estados, pois ocorreu a predominância na quantidade de projetos realizados com parceiros localizados no estado de São Paulo, em seguida do Rio de Janeiro e Distrito Federal. 
Neste contexto, foi importante realizar mais uma análise comparativa no que concerne a localidade do financiador, a qual refere-se à distribuição dos projetos estabelecidos entre a UFSCar e os parceiros locais (São Carlos). Tanto nos resultados obtidos por Oliveira (2002), referentes à caracterização da cooperação da UFSCar com o meio externo, como nos resultados obtidos por meio deste trabalho para o período entre 2008-2012 o estado de São Paulo trouxe o município de São Carlos com o maior número de projetos estabelecidos.

Em relação ao panorama da cooperação da UFSCar com os parceiros locais, por meio do estudo realizado entre o período de 2008-2012, ficou evidente a participação do tipo de financiador identificado como Pessoa Física e Administração Pública, tanto no número de projetos como em volume de recursos, cuja principal atividade referiu-se à participação em reuniões científicas e tecnológicas, cursos e outros eventos ligadas às atividades de difusão do conhecimento.

Além disso, foi possível identificar que a classe formada pelo financiador identificado como Empresas privadas localizadas em São Carlos, apresentou poucos projetos em parceria com a UFSCar, ao contrário, do que foi registrado na pesquisa realizada de 1990 a 2000, desenvolvida por Oliveira(2002). No referido estudo, as empresas privadas localizadas em São Carlos detinham grande participação nos projetos de cooperação da UFSCar, o que valorizava a imagem de São Carlos, como polo tecnológico. 


\section{CONCLUSÕES}

Este estudo buscou responder a questão de pesquisa: Quais são as principais características do perfil de cooperação da Universidade Federal de São Carlos (UFSCar) com a empresa atualmente? Houve alguma mudança em relação às características históricas da cooperação?

Sob esta perspectiva, este capítulo apresenta as considerações a respeito da cooperação da Universidade Federal de São Carlos com o meio externo, baseado no arcabouço teórico e na pesquisa desenvolvida, bem como através da coleta e análise dos dados obtidos. Os dados e informações necessários para responder a esta questão de pesquisa foram obtidos mediante avaliação de um conjunto de projetos firmados entre a UFSCar e seus parceiros externos, nos últimos cinco anos (2008-2012), que são gerenciados pela Fundação de Apoio Institucional ao Desenvolvimento Científico e Tecnológico (FAI).

Este capítulo está dividido em duas seções, sendo que em um primeiro momento são apresentadas as considerações sobre as características da cooperação da UFSCar com empresa no período entre 2008-2012, seguida das considerações referentes à análise comparativa da cooperação da UFSCar com empresa. Na sequência, e concluindo, são apresentadas as considerações finais e as sugestões para pesquisa futuras.

\subsection{Considerações sobre as características da Cooperação da UFSCar com empresa entre o período de 2008 e 2012}

Inicialmente apresentaram-se algumas considerações a respeito da cooperação da UFSCar com empresas, baseadas na pesquisa desenvolvida através da coleta e análise dos dados contidos nos projetos que estão sob gerenciamento da FAI, entre o período de 20082012.

A partir dos resultados obtidos e apresentados no capítulo 4, considera-se que o objetivo relacionado a apresentar as características da cooperação mantida entre a UFSCar e as empresas, utilizando como objeto de análise os projetos que estão sob coordenação da FAI, foi atingido satisfatoriamente, pois foi possível esboçar a caracterização da cooperação da universidade em estudo.

Resumidamente, a cooperação da UFSCar (2008-2012) é caracterizada pelo conjunto de 619 projetos. Sendo assim, a análise possibilitou verificar o potencial de crescimento da 
atividade de cooperação entre a UFSCar e o meio externo, bem como permitiu perceber que tal universidade tem desempenhado o seu papel no desenvolvimento econômico e social.

A magnitude dos recursos correspondeu a aproximadamente 51 milhões de reais durante o período analisado, mesmo com a restrição do Tribunal de Contas da União (TCU), no qual os recursos oriundos da modalidade (CCIs) foram impedidos de serem gerenciados pela FAI a partir de 2008, tais resultados demonstraram a importância da cooperação entre a UFSCar e o meio externo.

De forma mais específica, os projetos de cooperação da UFSCar com o meio externo caracterizaram-se, na grande maioria, por baixos intervalos de duração, aproximadamente 232 projetos foram estabelecidos com intervalos de duração menores que seis meses. Outro fato importante foi a indicação de que, aproximadamente $51 \%$ dos projetos, pertenceram à área de Ciências Exatas e Tecnológicas. Entretanto, os projetos estabelecidos entre a UFSCar e o meio externo nos demais Centros Científicos também foram evidentes, fortalecendo a visão da UFSCar como fonte de conhecimento, pesquisa e desenvolvimento em Ciência e Tecnologia.

Em relação à natureza dos projetos, destacou-se que as atividades que mais movimentaram recursos financeiros foram o grupo composto pelas atividades de Pesquisa, Pesquisa e Desenvolvimento, Cursos e Consultoria/Assessoria. Por sua vez, quando a análise foi transferida para o número de projetos, as atividades que se destacaram foram as de Cursos, Consultoria/Assessoria e Eventos. De modo geral, observou-se a existência de diferenças significativas na distribuição do número de projetos e volume de recursos.

Além disso, caracterizaram-se como os principais tipos de financiadores as empresas privadas, que procuram a universidade em estudo para desenvolver atividades como Consultoria/Assessoria, Pesquisa e Desenvolvimento e Cursos. Tal resultado demonstrou a importância da elaboração de políticas institucionais que estimulem a criação e o desenvolvimento de programas de transferência de tecnologia por meio de pesquisas geradas nas universidades.

Ainda em relação ao tipo de financiador, empresas privadas, as principais atividades desenvolvidas com a universidade em estudo foram as atividades de Consultoria/Assessoria e Projetos de Pesquisa e Desenvolvimento. Outro fator importante foi o de que $88 \%$ das parcerias com as empresas privadas ocorreram no Centro de Ciências Exatas e Tecnológicas (CCET) e nos Departamentos de Engenharia Civil e de Engenharia de Materiais, tanto em número de projetos quanto em volume de recursos. 
Por fim, o Quadro 16, apresenta de modo resumido, as principais características da cooperação da UFSCar com as empresas.

Quadro 16 - Quadro resumo com os principais resultados obtidos na pesquisa

\begin{tabular}{|c|c|}
\hline Características & Resultados \\
\hline Objeto de estudo & Projetos sob coordenação da FAI \\
\hline Período estudado & $2008-2012$ \\
\hline $\begin{array}{l}\text { Número total de } \\
\text { projetos estudados }\end{array}$ & 619 \\
\hline $\begin{array}{l}\text { Volume total de } \\
\text { recursos }\end{array}$ & $\mathrm{R} \$ 50.589,520$ milhões de reais \\
\hline \multirow[t]{2}{*}{ Intervalo de duração } & Maior concentração do total de projetos (60\%) para os intervalos $\leq 12$ meses \\
\hline & Maior concentração do volume de recursos (53\%) para intervalos $\geq 42$ meses \\
\hline \multirow[b]{2}{*}{ Tipo de atividade } & $\begin{array}{l}\text { Cursos ( } 223 \text { projetos), seguindo por Consultoria/Assessoria (122 projetos) e } \\
\text { Eventos ( } 97 \text { projetos) }\end{array}$ \\
\hline & $\begin{array}{l}\text { Pesquisa (R\$ 16,485.078,43 milhões de reais), seguindo por Pesquisa e } \\
\text { Desenvolvimento (P\&D) (11. 202.727,50 milhões de reais) e Cursos } \\
\text { (10.693.010,81 milhões de reais) }\end{array}$ \\
\hline $\begin{array}{l}\text { Área de } \\
\text { conhecimento: Centro } \\
\text { Científico }\end{array}$ & $\begin{array}{l}\text { Centro de Ciências Exatas e de Tecnologia (CCET) ( } 315 \text { projetos e R\$ } \\
24.618 .459,22 \text { milhões de reais), seguido pelo CCBS ( } 86 \text { projetos e } \\
5.595 .730,99 \text { milhões de reais); CECH ( } 72 \text { projetos e } 3.577 .872,61 \text { milhões de } \\
\text { reais; CCA ( } 27 \text { projetos e } 4.343 .971,11 \text { milhões de reais) e CCTS ( } 72 \text { projetos e } \\
1.165,45 \text { milhões de reais) }\end{array}$ \\
\hline \multirow{2}{*}{$\begin{array}{l}\text { Área de } \\
\text { conhecimento: } \\
\text { Departamento }\end{array}$} & $\begin{array}{l}\text { Departamento de Engenharia Civil (DECiv) ( } 87 \text { projetos), seguido pelo de } \\
\text { Engenharia de Materiais (DEMa) ( } 50 \text { projetos) e Engenharia de Produção } \\
\text { (DEP) ( } 56 \text { projetos) }\end{array}$ \\
\hline & $\begin{array}{l}\text { Departamento de Engenharia de Materiais (DEMa) (6.8 milhões de reais), } \\
\text { seguido pelo Departamento de Engenharia de Produção (DEP) (5.6 milhões de } \\
\text { reais) e pelo Departamento de Engenharia Química (DQ) ( } 5 \text { milhões de reais) }\end{array}$ \\
\hline \multirow{2}{*}{ Tipo de financiador } & $\begin{array}{l}\text { Empresa privada ( } 168 \text { projetos), seguido por Universidades e Institutos de } \\
\text { Pesquisa ( } 158 \text { projetos) }\end{array}$ \\
\hline & $\begin{array}{l}\text { Agência de Financiamento (14.402.619,43 milhões de reais), seguido por } \\
\text { empresas privadas (11.191.992,05 milhões de reais) }\end{array}$ \\
\hline \multirow{2}{*}{$\begin{array}{l}\text { Tipo de financiador e } \\
\text { tipo de atividade }\end{array}$} & $\begin{array}{l}\text { Empresas privadas têm como principais atividades: Consultoria/Assesoria (79 } \\
\text { projetos); Projetos de Pesquisa e Desenvolvimento ( } 36 \text { projetos) e Cursos ( } 25 \\
\text { projetos) }\end{array}$ \\
\hline & $\begin{array}{l}\text { Empresas privadas têm como principais atividades em relação ao volume de } \\
\text { recursos: Consultoria/Assessoria ( } 3.5 \text { milhões de reais) e Projetos de Pesquisa e } \\
\text { Desenvolvimento ( } 3.2 \text { milhões de reais) }\end{array}$ \\
\hline $\begin{array}{l}\text { Tipo de financiador e } \\
\text { Centro Científico }\end{array}$ & $\begin{array}{l}\text { Em número de projetos e volume de recursos destaca-se o Centro de Ciência } \\
\text { Exatas e da Terra }\end{array}$ \\
\hline $\begin{array}{l}\text { Localidade do } \\
\text { financiador }\end{array}$ & $\begin{array}{l}\text { Concentração na Região Sudeste ( } 560 \text { projetos) } \\
\text { Estado: São Paulo ( } 432 \text { projetos) } \\
\text { Município: São Carlos (193 projetos) }\end{array}$ \\
\hline
\end{tabular}

Fonte: Elaborado pela autora a partir dos dados fornecidos pela FAI, entre 2008-2012 


\subsection{Considerações sobre a análise comparativa da cooperação da UFSCar com o meio externo.}

Este estudo também se propôs a fazer uma análise comparativa dos projetos estabelecidos entre a UFSCar e as empresas que se encontram sob coordenação da Fundação de Apoio Institucional ao Desenvolvimento Científico e Tecnológico (FAI). Tal realização teve o intuito de verificar se houve alguma mudança no perfil da cooperação da UFSCar com o meio externo. Para isso, em um primeiro momento esta dissertação desenvolveu uma análise comparativa da cooperação da UFSCar com o meio externo, por meio dos resultados obtidos da cooperação da UFSCar com o meio externo para o período de 2008-2012, e dos resultados obtidos da pesquisa desenvolvida por Oliveira (2002).

A partir desta etapa empírica, foi possível verificar se houve mudanças no perfil da cooperação da UFSCar com o meio externo. Desta forma, o Quadro 17 apresenta uma sistematização dos resultados referente à análise comparativa da cooperação da universidade em estudo com o meio externo, representando uma forma de auxiliar os pesquisadores e gestores na compreensão das mudanças da cooperação. 
Quadro 17 - Quadro resumo com os principais resultados obtidos na pesquisa referente ao estudo comparativo

\begin{tabular}{|c|c|c|}
\hline Características & \multicolumn{2}{|c|}{ Resultados } \\
\hline Período estudado & 2008-2012 & Oliveira, 2002 \\
\hline $\begin{array}{l}\text { Número total de } \\
\text { projetos estudados }\end{array}$ & 619 & 601 \\
\hline $\begin{array}{l}\text { Volume total de } \\
\text { recursos }\end{array}$ & $\mathrm{R} \$ 50.589 .520,76$ milhões de reais & $\mathrm{R} \$ 37.336 .053,65$ milhões de reais \\
\hline \multirow{2}{*}{$\begin{array}{l}\text { Intervalo de } \\
\text { duração }\end{array}$} & $\begin{array}{l}\text { Maior concentração do total de projetos } \\
(60 \%) \text { para os intervalos } \leq 12 \text { meses }\end{array}$ & $\begin{array}{l}\text { Maior concentração do total de } \\
\text { contratos }(63 \%) \text { para os intervalos } \leq 12 \\
\text { meses }\end{array}$ \\
\hline & $\begin{array}{l}\text { Maior concentração do volume de recursos } \\
(47 \%) \text { para projetos contínuos }\end{array}$ & $\begin{array}{l}\text { Maior concentração do volume de } \\
\text { recursos }(57 \%) \text { para intervalos } \geq 36 \\
\text { meses }\end{array}$ \\
\hline \multirow[b]{2}{*}{ Tipo de atividade } & $\begin{array}{l}\text { Cursos (223 projetos), seguindo por } \\
\text { Consultoria/Assessoria (122 projetos) e } \\
\text { Eventos ( } 97 \text { projetos) }\end{array}$ & $\begin{array}{l}\text { P\&D (107 contratos), seguindo por } \\
\text { Prestação de Serviços, Assessoria e } \\
\text { Pesquisa }\end{array}$ \\
\hline & $\begin{array}{l}\text { Pesquisa ( } \mathrm{R} \$ 16,485.078,43 \text { milhões de } \\
\text { reais), seguindo por Pesquisa e } \\
\text { Desenvolvimento (P\&D) (11. 202.727,50 } \\
\text { milhões de reais), Cursos (10.693.010,81 } \\
\text { milhões de reais) }\end{array}$ & $\begin{array}{l}\text { Pesquisa (R\$ } 13,7 \text { milhões), seguindo } \\
\text { por P\&D, Assessoria e Prestação de } \\
\text { Serviço }\end{array}$ \\
\hline $\begin{array}{l}\text { Área de } \\
\text { conhecimento: } \\
\text { Centro Científico }\end{array}$ & $\begin{array}{l}\text { Centro de Ciências Exatas e de Tecnologia } \\
\text { (CCET) ( } 315 \text { projetos e R } \$ 24.618 .459,22 \\
\text { milhões de reais), seguido pelo CCBS ( } 86 \\
\text { projetos e 5.595.730,99 milhões de reais); } \\
1.165,45 \text { milhões de reais }\end{array}$ & $\begin{array}{l}\text { Centro de Ciências Exatas e de } \\
\text { Tecnologia (CCET) (369 contratos e } \\
\text { R\$ 21,4 milhões) }\end{array}$ \\
\hline \multirow{2}{*}{$\begin{array}{l}\text { Área de } \\
\text { conhecimento: } \\
\text { Departamento }\end{array}$} & $\begin{array}{l}\text { Departamento de Engenharia Civil } \\
\text { (DECiv) ( } 87 \text { projetos), seguido pelo de } \\
\text { Engenharia de Materiais (DEMa) (50 } \\
\text { projetos) e Engenharia de Produção (DEP) } \\
\text { (56 projetos) }\end{array}$ & $\begin{array}{l}\text { Engenharia de Produção (DEP) }(104 \\
\text { projetos), Biotecnologia Vegetal }(102 \\
\text { projetos) }\end{array}$ \\
\hline & $\begin{array}{l}\text { Departamento de Engenharia de Materiais } \\
\text { (DEMa) (6.8 milhões de reais), seguido } \\
\text { pelo Departamento de Engenharia de } \\
\text { Produção (DEP) ( } 5.6 \text { milhões de reais) e } \\
\text { pelo Departamento de Engenharia Química } \\
\text { (DQ) (5 milhões de reais) }\end{array}$ & $\begin{array}{l}\text { Engenharia de Materiais (DEMa) }(\mathrm{R} \$ \\
7,7 \text { milhões e Biotecnologia Vegetal } \\
(\mathrm{DBV})(\mathrm{R} \$ 5,5 \text { milhões })\end{array}$ \\
\hline \multirow[t]{2}{*}{ Tipo de financiador } & $\begin{array}{l}\text { Empresa privada (168 projetos), seguido } \\
\text { por Universidades e Institutos de Pesquisa } \\
\text { (158 projetos) }\end{array}$ & $\begin{array}{l}\text { Empresa privada (242 contratos), } \\
\text { seguida por Universidades e Institutos } \\
\text { de Pesquisa e Agência de } \\
\text { Financiamento }\end{array}$ \\
\hline & $\begin{array}{l}\text { Agência de Financiamento (14.402.619,43 } \\
\text { milhões de reais), seguido por empresas } \\
\text { privadas (11.191.992,05 milhões de reais) }\end{array}$ & $\begin{array}{l}\text { Agência de Financiamentos (R\$ } 15 \\
\text { milhões), seguido por Empresa Privada }\end{array}$ \\
\hline $\begin{array}{l}\text { Localidade do } \\
\text { financiador }\end{array}$ & $\begin{array}{l}\text { Concentração na Região Sudeste (560 } \\
\text { projetos) } \\
\text { Estado: São Paulo ( } 432 \text { projetos) } \\
\text { Município: São Carlos (193 projetos) }\end{array}$ & $\begin{array}{l}\text { Concentração na Região Sudeste - São } \\
\text { Paulo ( } 450 \text { contratos) }\end{array}$ \\
\hline
\end{tabular}

Fonte: Elaborado pela autora a partir dos dados de Oliveira (2002) e dos dados fornecidos pela FAI, entre 20082012. 
O resultado da pesquisa referente à análise comparativa da cooperação da UFSCar com o meio externo demonstrou certas particularidade na relação universidade-empresa. Observou-se ao longo do estudo que a cooperação da UFSCar com o meio externo caracterizam-se, na grande maioria, por baixos intervalos de duração ( $\leq 12$ meses). No entanto, quando se transferiu a análise para o volume de recursos financeiros dos projetos, atualmente, o volume de recursos para projetos estabelecidos por até 24 meses supera $52 \%$ do total, sendo que cerca de $30 \%$ do total advêm de projetos estabelecidos por intervalos maiores que 36 meses.

Além disso, os projetos de cooperação da UFSCar com o meio externo são executados na grande maioria pelos Departamentos pertencentes ao Centro Científico de Ciências Exatas e da Terra, apresentando divergências somente em relação os departamentos que se destacam em relação ao número de projetos estabelecidos, pois quando a análise foi transferia para o volume de recursos o departamento que concentra os recursos financeiros provenientes dos projetos de cooperação é o Departamento de Engenharia de Materiais.

No que concerne à natureza dos projetos, destacou-se o grupo composto pelas atividades de Pesquisa, Pesquisa e Desenvolvimento, Prestação de Serviços/Assessoria, tanto para o número de projetos quanto para o volume de recursos. Os resultados demonstram ainda que os principais tipos de financiadores continuam sendo a Empresa Privada, em número de projetos e as Agências de Financiamento Governamentais, em volume de recursos.

Neste contexto, é possível constatar que a maior parte das pesquisas acadêmicas depende substancialmente de recursos governamentais. Embora se reconheça a relativa importância da empresa privada como financiador da pesquisa acadêmica, a discussão sobre a fragilidade das propostas de substituição de recursos públicos para a pesquisa acadêmica frequentemente está fundamentada em informações sobre o poder de financiamento do estado. A UFSCar também encontra no estado (agências de financiamento, administração pública e empresas estatais) a maior fonte de recursos para suas pesquisas, com cerca de $88 \%$ do volume total de recursos para o período estudado.

Por fim, é importante mencionar as características da cooperação da UFSCar com os parceiros locais, pois ficou evidente a participação do tipo de financiador identificado como Pessoa Física, cuja principal atividade refere-se à participação em reuniões científicas e tecnológicas, cursos e outros eventos ligados às atividades de difusão de conhecimento. Esse resultado valoriza a imagem de São Carlos como Polo Tecnológico e sugere a possibilidade de realização de projetos cooperativos entre as universidades e a administração pública municipal, no sentido de promover a consolidação da infraestrutura de Ciência e Tecnologia. 


\subsection{Considerações Finais}

Os resultados obtidos foram analisados sob a ótica do referencial teórico e do paradigma brasileiro. Ao trabalharem juntas, empresa e universidade podem executar seus modelos de negócios e contribuírem mutuamente com suas competências e agregarem valor aos produtos levados ao mercado. A literatura sugere que uma estreita cooperação entre universidade e empresas é uma dimensão importante na construção de um sistema de inovação eficiente.

Neste contexto, no Brasil, mesmo o país sendo caracterizado com um país de Sistema Nacional de Inovação Imaturo, situando-se em uma posição intermediária entre os países desenvolvidos e alguns países em desenvolvimento (SIEGEL; WALDMAN; LINK, 2003B; RAPINI, 2009; SUZIGAN; ALBUQUERQUE, 2011 ), as universidades têm desempenhado um importante papel para o desenvolvimento tecnológico de empresa.

Deste modo, a dimensão dos resultados alcançados para o período estudado (20082012), com mais de 610 projetos e volume global de recursos gerenciados que supera 50 milhões de reais, denotando-se o potencial de cooperação universidade e meio externo, em especial a cooperação da Universidade Federal de São Carlos e permitiu notar que a universidade em estudo tem demonstrado, com crescente importância, que compreende e desempenha o seu papel de desenvolvimento econômico e social como sugerido por ETZKOWITZ (2009).

Além disso, os resultados obtidos colaboraram para contrariar a visão de que as universidades brasileiras são apenas formadoras de recursos humanos - na verdade, elas são também formadoras de recursos técnicos fundamentais para a inovação das empresas do país. Entretanto, percebeu-se que esse processo ainda não está maduro, devido ao baixo número de projetos de pesquisa com empresas privadas.

A principal contribuição desta pesquisa foi a possibilidade de mostrar que, como em outros países e universidades, a cooperação universidade e empresa vem ocorrendo há muitos anos na UFSCar, mesmo recebendo escassos incentivos da universidade, contando principalmente com o espírito empreendedor de alguns pesquisadores e apoio de algumas entidades.

A atividade de transferência de tecnologias universitárias é um processo dinâmico que requer comprometimento da universidade e das empresas em ações de superação das barreiras para levar a tecnologia à sociedade. Como responsabilidades das universidades, estas ações englobam investir na estrutura e profissionalização de departamentos que façam a interface 
com o mercado, buscando a convergência dos interesses da academia com os do mercado. Em relação às empresas interessadas em receber as tecnologias universitárias é preciso que se empenhem em estruturar áreas de P\&D internas, de modo a ampliar sua capacidade de criação e de absorção de novas tecnologias.

Por fim, se o Brasil inserir-se entre os países produtores de tecnologia, este futuro depende da habilidade de diversos atores em comprometer-se com a inovação, entre eles a universidade e o setor empresarial.

\subsection{Limitações da Pesquisa}

O principal obstáculo encontrado durante a realização da presente pesquisa refere-se ao procedimento de coleta de dados, caracterizado pela excessiva quantidade de dados e detalhes de cada projeto e pelo tempo necessário para a execução dessa coleta. O tempo gasto durante o processo de coleta de dados está intimamente relacionado à delimitação do período estudado e ao número de projetos disponíveis para a análise.

Além da etapa de coleta, a fase de compilação das informações e a de elaboração dos resultados também consumiram um tempo significativo por envolver análises relativamente complexas, como o cruzamento de até três variáveis. Outra complicação foi o número de variáveis para cada uma das modalidades de financiamento. $\mathrm{Na}$ fase de compilação e elaboração dos resultados houve consumo de um tempo significativo, por envolver análises relativamente complexas.

\subsection{Sugestões para Novos Estudos}

As sugestões elaboradas neste tópico seguem uma lógica de ampliação do ambiente estudado, das lacunas ainda existentes no que se refere à cooperação universidade-empresa.

A primeira lacuna é reconhecer que o fato desta pesquisa ter sido baseada exclusivamente em um objeto impessoal (projetos) não possibilitou avaliar outros aspectos envolvidos na cooperação universidade-empresa. Desta forma, sugere-se como continuidade desse trabalho, juntamente com uma revisão sistemática da literatura, a realização de uma pesquisa qualitativa que aborde o pesquisador da UFSCar a respeito dos seus projetos de cooperação com empresas. Outra indicação é desenvolver a pesquisa com as empresas privadas que possuem parceria com a universidade. 
Por fim, de forma complementar a ideia elaborada acima, sugere-se a realização de estudos com enfoque em outro agente do binômio da cooperação universidade-empresa. As empresas, em particular aquelas localizadas no polo de alta tecnologia de São Carlos, podem vir a ser objetos de estudos sobre o papel que pretendem desempenhar nos processos de cooperação com as universidade e centros de pesquisa locais. 


\section{Referências Bibliográficas}

ABREU, A. Esforço para inovação tecnológica: uma caracterização da indústria de alimentos do município de Marília/SP. 2007. 189 p. Dissertação de mestrado - Departamento de Engenharia de Produção - Universidade Federal de São Carlos, São Carlos, 2007.

ARVANTITIS, S.; SYDOW, N.; WOERTER, M. Is there any impact university-industry knowledy transfer on innovation an productivity? An empirical Analysis based on swiss firm data. Review of industrial organization, v. 32, n. 2, p. 77-94, 2008.

ARZA, V. Channels, benefits and risks of public-private interactions for knowledge transfer: a conceptual framework inspired by Latin America. Science and Public Policy, v. 37, n. 7, p. 473-484, 2010.

ARAUJO, S. V.; TEIXEIRA, F. L. C. Parcerias em projetos de P\&D: uma relação entre requisitos e fases de cooperação. Revista de Administração e Inovação, v. 7, n. 1, p. 84-108, 2010 .

ALBUQUERQUE, E. M.; SILVA, L. A.; PÓVOA, L. Diferenciação intersetorial na interação entre empresas e universidades no Brasil. São Paulo em Perspectiva, v. 19, n. 1, p. 95104,2005 .

ALBUQUERQUE, E.et al. An investigation on the contribution of universities and research institutes for maturing the Brazilian innovation system: preliminary results. In: Paper presented at the Globelics Conference, Mexico City, 2008.

AMARATUNGA, G. et al. Quantitative and qualitative research in the built environment: application of "mixed" research approach. Work Study, v.51, n1, p.17-31, 2002.

ANTOLIN, M. N. Proposicionebasicas para elstudiodel processo de innovactiontecnologicaenla empresa. In: XXI Simpósio de Gestão da Inovação Tecnológica, Salvador, Bahia, novembro, 2002.

AUDRETSCH, D. B.; STEPHAN, P. E. Knowledge spillovers in biotechnology: sources and Incentives. Journal of Evolutionary Economics, vol. 19, n. 1, p. 97-107, 1999.

AGÊNCIA DE INOVAÇÃO. UFSCAR. Propriedade Intelectual. 2013. Disponível em: < http://www.fai.ufscar.br>. Acesso em: 15 out. 2013.

AGRAWAL, A. Henderson, R. Putting patents in context: exploiting knowledge transfer from MIT. Management Science, n. 48, v. 1, p. 44-60, 2002.

BALCONI, M., LABORANTI, A. University-Industry Interactions in Applied Research: The Case of Microelectronics. Research Policy, v.35, n.10, p.1616-1630, 2006. 
BERTO, R. M. V. S.; NAKANO, D. M. A produção científica nos anais do encontro Nacional de Engenharia de Produção: um levantamento de métodos e tipos de pesquisa. Produção, v.9, n.2, p. 65-76, 2000.

BEKKERS, R., FREITAS, I. M. B. Analysing knowledge transfer channels between universities and industry: To what degree do sectors also matter? Research Policy, n.37, p.1837-1853, 2008.

BERCOVITZ, J. et al. Organizational structure as determinants of academic patent and licensing behavior: an exploratory study of Duke, Johns Hopkins, and Pennsylvania State Universities. Journal of Technology Transfer, v. 26, p. 21-35, 2001.

BELKHODJA, O.; LANDRY, R. "The Triple-Helix collaboration: Why do researchers collaborate with industry and the government? What are the factors that influence the perceived barriers?. Scientometrics, v. 70, n. 2, p. 301-332, 2007.

BISHOP, K.; D’ESTE, P.; NEELY, A. Gaining from interactions with universities: multiple methods for nurturing absorptive capacity. Research Policy, v. 40, p.30-40, 2011.

BRUNEEL, J.; D'ESTE, P.; SALTER, A. Investigating the factors that diminish the barriers to university-industry collaboration. Research Policy, v. 39, n. 1, p. 858-868, 2010.

BRYMAN, A. Research methods and organization studies. London: Unwin, 1989.

BRYMAN, Alan. Quantity and quality in social research. London and New York: Routledge, 1992. 198 p. Disponível em: <http://books.google.com/books?hl=pt-

$\mathrm{BR} \& \mathrm{lr}=\& \mathrm{id}=7 \mathrm{pyt} 0 \mathrm{yqQAcQC} \& \mathrm{i}=$ fnd $\& \mathrm{pg}=\mathrm{PA} 1 \& \mathrm{dq}=$ quantity+research $\&$ ots $=49 \mathrm{RGCvWMt}$ O\&sig=BRxwE50wPhNFPS4GnEz6B3yIJTM>. Acesso em: 17 jul. 2013.

BOZEMAN, B. Technology transfer and public policy: a review of research and theory. ResearchPolicy, v. 5, n. 29,p. 627-655, 2000.

BUENO, A. Utilização dos mecanismos de apoio financeiro à inovação tecnológica por empresas de São Carlos - SP. 2011, p. 236. Dissertação de mestrado - Departamento de Engenharia de Produção - Universidade Federal de São Carlos, São Carlos, 2011.

BROWN, C. R. Economic theories of the entrepreneur: a systematic review of the literature. School of Management. Cranfield University, 2003.

CASSIOLATO, J. E.; LASTRES, H. Sistemas de inovação: políticas e perspectivas. Parcerias Estratégicas, Brasilia, n. 8, p. 237-255, 2000.

CARLSSON, B.; FRIDH, A.C. Technology transfer in United States universities. Journal Evolutionary Economics, v. 12-1, p. 199-232, 2002. 
CÁRIO, S. A. F. C.; LEMOS, D. C.; SIMONINI, A. Avaliação da interação universidadeempresa em Santa Catarina por intensidade tecnológica. Revista de Economia, v. 37, n. 4, p.239-278, 2011.

COSTA, L. B.; TORKOMIAN, A. L. V. Um estudo exploratório sobre um novo tipo de empreendimento: os Spin-off Acadêmicos. Revista de Administração Contemporânea, v. 12, n. 2, p. 395-427, 2008.

COHEN, W.; NELSON, R.; WALSH, J. Links and impacts: the influence of public research on industrial R\&D. Management Science, v. 48, n. 1, p. 1-23, 2002.

CODURAS, A. et al The Relationship Between University Support to Entrepreneurship with Entrepreneurial Activity in Spain: A Gem Data Based Analysis. International Advances in Economic Research, v. 14, n. 4, p. 395-406, 2008.

COSTA, L. B. Criação de empresas como mecanismo de cooperação universidadeempresa: os spin-offs acadêmicos. 2006. 127 f. Dissertação (Mestrado em Engenharia de Produção), Departamento de Engenharia de Produção, Universidade Federal de São Carlos. São Carlos. 2006.

CRESWELl, J. W. Projeto de Pesquisa: método qualitativo, quantitativo e misto. Trad. Luciana de Oliveira Rocha. 2. Ed. Porto Alegre: Artmed, 2007.

CHESBROUGH, H. Open Innovation: A New Paradigm for Understanding Industrial Innovation. Oxford: Oxford University Press, 2006.

DAN, C. M. Why Should University and Business Cooperate? A Discussion of Advantages and Disadvantages. International Journal of Economic Practices and Theories, v. 3, n. 1, p. 67-74, 2013.

DALMARCO, G.; ZAWISLAKA, P.; HULSINK, W. Knowledge flow on innovative sectors: How can university-industry relations in the Netherlands bring new outcomes to innovation in Brazil? In: 9th GLOBELICS International Conference, 2011, Buenos Aires. 9th GLOBELICS International Conference, 2011. v. 1. p. 1-20.

DENYER, D; TRANFIELD, D. Producing a systematic review. In BUCHANAN, D.A.; BRYMAN, A. (Ed.), The sage handbook of organizational research methods. London: Sage Publications, 2009, p. 671-689.

DOSI, G. Fontes, procedimentos e efeitos microeconômicos da inovação. Jornal da Literatura Econômica. Traduzido por José Ricardo Fucidji. v. 26, p.1126-1171, 1998 Tradução de: Journal of Economic Literature. 
D'ESTE, P. Entrepreneurship and innovation - organizations, institutions, systems and regions. Science and Technology Policy Research, 2008.

D'ESTE, P.; PATEL. P. University-industry linkages in the UK: What are the factors underlying the variety of interactions with industry? Research Policy, n. 36, p. 1295-1313, 2007

D'ESTE, P; PERKMANN, M. Why do academics engage with industry? The entrepreneurial university and individual motivations. Journal of Technology Transfer, v. 36, n. 3, p. 316$339,2010$.

DOSI, G. Technological paradigms and technological trajectories: a suggested interpretation of the determinants and directions of technical change. Research Policy, v. 11, n. 3, p. 147$162,1982$.

DOSI, G.; LLERENA, P.; LABINI, M. S. The relationships between Science, Technologies and their industrial exploitation: Na illustration through the mythe and realities of the socalled 'Europran Paradox'. Research Pollicy, v. 35, n. 10, p. 1450-1464, 2006.

DUTRÉNIT, G.; ARZA, V. Interactions between public research organizations and industry in Argentina. Science and Public Policy, v. 37, n. 7, p. 541-553, 2010.

OLAVE, M. E. L.; AMATO NETO, L. Redes de cooperação produtiva: uma estratégia de competitividade e sobrevivência para as pequenas e médias empresas. Gestão e Produção, v.8, n.3, p.289-303, 2001.

ELMUTI, D.; ABEBE, M.; NICOLOSI, M.An overview of strategic alliances between universities and corporations. The Journal of Workplace Learning, v. 17, n. 2, p. 115-129, 2005 .

ETZKOWITZ, H. Hélice Tríplice: universidade-empresa-governo: inovação em movimento. Porto Alegre: EdiPUCRS, 2009.

ETZKOWITZ, H. The evolution of the entrepreneurial university. International Journal Technology and Globalization, v.1, n.1, p. 64-77, 2004.

ETZKOWITZ, H.; LEYDESDORFF, L. The dynamics of innovation: from national systems and "mode 2" to a triple helix of university-industry-government relations. Research Policy, v.29, p.109-123, 2000.

ETZKOWITZ, H. Research groups as 'quase-firms': the invention of the entrepreneurial university. Research Policy, v. 32, p. 109-121, 2003. 
ETZKOWITZ, H.; STEVENS, A. J. Toward industrial policy: the university's role in government initiatives to assist small, innovative companies in the United States. In: ETZKOWITZ, H.; WEBSTER, A.; HEALEY, P. (Org.) Capitalizing knowledge: new intersections of industry and academia. Albany: State Univ. of New York, 1998.

ETZKOWITZ, H.; WEBSTER, A. Entrepreneurial science: the second academic revolution. In: ETZKOWITZ, H.; WEBSTER, A.; HEALEY, P. (Org.) Capitalizing knowledge: new intersections of industry and academia. Albany: State Univ. of New York, 1998.

ETZKOWITZ, H.; ZHOU, C. Introduction to special issue Building the entrepreneurial university: a global perspective. Science and Public Policy, v. 35, n. 9, p. 627-635, 2008.

ETZKOWITZ, H.; VIALE, R. Polyvalent knowledge and the Entrepreneurial University: a Third Academic Revolution? Published in Critical Sociology, v. 36, n. 4, p. 1-15, 2010.

FERNANDES, A.C.; CAMPELLO DE SOUZA, B., STAMFORD DA SILVA, A.; SUZIGAN, W., CHAVES, C.V.; ALBUQUERQUE, E. The importance of academy-industry interaction for the Brazilian immature innovation system: evidences from a comprehensive database. Science and Public Policy, n. 37, v. 7, p. 485-498, 2010.

Fundação de Apoio Institucional ao Desenvolvimento Científico e TecnológicoUFSCar.. FAI.UFSCar: histórico. 2012. Disponível em: <http://www.fai.ufscar.br>. Acesso em: 15 ago. 2013.

Fundação de Apoio Institucional ao Desenvolvimento Científico e Tecnológico. UFSCar. Documentos: relatórios anuais. 2011. Disponível em: <http://www.fai.ufscar.br>. Acesso em:15 out. 2012 .

FREEMAN, C. The economy of technical change. Cambridge Journal of Economics, v. 18, n. 5, p. 499-514, 1994.

FREEMAN, C. The national system of innovation in historical perspective. Cambridge Journal of Economics, v. 19, p.5-24, 1995.

FRANKO, L. G. Global Corporate competition: who's winning, wh's losing, and the R\&P factor as one reason whay. Strategic Management Journal, v.10, p. 449-474, 1989.

FUENTES, C.; DUTRÉNIT, G. Best channels of academia-industry interaction for long-term benefic. Research Policy, n. 4, p.1666- 1682, 2012.

FREITAS, I. M. B.; MARQUES, R. A. SILVA, E. M. P. University-Industry collaboration and the development of high-technology sectors in Brazil. Paper presented in the IV Globelics Conference at Mexico City, 2008. 
FONTANA, R., GEUNA, A., MATT, M. Factors affecting university-industry R\&D projects: The importance of searching, screening and signalling. Research Policy,v.35, n.2, p.309-323, 2006.

GIL, A. C. Como elaborar projetos de pesquisa. são Paulo , Atlas: 1998.

GUAN, J.; YAM, R.; MOK, C. Collaboration between industry and research institutes/universities on industrial innovation in Beijing, China. Technology Analysis \& Strategic Management, v. 17, n. 3, p. 339-353, 2005.

GARNICA, L. A. Transferência de tecnologia e gestão da propriedade intelectual em universidades públicas no Estado de São Paulo. 2007. 206 p. Dissertação (Mestrado) Universidade Federal de São Carlos - UFSCar, São Carlos, 2007.

GARNICA, L. A.; OLIVEIRA, R. M. de; TORKOMIAN, A. L. V. Propriedade intelectual e titularidade de patentes universitárias: um estudo piloto na Universidade Federal de São Carlos - UFSCar. In: XXIV Simpósio de Gestão de Inovação Tecnológica. Gramado, RS, 17 a 20 de out, 2006.

GUERRERO, M.; URBANO, D.The development of an entrepreneurial university. The Journal of Technology Transfer, v. 37, n. 1, p. 43-74, 2012.

GODOY, A. S. Introdução à Pesquisa Qualitativa e suas Possibilidades. São Paulo: Revista de Administração de Empresas, v. 35, n. 2, p. 57-63, 1995.

JAIN, S.; GEORGE, G. Technology transfer offices as institutional enterpreneurs: the case of Wisconsin Alumni Research Foundation and human embryonic stem cells. Industrial and Corporate Change, v. 6, n. 4, p. 535-567, 2007.

IPIRANGA, A. S. R.; FREITAS, A. A. F.; PAIVA, T. A. O empreendedorismo acadêmico no contexto da interação universidade - empresa - governo. Cadernos EBAPE BR, v. 8, n. 4, p 676-693, 2010.

KAYMAZ, K.; ERYIĞIT, K, Y. Determining Factors Hindering University-Industry Collaboration: An Analysis from the Perspective of Academicians in the Context of Entrepreneurial Science Paradigm. International Journal of Social Inquiry, v. 4, n. 1, p. 185-213, 2011.

LANGFORD, C.H. et al. Indicators and outcomes of Canadian university research: Proxies becoming goals? Research Policy v.35, n.10, p. 1586-1598, 2006

LAREDO, P., Revisiting the Third Mission of Universities: Toward a Renewed Categorization of University Activities? Higher Education Policy, v. 20, p. 441-456, 2007. 
LAKATOS, E. M.; MARCONI, M. A. Fundamentos de metodologia científica. 3. ed. São Paulo: Atlas, 2001.

LEE, Y. The sustainability of university-industry research collaboration: a empirical assessment. Journal of Technology Transfer, n. 25, p. 111-133, 2000.

LOCKETT, A. et al. The creation of spin-off firms at public research institutions: managerial and policy implications. Research Policy, v. 34, n. 7, p. 981- 993, 2005.

LOUIS, K. S. et al. Entrepreneurs in academe: an exploration of behaviours among life scientists. Administrative Science Quarterly, v. 34, p. 110-131. 1989.

LUNDBERG, H.; ANDRESEN, E. Cooperation among companies, universities and local government in a Swedish context. Industrial Marketing Management, n. 41, p. 429-439, 2012.

LEYDESDORFF, L.; MEYER, M. Triple Helix indicators of knowledge-based innovation systems Introduction to the special issue. Research Policy, v. 35, 2006.

LIPINSKI, J.; MINUTOLO, M. C.; CROTHERS, J. M. The complex relationship driving technology transferer: the potencial opportunities missed by universities. Institute of Behavioral and Applied Management, v. 9, n. 2, p. 112-133, 2008.

MARCONI, Marina de Andrade; LAKATOS, Eva Maria. Técnicas de pesquisa: planejamento e execução de pesquisas, amostragens e técnicas de pesquisas, elaboração, análise e interpretação de dados. 6 ed. São Paulo: Atlas, 2007.

MARTINS, R. A. Abordagens quantitativa e qualitativa. In: MIGUEL, Paulo A.M (org.). Metodologia de pesquisa em engenharia de produção e gestão de operações. Rio de Janeiro: Elsevier, 2010, p.45-61.

MARTINS, P. V. Percepção de docentes da UFSCar sobre sua agência de inovação. P. 181, 2010. Dissertação de Mestrado (Mestrado em Engenharia de Produção) - Departamento de Engenharia de Produção, Universidade Federal de São Carlos, 2010.

MAZZOLENI, R.; NELSON, R. The roles of research at universities and public labs in economic catch-up. Research Policy, v. 36, n. 10, p. 1512-1528, 2007.

MEYER, M. Academic entrepreneurs or entrepreneurial academics? Research-based ventures and public support mechanisms. R\&D Management, v. 33, n. 2, p. 107-115, 2003.

MIGUEL, P. A. C.; HO, L. L. Levantamento tipo survey. In: MIGUEL, Paulo A.M (org.). Metodologia de pesquisa em engenharia de produção e gestão de operações. Rio de Janeiro: Elsevier, 2010, p.73 - 99. 
MIGUEL, P. A. C. Adoção do estudo de caso na engenharia de produção. In: MIGUEL, Paulo A.M (org.). Metodologia de pesquisa em engenharia de produção e gestão de operações. Rio de Janeiro: Elsevier, 2010, p.129 - 143.

MOWERY, D. C. et al. The growth of patenting and licensing by U.S. universities: an assessment of the effects of the Bayh-Dole act of 1980, Research Policy, v. 30, p. 99-119, 2001.

MOWERY, D. C.; SAMPAT, B. N.; ZIEDONIS, A. A. Learning to Patent: Institutional Experience, Learning, and the Characteristics of U.S. University Patents After the Bayh-Dole Act, 1981-1992. Management Science, v. 48-1, p. 73-89, 2002.

MOWERY, D. C.; SAMPAT, B. Universities in National Innovation Systems. In: FAGERBERG, J.; MOWERY, D. C.; NELSON, R. R. (eds.). The Oxford Handbook of Innovation. New York: Oxford University Press, 2004, p. 209-236.

MORABITO, R.; PUREZA, V. Modelagem e simulação. In: MIGUEL, P. A.M (org.). Metodologia de pesquisa em engenharia de produção e gestão de operações. Rio de Janeiro: Elsevier, 2010, p.165-194.

NOVELI, M.; SEGATTO, A. P. Processo de cooperação universidade-empresa para a inovação tecnológica em um parque tecnológico: evidências empíricas e proposição de um modelo conceitual. Revista de Administração e Inovação, v. 9, n. 1, p.81-105. 2012.

NELSON, R. R.; WINTER, S. G. Uma teoria evolucionaria da mudança econômica. São Paulo:Editora. Unicamp, 2005.

NELSON, R.R. As Fontes do Crescimento Econômico. São Paulo:Editora. Unicamp, 2006.

NEMET, G. Demand-pull, technology-push, and government-led incentives for nonincremental technical change. Research Policy, v. 38, p. 700-709, 2009.

OCDE-MANUAL DE OLSO. Proposta de diretrizes para coleta e interpretação de dados sobre inovação tecnológica. Finep - traduçãoportuguês, 2005.

ØSTERGAARD, C.R. Knowledge flows through social networks in a cluster: Comparing university and industry links. Structural Change and Economic Dynamics. v.20, n.3, p.196210, 2009.

OLIVEIRA, R. M. A cooperação da universidade federal de São Carlos com a sociedade. p. 209. 2002. Dissertação de Mestrado (Mestrado em Engenharia de Produção) Departamento de Engenharia de Produção, Universidade Federal de São Carlo - UFSCar, 2002. 
PINHO, M. visão das empresas sobre as relações entre universidade e empresa no Brasil: uma análise baseada nas categorias de intensidade tecnológica. Revista de Economia, v. 37, n 4, p.279-305, 2011.

PINTEC - Pesquisa industrial de inovação tecnológica. Instituto Brasileiro de Geografia e Estatística (IBGE). Dados regionais. 2006 e 2008. Rio de Janeiro, 2013.

PERKMANN, M.; WALSH, K. The two faces of collaboration: impacts of universityindustry relations on public research. Industrial and Corporate Change, n. 18, v. 6, p. 1033-1065, 2009.

PÓVOA, L. M. C.; RAPINI, M. S. Technology transfer from universities and public research institutes to firms in Brazil: what is transferred and how the transfer is carried out. Science and Public Policy, v. 2 , n. 37, p. 147-159, 2010.

PÓVOA, L. M. Patentes de universidades e institutos públicos de pesquisa e a transferência de tecnologia para empresas no Brasil. p. 153, 2008. Tese de Doutorado (Doutorado em Economia) - Universidade Federal de Minas Gerais, 2008.

PORTER, M. E. What is strategy? Harvard Business Review, p. 61, 1996

RAPINI, M. S. Interação Universidade-Empresa no Brasil: evidencias do Diretório dos Grupos de Pesquisa do CNPq. Estudos Econômicos, v. 37, n. 1, p. 211-233, 2007.

PORTO, G. S. A decisão a cooperação universidade-empresa sob a ótica dos lideres dos grupos de pesquisa da USP cadastrados no diretório de pesquisa CNPp. p. 187. 2006. Tese de doutorado (Doutorado em Administração) - departamento de Adminstração. Universidade de São Paulo - SUP, 2006.

PORTO, G. S; JÚNIOR, S. K; SELAN, B; BARONI, J. P. T. Rede de interações universidade-empresa no Brasil: uma análise de redes sociais. Revista de Economia, v. 37, n. 4, p.49-81, 2011.

PLONSKI, G. A. Cooperação empresa-universidade: antigos dilemas, novos desafios. Revista USP: Dossiê Universidade-empresa, v. 25, p. 32-41, 1995.

RENAULT, C. S. Academic Capitalism and University Incentives for Faculty Entrepreneurship. Journal of Technology Transfer, v. 31, p. 227-239, 2006.

RIGHI, H. M.; CRUZ, W. M. S. University industry interactions in an immature system of innovation: evidence from Minas Gerais, Brazil. Science and Public Policy, v. 36, n.5, p.373-386, 2009. 
RODRIGUES, H. G.; LACERDA, L. P. A Relação Universidade-Empresa no Contexto do Sistema Local de Inovação de Uberlândia. In: XXX Encontro Nacional de Engenharia de Produção (ENEGEP), 2010, Salvador, 2010.

ROGERS, E. M.; TAKEGAMI, S.; YIN, J. Lessons learned about technology transfer. Technovation, v. 21, p. 253-261, 2001.

ROHRBECK, R.; ARNOLD, H. M. Making university-industry collaboration work - a case study on the Deutsche Telekom Laboratories contrasted with findings in literature. ISPIM Annual Conference: "Networks for Innovation", 2006.

SALOMON, D. V. Como fazer monografia. 9 ed. São Paulo: Martins Fontes, 1999.

SANTORO, M. Success breeds success: the linkage between relationship intensity and tangible outcomes in industry-university collaborative ventures. The Journal of High Technology Management Research, v. 11, n. 2, p. 255-273, 2000.

SEGATTO-MENDES, A. P.; SBRAGIA, R. O Processo de cooperação universidade-empresa em universidades brasileiras. Revista de Administração da USP (RAUSP), v. 37, n. 4, p. 58$71,2002$.

SEPPO, M.; ROOLAHT, T.The Policy Suggestions Concerning Motivations and Barriers of University-Industry Cooperation. Discussions on Estonian Economic Policy: Theory and Practice of Economic Policy, v. 20, n. 1, p 226-246, 2012.

SCHARTINGER, D. et al. Knowledge interactions between universities and industry in Austria: sectoral patterns and determinants. Research Policy, n.31, p.303-328, 2002.

SIEGEL, D. S.; VEUGELERS, R.; WRIGH, M. Technology transfer offices and commercialization of university intellectual property: performance and policy implications. Oxford Review of Economic Policy, v. 23, p. 640-660, 2007.

SIEGEL, D. S. et al. Commercial knowledge transfer from universities to firms: imporging the effectiveness of university-industry collaboration. Jornal of High Tecnology Management Research, v. 14, p. 111-133, 2003a.

SIEGEL, D. S, WALDMAN, D., LINK, A. Assessing the impact of organizational practices on the relative productivity of university technology transfer offices: an exploratory study. Research Policy, n.32, p.27-48, $2003 b$.

SUZIGAN, W; ALBUQUERQUE, E. M. A interação entre universidades e empresas em perspectiva histórica no Brasil. In: SUZIGAN, W.; ALBUQUERQUE, E. M.; CÁRIO, S.. (Org.). Em busca da inovação: Interações de universidades e institutos de pesquisa com empresas no Brasil. 1ed. Belo Horizonte: Editora Autentica, 2011, v. 1, p. 1-28. 
SUTZ, J. The university-industry-government relations in Latin America, Research Policy, v. 29, p. 279-290, 2000.

STOKES, Donald E. O quadrante de Pasteur: a ciência básica e a inovação tecnológica. Tradutor: José Emilio Maiorino. Campinas: Editora Unicamp, 2005.

SCHUMPETER, J. A. A teoria do desenvolvimento econômico. 3 ed. São Paulo: Nova Cultural, 1988.

SBICCA, A.; PELAEZ, V. Sistemas de inovação. In: PELAEZ, V.; SZMRECSÁNYI, T. Economia da inovação tecnológica. São Paulo: Hucitec, 2006, p. 415-448.

SÁBATO, J.; BONATA, N. La ciencia e latecnologíaeneldesarrollo futuro de América Latina. Revista Integración latino-americana, n.3, p. 15-36, 1968.

TAFNER, M. A.; TAFNER, J.; FISCHER,J. Metodologia do trabalho acadêmico. Curitiba: Juruá, 1999

TERRA, B. A transferência de tecnologia em universidades empreendedoras: um caminho para a inovação tecnológica. Rio de Janeiro: Qualitymark, 2001.

TETHER, B.S., TAJAR, A. Beyond industry-university links: Sourcing knowledge fo innovation from consultants, private research organisations and the public science-base. Research Policy, v.37, n.6-7, p.1079-1095, 2008.

TURRIONI, J. B.; MELlO, C. H. P. Pesquisa-ação em engenharia de produção. In: MIGUEL, Paulo A.M (org.). Metodologia de pesquisa em engenharia de produção e gestão de operações. Rio de Janeiro: Elsevier, 2010, p.145-163.

THURSBY, J.; THURSBT, M. Who is selling the ivory tower? Sources of growth in university licensing. Management Science, v. 48, n.1, p. 90-104, 2002.

TRANFIELD, D.; DENYER, D.; SMART, P. Towards a methodology for developing evidence-informed management knowledge by means of systematic review. British Journal of Management, v. 14, 2003.

TRANFIELD, D.; DENYER, D.; MARCOS, J.; BURR, M. Co-producing management knowledge. Management Decision, v. 42, n. 3/4, 2004.

UNIVERSIDADE FEDERAL DE SÃO CARLOS. Centros Acadêmicos. 2012. Disponível em: <http://www2.ufscar.br/vidaacademica/centrosacademicos.php>. Acesso em: 15 out. 2013. 
UNIVERSIDADE FEDERAL DE SÃO CARLOS. A UFSCar- história. 2013a. Disponível em: < http://www2.ufscar.br/home/index.php\#>. Acesso em: 15 out. 2013.

UNIVERSIDADE FEDERAL DE SÃO CARLOS. Centros Acadêmicos. 2013b. Disponível em: <http://www2.ufscar.br/vidaacademica/departamentos.php>. Acesso em 15 out. 2013.

UNIVERSIDADE FEDERAL DE SÃO CARLOS. Portaria nº 664/99, de 06 de abril de 1999. Proex Pró-Reitoria de Extensão, São Carlos, 1999.

VEDPURISWAR, A. V. Business Innovation. In: Managing process innovations. The practice of innovation. ICFAI University Presse: September 2003, v. 2, p. 71-79. (Management Series). Disponível em: < http://www.vedpuriswar.org/>. Acesso em: 20 fev. 2013

VOSS, C.; TSIKRIKTSIS, N.; FROHLICH, M. Case research in operations management. International Journal of Operations and Production Management, v.22, n.2, p.195-219, 2002 .

WEBSTER, A. J.; ETZKOWITZ H. Academic-Industry relations: the second academic revolution? London: Science Policy Support Group, 1991.

WRIGHT, M.et al. Mid-range universities linkages with industry: knowledge types and the role of intermediaries. Research Policy, v. 8, n. 37, p. 1205-1223, 2008.

WIDIAWAN, K. Identifying the Most Suitable University-Industry Partnership Model in Developing Countries. The 4th IEEE International Conference on Management of Innovation and Technology (ICMIT) Proceedings, p. 128-133, 2008.

WANG, Y.; LU, L. Knowledge transfer through effective university-industry interactions: Empirical experiences from China. Journal of Technology Management, v. 2, n. 2, p. 119133, 2007.

YIN, R. K. Estudo de caso: planejamento e métodos. 2.ed. Porto Alegre: Bookman, 2001.

YIN, R. K.; Estudo de Casos. 3 ed. Porto Alegre: Bookman, 2005

ZAWISLAK, P. A.; DALMARCO, G. The silente run: New inssues and outcomes for university-industry relations in Brazil. Jornal of Techonology Management and Innovation, v. 6, n. 2, p. 66-82, 2011. 


\section{ANEXO A \\ Descrição do Procedimento Utilizado para a Realização da Revisão Sistemática da Literatura}

O objetivo da revisão da literatura é permitir ao pesquisador mapear e analisar o território intelectual existente sobre determinado tema e especificar a questão de pesquisa para desenvolver mais profundamente um campo do conhecimento.

Uma alternativa para a revisão da literatura é a sua revisão sistemática (TRANFIELD, DENYER, SMART, 2003). A revisão sistemática é um método que utiliza como fonte de dados a literatura sobre determinado tema, seleciona e avalia contribuições, analisa e sintetiza dados. A revisão sistemática descreve as evidências de forma a permitir que sejam tiradas conclusões claras sobre o que já se conhece e o que não se conhece sobre o assunto em questão (DENYER; TRANFIELD, 2009) e permite identificar e apresentar de forma sintética o conhecimento relevante sobre o determinado tópico, realçando os temas estudados e ajudando a posicionar estudos futuros.

Segundo Denyer e Tranfield (2009) esse tipo de revisão possui princípios como transparência, inclusividade, explanatoriedade e natureza heurística, que permitem uma visão geral mais objetiva acerca do tema estudado, sendo ainda uma forma de superar possíveis vieses associados às revisões tradicionais.

Neste sentido, a partir da divisão proposta por Tranfield, Denyer e Smart (2003) e Tranfield et al. (2004), a primeira etapa do desenvolvimento deste trabalho foi a revisão sistemática da literatura centrada, especificamente, nas questões relacionadas à inovação tecnológica e à cooperação universidade-empresa. Assim, esta revisão sistemática está dividida em três estágios: planejamento da revisão, condução da revisão e apresentação dos resultados, conforme Quadro 18.

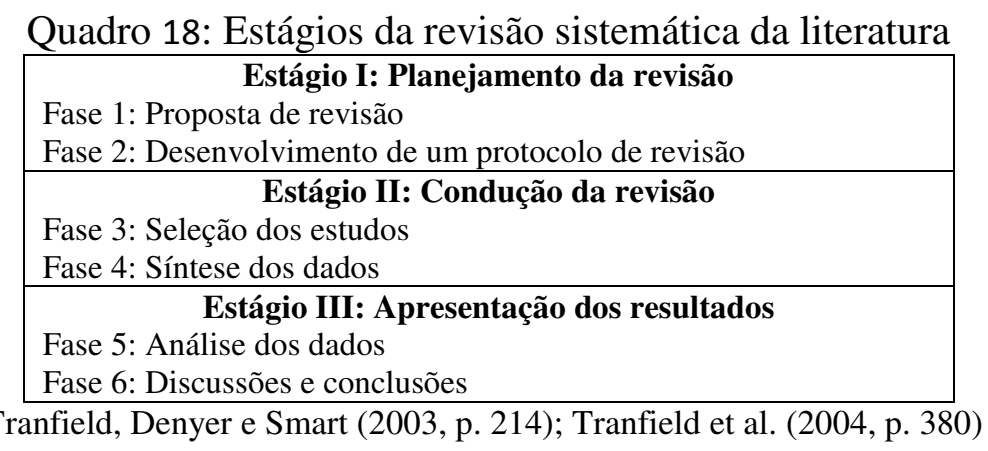


A seguir são descritos os estágios da revisão sistemática da literatura realizada.

\section{Estágio I: Planejamento da revisão}

A proposta desta revisão é identificar os conceitos da cooperação universidadeempresa sob a perspectiva da sua importância para o desenvolvimento econômico da sociedade.

Sendo assim, de forma a responder a proposta da revisão da literatura, este estudo procurou trabalhar com a interseção de três literaturas distintas, que são descritas a seguir e apresentadas na Figura 9:

$\checkmark$ Inovação tecnológica, considerando aspectos conceituais de inovação e de cooperação universidade-empresa;

$\checkmark$ Cooperação universidade-empresa-governo, destacando-se as relações estabelecidas entre essas três esferas;

$\checkmark$ Benefícios, entraves e condicionantes da relação universidade-empresa.

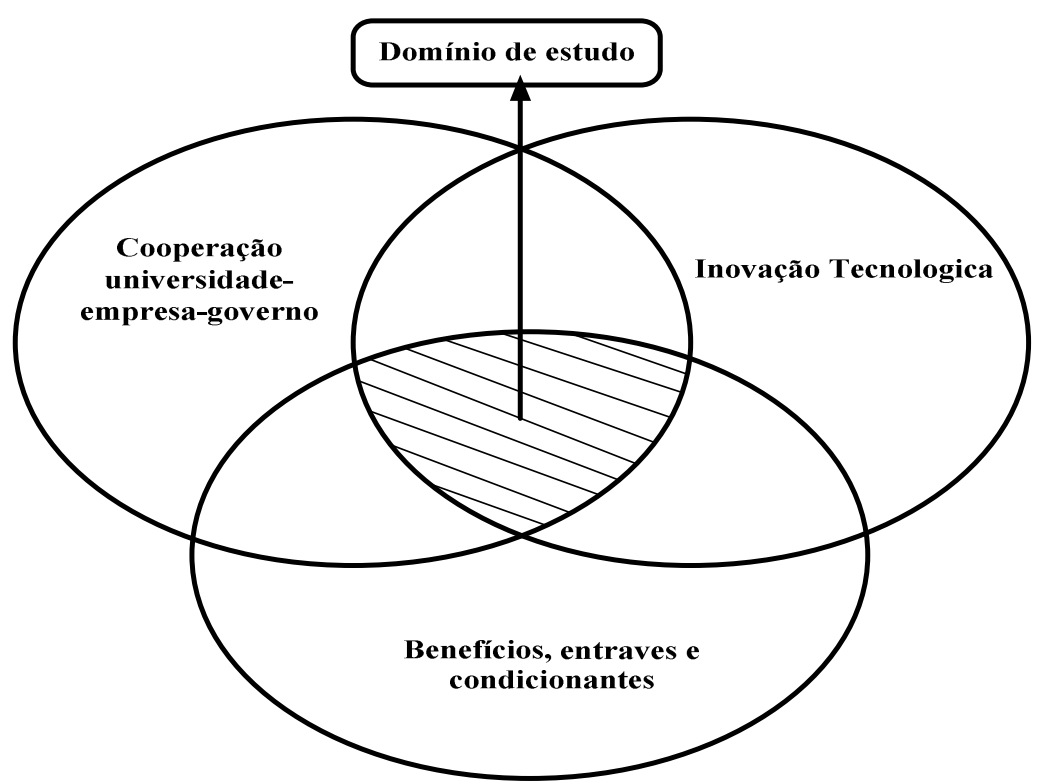

Figura 18: Domínios da literatura envolvidos na revisão Fonte: Elaborado pela autora

Posteriormente, foi elaborado um protocolo de pesquisa contendo como os estudos seriam encontrados:

$\checkmark$ Acesso aos artigos e livros sobre "inovação tecnológica", a fim de trazer o entendimento sobre o conceito de inovação tecnológica de forma mais ampla, para dar 
suporte ao leitor sobre o tema central deste trabalho, a saber, a cooperação universidade-empresa;

$\checkmark$ Acesso aos artigos e capítulos de livros referentes "a cooperação universidadeempresa";

$\checkmark$ Acesso às bases de dados: Scopus da editora Elsevier e Web of Science da Thomson Reuters. O Web of Science é uma base de dados de textos científicos completos provenientes de livros e periódicos, também conta com anais de congressos, simpósios e conferências. Por sua vez, o Scopus é ainda mais abrangente, incluindo em suas buscas resumos, citações e fontes da web;

$\checkmark$ Acesso às bibliotecas digitais de Teses e Dissertações;

$\checkmark$ Acesso aos principais periódicos nacionais nas áreas de Administração e de Engenharia de Produção;

$\checkmark$ Acesso aos anais dos principais eventos e simpósios nas áreas de Administração e de Engenharia de Produção.

Sendo assim, para a consulta na base de dados Scopus e Web of Science, nos periódicos nacionais e anais dos principais eventos e simpósios nas áreas de Administração e de Engenharia de Produção, foram utilizados os termos descritos no Quadro 19 a seguir.

Quadro 9: Termos utilizados na busca

\begin{tabular}{|c|c|c|}
\hline Bases de dados & Buscas & Termos utilizados \\
\hline $\begin{array}{l}\text { Scopus e } \\
\text { Web of Science }\end{array}$ & $\begin{array}{l}1 \\
2 \\
3 \\
4 \\
5\end{array}$ & 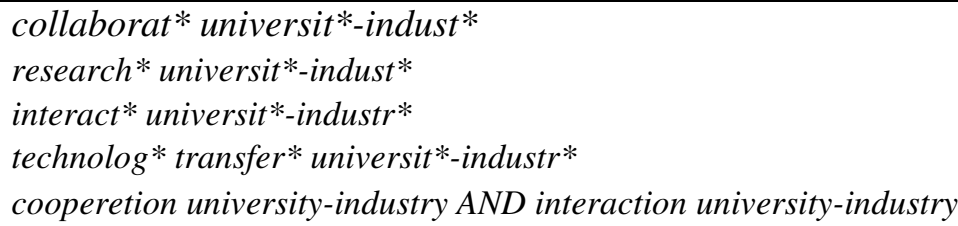 \\
\hline $\begin{array}{l}\text { Periódicos nacionais e } \\
\text { anais dos principais } \\
\text { eventos e simpósios }\end{array}$ & $\begin{array}{l}1 \\
2 \\
3 \\
4\end{array}$ & $\begin{array}{l}\text { Interação universidade-empresa } \\
\text { Cooperação universidade-empresa } \\
\text { Relação universidade-empresa } \\
\text { Cooperação tecnológica universidade-empresa }\end{array}$ \\
\hline
\end{tabular}

Fonte: Elaborado pela autora

\section{Estágio II: Condução da revisão}

A revisão da literatura iniciou-se pelo estudo do tema inovação tecnológica, acessando os livros nacionais e internacionais, como também artigos nacionais e internacionais sobre o tema. Entre os quais se destacam: Freeman (1994); Poter (1996); Franko (1989); Manual de Oslo da Organização para a Cooperação e o Desenvolvimento Econômico (OCDE, 2005); Schumpeter (1989); Rapini (2007); Suzigan; Albuquerque (2011). 
Durante a seleção dos estudos, foram avaliados os títulos e os resumos que contemplassem a conceituação da inovação tecnológica e a realização de inovação por meio da cooperação universidades-empresa. Após a conceituação de inovação tecnológica para dar suporte ao leitor sobre o tema cooperação universidade-empresa, foram excluídos os capítulos de livros, artigos, teses ou dissertações que não contemplavam a cooperação universidadeempresa.

As bases de dados eletrônicas Scopus da editora Elsevier e Web of Science da Thomson Reuters, disponíveis por meio do Portal de Periódicos da Capes foram consultadas retrospectivamente até o ano de 2013. Efetuou-se uma busca avançada utilizando os termos do Quadro 2, no título do artigo ou nas palavras-chave.

A amplitude dos termos de busca se deu para que fosse obtido o maior número possível de resultados que envolvessem a parceria universidade-empresa como um todo. Destaca-se o uso dos termos "collaborat*; research*; interact*; technolog * e transfer*", bem como dos termos "universit*-indust*", que é uma maneira de garantir que os resultados que possuam essa raiz de palavra sejam incorporados à pesquisa. Dessa forma, artigos que possuam palavras como, por exemplo, "collaborate", "collaboration", e suas variáveis foram incorporadas às buscas a partir do uso dessa expressão. O Quadro 20 mostra o número de artigos gerados na pesquisa por base de dados e por termo.

Quadro20: Número de artigos gerados na pesquisa por base de dados e por termo

\begin{tabular}{|c|c|c|}
\hline \multirow{2}{*}{ Termos utilizados nas buscas } & \multicolumn{2}{|c|}{ Número de artigos por base de dados } \\
\hline & Scopus & Web of Science \\
\hline collaborat $^{*}$ universit $^{*}$-indust ${ }^{*}$ & 574 & 139 \\
\hline interact $^{*}$ universit ${ }^{*}$-industr* & 309 & 50 \\
\hline technolog $*$ transfer $^{*}$ universit ${ }^{*}$-industr* & 343 & 28 \\
\hline $\begin{array}{l}\text { cooperetion university-industry AND } \\
\text { interaction university-industry }\end{array}$ & 26 & 103 \\
\hline Total & 1.252 & 320 \\
\hline
\end{tabular}

Fonte: Elaborado pela autora

Após realizar as buscas com as palavras-chave desejadas, foram encontrados 1.572 artigos somando as duas bases de dados pesquisadas. Todos os resumos foram lidos e os critérios de exclusão foram aplicados, como mostra o Quadro 21 referente ao protocolo utilizada na base Scopus. 
Quadro 21: Protocolo referente aos filtros aplicados na consulta à Scopus

\begin{tabular}{|c|c|c|c|}
\hline Filtros & Termos utilizados nas buscas & Saídas & $\begin{array}{l}\text { Saída } \\
\text { Total }\end{array}$ \\
\hline $\begin{array}{l}\text { Filtro I: apenas resultados das áreas: } \\
\text { Business, } \quad \text { Management } \quad \text { and } \\
\text { Acoounting; } \quad \text { Engineering; Social } \\
\text { Sciences; } \quad \text { Decision Sciences; } \\
\text { Economics, Ecnometrics and Finance. }\end{array}$ & $\begin{array}{l}\text { - collaborat* } \text { universit }^{*} \text {-indust* } \\
\text { - interact }{ }^{*} \text { universit*-industr* } \\
\text { - technolog* } \text { transfer }^{*} \text { universit*_ } \\
\text { industr* } \\
\text { - cooperetion university-industry AND } \\
\text { interaction university-industry }\end{array}$ & $\begin{array}{l}338 \\
212 \\
240 \\
21\end{array}$ & 611 \\
\hline $\begin{array}{l}\text { Filtro II: Leitura dos resumos e } \\
\text { seleção }\end{array}$ & $\begin{array}{l}\text { - collaborat* } \text { universit*-indust* }^{*} \\
\text { - interact* universit*-industr* } \\
\text { - technolog* } \text { transfer }^{*} \text { universit*- } \\
\text { industr* } \\
\text {-cooperetion university-industry AND } \\
\text { interaction university-industry }\end{array}$ & $\begin{array}{c}112 \\
91 \\
79 \\
15\end{array}$ & 297 \\
\hline $\begin{array}{l}\text { Filtro III: Desconsideração dos } \\
\text { resumos com texto não disponíveis }\end{array}$ & $\begin{array}{l}\text { - collaborat* } \text { universit }^{*} \text {-indust* } \\
\text { - interact* universit*-industr* } \\
\text { - technolog* } \text { transfer }^{*} \text { universit*- } \\
\text { industr }^{*} \\
\text { - cooperetion university-industry AND } \\
\text { interaction university-industry }\end{array}$ & $\begin{array}{c}102 \\
78 \\
14 \\
12\end{array}$ & 206 \\
\hline $\begin{array}{l}\text { Filtro IV: Exclusão de duplicação e de } \\
\text { texto não pertinentes a pesquisa }\end{array}$ & $\begin{array}{l}\text { - collaborat* } \text { universit }^{*} \text {-indust* } \\
\text { - interact }{ }^{*} \text { universit }{ }^{*} \text {-industr } * \\
\text { - technolog* } \text { transfer }^{*} \text { universit*_ } \\
\text { industr* } \\
\text {-cooperetion university-industry AND } \\
\text { interaction university-industry }\end{array}$ & $\begin{array}{l}27 \\
35 \\
11 \\
-\end{array}$ & 48 \\
\hline
\end{tabular}

Fonte: Elaborado pela autora

Sendo assim, a princípio, tem-se que as buscas 1, 2, 3 e 4 apresentaram 1.252 saídas (Quadro 3). A partir do refinamento dos resultados realizou-se a leitura dos 611 resumos obtidos para a devida avaliação da adequação do conteúdo à pesquisa, de forma que fossem selecionados apenas artigos pertinentes ao tema central deste trabalho. A partir dessa leitura, foram obtidos 297 resultados.

No entanto, foram considerados apenas os artigos disponíveis na íntegra pela base SCOPUS, tendo sido eliminados 91 resumos que não apresentavam o texto completo. Finalmente, algumas saídas se repetiram ao longo das buscas, sendo então retiradas as duplicações e textos que não eram pertinentes ao trabalho, chegando-se ao número final de 48 artigos que tratavam do conceito, e/ou das abordagens, e/ou dos entraves, benefícios e condicionantes da cooperação universidade-empresa.

Para a consulta à base Web of Science foram utilizados os mesmo termos apresentados no Quadro 2 na busca avançada da Base. Foram considerados esses termos para todos os campos, considerando-se apenas os artigos, e sem restrição quanto ao idioma e ano de publicação, resultando em um total de 320 artigos (Quadro 20). Destes foram selecionados somente 12 artigos para complementar a busca feita à base de dados Scopus. 
Dessa forma, a lista final, considerada após as consultas nas bases de dados constituise de 60 artigos, como mostra a Figura 10. Além disso, após a leitura dos artigos resultantes da base Scopus e Web of Science, foram adicionados 8 artigos à lista final, sendo eles encontrados na base de dados da Science Direct.

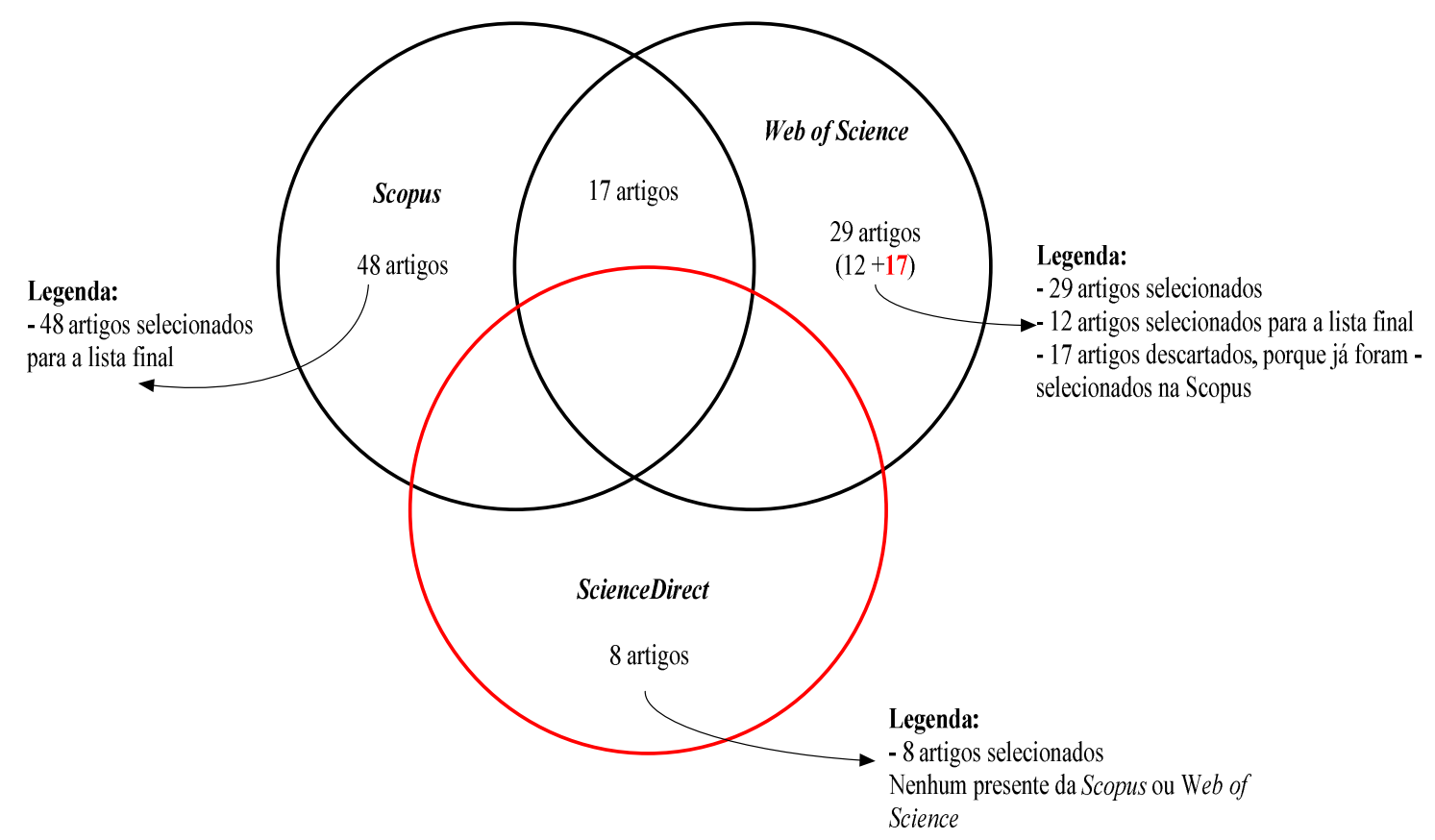

Figura 19: Representação dos artigos obtidos em cada base de dados Fonte: Elaborado pela autora

As pesquisas nacionais englobaram o acervo de bibliotecas digitais de teses e dissertações, publicações em periódicos e anais de eventos (encontros e simpósios) nas áreas de Engenharia de Produção e de Administração. As bibliotecas digitais acessadas foram: Biblioteca Digital Brasileira de Teses e Dissertações, Pesquisa Teses e Dissertações (CAPES), Biblioteca Digital de Teses e Dissertações da USP e Biblioteca Comunitária UFSCar.

Foi realizada uma busca avançada utilizando o termo 'cooperação universidadeempresa' e 'integração universidade-empresa' no título ou nas palavras-chave. A partir das buscas, apenas duas teses (PORTO, 2006 e PÓVOA, 2008) e quadro dissertações (OLIVEIRA, 2002; MARTINS, 2010; GARNICA, 2007; COSTA, 2006) foram selecionadas. Além disso, foi pesquisada uma dissertação referente à 'inovação tecnológica' de ABREU (2007).

Os periódicos nacionais consultados foram: Gestão \& Produção, Revista de Administração da Universidade de São Paulo (RAUSP), Revista de Economia (ANPEC), 
Revista de Administração e Inovação (RAI), resultando em um total de 10 artigos pertinentes para a pesquisa. Estes periódicos foram escolhidos por apresentarem qualidade de produção intelectual conforme avaliação Coordenação de Aperfeiçoamento de Pessoal de Nível Superior (Qualis da CAPES) nas áreas de Engenharias III (Engenharia de Produção) e por apresentarem artigos pertinentes ao tema estudado.

Nos encontros e simpósios, visando identificar artigos mais recentes, foi delimitado o período a partir do ano de 2000. Foram identificados 22 artigos que continham o termo 'cooperação universidade-empresa' no título (não há busca avançada) e selecionado 1 artigo para análise (Quadro 5).

Quadro 10: Número de artigos identificados e selecionados em eventos e simpósios

\begin{tabular}{|l|c|c|}
\hline \multicolumn{1}{|c|}{ Encontros e Simpósios } & $\begin{array}{c}\mathbf{N}^{\mathbf{o}} \text { de } \\
\text { artigos }\end{array}$ & $\begin{array}{c}\mathbf{N}^{\mathbf{o}} \text { de artigos } \\
\text { selecionados }\end{array}$ \\
\hline Encontro Nacional de Engenharia de Produção (ENEGEP) - de 2000 a 2012 & 8 & 1 \\
SIMPEP (Simpósio de Engenharia de Produção) - de 200 a 2012 & 5 & \\
ENANPAD (Encontro da Associação Nacional de Pós-Graduação e & 9 & \\
Pesquisa em Administração) - todos os anos & & \\
\hline
\end{tabular}

Fonte: Elaborado pela autora

Os capítulos de livros, artigos, teses e dissertações incluídos na revisão sistemática foram sintetizados destacando os pontos principais de cada um. Por fim, vale evidenciar que o estágio III da revisão sistemática da literatura, será descrito no capítulo referente à revisão da literatura deste trabalho. 


\section{ANEXO B \\ Análise Bibliométrica Sobre as Publicações Científicas Acerta do Tema Cooperação Universidade-Empresa}

Com base nos 68 artigos gerados pela busca previamente mencionada no capítulo II, referente ao procedimento metodológico adotado para a realização da revisão sistemática de literatura, este texto trará uma série de parâmetros descritivos sobre as publicações encontradas nas bases de dados Scopus, Web of Science e Science Direct.

Nessa perspectiva, a Figura 11 ilustra o ano de publicação dos artigos, de forma a contextualizar tal produção de conhecimento ao longo do tempo. Como pode ser observado, o número de publicações tem aumentado ao longo dos últimos anos, principalmente de 2000 para frente, pois este período concentra $96 \%$ do total de publicações, com uma média de 6,7 publicações por ano.

De acordo com Arza (2010), estudos relacionando a cooperação universidade-empresa vêm crescendo nos últimos anos, porque a cooperação universidade-empresa apresenta grande potencial de alavancar o crescimento econômico. Alguns trabalhos já propõem e discutem essa temática, apresentando levantamentos teóricos e resultados empíricos.

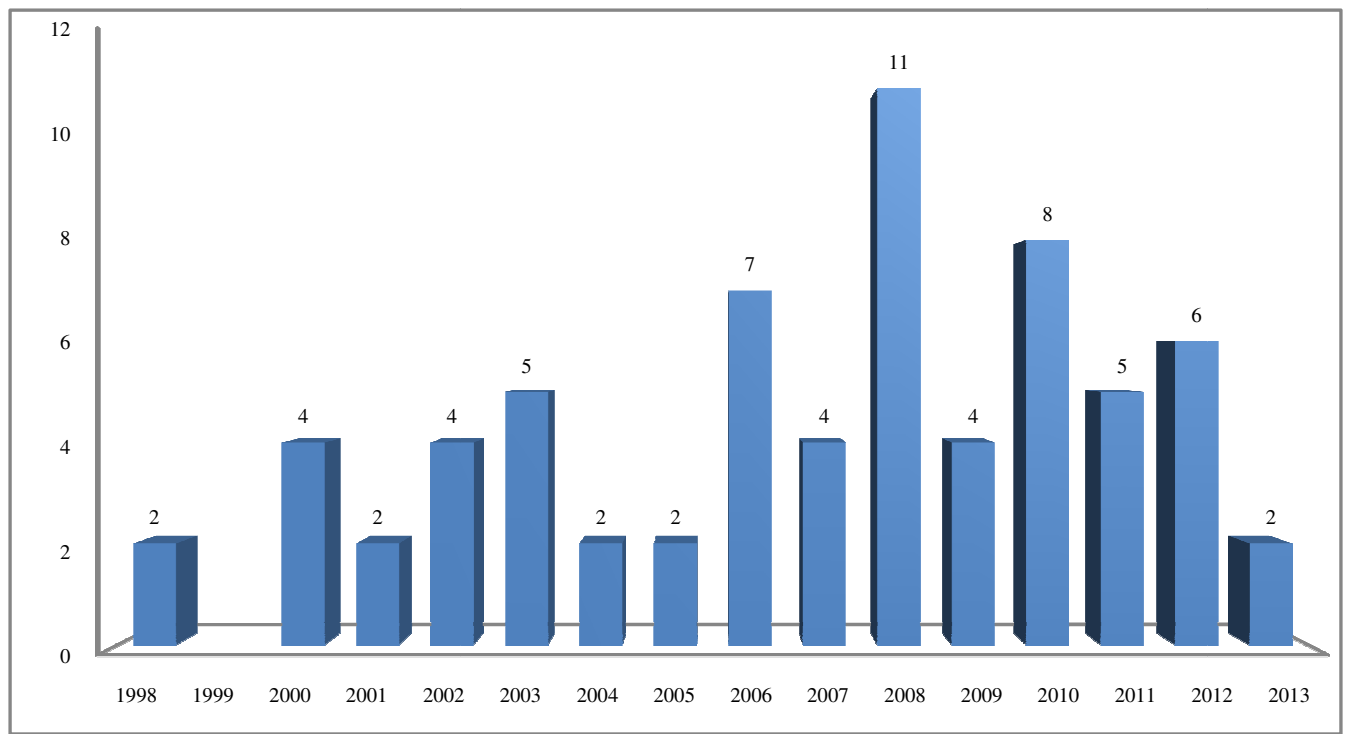

Figura 11: Distribuição total dos artigos selecionados pelas bases Scopus, Web of science e Science Direct, ao longo do tempo.

Fonte: Elaborado pela autora a partir das consultas nas bases Scopus; Web of Science e Science Direct - 2013.

De forma complementar, a Figura 12 ilustra a quantidade de citações para os artigos publicados ao longo de cada um dos anos, referente aos 48 artigos resultante da Scopus, 12 da 
Web of Science e 8 artigos selecionados na base de dados Scienc Direct. Observa-se que a maior parte das citações ocorre em 2011.

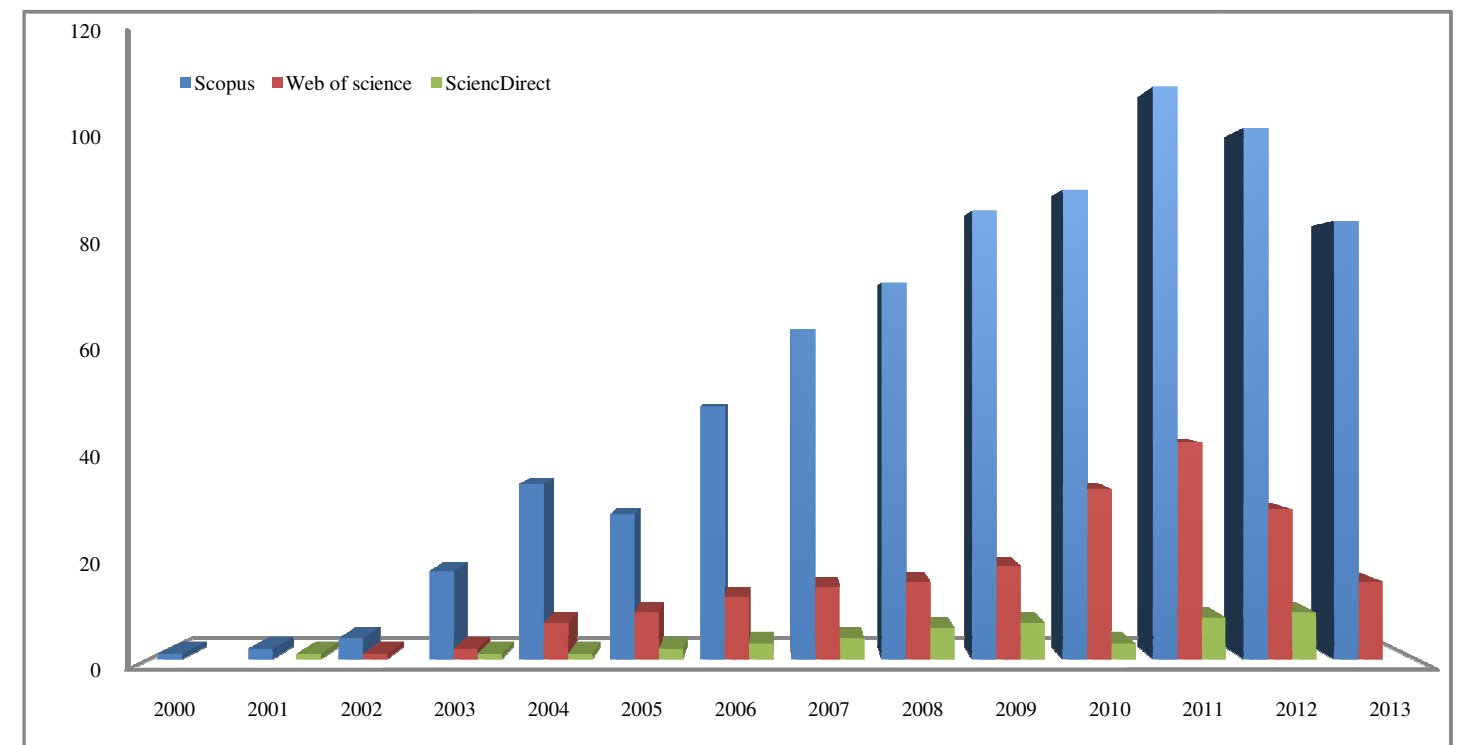

Figura 12: Número de citações aos artigos das bases Scopus, Web of Science e ScienceDirect, por ano

Fonte: Elaborado pela autora a partir das consultas nas bases Scopus; Web of Science e Science Direct- 2013.

No que diz respeito aos artigos mais citados nas bases de dados pesquisadas, optou pela divisão do mesmo entre os artigos que estavam disponibilizados pela Scopus e Web of Science. Dessa forma, o Quadro 22 demonstra que os artigos mais citados foram dos autores Etzkowitz Leydesdorff (2000), seguido pelo artigo de Cohen, Nelson e Walsh (2002) citados 820 e 427 vezes pela base Scopus, respectivamente. Por sua vez, o artigo mais citado pela Web of Science é o do autor Nemet (2009), ocupando a sexta posição. 
Quadro 22: Os dezesseis artigos mais citados, classificados conforme a base de dados que estava disponível - Scopus e Web of Sicence

\begin{tabular}{|c|c|c|c|c|c|}
\hline \multirow{2}{*}{$\begin{array}{l}\text { Posiçã } \\
\quad \text { o }\end{array}$} & \multicolumn{2}{|c|}{ Citações } & \multirow[b]{2}{*}{ Autores } & \multirow[b]{2}{*}{ Título } & \multirow[b]{2}{*}{ Ano } \\
\hline & Scopus & $\begin{array}{l}\text { Web of } \\
\text { Sicence }\end{array}$ & & & \\
\hline 1 & 820 & 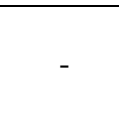 & $\begin{array}{l}\text { ETZKOWITZ, H.; } \\
\text { LEYDESDORFF, L }\end{array}$ & $\begin{array}{l}\text { The dynamics of innovation: from national systems } \\
\text { and "mode 2" to a triple helix of university-industry- } \\
\text { government relations }\end{array}$ & 2000 \\
\hline 2 & 427 & - & $\begin{array}{l}\text { COHEN, W.; NELSON, } \\
\text { R.; WALSH, J. }\end{array}$ & $\begin{array}{l}\text { Links and impacts: the influence of public research } \\
\text { on industrial R\&D }\end{array}$ & 2002 \\
\hline 3 & 266 & - & Bozeman, B & $\begin{array}{l}\text { Technology transfer and public policy: a review of } \\
\text { research and theory }\end{array}$ & 2000 \\
\hline 4 & 139 & - & D"eSTE, P.; PATEL. P & $\begin{array}{l}\text { University-industry linkages in the UK: What are } \\
\text { the factors underlying the variety of interactions with } \\
\text { industry }\end{array}$ & 2007 \\
\hline 5 & 58 & - & $\begin{array}{l}\text { BEKKERS, R., } \\
\text { FREITAS, I. M. B. }\end{array}$ & $\begin{array}{l}\text { Analysing knowledge transfer channels between } \\
\text { universities and industry: To what degree do sectors } \\
\text { also matter }\end{array}$ & 2008 \\
\hline 6 & - & 49 & NEMET, G. & $\begin{array}{l}\text { Demand-pull, technology-push, and government-led } \\
\text { incentives for non-incremental technical change }\end{array}$ & 2009 \\
\hline 7 & 40 & - & $\begin{array}{l}\text { BALCONI, M., } \\
\text { LABORANTI, A. }\end{array}$ & $\begin{array}{l}\text { University-Industry Interactions in Applied } \\
\text { Research: The Case of Microelectronics }\end{array}$ & 2006 \\
\hline 8 & - & 39 & $\begin{array}{l}\text { BRUNEEL, J.; D ESTE, } \\
\text { P.; SALTER, A }\end{array}$ & $\begin{array}{l}\text { Investigating the factors that diminish the barriers to } \\
\text { university-industry collaboration }\end{array}$ & 2010 \\
\hline 9 & - & 36 & $\begin{array}{l}\text { LEYDESDORFF, L.; } \\
\text { MEYER, M. }\end{array}$ & $\begin{array}{l}\text { Triple Helix indicators of knowledge-based } \\
\text { innovation systems Introduction to the special issue }\end{array}$ & 2006 \\
\hline 10 & - & 22 & $\begin{array}{l}\text { PERKMANN, M.; } \\
\text { WALSH, K }\end{array}$ & $\begin{array}{l}\text { The two faces of collaboration: impacts of } \\
\text { university-industry relations on public research }\end{array}$ & 2009 \\
\hline 11 & 21 & - & $\begin{array}{l}\text { Langford, C.H., Hall, } \\
\text { J., Josty, P.,Matos, } \\
\text { S., Jacobson, A. }\end{array}$ & $\begin{array}{l}\text { Indicators and outcomes of Canadian university } \\
\text { research: Proxies becoming goals? }\end{array}$ & 2006 \\
\hline 12 & - & 15 & $\begin{array}{l}\text { ELMUTI, D.; ABEBE, } \\
\text { M.; NICOLOSI, M }\end{array}$ & $\begin{array}{l}\text { An overview of strategic alliances between } \\
\text { universities and corporations }\end{array}$ & 2005 \\
\hline 13 & - & 12 & ARZA, V. & $\begin{array}{l}\text { Channels, benefits and risks of public-private } \\
\text { interactions for knowledge transfer: a conceptual } \\
\text { framework inspired by Latin America }\end{array}$ & 2010 \\
\hline 14 & 11 & - & ØSTERGAARD, C.R & $\begin{array}{l}\text { Knowledge flows through social networks in a } \\
\text { cluster: Comparing university and industry links }\end{array}$ & 2009 \\
\hline 15 & 10 & - & Dutrénit, G.; Arza, V. & $\begin{array}{l}\text { Interactions between public research organisations } \\
\text { and industry in Argentina }\end{array}$ & 2010 \\
\hline 16 & 7 & - & $\begin{array}{l}\text { ETZKOWITZ, H.; Viale, } \\
\mathrm{R}\end{array}$ & $\begin{array}{l}\text { Polyvalent knowledge and the Entrepreneurial } \\
\text { University: a Third Academic Revolution }\end{array}$ & 2010 \\
\hline
\end{tabular}

Fonte: Elaborado pela autora a partir das consultas nas bases Scopus; Web of Science e Science Direct- 2013.

A revisão sistemática de literatura também permitiu identificar os periódicos mais relevantes para esta pesquisa (Figura 13). Destacam-se dois: o Research Policy e o Science and Public Policy, com $15(23 \%)$ e 12 (18\%) artigos constantes na lista final, respectivamente. Há ainda dois outros periódicos que publicaram responsáveis por $17 \%$ (Journal of Technology Transfer) e 8\% (International Jounal of Economic Practices and Theories) da lista final da revisão bibliográfica.

A importância desses dois periódicos de destaque é reforçada pela sua qualidade. $\mathrm{O}$ primeiro é avaliado como A1 pela CAPES (Coordenação de Aperfeiçoamento de Pessoal de 
Nível Superior) (2012) nas áreas de Engenharias III e de Administração. Por sua vez, o Science and Public é avaliado como A2 nas áreas de Engenharias III e de Administração.

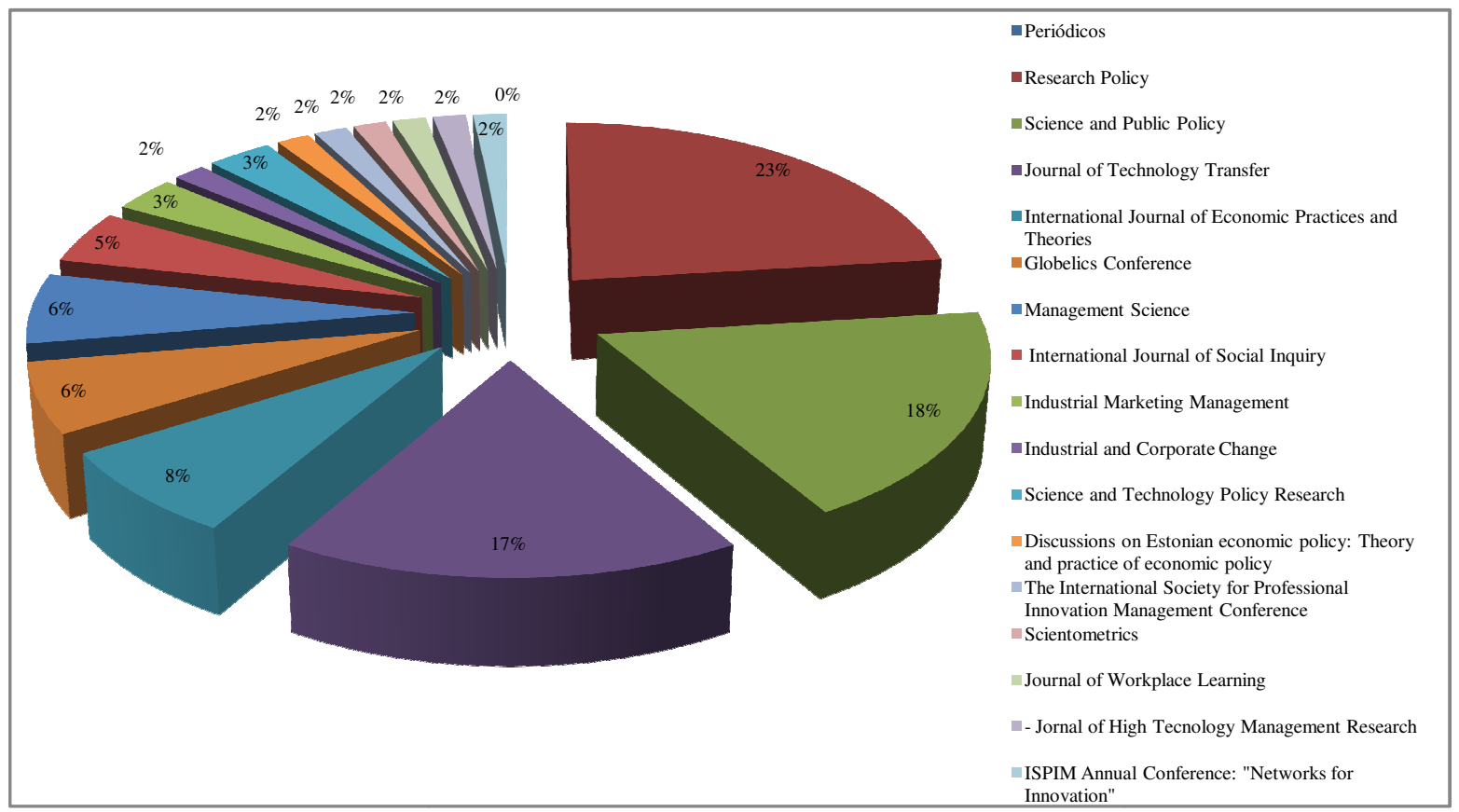

Figura 13: Periódicos e número de publicações

Fonte: Elaborado pela autora a partir das consultas nas bases Scopus; Web of Science e Science Direct- 2013.

Dentre os artigos revisados, todas as palavras-chave foram analisadas, resultando num total de 290 palavras-chave diferentes. A Figura 14 ilustra quais foram citadas mais de uma vez, assim sendo, 71 palavras-chave foram citadas apenas uma vez. 


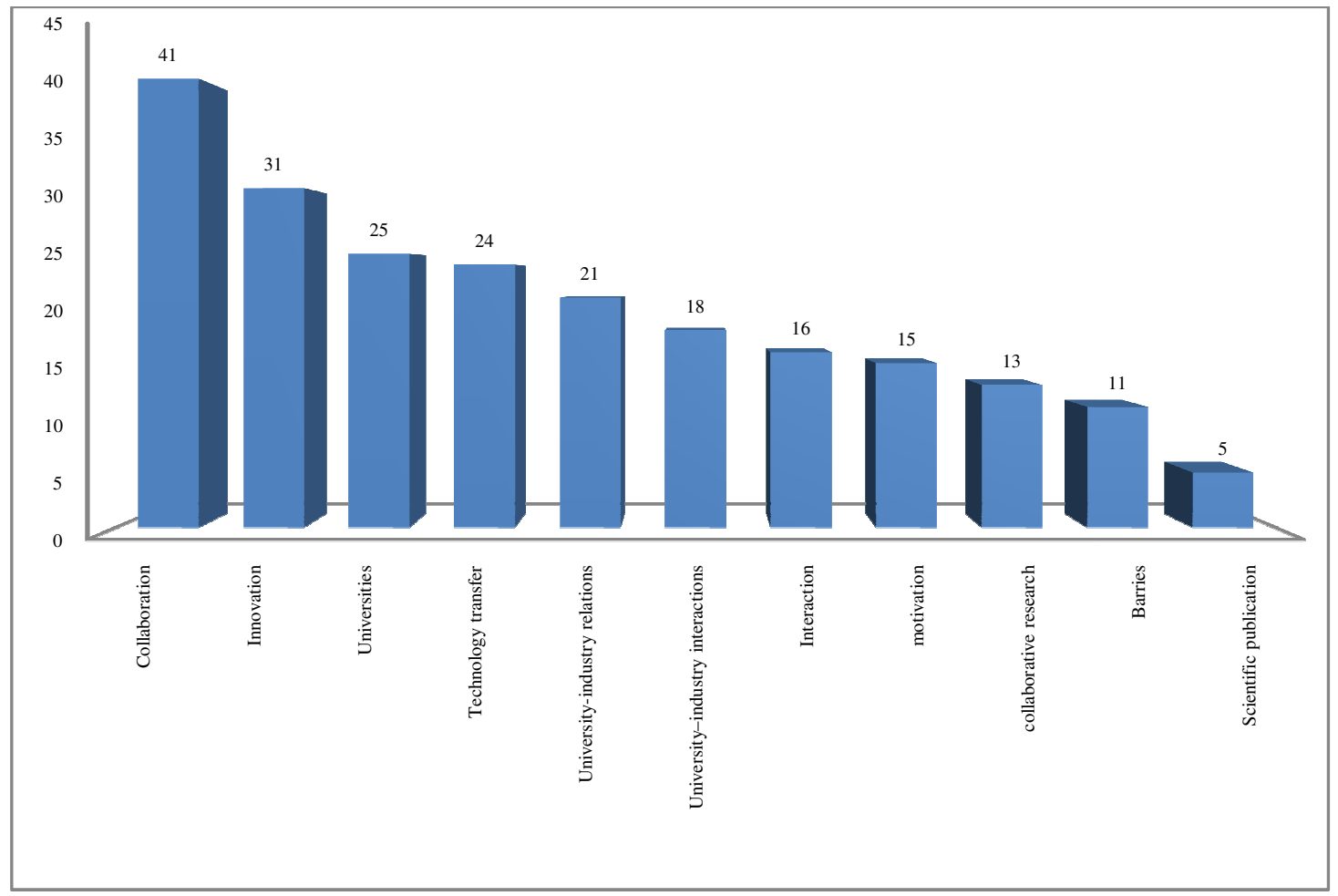

Figura 14: Distribuição das Palavras-Chave mais freqüentes

Fonte: Elaborado pela autora a partir das consultas nas bases Scopus; Web of Science e Science Direct- 2013.

É possível dividir as palavras da Figura AS em dois grupos principais, um primeiro que abrange o conceito de cooperação universidade-empresa: Collaboration, Innovation Universities, University-industry relations, University-industry interactions, Interaction e collaborative research, e um segundo grupo relacionado às barreiras, benefícios de cooperação universidade-empresa e os canais de transferência de tecnologia: Technology Transfer, Motivation e Barries. 